\title{
Chemical Synthesis of Oligosaccharides related to the Cell Walls of Plants and Algae
}

\author{
Kinnaert, Christine; Daugaard, Mathilde; Nami, Faranak; Clausen, Mads Hartvig
}

Published in:

Chemical Reviews

Link to article, DOI:

10.1021/acs.chemrev.7b00162

Publication date:

2017

Document Version

Peer reviewed version

Link back to DTU Orbit

Citation (APA):

Kinnaert, C., Daugaard, M., Nami, F., \& Clausen, M. H. (2017). Chemical Synthesis of Oligosaccharides related to the Cell Walls of Plants and Algae. Chemical Reviews, 117(17), 11337-11405.

https://doi.org/10.1021/acs.chemrev.7b00162

\section{General rights}

Copyright and moral rights for the publications made accessible in the public portal are retained by the authors and/or other copyright owners and it is a condition of accessing publications that users recognise and abide by the legal requirements associated with these rights.

- Users may download and print one copy of any publication from the public portal for the purpose of private study or research.

- You may not further distribute the material or use it for any profit-making activity or commercial gain

- You may freely distribute the URL identifying the publication in the public portal

If you believe that this document breaches copyright please contact us providing details, and we will remove access to the work immediately and investigate your claim. 


\title{
Chemical Synthesis of Oligosaccharides related to the Cell Walls of Plants and
}

\author{
Algae \\ Christine Kinnaert, Mathilde Daugaard, Faranak Nami, Mads H. Clausen* \\ Center for Nanomedicine and Theranostics, Department of Chemistry, \\ Technical University of Denmark, Kemitorvet, Building 207, 2800 Kgs. Lyngby, Denmark \\ mhc@kemi.dtu.dk
}

\begin{abstract}
Plant cell walls are composed of an intricate network of polysaccharides and proteins that varies during the developmental stages of the cell. This makes it very challenging to address the functions of individual wall components in cells, especially for highly complex glycans. Fortunately, structurally defined oligosaccharides can be used as models for the glycans, to study processes such as cell wall biosynthesis, polysaccharide deposition, protein-carbohydrate interactions, and cell-cell adhesion. Synthetic chemists have focused on preparing such model compounds, as they can be produced in good quantities and with high purity. This review contains an overview of those plant and algal polysaccharides, which have been elucidated to date. The majority of the content is devoted to detailed summaries of the chemical syntheses of oligosaccharide fragments of cellulose, hemicellulose, pectin, and arabinogalactans, as well as glycans unique to algae. Representative synthetic routes within each class are discussed in detail and the progress in carbohydrate chemistry over recent decades is highlighted.
\end{abstract}




\section{Contents}

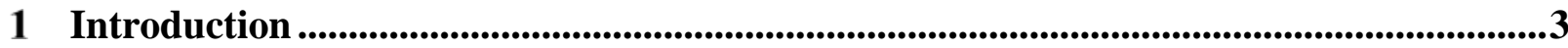

2 Architecture and composition of plant cell walls ......................................................................6

2.1 Polysaccharides in plant and algal cell walls ............................................. 8

2.2 The study of cell wall composition, function and evolution ....................... 10

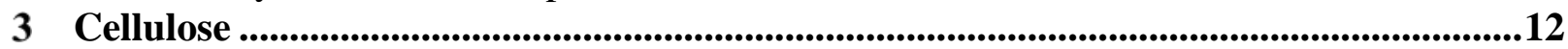

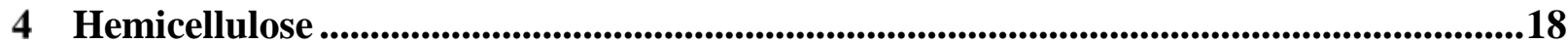

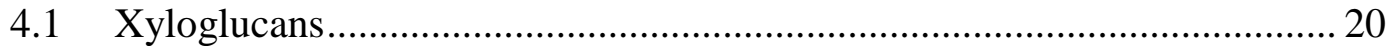

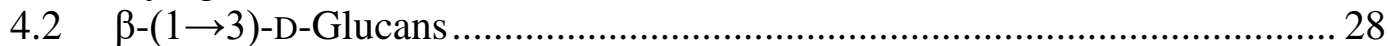

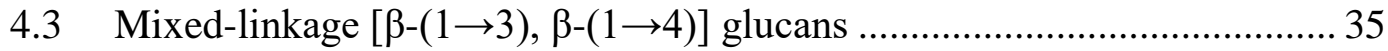

4.4 Xylans (arabinoxylans, glucuronoxylans and glucurono-arabinoxylans) ... 38

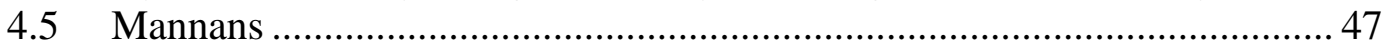

5 Pectin ..........................................................................................................................................56

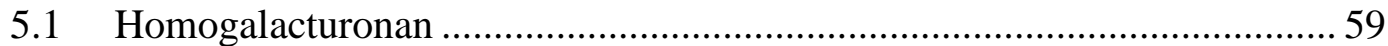

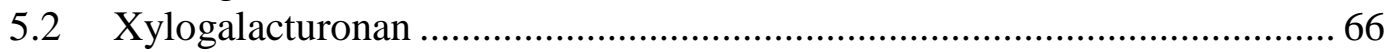

5.3 Apiogalacturonan ...................................................................................6 66

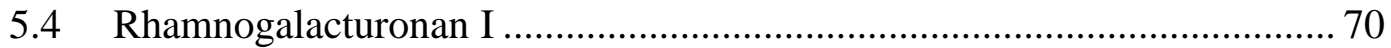

5.4.1 RG-I backbone ....................................................................................................

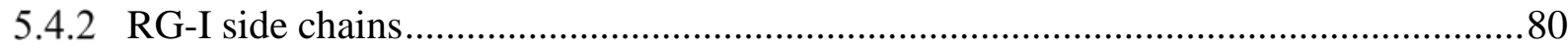

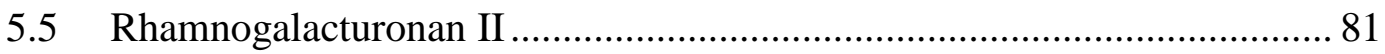

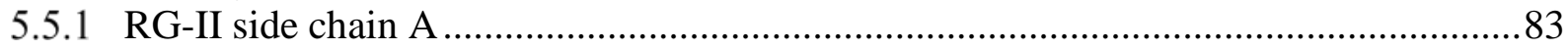

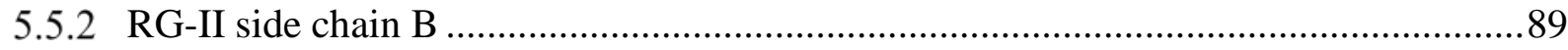

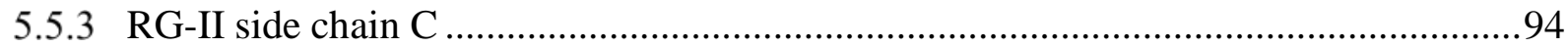

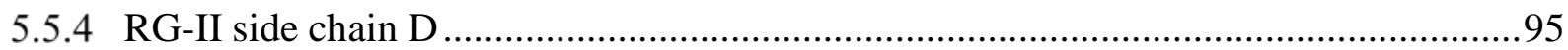

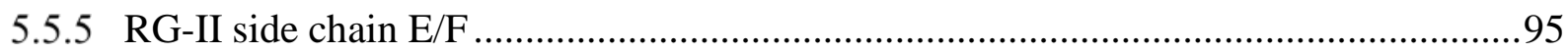

6 (Arabino)galactans and arabinans .....................................................................................96

6.1 Type I AGs and galactans ................................................................... 97

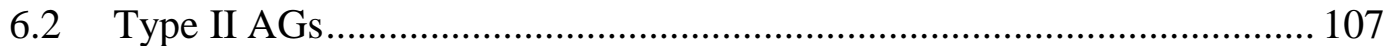

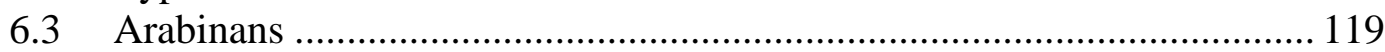

7 Polysaccharides exclusive to algae ........................................................................................124

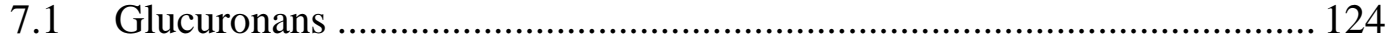

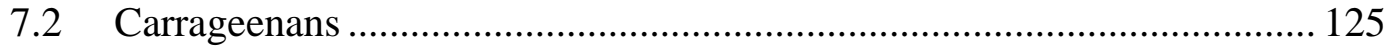

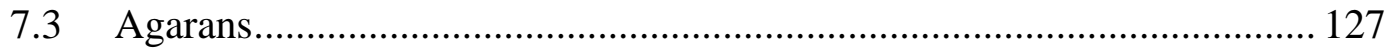

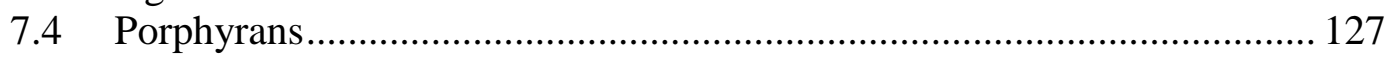

7.5 Alginates........................................................................................ 128

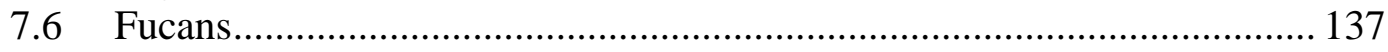

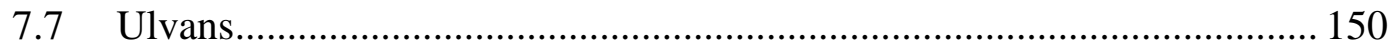

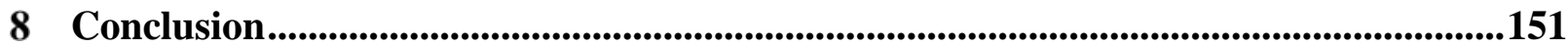

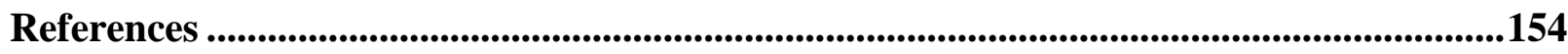

TOC Graphic ..................................................................................................................................183 


\section{Introduction}

Plant cell walls are highly sophisticated fiber composite structures. They are dynamic systems, which have evolved to fulfill the wide range of biological functions necessary to support plant life. The wall is the outer layer of the cell, providing a strong and protective supporting boundary, and defining the size and shape of the cell. Beyond its structural function, the cell wall also plays an important role in cell expansion during plant growth, and in plant-microbe interactions, in particular the defense response against pathogens. ${ }^{1,2}$ The cell wall is not just a boundary between plant cells, but forms the interface to neighboring cells, contributing to intercellular communication.

Plant cell walls are highly heterogeneous, with a wide range of constituent components. Table 1 compares the monosaccharides found in mammalian cells with the ones occurring in plant and/or algal cell wall, together with the symbols used here and in the CFG nomenclature. The diversity can make it challenging to distinguish the function of individual components and how they interact. Researchers have therefore used well-defined oligosaccharides as model compounds to represent domains from the larger, more complex polysaccharides. Many groups have succeeded in synthesizing such oligosaccharides using different strategies. This review will introduce the glycans found in plant cell walls and describe all relevant chemical oligosaccharide synthesis, up to and including February 2017. The material is organized in tables showing the structures according to glycan nomenclature given in Figure 1. With the exception of some rare disaccharide combinations found in pectin, we present only trisaccharides and longer structures, and only oligosaccharides that have been deprotected successfully. Representative syntheses are discussed in detail, in order to include different approaches to plant cell wall glycan assembly. Some of the syntheses described here have been covered in 
previous reviews; we are endeavoring to provide a comprehensive overview of the field, and therefore have chosen not to exclude these.

Table 1. Comparison between mammalian monosaccharides and plant/ algae cell wall monosaccharides.

\begin{tabular}{|c|c|c|c|c|}
\hline Monosaccharide & $\begin{array}{c}\text { CFG symbol } \\
\text { (existing or } \\
\text { suggested) }\end{array}$ & Symbol used here & $\begin{array}{c}\text { Plant/algal cell wall } \\
\text { glycans }\end{array}$ & Mammalian glycans \\
\hline Glucose & & & $\mathrm{D}$ & $\mathrm{D}$ \\
\hline Galactose & & & $\mathrm{D}$ and $\mathrm{L}$ & $\mathrm{D}$ \\
\hline $\begin{array}{l}N \text {-Acetyl- } \\
\text { glucosamine }\end{array}$ & & & & $\mathrm{D}$ \\
\hline $\begin{array}{c}N \text {-Acetyl- } \\
\text { galactosamine }\end{array}$ & & & & D \\
\hline Mannose & & & $\mathrm{D}$ & $\mathrm{D}$ \\
\hline Galacturonic acid & & & $\mathrm{D}$ & $\mathrm{D}$ \\
\hline Xylose & & & $\mathrm{D}$ & $\mathrm{D}$ \\
\hline Fucose & & & $\mathrm{L}$ & $\mathrm{L}$ \\
\hline Sialic acid & & & & $\mathrm{D}$ \\
\hline Iduronic acid & & & $\mathrm{L}$ & $\mathrm{L}$ \\
\hline Rhamnose & & & $\mathrm{L}$ & \\
\hline Gulose & & & $\mathrm{L}$ & \\
\hline Arabinose & & & $\mathrm{L}$ & \\
\hline
\end{tabular}




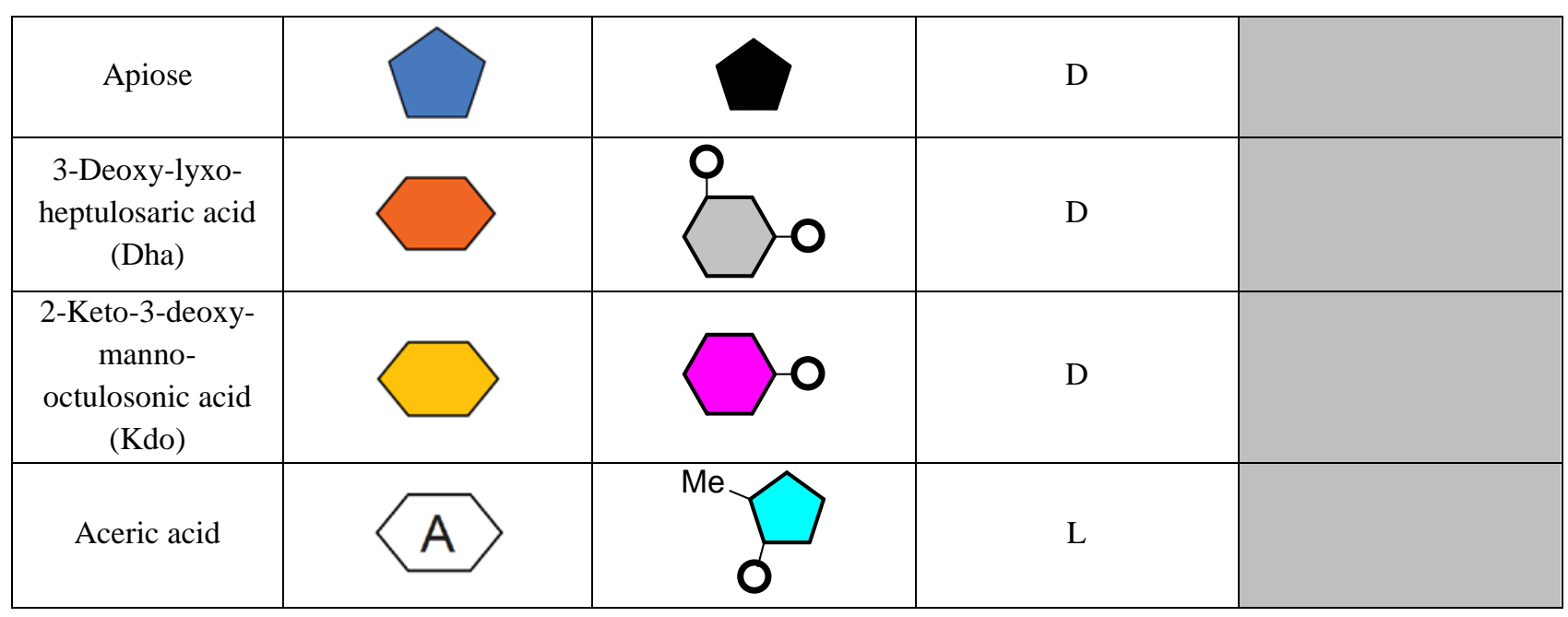

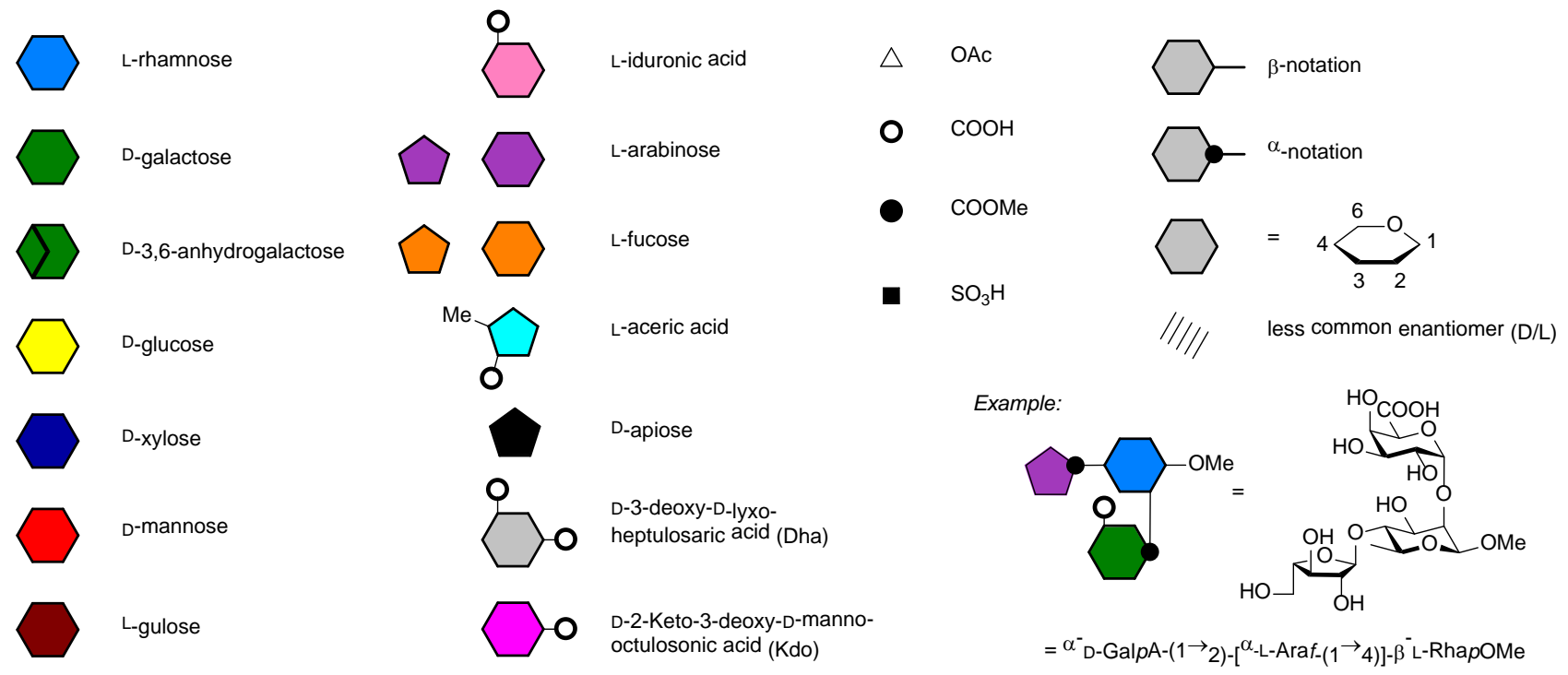

Figure 1. Glycan notation. 


\section{Architecture and composition of plant cell walls}

As a simple model, plant cell walls can be grouped in two types: the primary and the secondary cell wall. The primary cell wall is a thin and flexible structure deposited when the cell is growing, while the secondary cell wall, much thicker and stronger, is deposited on certain cells when they have ceased to grow. Primary cell walls are typically composed of around $70 \%$ water. The dry material is made up of polysaccharides (approximately 90\%) and (glyco)proteins ( 10\%). In the primary cell wall, cellulose microfibrils are cross-linked by non-cellulosic polysaccharides (often referred to as hemicellulose), and these are intertwined with pectic polysaccharides. The chemical composition of the main polysaccharides found in land plants is summarized in Table 2.

There is strong evidence that hemicellulose, mostly xyloglucans, bind to the cellulose microfibrils via two different mechanisms: being entwined in the microfibril during crystallization, which occurs immediately after synthesis; and by hydrogen bonding between the glycan chains. ${ }^{3-5}$ The polysaccharide network in the cell wall helps the plant resist turgor pressure and other deformations. Less is known about the interaction of pectic polysaccharides with the other wall components, but there is evidence that neutral glycans side chains also interact with cellulose, a factor that is usually not accounted for in models describing plant cell wall architecture. ${ }^{6-8}$ Pectic polysaccharides are usually divided into four different domains (HG, RG-I, RG-II, and XGA / AGA, see Table 1), which are believed to be covalently linked to form the pectin macromolecule. Evidence suggests that some pectic polysaccharides are also crosslinked to hemicelluloses, phenolic compounds and wall proteins,

which provides an even higher degree of complexity in the structure and function of the wall. ${ }^{5,9} \mathrm{~A}$ 2009 paper detailing the structure, function and biosynthesis of plant cell wall pectic polysaccharides by Mohnen \& Caffall provides a good overview. ${ }^{6}$ 
Table 2. Cellulose, hemicellulose and pectin structures.

\begin{tabular}{|c|c|c|c|c|c|}
\hline Cellulose & $\beta$-(1 $\rightarrow 4)$-Glup & & & & \\
\hline Hemicellulose & $\begin{array}{l}\text { Xyloglucans (XyG) } \beta \text { - } \\
(1 \rightarrow 4) \text {-Glup with } \\
\text { mainly Xylp } \\
\text { branching }\end{array}$ & $\begin{array}{l}\text { Glucans } \\
\beta-(1 \rightarrow 3) \text {-Glup } \\
\text { with } \beta-(1 \rightarrow 6) \\
\text { branching }\end{array}$ & $\begin{array}{l}\text { Mixed-linkage } \\
\text { glucans (MLGs) } \\
\beta-(1 \rightarrow 3)-\beta-(1 \rightarrow 4)- \\
\text { Glup }\end{array}$ & $\begin{array}{l}\text { Xylans } \\
\beta-(1 \rightarrow 4) \text {-Xylp } \\
\text { (potentially with Araf } \\
\text { and GlupA branching) }\end{array}$ & $\begin{array}{l}\text { Mannans } \\
\beta-(1 \rightarrow 4)-M a n p \text { and } \\
\beta-(1 \rightarrow 4)-G l u p / M a n p \\
\text { with Galp branching }\end{array}$ \\
\hline Pectin & $\begin{array}{l}\text { Homogalacturonan } \\
(\mathrm{HG}) \\
\alpha-(1 \rightarrow 4)-G a l p \mathrm{~A}\end{array}$ & $\begin{array}{l}\text { Rhamnogalacturonan I } \\
(\mathrm{RG}-\mathrm{I}) \\
\alpha-(1 \rightarrow 4)-\mathrm{Gal} p \mathrm{~A}-\alpha- \\
(1 \rightarrow 2)-\mathrm{Rha} p \text { backbone } \\
\text { with side chains of } \\
\text { Galp and Araf }\end{array}$ & $\begin{array}{l}\text { Rhamnogalacturonan } \\
\text { II (RG-II) } \\
\alpha-(1 \rightarrow 4)-G a l p A \\
\text { with conserved side } \\
\text { chains of mainly rare } \\
\text { sugars }\end{array}$ & $\begin{array}{l}\text { Xylogalacturonan } \\
\text { (XGA) } \\
\alpha-(1 \rightarrow 4)-G a l p A \\
\text { with Xylp branching }\end{array}$ & $\begin{array}{l}\text { Apiogalacturonan } \\
\text { (AGA) } \\
\alpha-(1 \rightarrow 4)-G a l p A \\
\text { with Apif branching }\end{array}$ \\
\hline
\end{tabular}

In addition to polysaccharides, the primary cell wall also contains about $10 \%$ protein, which is mostly glycosylated. Arabinogalactan proteins (AGPs) are some of the most abundant and most studied glycoproteins in plant cell walls and they are thought to be involved in recognition and signaling events at the cell surface. ${ }^{10}$ However, as the focus of this review is on polysaccharides, we will not describe the plant cell wall proteome. We invite the reader to look at some comprehensive reviews covering this subject. ${ }^{11,12}$

In secondary cell walls, the embedding material is not pectin, but rather the phenolic polymer lignin, which constitutes up to $30 \%$ of the dry weight of the wall. ${ }^{13}$ The secondary cell wall also contains cellulose and a network of connecting hemicellulosic polysaccharides with a lower degree of backbone branching (mainly xylan and mannans). The deposition of lignin results in dehydration of the wall, rendering it more hydrophobic and less dynamic. Other components such as the aliphatic polyesters cutin and suberin can also be found in the plant cell wall as minor components. ${ }^{14}$ Plant cell walls display a considerable degree of diversity in their composition and molecular architecture depending on plant species but also related to cell type and cell wall microstructure. ${ }^{15}$ An interesting 
review of the heterogeneity in the chemistry, structure and function of plant cell walls has been published by Fincher and co-workers recently. ${ }^{15}$

\subsection{Polysaccharides in plant and algal cell walls}

The primary cell walls of seed plants and especially angiosperms (flowering plants) are by far the most studied. However, since land plants have algal ancestors, the cell walls of algae can be interesting from an evolutionary point of view. Land plants originate from freshwater green algae of the Charophytes class, which emerged from their aquatic habitat approximately 450 million years ago. ${ }^{16,17,18}$ As shown in the phylogenetic tree of eukaryotic organisms (Figure 2), land plants (Embryophytes), red algae (Rhodophytes) and green algae (Chlorophytes) all belong to the Archaeplastida clade, while brown algae (Phaeophytes) belong to the separate Chromalveolata clade. The phylogenetics can explain why the cell walls of brown algae share polysaccharides with both plants (cellulose) and animals (sulfated fucans), but also with some bacteria (alginates). ${ }^{19}$ 


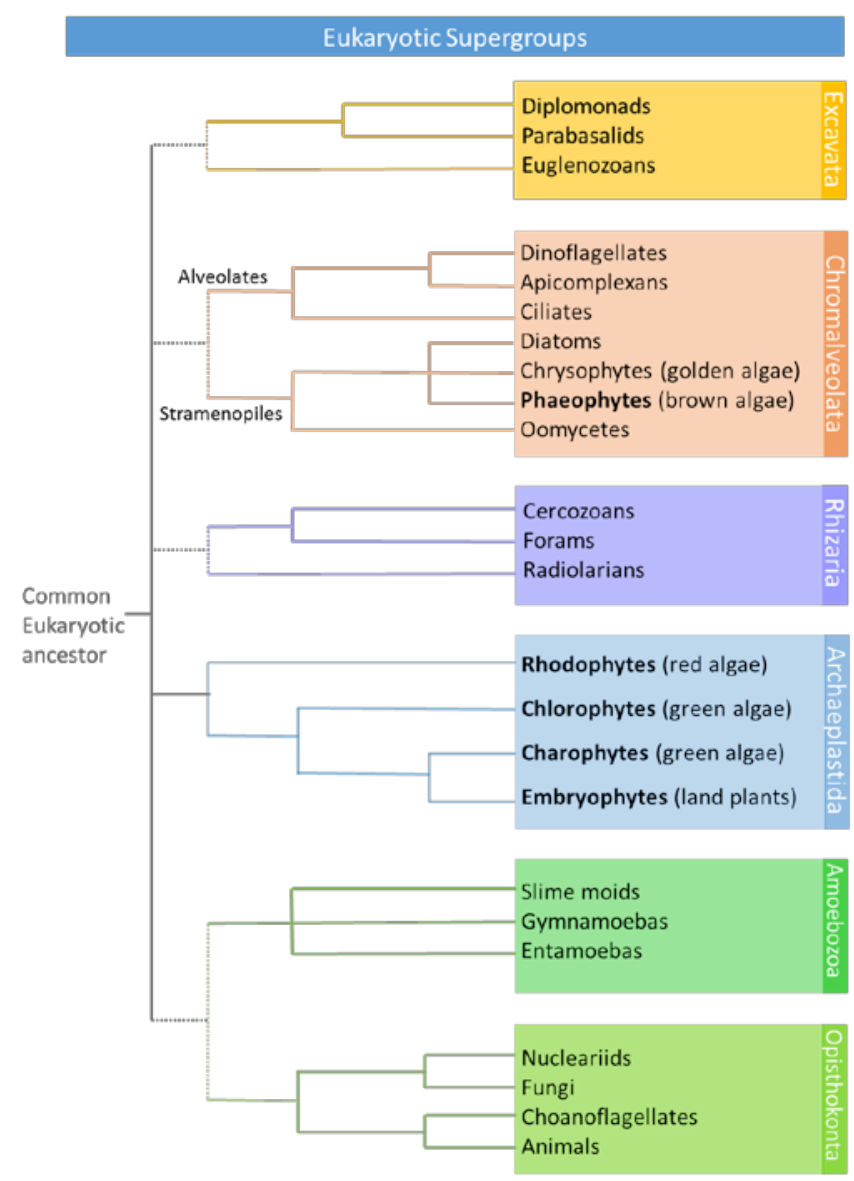

Figure 2. Phylogenetic tree of eukaryotic organisms.

The nature of the different cell wall components from the major plant and algal families has been the topic of several reviews and is summarized in Table $3 .^{16,20,21}$ The unique presence of different sulfated polysaccharides in the Rhodophytes and Phaeophytes is noteworthy. Agar, carrageenan and porphyran are the most important sulfated polysaccharides found in the red algae, while brown algae produce homofucans. The structure of these polysaccharides will be described in detail later in this review. 
Table 3. Major cell wall polymers present in different plant and algal taxa. ${ }^{22}$

\begin{tabular}{|c|c|c|c|c|c|}
\hline \multirow{2}{*}{ Polymer } & \multicolumn{3}{|c|}{ Chloroplastida } & \multirow{2}{*}{$\begin{array}{c}\text { Rhodophytes } \\
\text { (red algae) }\end{array}$} & \multirow{2}{*}{$\begin{array}{l}\text { Phaeophytes } \\
\text { (brown algae) }\end{array}$} \\
\hline & $\begin{array}{c}\text { Embryophytes } \\
\text { (land plants) }\end{array}$ & $\begin{array}{l}\text { Charophytes } \\
\text { (green algae) }\end{array}$ & $\begin{array}{l}\text { Chlorophytes } \\
\text { (green algae) }\end{array}$ & & \\
\hline $\begin{array}{c}\text { Crystalline } \\
\text { polysaccharides }\end{array}$ & cellulose & cellulose & cellulose & $\begin{array}{c}\text { cellulose } \\
\text { mannan } \\
\text { xylan } \\
(1 \rightarrow 3)-\beta \text {-D-xylan } \\
\end{array}$ & cellulose \\
\hline Hemicellulose & $\begin{array}{c}\text { xyloglucan } \\
\text { mannans } \\
\text { xylans } \\
\text { MLG } \\
\text { glucan (callose) }\end{array}$ & $\begin{array}{c}\text { xyloglucan } \\
\text { mannans } \\
\text { xylans } \\
\text { glucan (callose) }\end{array}$ & $\begin{array}{c}\text { xyloglucan } \\
\text { mannans } \\
\text { glucuronan } \\
\text { glucan (callose) }\end{array}$ & $\begin{array}{c}\text { mannan } \\
\text { sulfated MLG } \\
(1 \rightarrow 3),(1 \rightarrow 4)-\beta \text {-D- } \\
\text { xylan }\end{array}$ & $\begin{array}{c}\text { sulfated } \\
\text { xylofucoglucan } \\
\text { sulfated xylofuco- } \\
\text { glucuronan } \\
\text { glucan (laminarin) }\end{array}$ \\
\hline $\begin{array}{c}\text { Matrix } \\
\text { carboxylic } \\
\text { polysaccharides }\end{array}$ & pectins & pectins & ulvans & & alginates \\
\hline $\begin{array}{c}\text { Matrix } \\
\text { sulfated } \\
\text { polysaccharides }\end{array}$ & & & ulvans & $\begin{array}{c}\text { agars } \\
\text { carrageenans } \\
\text { porphyran }\end{array}$ & fucans \\
\hline
\end{tabular}

\subsection{The study of cell wall composition, function and evolution}

The study of the plant cell wall requires a multi-disciplinary approach and there are many challenges in trying to elucidate cell wall architecture, function, and evolution. The field is being advanced by technologies such as atomic force microscopy, immunofluorescence microscopy and the development of molecular probe sets. ${ }^{23}$ In a 2012 review, Willats and co-workers discussed a multiple-level strategy for correlating the occurrence of cell wall polysaccharides with genetic diversity in order to get an insight into underlying evolutionary mechanisms. ${ }^{24}$ Many of the most efficient techniques employ molecular probes that interact specifically with glycans, such as monoclonal antibodies (mAbs) and carbohydrate-binding modules (CBMs). Well-defined oligosaccharides provide the highest resolution possible when characterizing protein-carbohydrate interactions, and they contribute significantly to 
the toolkit available for plant research. Figure 3 shows an example of in situ mapping of cellulose, rhamnogalacturonan I and methyl esterified homogalacturonan in seed coat epidermal cells and mucilage in Arapidopsis thaliana.

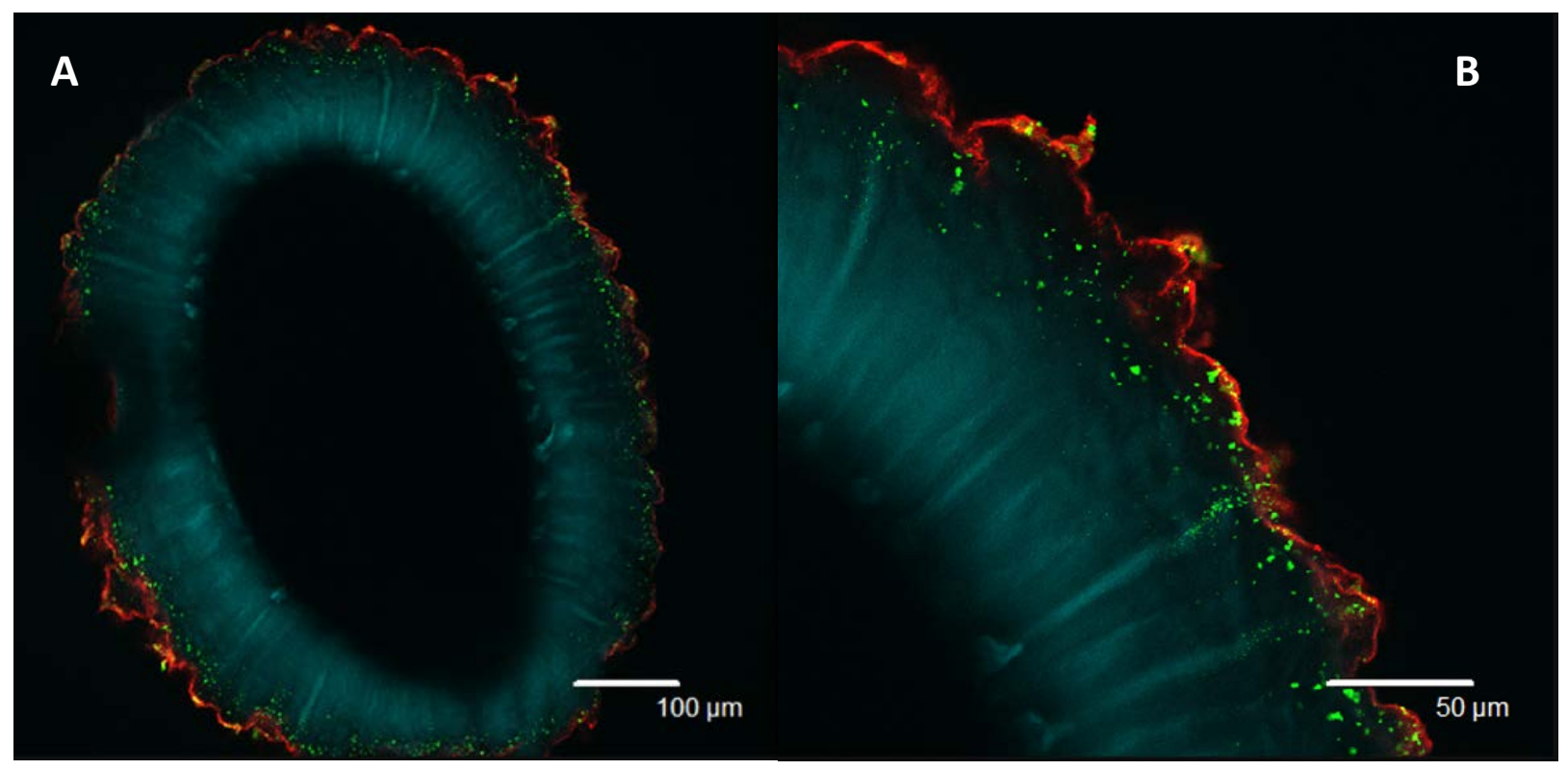

Figure 3. Labelling of polysaccharidic components of seed coat epidermal cells and mucilage in Arabidopsis thaliana. (A) Composite image of a section through whole seed and mucilage. Scale bar $=100 \mu \mathrm{m}$. (B) Magnification of region in (A). Scale bar $=50 \mu \mathrm{m}$. Blue: calcofluor-labeled cellulose; red: INRA-RU1-immunolabelled rhamnogalacturonan; green: JIM7-immunolabelled highly methyl esterified homogalacturonan. ${ }^{23}$ Images used with permission from Adeline Berger. 


\section{Cellulose}

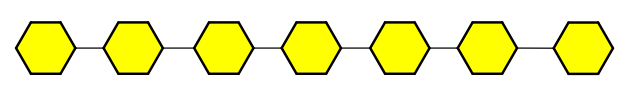

Figure 4. Structure of cellulose.

Cellulose is the main component of the primary cell wall in plants. It is the most abundant organic compound on earth and consists of an unbranched homopolymer of $\beta$-(1 $\rightarrow 4)$-glucan units (Figure 4 ). The biopolymer is currently used in a wide variety of applications including the production of biofuels, paper products, and textile fibers. ${ }^{25}$ Cellulosic chains are held together tightly by both intra- and intermolecular hydrogen bonds facilitated by the conformation of the polymer. The chain length depends on the source of the cellulose; the degree of polymerization (DP) is believed to reach up to 8,000 glucose residues in primary cell walls and 15,000 in secondary cell walls. This makes cellulose one of the longest bio-macromolecules known.

Table 4 shows all chemically synthesized $\beta$ - $(1 \rightarrow 4)$-glucans with at least three glucose residues. It is worth noting that the majority of the reports on the preparation of $\beta-(1 \rightarrow 4)$-glucans detail enzymatic procedures.

Table 4. The cellulose fragments synthesized chemically.

\begin{tabular}{|l|l|l|l|}
\hline Structure & R & Year & Reference \\
\hline$\square-O R$ & Me & 1981 & Takeo et al. $^{26}$ \\
& & 1983 & Takeo et al. ${ }^{27}$ \\
& $\mathrm{H}$ & 1983 & Takeo et al. ${ }^{27}$ \\
& $\left(\mathrm{CH}_{2}\right)_{3}(\mathrm{CH})_{2} \mathrm{O}$ & 1990 & Rodriguez and Stick ${ }^{28}$ \\
\hline
\end{tabular}




\begin{tabular}{|c|c|c|c|}
\hline & $\begin{array}{l}\mathrm{CH}_{2} \mathrm{CH}_{2} \mathrm{C}_{10} \mathrm{H}_{7} \\
\left(\mathrm{CH}_{2}\right)_{5} \mathrm{NHCOO}\left(\mathrm{CH}_{2}\right)_{3} \mathrm{C}_{8} \mathrm{~F}_{17} \\
\left(\mathrm{CH}_{2}\right)_{5} \mathrm{NH}_{2}\end{array}$ & $\begin{array}{l}1999 \\
2010 \\
2016\end{array}$ & $\begin{array}{l}\text { Xu and Vasella }{ }^{29} \\
\text { Chang et al. }{ }^{30} \\
\text { Dallabernardina et al. }{ }^{31}\end{array}$ \\
\hline$r$ & $\begin{array}{l}\mathrm{Me} \\
(S)-\mathrm{CH}-\mathrm{CH}_{3} \mathrm{CH}_{2} \mathrm{OH} \\
(R)-\mathrm{CH}-\mathrm{CH}_{3} \mathrm{CH}_{2} \mathrm{OH} \\
(S)-\mathrm{CH}_{2} \mathrm{CH}-\mathrm{OHCH}_{3}\end{array}$ & \begin{tabular}{r|r}
1983 \\
1983 \\
1986 \\
1983 \\
1986 \\
1983 \\
1985 \\
1986 \\
1983 \\
1985 \\
1986
\end{tabular} & 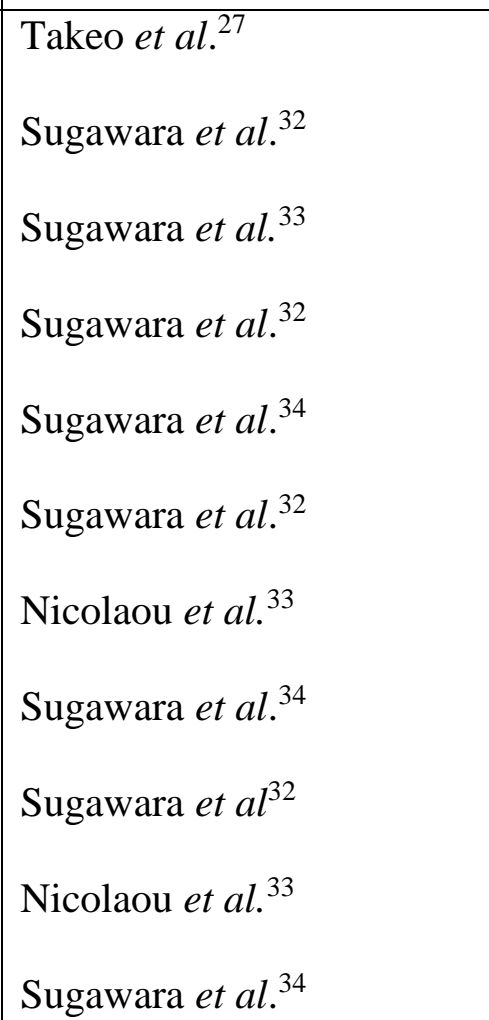 \\
\hline & $\begin{array}{l}\left(\mathrm{CH}_{2}\right)_{5} \mathrm{NHCOO}\left(\mathrm{CH}_{2}\right)_{3} \mathrm{C}_{8} \mathrm{~F}_{17} \\
\mathrm{CH}_{2} \mathrm{CH}_{2} \mathrm{C}_{10} \mathrm{H}_{7}\end{array}$ & $\begin{array}{r}1983 \\
1996 \\
2010 \\
1999\end{array}$ & $\begin{array}{l}\text { Takeo et } \text { al. }^{27} \\
\text { Nishimura and Nakatsubo } \\
\text { Chang et al. }{ }^{30} \\
\text { Xu and Vasella }\end{array}$ \\
\hline & $\begin{array}{l}\text { (S)- } \mathrm{CH}_{2} \mathrm{CH}-\mathrm{OHCH}_{3} \\
(R)-\mathrm{CH}_{2} \mathrm{CH}-\mathrm{OHCH}{ }_{3}\end{array}$ & $\begin{array}{l}1985 \\
1985\end{array}$ & $\begin{array}{l}\text { Nicolaou et al. } \\
\text { Nicolaou et al. }\end{array}$ \\
\hline & $\left(\mathrm{CH}_{2}\right)_{5} \mathrm{NH}_{2}$ & 2016 & Dallabernardina et al. ${ }^{31}$ \\
\hline
\end{tabular}




\begin{tabular}{|c|c|c|c|}
\hline Cor & $\begin{array}{l}(S)-\mathrm{CH}_{2} \mathrm{CH}-\mathrm{OHCH} \\
(R)-\mathrm{CH}_{2} \mathrm{CH}-\mathrm{OHCH}_{3}\end{array}$ & $\begin{array}{l}1985 \\
1985\end{array}$ & $\begin{array}{l}\text { Nicolaou et al. } \\
\text { Nicolaou et } a .^{33}\end{array}$ \\
\hline & $\mathrm{H}$ & $\begin{array}{l}1996 \\
1999\end{array}$ & $\begin{array}{l}\text { Nishimura and Nakatsubo } \\
\text { Xu and Vasella } \\
\text { 29 }\end{array}$ \\
\hline
\end{tabular}

In 1981 Takeo and co-workers reported the synthesis of $\beta$-methylcellotrioside using a Koenigs-Knorr glycosylation ${ }^{36}$ between building blocks 1 and 2 (Scheme 1) ${ }^{26}$ This produced the trisaccharide in 39\% yield alongside unreacted $\mathbf{1}$ and 2. The trisaccharide was converted into the bromide $\mathbf{4}$ before methanolysis in the presence of mercuric cyanide, which gave $84 \%$ of 5 . Zemplén deacetylation ${ }^{37}$ then resulted in the targeted cellotrioside 6 in 92\% yield. 
Scheme 1 . Synthesis of $\beta$-methyl cellotrioside reported by Takeo and co-workers in $1981 .^{26}$
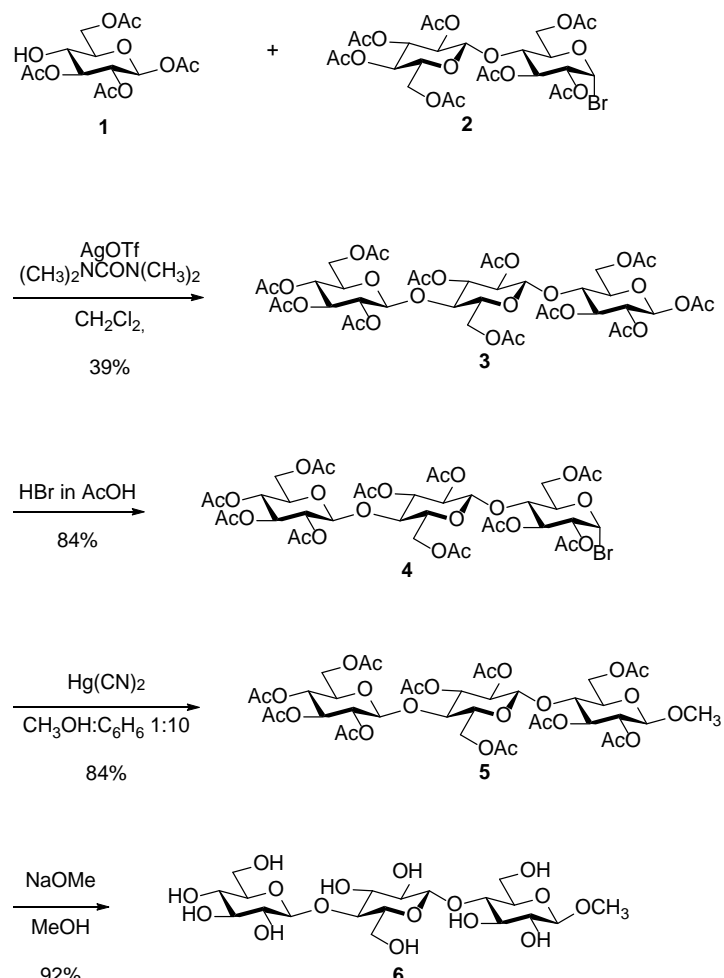

$92 \%$

Nishimura and Nakatsubo published the first synthesis of cellooctaose using a convergent synthetic strategy in $1996 .^{35}$ The synthesis is depicted in Scheme 2. The tetrasaccharide 8 (derived from allyl 3-O-benzyl-4-O-(p-methoxybenzyl)-2,6-di-O-pivaloyl- $\beta$-D-glucopyranoside $\quad 7 \quad$ using a linear synthetic method described by Nishimura et $a l .^{38}$ ) was used as a common precursor for the tetrasaccharide acceptor 9 and Schmidt ${ }^{39}$ donor 11. These two were coupled under standard conditions $\left(\mathrm{BF}_{3} \cdot \mathrm{OEt}_{2}\right)$ giving the octasaccharide 12 in $95 \%$ yield. The glycosylation was conducted in a high-vacuum system allowing for better control of the anhydrous reaction conditions. Protecting group manipulations afforded the fully protected oligosaccharide $\mathbf{1 4}$. The allyl group was removed using a one-pot procedure first reported by Kariyone and Yazawa ${ }^{40}$ before the anomeric position was acetylated. Catalytic hydrogenolysis followed by acetylation yielded the fully acetylated 
octasaccharide 18. After purification, deacetylation afforded cellooctaose 19 in $87 \%$ yield. In a similar sequence, tetrasaccharide 8 was converted into cellotetraose 25 (see Scheme 2). More recently, Pfrengle and co-workers produced linear $\beta$ - $(1 \rightarrow 4)$-glucans using solid-phase oligosaccharide synthesis. ${ }^{31}$ This work was part of a larger study of xyloglucan synthesis and will be described in section 4.1. 
Scheme 2. Synthesis of cellotetraose and cellooctaose published by Nishimura and Nakatsubo. ${ }^{35}$

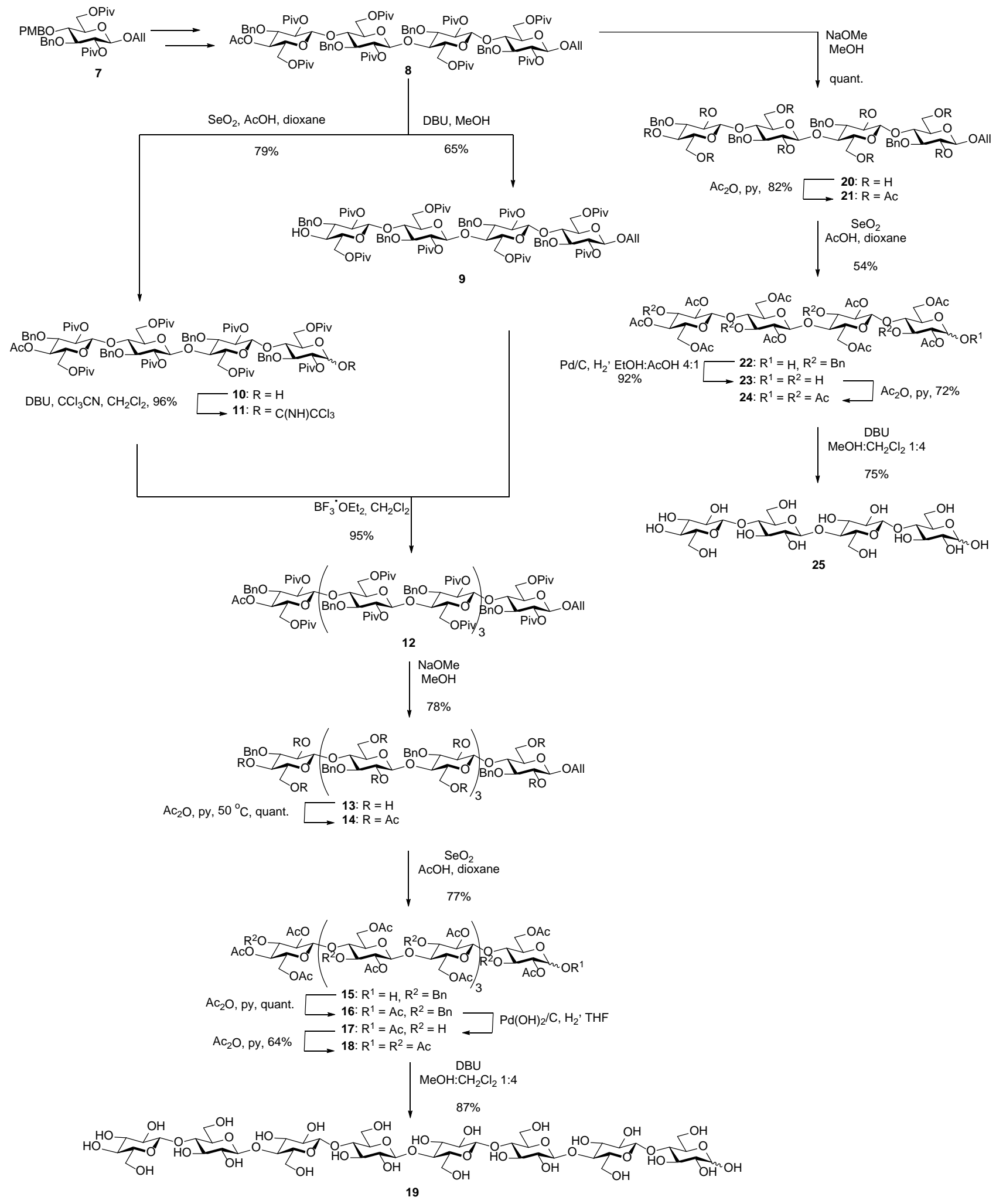




\section{Hemicellulose}

Hemicellulose was first described in 1891 by Ernst Schulze, as the components of the cell wall that are easily dissolved in hot diluted mineral acids. ${ }^{41}$ Such a definition based on extractability was not, however, found to be useful, and these days the term is commonly used to refer to a group of nonstarch, non-pectic polysaccharides found in association with cellulose in the cell walls of higher plants. Based on current knowledge, hemicellulose is generally divided into four classes of structurally different cell-wall polysaccharides: xylans, mannans, xyloglucans and glucans including mixed linkage glucans $\left(\beta-(1 \rightarrow 3),(1 \rightarrow 4)\right.$-glucans, MLGs) as shown in Figure $5 .{ }^{42}$ These are the types of polysaccharides described in most reviews about hemicellulose, but Peter Ulvskov and Henrik Scheller, in their review of hemicellulose, further narrow down the definition to glycans sharing a $\beta$ $(1 \rightarrow 4)$-linked backbone with an equatorial configuration at the C-4 position. This excludes MLGs, callose and laminarin $\left(\beta-(1 \rightarrow 3)\right.$-linked glucans) from the hemicelluloses. ${ }^{4,42}$ Other polysaccharides, such as galactans, arabinans, and arabinogalactans are sometimes included in this group as well, but these will be discussed separately in section $6 .{ }^{42}$ 


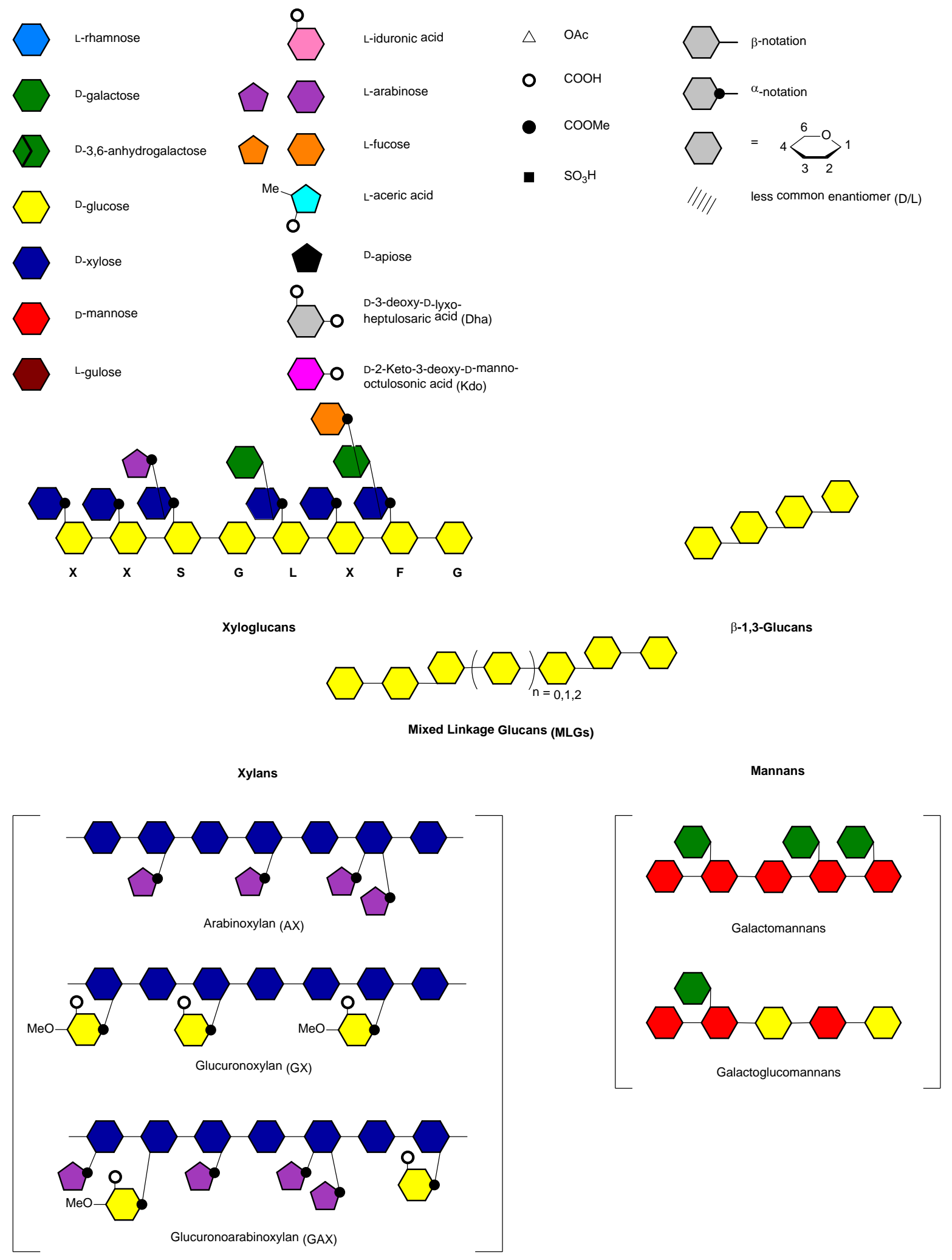

Figure 5. Overview of the different families of hemicellulose polysaccharides. 


\subsection{Xyloglucans}

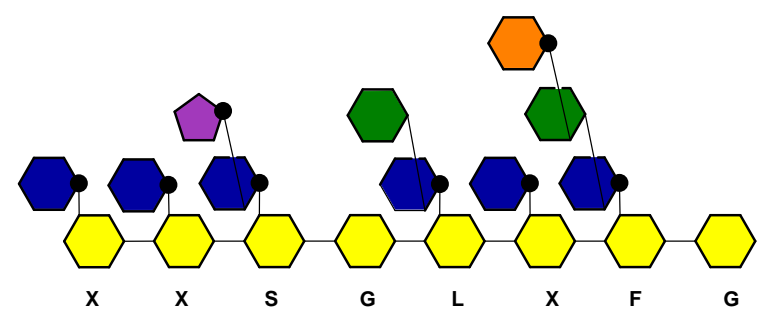

Figure 6. Structure of XyGs with the most common side chains.

Xyloglucans (XyGs) constitute the most abundant class of hemicellulose in the primary cell wall of higher plants. They have been found in every species of land plant that has been analyzed, except charophytes. ${ }^{4}$ An exemplary structure of XyG with the different side chains is shown in Figure 6. However, this schematic representation does not indicate the frequency of each side chain and many variations in this general pattern can be observed. XyGs have a backbone of $\beta$-D- $(1 \rightarrow 4)$-glucans substituted by $\alpha$-D-( $1 \rightarrow 6)$-linked xylose residues. A special one-letter code is used to label the different XyG side chains. $\mathbf{G}$ denotes an unbranched Glcp residue, while $\mathbf{X}$ corresponds to an $\alpha$-D-

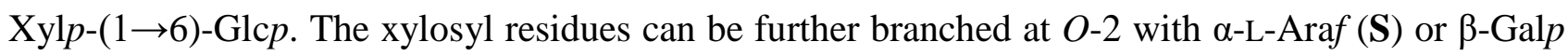
(L), which can be further substituted at $O-2$ with $\alpha$-L-Fucp $(\mathbf{F})$. The galactose residues can be acetylated. The branches dictate the physical properties of the molecules; the fewer the branches, the less soluble the XyG. Only a few syntheses of XyGs with substituted xylose (side chains $\mathbf{S}$, $\mathbf{L}$ or $\mathbf{F}$ ) have been reported to date, including an LG fragment produced by Jacquinet and co-workers ${ }^{43}$ and an XXFG fragment synthesized by Ogawa and co-workers. ${ }^{44}$ In 2016, Pfrengle and co-workers achieved the automated solid phase synthesis of a variety of XyG oligomers without xylose substitution. ${ }^{31}$ Table 5 shows all the XyG fragments synthesized to date. 
Table 5. The synthetic XyG fragments.

\begin{tabular}{|l|l|l|l|}
\hline Structure & R & Year & Reference \\
\hline & $\left(\mathrm{CH}_{2}\right)_{5} \mathrm{NH}_{2}$ & 2016 & Dallabernardina et $_{\text {al. }}{ }^{31}$ \\
\hline & & & \\
\hline
\end{tabular}


In 1990, Jacquinet and co-workers synthesized tetrasaccharide LG (38) by condensation of the two key disaccharides galactoxylose and cellobiose $\mathbf{3 3}$ and $\mathbf{3 6}$ respectively, as shown in Scheme 3. The building blocks 33 and 36 were synthesized through standard protection group manipulations and glycosylation reactions. Coupling of donor $\mathbf{3 3}$ and diol acceptor $\mathbf{3 6}$ afforded tetrasaccharide $\mathbf{3 7}$ in 50\% yield as a single regio- and stereoisomer. However, the authors showed that steric hindrance around the $O-6$ ' position of the acceptor had a dramatic impact on the regioselectivity as well as the yield of the reaction. Indeed, when using a diol acceptor with benzyl protecting groups in lieu of acetyl groups, only $10 \%$ of the undesired $\beta$-linked tetrasaccharide could be isolated, while none of the desired stereoisomer was observed. 
Scheme 3. Synthesis of LG tetrasaccharide by Jacquinet and co-workers. ${ }^{43}$
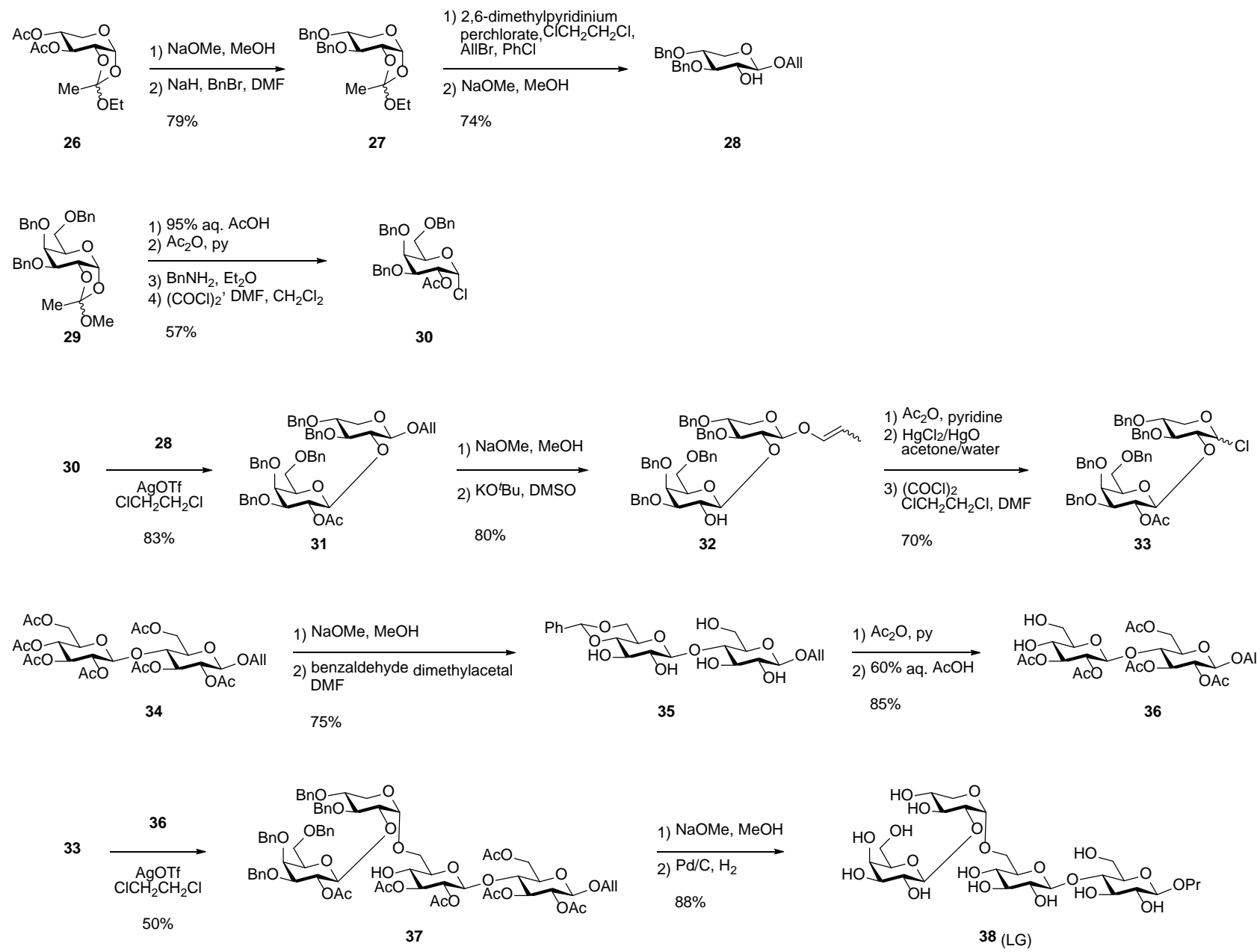

The same year, Ogawa and co-workers ${ }^{44}$ reported the synthesis of both the heptasaccharide XXXG (48) and the branched nonasaccharide XXFG (57) using a convergent approach as shown in Scheme 4. To reach the two targets, they used the key glycohexaosyl acceptor 46 (XXGG) as a common precursor. This resulted from a coupling between fragment $\mathbf{4 3}(\mathbf{X X})$ and cellobiose acceptor $\mathbf{4 4}$ (GG). Glycosylation with xylopyranose donor $\mathbf{4 0}$ and hexose acceptor $\mathbf{4 6}$ afforded the heptasaccharide $\mathbf{4 7}$ in $64 \%$ yield as a $4: 3$ ratio of separable $\alpha: \beta$ stereoisomers. Finally, saponification and hydrogenolysis 
afforded the desired unprotected XXXG target 48. In the same manner, coupling between trisaccharide donor 55 and $\mathbf{4 6}$ afforded the nonasacharide 56 as a 3:1 mixture of stereoisomers which, after separation and deprotection, gave the XXFG xyloglucan oligosaccharide 57. Even though the crucial glycosylation steps were plagued by low yields and poor stereoselectivity, both XyG targets could be reached by way of a common advanced intermediate using this convergent strategy. 
Scheme 4. Synthesis of XXXG and XXFG oligomers by Ogawa and co-workers. ${ }^{44}$

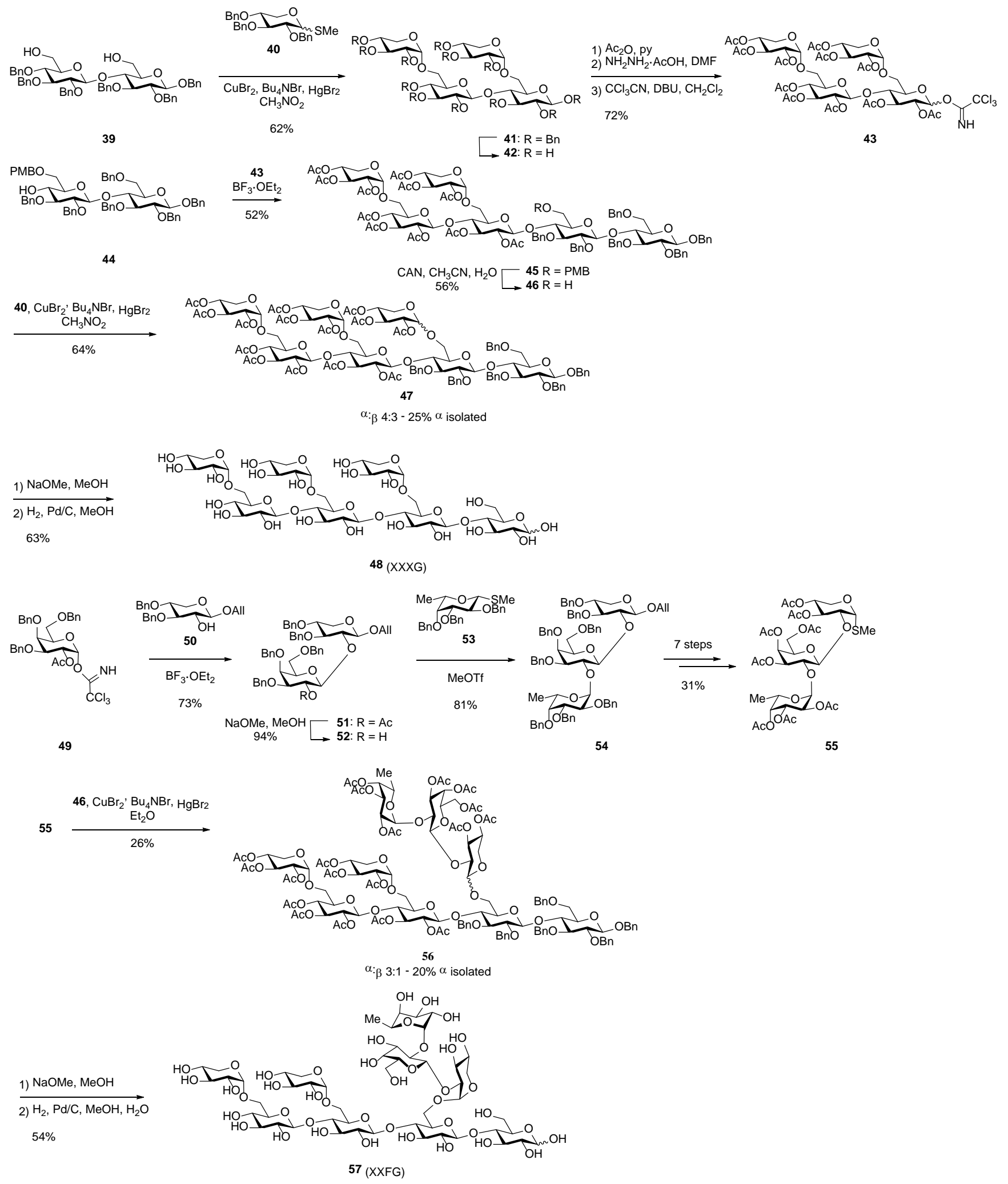


More recently, Pfrengle and co-workers reported an automated glycan assembly of five XG oligosaccharides using monosaccharide $\mathbf{5 8}$ and disaccharide $\mathbf{5 9}$ as building blocks (Scheme 5). ${ }^{31}$ This solid phase synthesis also enabled the production of linear cellotriose and cellopentaose (see Table 4). The authors used a Merrifield resin ${ }^{46}$ with a photocleavable linker ${ }^{47}$ and two phosphate glycosyl donors ${ }^{48}$ with either Fmoc or a Lev groups as temporary O-4 protection. Using this strategy, the five XyG oligomers (60-64) were produced in overall yields of 2-16\%. 
Scheme 5. Automated glycan assembly of five XyG oligosaccharides by Pfrengle and co-workers. ${ }^{31}$

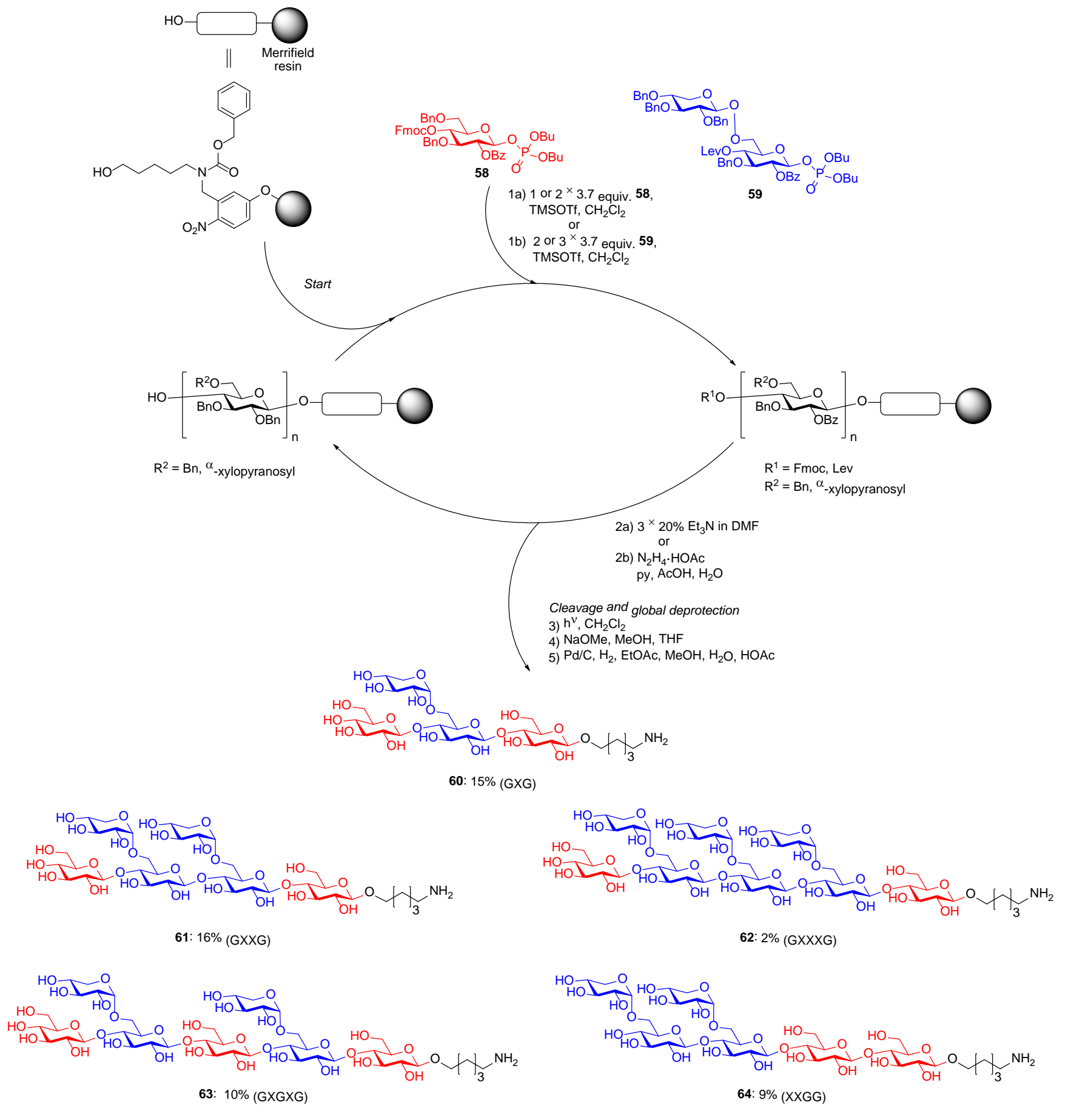




\section{$4.2 \beta-(1 \rightarrow 3)-D-G l u c a n s$}

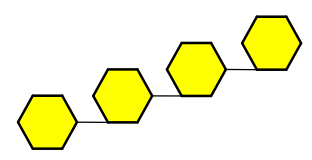

Figure 7. Structure of $\beta$-(1 $\rightarrow 3)$-D-glucan (callose).

$\beta$-(1 $\rightarrow 3)$-D-Glucans with various short $\beta$ - $(1 \rightarrow 3)$-D-glucan chains branched at the 6 -position of the backbone are found in the cell walls of land plants, algae and also fungi. ${ }^{49}$ Callose is in this class of polysaccharide and has been isolated from all multicellular green algae as well as some higher plants (embryophytes). ${ }^{50}$ This polymer plays an important role in maintaining cell wall integrity as well as in plant defense. In response to pathogen attack, callose is deposited between the plasma membrane and the pre-existing cell wall at the sites of attack. ${ }^{51}$ Another member of this class, laminarin, has been found in brown algae. As certain types of $\beta$-glucans containing $(1 \rightarrow 3)$ and $(1 \rightarrow 6)$ linkages exhibit biological activity by stimulating the innate immune system in man, their synthesis has attracted much interest. $^{52}$ Several groups have successfully accomplished syntheses of linear as well as branched oligosaccharides mostly with the motivation of synthesizing fungal glycans. The synthesized fragments are summarized in Table 6.

Table 6 . The $\beta$-(1 $\rightarrow 3)$-D-glucan fragments synthesized to date.

\begin{tabular}{|c|c|c|c|}
\hline Structure & $\mathbf{R}$ & Year & Reference \\
\hline $\mathrm{OPR}_{\mathrm{O}}$ & $\begin{array}{l}\text { Me } \\
\text { H }\end{array}$ & $\begin{array}{l}1993 \\
2011 \\
2005\end{array}$ & $\begin{array}{l}\text { Takeo et al. }{ }^{53} \\
\text { Adamo et al. }{ }^{54} \\
\text { Jamois et al. }{ }^{55}\end{array}$ \\
\hline
\end{tabular}




\begin{tabular}{|c|c|c|c|}
\hline & $\begin{array}{l}\left(\mathrm{CH}_{2}\right)_{3} \mathrm{~S}\left(\mathrm{CH}_{2}\right)_{2} \mathrm{NH}_{2} \\
\mathrm{Cy}-\left(\mathrm{C}_{5} \mathrm{H}_{9}\right)\end{array}$ & $\begin{array}{l}2011 \\
2013\end{array}$ & $\begin{array}{l}\text { Adamo et } a .^{54} \\
\text { Jong et al. }{ }^{56}\end{array}$ \\
\hline & $\mathrm{Me}$ & 2011 & Adamo et al. ${ }^{54}$ \\
\hline & All & 2003 & Zeng et al. ${ }^{57}$ \\
\hline & $\begin{array}{l}\mathrm{Me} \\
\mathrm{H}\end{array}$ & $\begin{array}{l}1993 \\
2003 \\
2005\end{array}$ & $\begin{array}{l}\text { Takeo et al. }{ }^{53} \\
\text { Zeng et al. }{ }^{57} \\
\text { Jamois et al. }{ }^{55}\end{array}$ \\
\hline & $\begin{array}{l}\mathrm{Me} \\
\mathrm{CH}_{2} \mathrm{CHOCH}_{2} \\
\mathrm{H}\end{array}$ & $\begin{array}{l}1993 \\
2005 \\
2005\end{array}$ & $\begin{array}{l}\text { Takeo et al. } .^{53} \\
\text { Huang et al. }{ }^{58} \\
\text { Jamois et al. }\end{array}$ \\
\hline , & $\left(\mathrm{CH}_{2}\right)_{3} \mathrm{NH}_{2}$ & 2016 & Yashunsky et al. ${ }^{59}$ \\
\hline & $\begin{array}{l}\mathrm{Me} \\
\mathrm{H} \\
\left(\mathrm{CH}_{2}\right)_{3} \mathrm{~S}\left(\mathrm{CH}_{2}\right)_{2} \mathrm{NH}_{2} \\
\left(\mathrm{CH}_{2}\right)_{5} \mathrm{COOCH}_{3} \\
\left(\mathrm{CH}_{2}\right)_{2} \mathrm{NHCO}\left(\mathrm{CH}_{2}\right)_{3} \mathrm{COOSu}\end{array}$ & $\begin{array}{l}1993 \\
2009 \\
2011 \\
2015 \\
2015\end{array}$ & $\begin{array}{l}\text { Takeo et al. }{ }^{53} \\
\text { Mo et al. }{ }^{60} \\
\text { Adamo et al. }{ }^{54} \\
\text { Elsaidi et al. }{ }^{61} \\
\text { Liao et al. }{ }^{62}\end{array}$ \\
\hline$(\square)^{-O R}$ & $\mathrm{Me}$ & 1993 & Takeo et al. ${ }^{53}$ \\
\hline
\end{tabular}




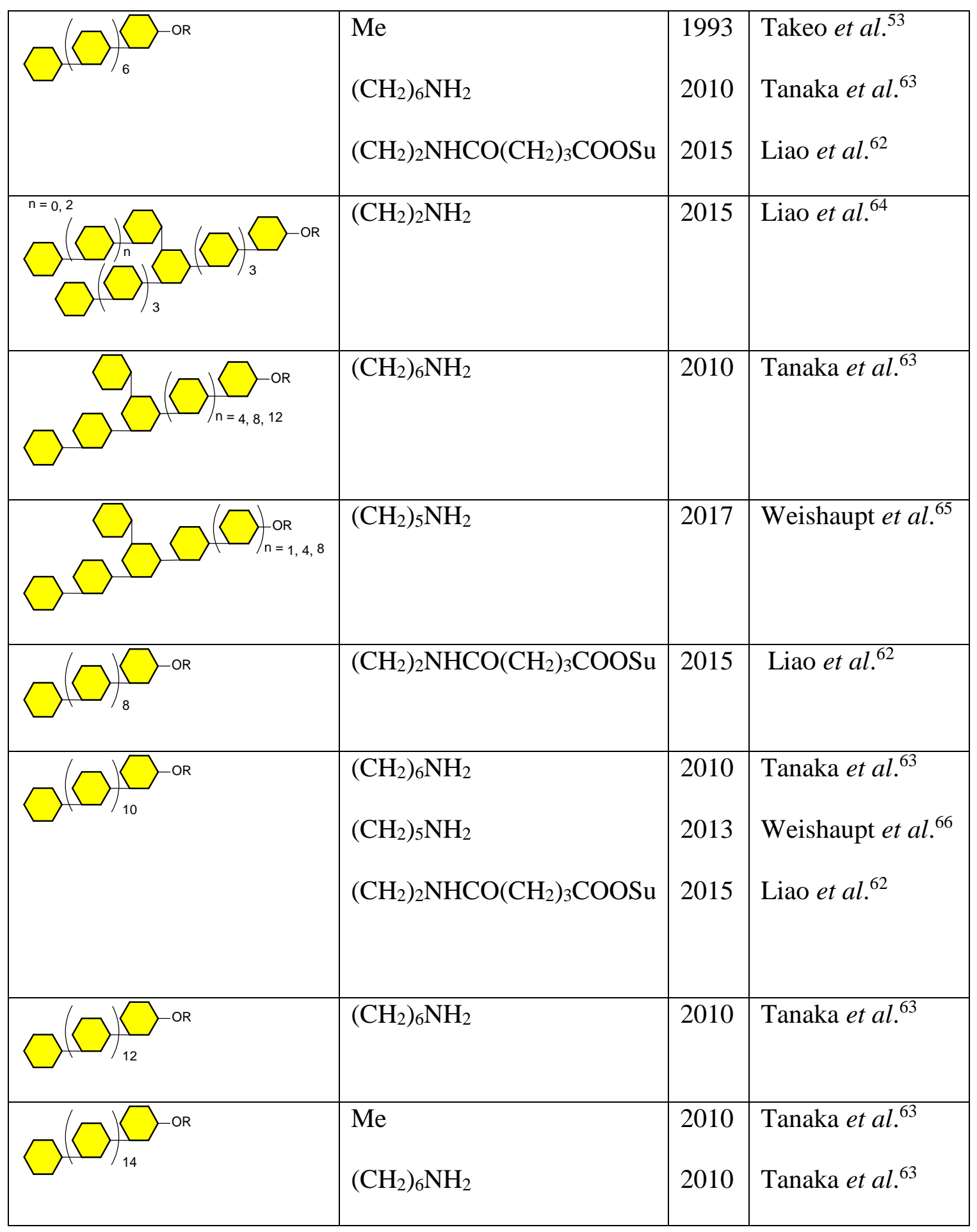

Several strategies have been developed to produce both linear and branched $\beta-(1 \rightarrow 3)$-D-glucan oligosaccharides through solution phase synthesis. For oligosaccharides up to the pentasaccharide 
level, an iterative approach has been used, which has enabled the synthesis of tri-, tetra- and pentasaccharides in the same sequence, as exemplified by the preparation of $\beta$-(1 $\rightarrow 3)$-D-glucan oligosaccharides reported by Vetvicka and co-workers (Scheme 6). ${ }^{55,56}$ The group used an iterative deprotection-glycosylation approach with monosaccharide 65 to elongate the chain. This key monosaccharide could act successfully as both donor and acceptor to afford linear glucans 66-69. In common with most other reported syntheses of linear $\beta-(1 \rightarrow 3)$-D-glucans, the glucoside building block 65 carried a benzoyl group at the 2-position to invoke neighboring group participation and a 4,6-benzylidene acetal as a permanent protecting group. The short length oligosaccharides were easily deprotected using Zemplén conditions and catalytic hydrogenolysis to afford the corresponding reducing oligosaccharides.

Scheme 6. Synthesis of protected di, tri, tetra- and penta- $\beta$-D- $(1 \rightarrow 3)$-glucans by Vetvicka and coworkers. ${ }^{55}$
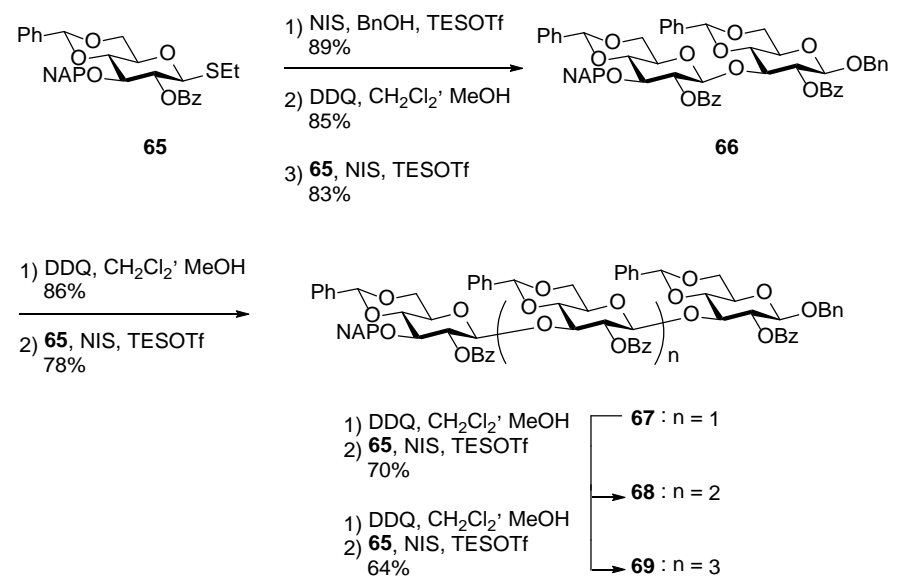

For the synthesis of longer $\beta$-D-glucan oligosaccharides in solution, the use of convergent strategies employing di- ${ }^{53,59-62,64}$, tri- ${ }^{54,57-59,64}$, tetra- ${ }^{52,64}$ and pentasaccharide ${ }^{52,59}$ building blocks has been demonstrated to be advantageous, as it reduces the number of steps. This type of approach has been 
used to synthesize long linear ${ }^{52,62}$ and branched ${ }^{52,59,64}$ oligosaccharides. In 2015, Guo and co-workers $^{62}$ reported a convergent synthesis of tetra-, hexa-, octa-, deca- and dodeca- $\beta$-( $1 \rightarrow 3)$-D-glucans, which they achieved through pre-activation-based iterative glycosylation with p-tolylthioglycosides as donors and disaccharide $\mathbf{7 0}$ as the key building block. The latter was used as a donor to elongate the chain from disaccharide to tetra-, hexa-, octa-, deca- and finally dodecasaccharides.

Scheme 7. Convergent linear synthesis of tetra-, hexa-, octa-, deca-, and dodecasaccharides by Guo and co-workers. ${ }^{62}$
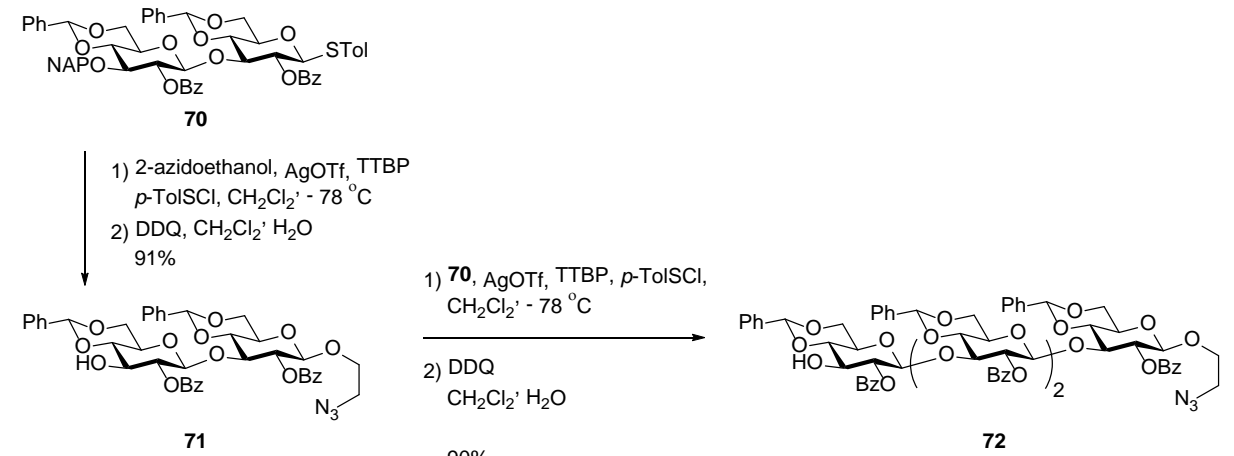

$90 \%$

72

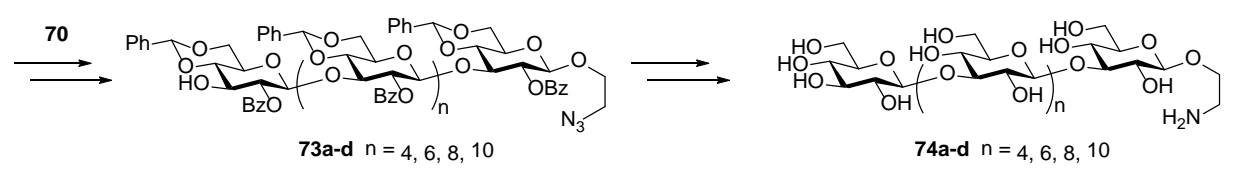

Using another highly convergent and efficient synthesis, the same group prepared two branched oligosaccharides consisting of a nonaglucan backbone carrying a $\beta$-(1 $\rightarrow 3)$-D-glucodiose or -tetraose at the 6",',-position. ${ }^{64}$ The backbone was assembled in a $[4+1+4]$ fashion, in which each tetrasaccharide building block was generated using an iterative one-pot glycosylation as shown in Scheme 8. 
Scheme 8. Retrosynthesis of branched glucans by Guo and co-workers. ${ }^{64}$

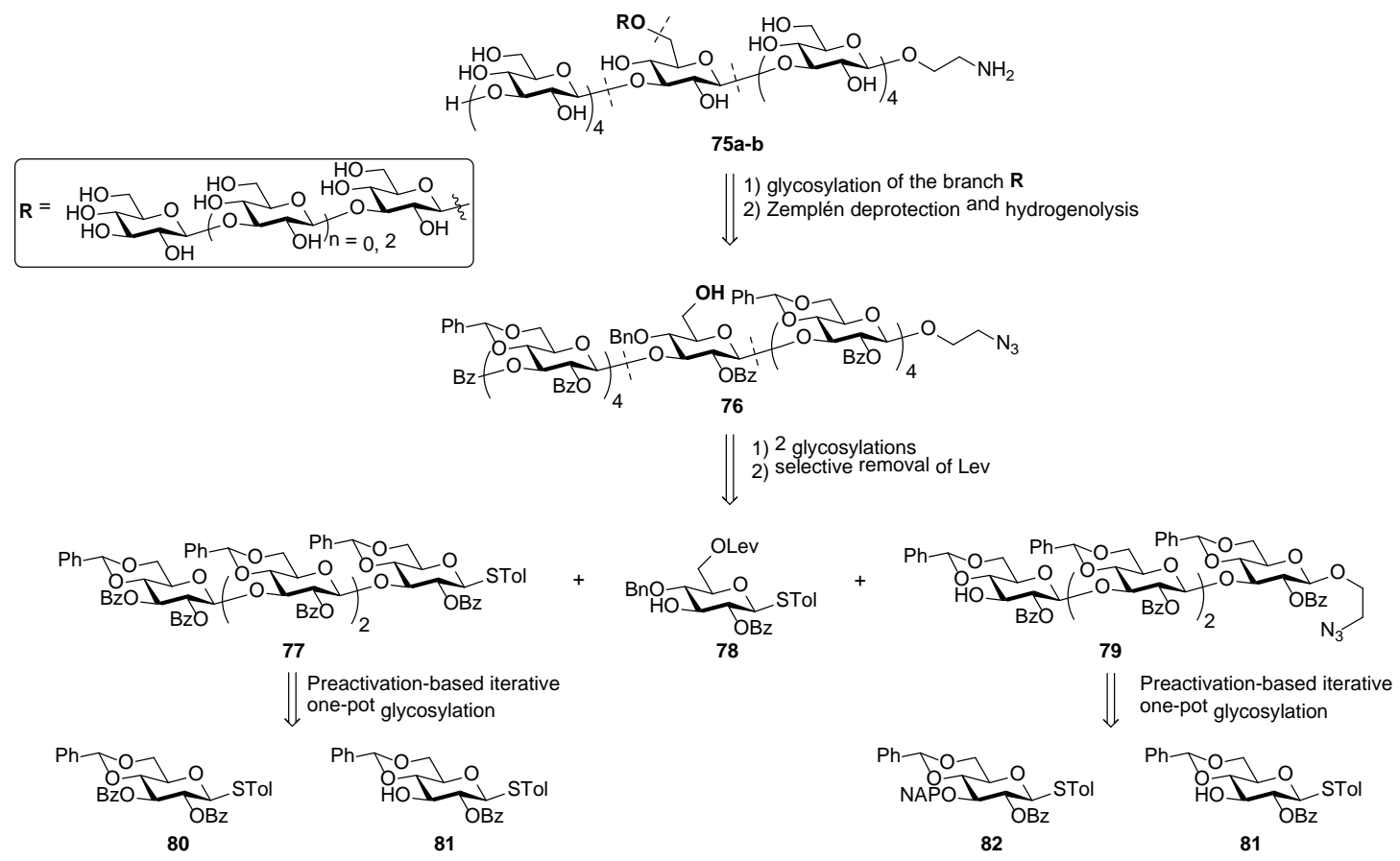

Takahashi and co-workers achieved the impressive syntheses of linear hexadeca- and branched heptadeca-saccharides by conducting a convergent synthesis employing a tetrasaccharide as the key building block. $^{52}$ In this case, 2,3-diol glycosides with a 4,6-O-benzylidene protecting group were effective as glycosyl acceptors, made possible by the higher reactivity of the 3-position over the 2position. This afforded the desired $(1 \rightarrow 3)$-linked regioisomer in each glycosylation reaction.

As shown by these examples, the use of pre-assembled building blocks is efficient but only gives access to glucans of limited chain lengths. In 2013, the group of Seeberger developed an iterative automated solid-phase synthesis of linear $\beta$-D-glucan oligosaccharides giving great flexibility in terms of the length of the targeted oligosaccharides. They showed the efficiency of the approach by synthesizing a linear $\beta$-(1 $\rightarrow 3)$-D-glucan dodecasaccharide, as shown in Scheme $9 .{ }^{66}$ Glycosyl 
phosphate building block 83 in combination with the resin-linker construct $\mathbf{8 4}$ (see also Scheme 5) proved to be a suitable choice for the automated synthesis of linear glucans. The efficiency of this glycosylation sequence was proven by the average glycosylation yield over 12 cycles: 89\%. In 2017, the group further optimized the conditions to synthesize a series of branched $\beta-(1 \rightarrow 3)$-D-glucans. ${ }^{65}$

Scheme 9. Automated solid-phase synthesis of $\beta$-glucan dodecasaccharide 87 by Seeberger and coworkers. ${ }^{66}$

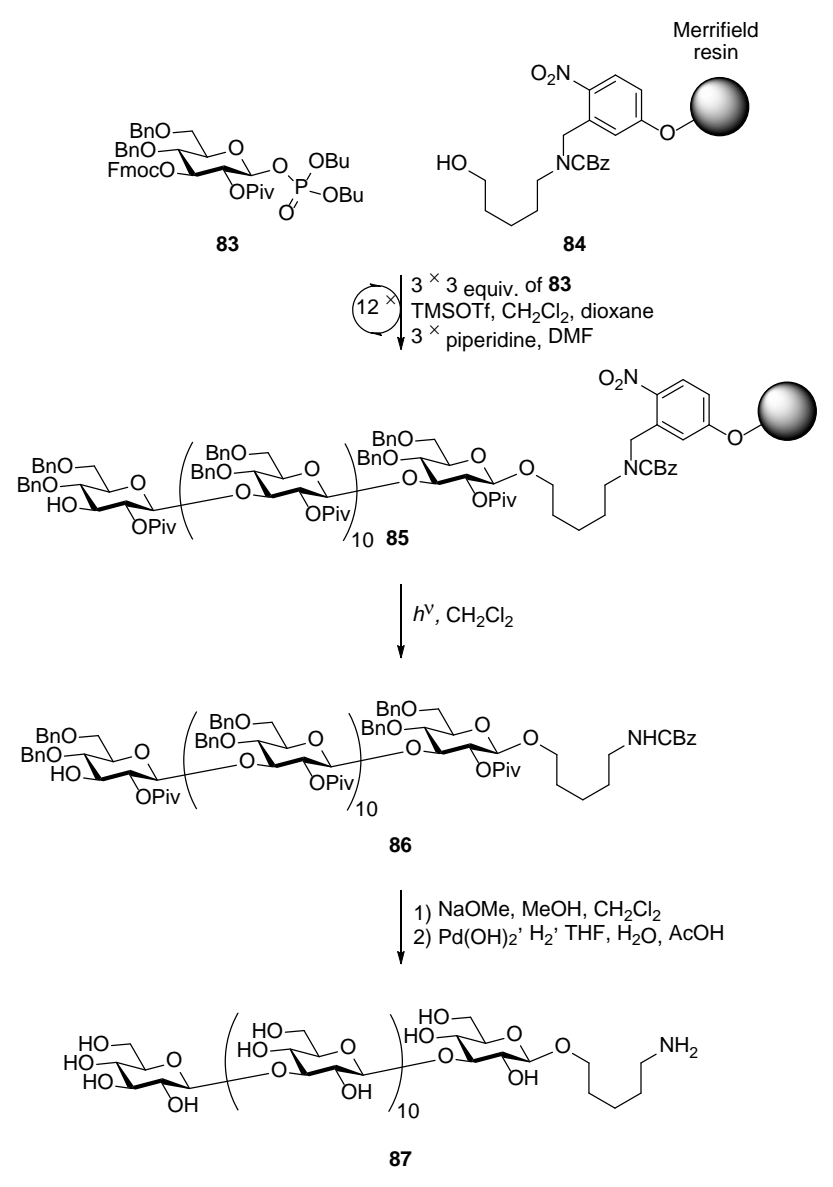




\subsection{Mixed-linkage $[\beta-(1 \rightarrow 3), \beta-(1 \rightarrow 4)]$ glucans}

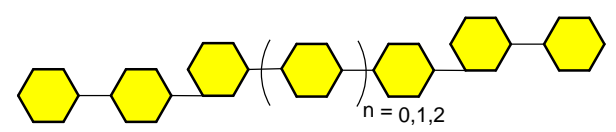

Figure 8. Structure of MLGs.

Mixed-linkage glucans (MLGs) are usually composed of short stretches of $\beta$-(1 $\rightarrow 4)$-glucans connected through $\beta$-(1 $\rightarrow 3)$-linkages. They are a type of hemicellulose characteristically found in both the primary and secondary cell walls of grasses. These glucans have also been isolated from bryophytes $^{67}$ and from the horsetail plant (Equisetum). ${ }^{68}$ More recently, in 2000, Lahaye and coworkers discovered MLG 6-sulfate in the cell wall of the red alga Kappaphycus alvarezii. No chemical synthesis of MLG oligosaccharides had been reported before the automated synthesis achieved by Pfrengle and co-workers in $2017 .{ }^{69}$

Table 7. The synthetic MLG fragments prepared by Pfrengle and co-workers.

\begin{tabular}{|l|l|l|}
\hline Structure & $\mathbf{R}$ & Reference \\
\hline & $\left(\mathrm{CH}_{2}\right)_{5} \mathrm{NH}_{2}$ & Dallabernardina et $a .^{69}$ \\
\hline
\end{tabular}




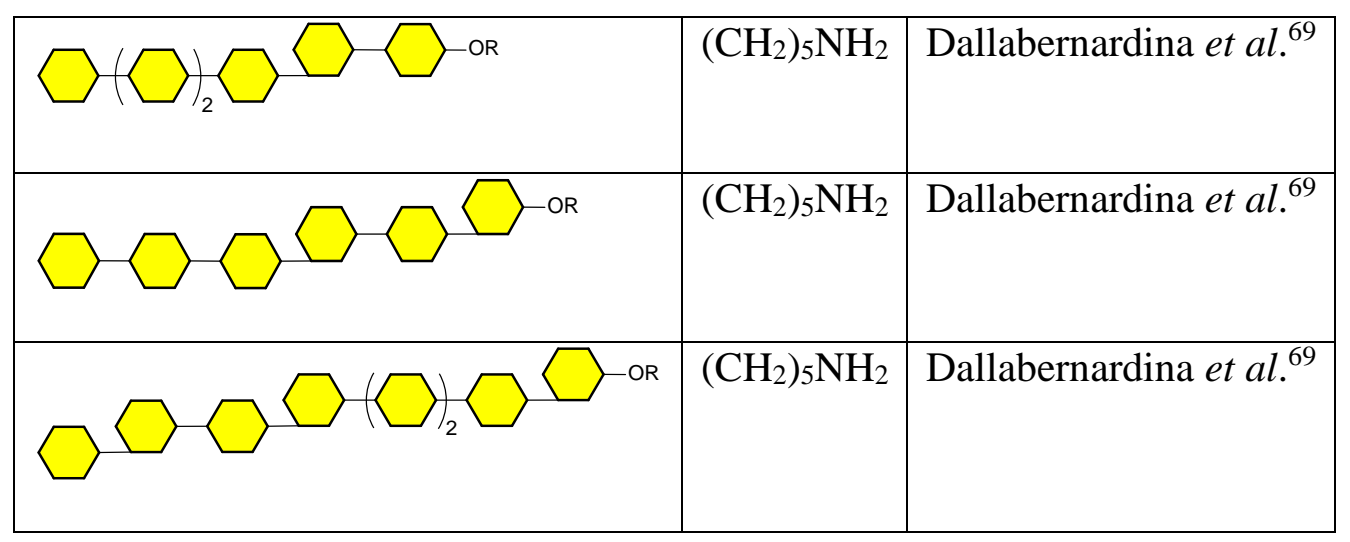

This group performed the automated synthesis of seven MLG oligosaccharides using glucose building blocks $\mathbf{5 8}$ and $\mathbf{8 8}$ as shown in Scheme 10. After optimizing the conditions for trisaccharide $\mathbf{8 9}$, they concluded that two glycosylation cycles were required for the formation of $\beta-(1 \rightarrow 3)$-linkages while one coupling sufficed to form the $\beta$-(1 $\rightarrow 4)$-linkages. After completion of the solid-phase synthesis, the oligomers were cleaved from the resin in a continuous flow reactor, and deprotected under standard conditions to afford the targets (89-95). 
Scheme 10. Automated synthesis of seven MLG oligosaccharides by Pfrengle and co-workers. ${ }^{\mathbf{6 9}}$

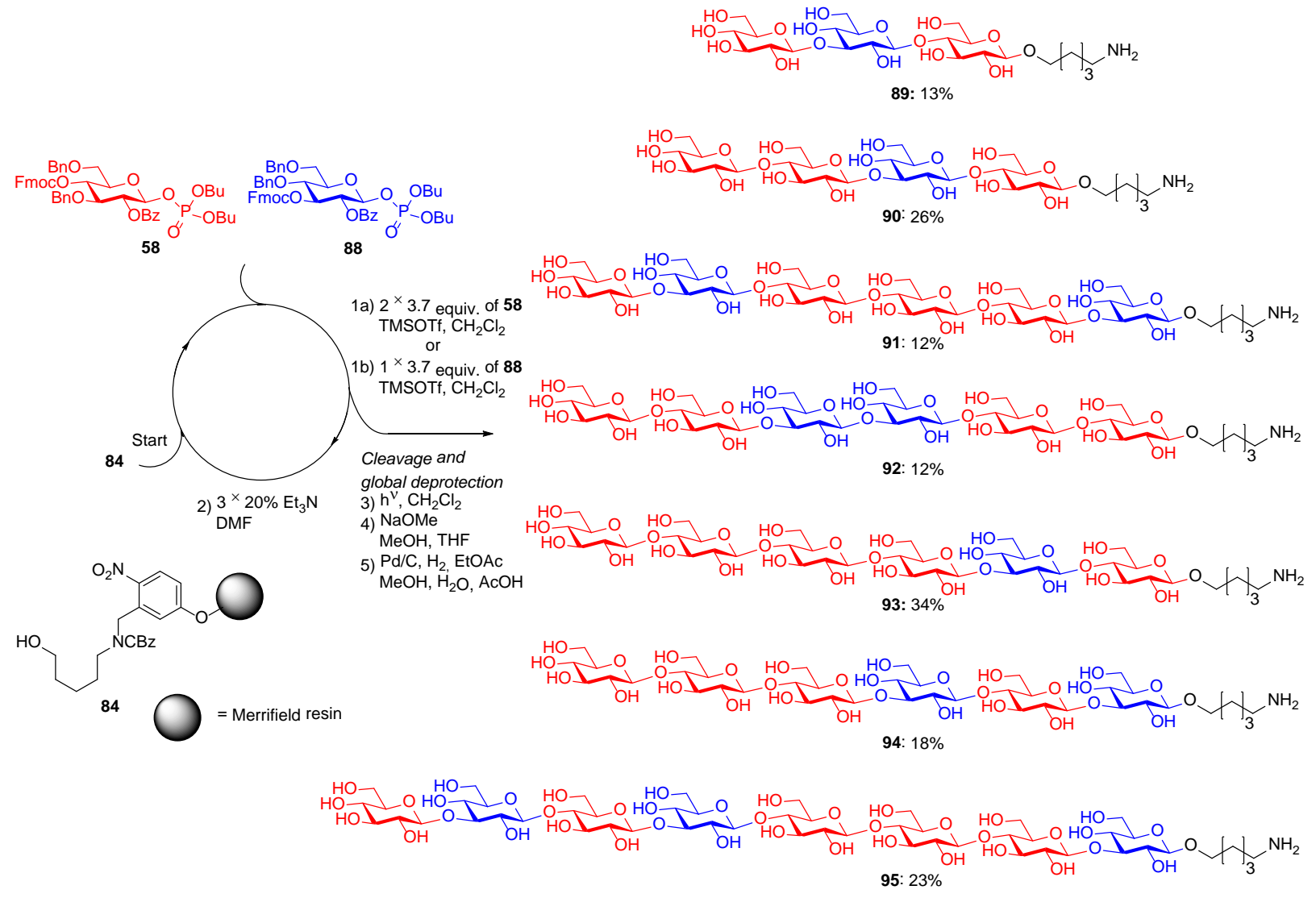




\subsection{Xylans (arabinoxylans, glucuronoxylans and glucurono-}

\section{arabinoxylans)}
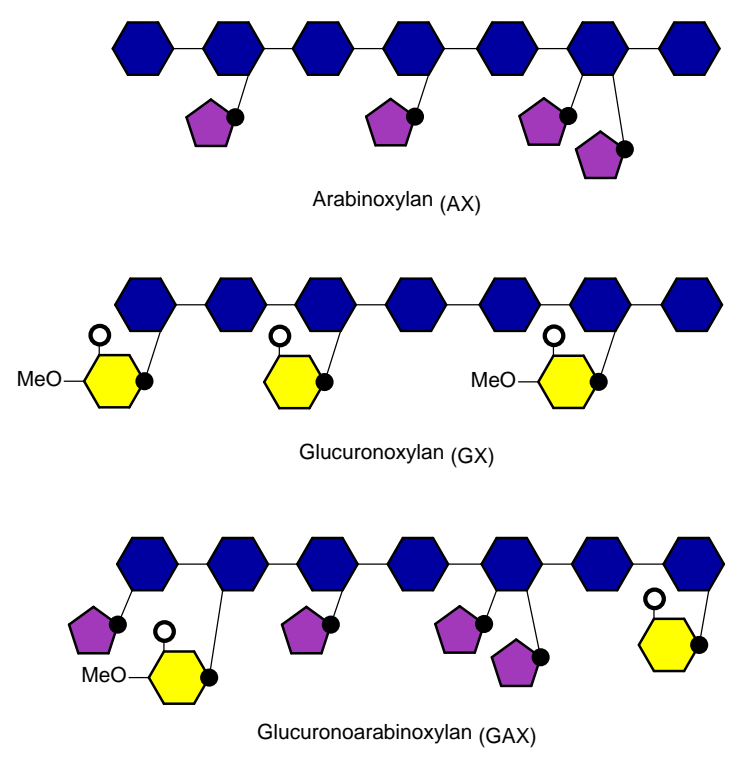

Figure 9. Schematic representation of different common heteroxylans.

Xylan, the most prevalent non-cellulosic polysaccharide in plant cell walls, binds to cellulose microfibrils and to lignin in order to strengthen the cell wall. ${ }^{4}$ Recently, Dupree and co-workers used ${ }^{13} \mathrm{C}$ solid-state magic-angle spinning (MAS) nuclear magnetic resonance (NMR) spectroscopy to show that xylans, which form a threefold helical screw in solution, flatten into a twofold helical screw ribbon to bind intimately to cellulose microfibrils in the plant cell wall. ${ }^{70}$ Xylans have a backbone of $\beta$ - $(1 \rightarrow 4)$ linked D-xylose and they are known to have highly complex and heterogeneous structures due to the number, distribution and differentiation of side chains. Xylans are usually classified into homoxylans and heteroxylans, where the latter includes arabinoxylans (AX), glucuronoxylans (GX) and glucuronoarabinoxylans (GAX) as shown in Figure 9. Arabinoxylans present L-arabinofuranosyl substituents $\alpha-(1 \rightarrow 2)$ and/or $\alpha-(1 \rightarrow 3)$ linked to the xylose residues of the backbone. Additionally, it 
has been found that in grasses, the $O-5$ position of arabinose can be esterified with for example ferulic acid that can form covalent bonds to lignin. ${ }^{71,72}$ In glucuronoxylans, 4-O-methyl-D-glucuronic acid and/or D-glucuronic acid residues are generally $\alpha$-(1 $(12)$-linked to xylose substituents, with an average substitution ratio of $1: 10 .^{73}$ Finally, GAX has $4-O$-methyl-D-glucuronic acid in the $O-2$ postitions and arabinofuranosides in the $O$-3-position with a ratio of xylan:substituents of approximately $10: 1.4 .^{73}$ In addition to these substituents, most xylans are acetylated to a varying degree. Esterification is mainly found in the $O-3$ position, and more rarely in the $O-2$ position. An overview of the xylan fragments that have been synthesized is presented in Table 8.

Table 8. Synthetic xylan fragments.

\begin{tabular}{|c|c|c|c|}
\hline Structure & $\mathbf{R}$ & Year & Reference \\
\hline & $\mathrm{H}$ & 1982 & Hirsch et al..$^{74}$ \\
\hline & $\begin{array}{l}\mathrm{Me} \\
\mathrm{H} \\
\mathrm{Bn} \\
\left(\mathrm{CH}_{2}\right)_{5} \mathrm{NH}_{2}\end{array}$ & $\begin{array}{r}1981 \\
1982 \\
1995 \\
2015\end{array}$ & $\begin{array}{l}\text { Kováč et al. }{ }^{75} \\
\text { Hirsch et al. }{ }^{74} \\
\text { Takeo et al. }{ }^{76} \\
\text { Schmidt et al. }{ }^{77}\end{array}$ \\
\hline & $\begin{array}{l}\mathrm{H} \\
\mathrm{Bn}\end{array}$ & $\begin{array}{l}1982 \\
1995\end{array}$ & $\begin{array}{l}\text { Hirsch et al. }{ }^{74} \\
\text { Takeo et al. }{ }^{76}\end{array}$ \\
\hline & $\begin{array}{l}\left(\mathrm{CH}_{2}\right)_{5} \mathrm{NH}_{2} \\
\mathrm{Bn}\end{array}$ & $\begin{array}{l}2015 \\
1995\end{array}$ & $\begin{array}{l}\text { Schmidt et al. }{ }^{77} \\
\text { Takeo et al. }{ }^{76}\end{array}$ \\
\hline & $\mathrm{Bn}$ & 1995 & Takeo et al. ${ }^{76}$ \\
\hline
\end{tabular}




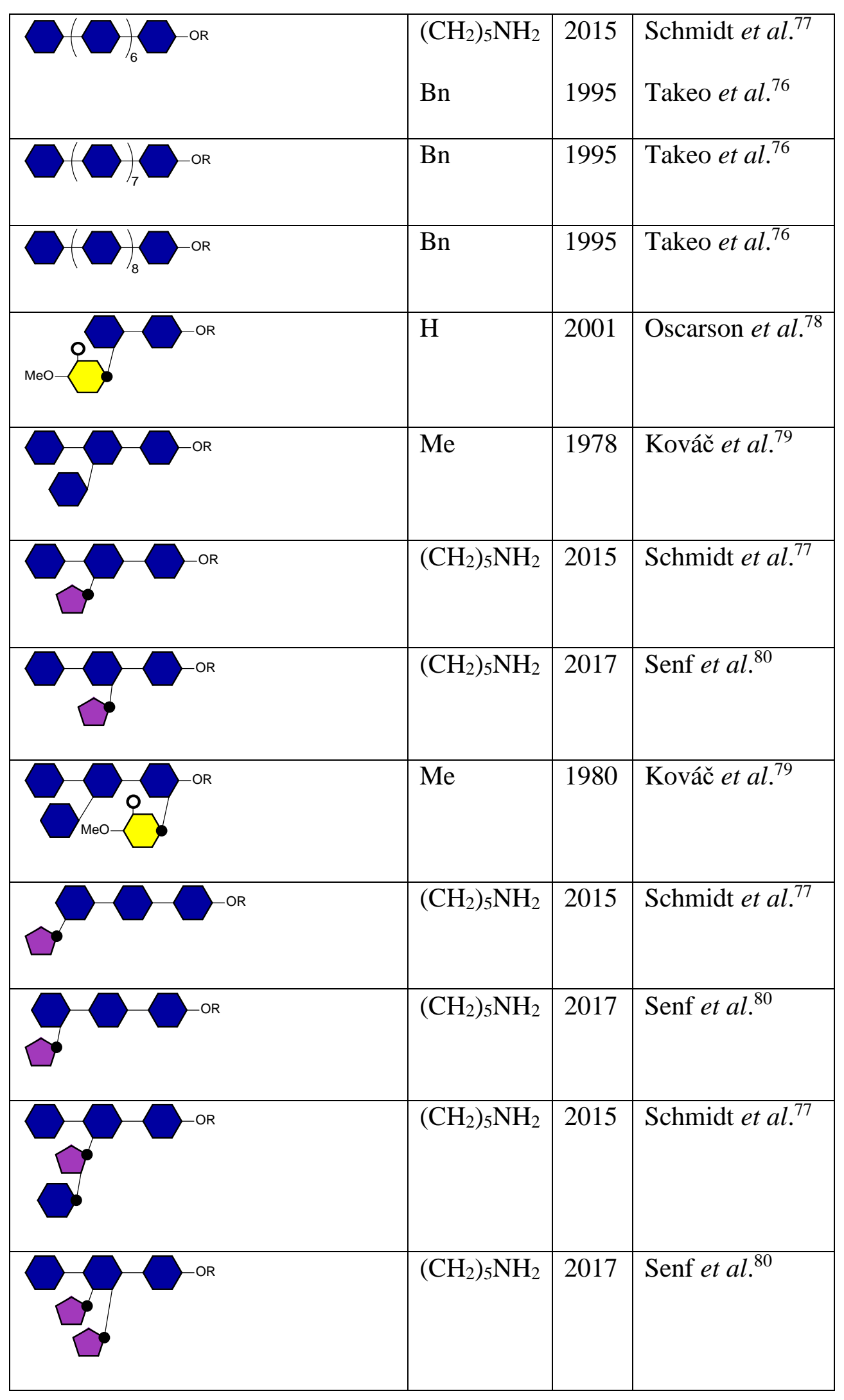




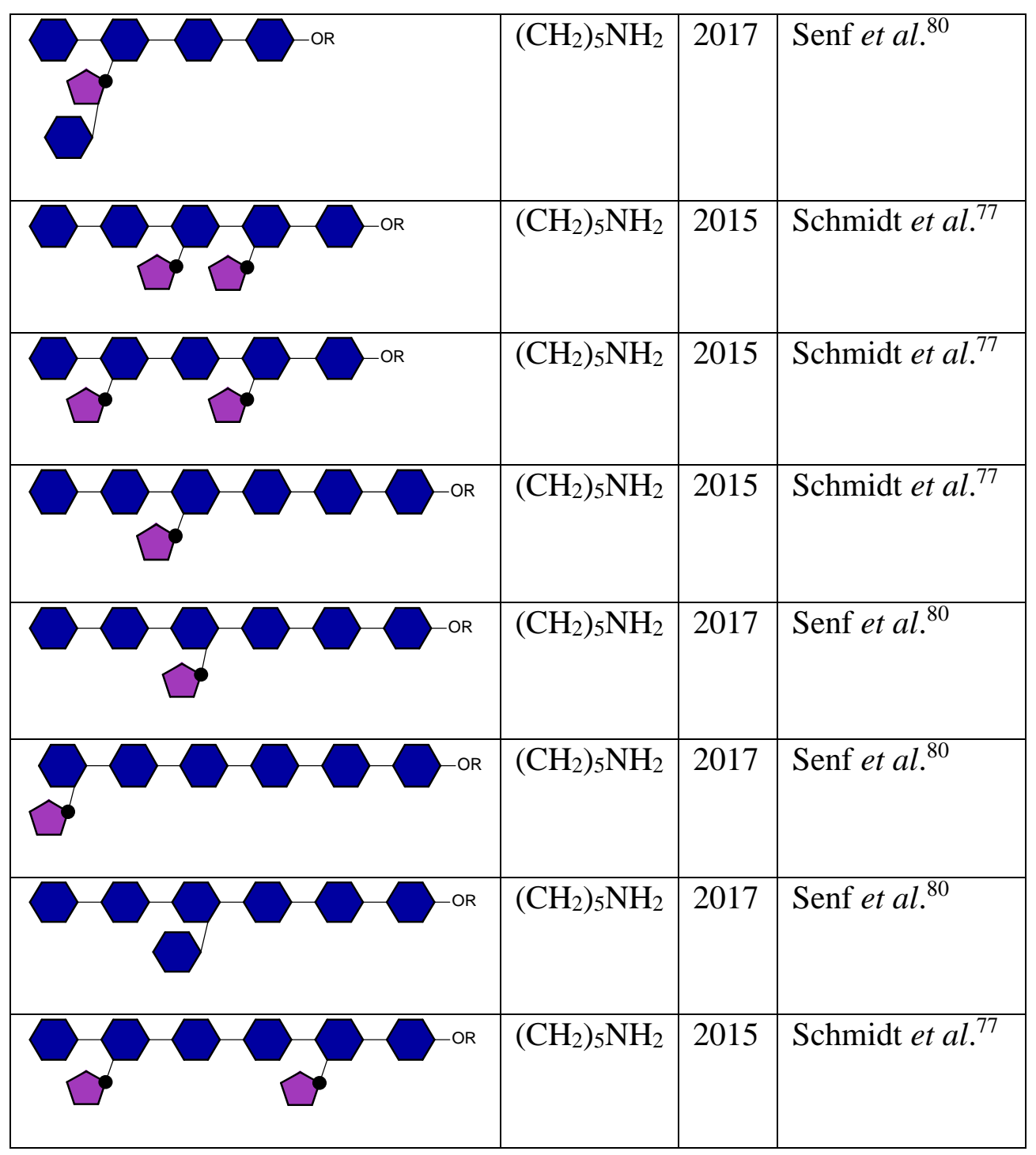

The chemical synthesis of well-defined homoxylans has been reported over recent decades by several groups using a range of synthetic strategies. ${ }^{74-77}$ Fewer have described the synthesis of heteroxylans, ${ }^{77-79}$ probably due to the difficulty in producing differentially-protected xylose building blocks needed to introduce side chains. Xylobiose was first synthesized by Myrhe and Smith in 1961, and the reaction was carried out via Helferich coupling ${ }^{81}$ between benzyl 2,3-di-O-benzyl-D-xylopyranoside and a peracetylated xylosyl bromide in the presence of $\mathrm{Hg}(\mathrm{CN})_{2}{ }^{82}$ Twenty years later, Hirsch and Kováč synthesized a series of oligoxylans in the same fashion by using a sequential approach to elongate the 
chain and reach up to a pentaxylan as shown in Scheme $11 .^{74,75} 1,2,3$-Tri-O-acetyl-4-O-benzyl- $\beta$-Dxylopyranose 96 was used as common building block to form both the bromide donor $\mathbf{9 7}$ and acceptor 98. Mercury cyanide-mediated coupling of the two afforded the disaccharide product as a 1:1.5 mixture of $\alpha: \beta$ stereoisomers, which could be separated by column chromatography to afford $23 \%$ of the desired $\beta$-(1 $\rightarrow 4)$-linked disaccharide 99. Subsequent hydrogenolysis afforded the 4'-OH disaccharide acceptor 100 ready for coupling with donor 97. Repetition of the two last steps enabled the researchers to reach tri-, tetra- and pentaxylans (103a-c) after saponification. Using this procedure, the yields of the glycosylation reactions were all quite low $(<25 \%)$. The same iterative strategy was subsequently employed to obtain a series of methyl $\beta$-xylosides up to a xylohexaoside. ${ }^{83}$

Scheme 11. Hirsch and Kováč strategy for the synthesis of oligohomoxylans. ${ }^{75}$
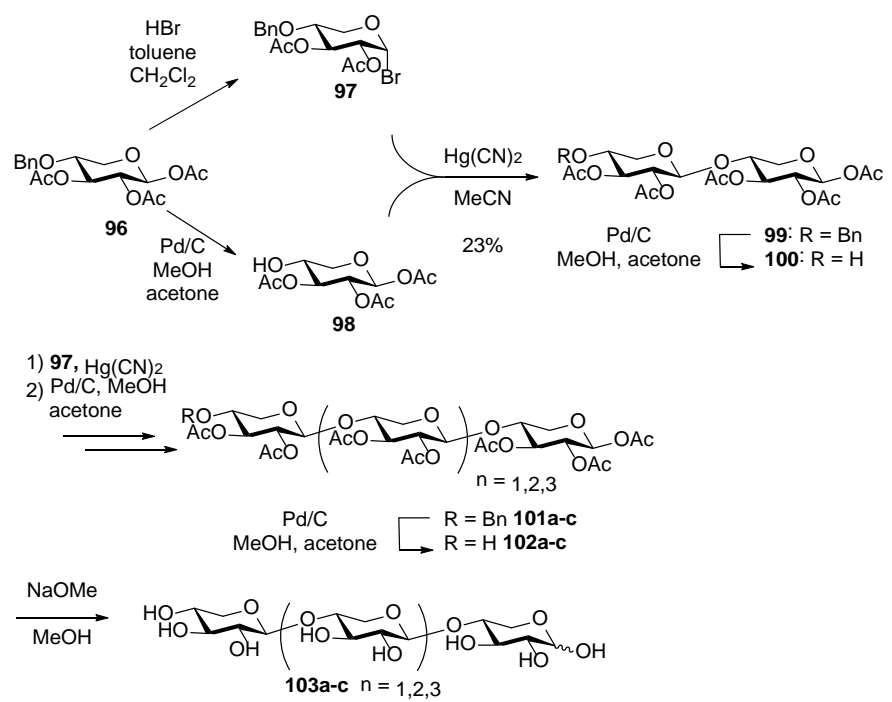

More recently, Takeo and co-workers developed a blockwise approach to a series of linear xylooligosaccharides up to xylodecaose using suitably protected thio-xylobiosides as building blocks and 
$\mathrm{N}$-iodosuccinimide (NIS) in combination with silver triflate as promoting agent. This strategy afforded glycosylation yields of around $80 \% .^{76}$

The first synthesis of heteroxylan oligosaccharides was reported by Hirsch and Kováč in 1982. ${ }^{75,79}$ The fragment was a xylotriose backbone bearing a $\beta-(1 \rightarrow 3)$-linked xylose unit and an $\alpha-(1 \rightarrow 2)$-linked glucuronic acid. The researchers started a stepwise synthesis from methyl 2,3-anhydro- $\beta$-Dribopyranoside 104 as shown in Scheme 12. This epoxide was coupled with a xylosyl bromide donor 105 and the resulting disaccharide 106 was then selectively deprotected at positions $O-3$ and $O-4$ and further glycosylated with xylosyl bromide $\mathbf{1 0 8}$ to afford the tetrasaccharide $\mathbf{1 0 9}$ in $40 \%$ yield. The epoxide was then opened selectively with benzyl alcohol following the Fürst-Plattner rule ${ }^{84}$, in order to produce the xylose tetrasaccharide 112. The free hydroxyl group in position 2 was then glycosylated with glucoronate donor $\mathbf{1 1 3}$ in the presence of silver perchlorate and 2,4,6-collidine affording the desired $\alpha$-branched pentasaccharide in 57\% yield.

Scheme 12. Synthesis of a branched 4-O-methyl- $\alpha$-D-glucuronic acid-containing xylotetraose by Hirsch and Kováč. ${ }^{75,79}$
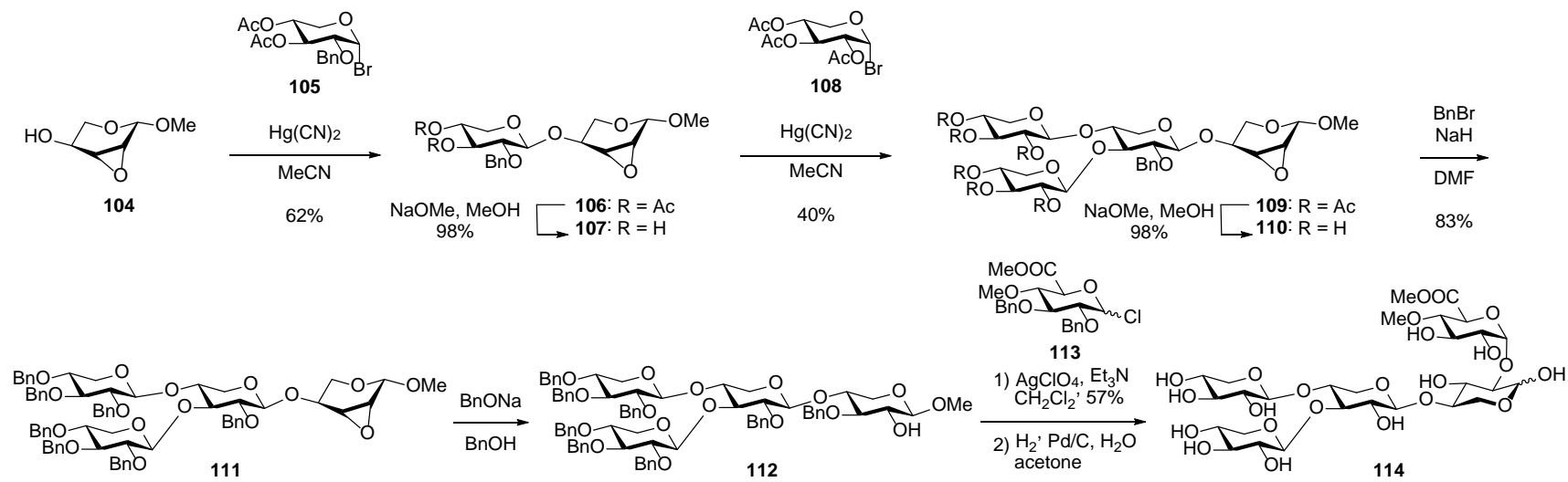
In 2001, Oscarson and Svahnberg reported the synthesis of two glucuronoxylan fragments based on xylobiose. Using dimethyl(methylthio)sulfonium trifluoromethane sulfonate (DMTST) in diethyl ether, they were able to couple the glucuronic acid donor $\mathbf{1 1 6}$ with complete $\alpha$-selectivity to the disaccharide acceptor 115 (Scheme 13). ${ }^{78}$

Scheme 13. Synthesis of a glucuronoxylan trisaccharide by Oscarson and Svahnberg. ${ }^{78}$

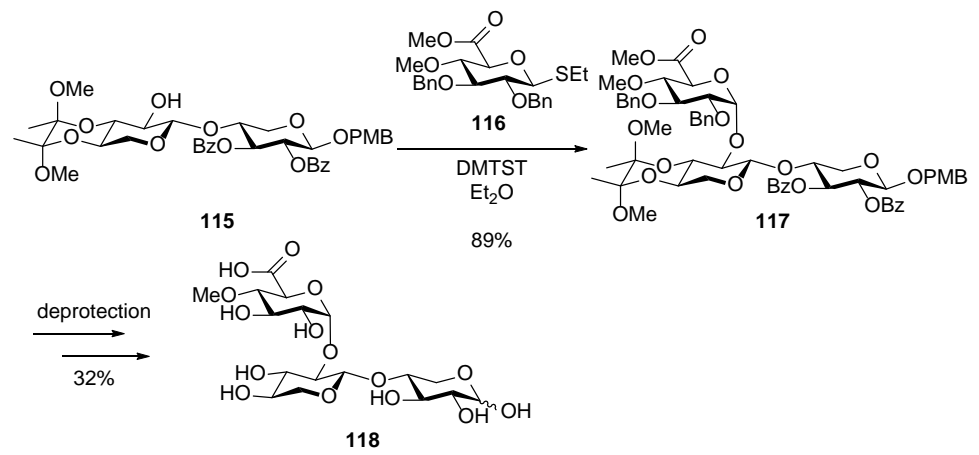

Recently, Pfrengle and co-workers developed an automated synthesis of arabinoxylans. ${ }^{77,80}$ They first reported the synthesis of a set of xylan oligosaccharides up to an octasaccharide decorated in different positions with either one or two $\alpha-(1 \rightarrow 3)$-linked arabinofuranosides as shown in Scheme $14{ }^{65}$ 
Scheme 14. Automated synthesis of arabinoxylan fragments by Pfrengle and co-workers. ${ }^{76}$

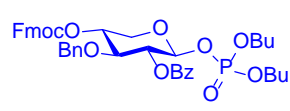

119

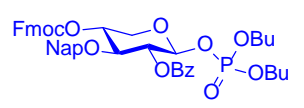

120

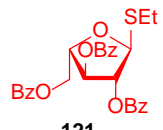

121

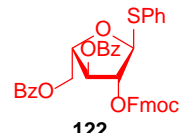

122

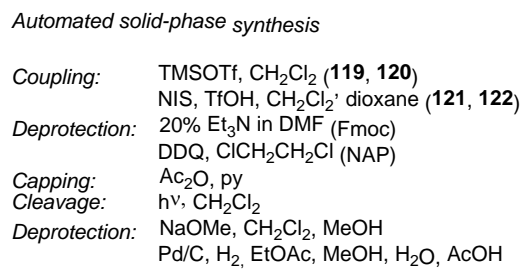

Automated solid-phase synthesis

Coupling: $\quad$ TMSOTf, $\mathrm{CH}_{2} \mathrm{Cl}_{2}(119,120$

NIS, TfOH, $\mathrm{CH}_{2} \mathrm{Cl}_{2}$ ' dioxane $(121,122)$

Deprotection: $20 \% \mathrm{Et}_{3} \mathrm{~N}$ in DMF (Fmoc)

DDQ, $\mathrm{ClCH}_{2} \mathrm{CH}_{2} \mathrm{Cl}$ (NAP)

$\begin{array}{ll}\text { Capping: } & \mathrm{Ac}_{2} \mathrm{O}, \mathrm{py} \\ \text { Cleavage: } & \mathrm{hv}, \mathrm{CH}_{2} \mathrm{Cl}_{2}\end{array}$

Deprotection: $\mathrm{NaOMe}, \mathrm{CH}_{2} \mathrm{Cl}_{2}, \mathrm{MeOH}$

$\mathrm{Pd} / \mathrm{C}, \mathrm{H}_{2}$, EtOAc, MeOH, $\mathrm{H}_{2} \mathrm{O}, \mathrm{AcOH}$

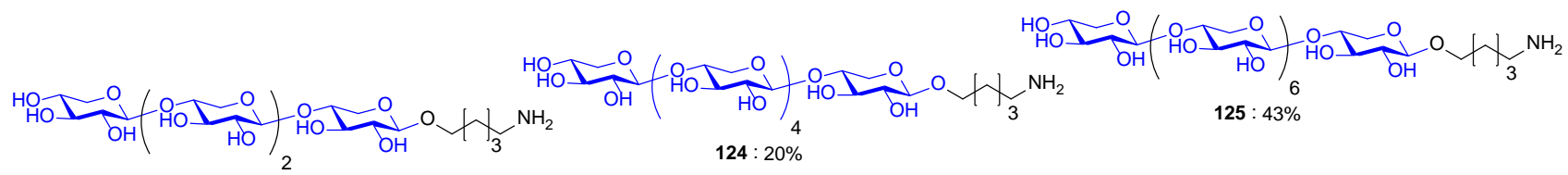

$123: 27 \%$

$124: 20 \%$

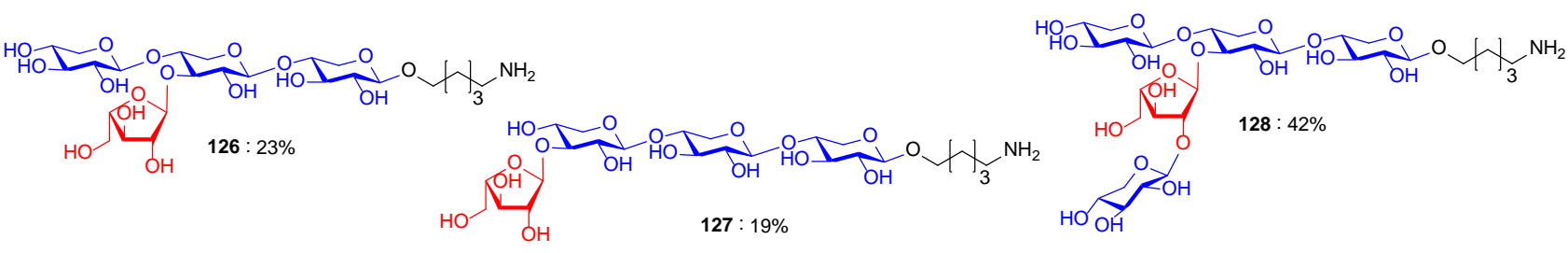

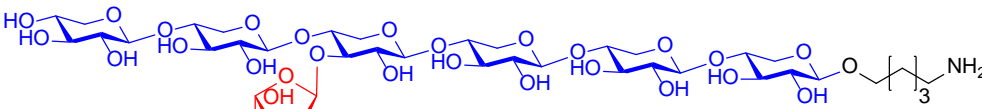

HO $\overbrace{\mathrm{OH}}^{\mathrm{OH}} 129: 8 \%$

HOH
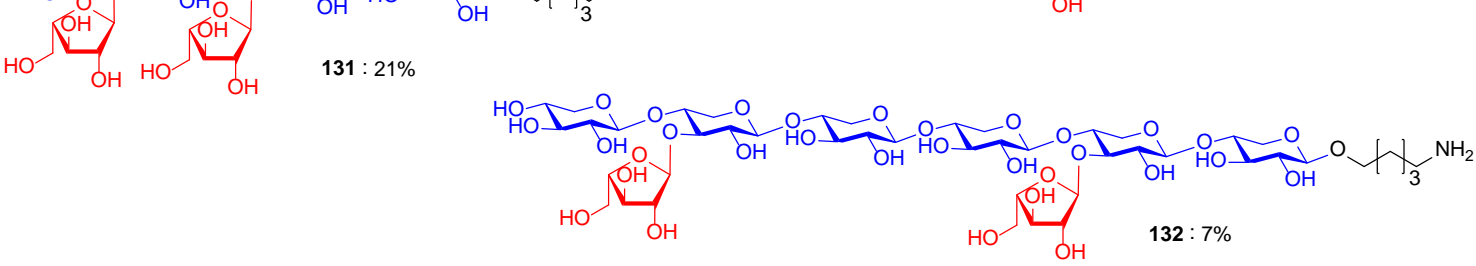

To achieve their synthesis, two xylosides 119 and 120, differentially protected at their $O$-3 position, were used as building blocks for the assembly of the linear xylan backbone, while perbenzoylated and 2-O-Fmoc-L-arabinofuranosides 121 and 122 were used for substitution. The sequential synthesis provided, within short timeframes and with overall yields of 7-43\%, a collection of arabinoxylan 
fragments (123-132) as shown in Scheme 14. Very recently, they optimized this strategy in order to supplement this set of $\alpha-(1 \rightarrow 3)$-substituted glycans with $\alpha-(1 \rightarrow 2)$-substituted arabinoxylan oligosaccharides 135 to 139 (see Figure 10). By using the 2-O-(azidomethyl)benzoyl (Azmb)protected donor $\mathbf{1 3 3}$ the team could make oligosaccharides containing monosubsituted xylose residues. With the inclusion of the orthogonally protected donor 134, synthesis of the disubstituted arabinoxylan 135 was possible.
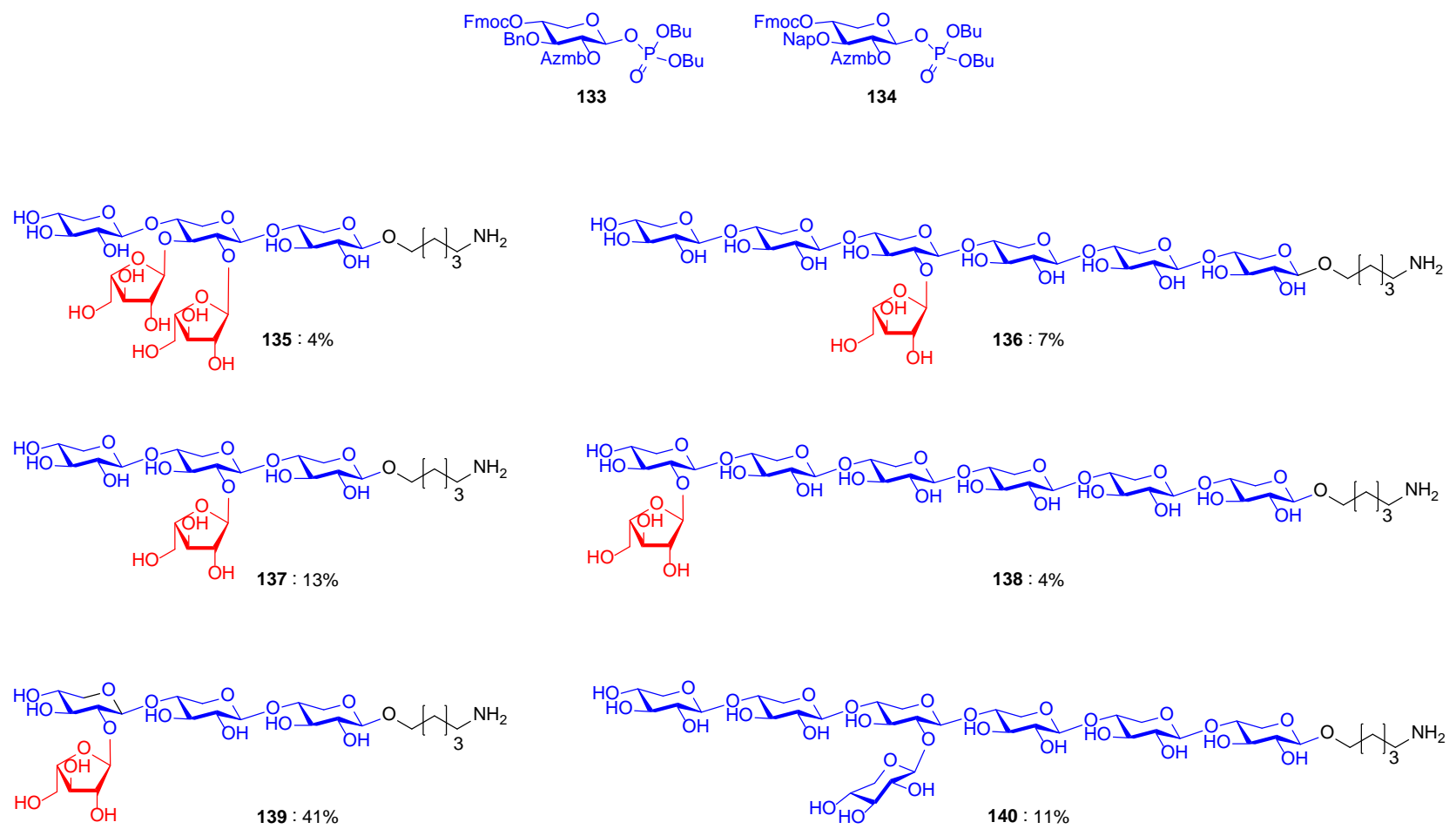

Figure 10. A set of substituted (arabino)xylan oligosaccharides synthesized in 2017 by Pfrengle and co-workers. ${ }^{80}$ The strategy is presented in Scheme 14. 


\subsection{Mannans}
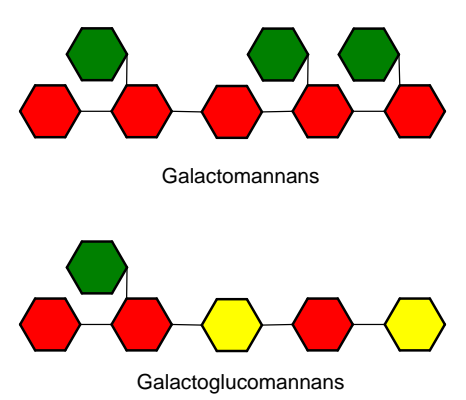

Figure 11. Schematic representation of different mannans.

Mannans are widely distributed and the main hemicellulose in Charophytes. ${ }^{67}$ They have been intensively studied due to their role as seed storage compounds, but they are found in variable amounts in all cell walls. ${ }^{4}$ The mannan class of polysaccharides in higher plants can be divided into two categories: galactomannans and glucomannans. Galactomannans have a homologous backbone made up of $\beta$-(1 $\rightarrow 4)$-linked mannose residues only, and can be substituted at some of the $O-6$ positions by $\beta$-D-galactose units. The glucomannan backbone is composed of $\beta$ - $(1 \rightarrow 4)$-linked glucose and mannose units assembled in a random pattern with a higher number of mannose than glucose monosaccharides. Galactoglucomannans are further substituted with galactose at the $O-6$ positions of some backbone mannose residues. Furthermore, mannans are often acetylated at C-2, C-3 and more rarely at C-6 positions depending on the plant species. ${ }^{85}$ Mannans and glucomannans have been highly conserved throughout plant evolution, however their role and function in the plant cell wall remain largely unclear. The exception is the galactoglucomannans which are often described as seed storage compounds. ${ }^{4}$ The formation of $\beta$-linked mannosides is an exceedingly difficult glycosylation reaction since neighboring group participation, the steric hindrance from a protecting group at the $O-2$ position and the anomeric effect uniformly favor the formation of $\alpha$-D-mannopyranosides. Nevertheless, 
several groups have developed strategies to circumvent the challenges and have successfully synthesized certain mannan fragments, as shown in Table 9. Numerous reviews dealing with advances in the construction of $\beta$-D-mannosides have been published. Among those, a review by Gridley and co-workers ${ }^{86}$ deals with most of the strategies. A more recent one, by Lichtenthaler, presents the use of 2-oxoglycosyl donors in assembling oligosaccharides with $\beta$-D-mannose, $\beta$-L-rhamnose, $N$-acetyl$\beta$-D-mannosamine, and $N$-acetyl- $\beta$-D-mannosaminuronic acid residues. ${ }^{87}$

Table 9. Synthetic mannan fragments.

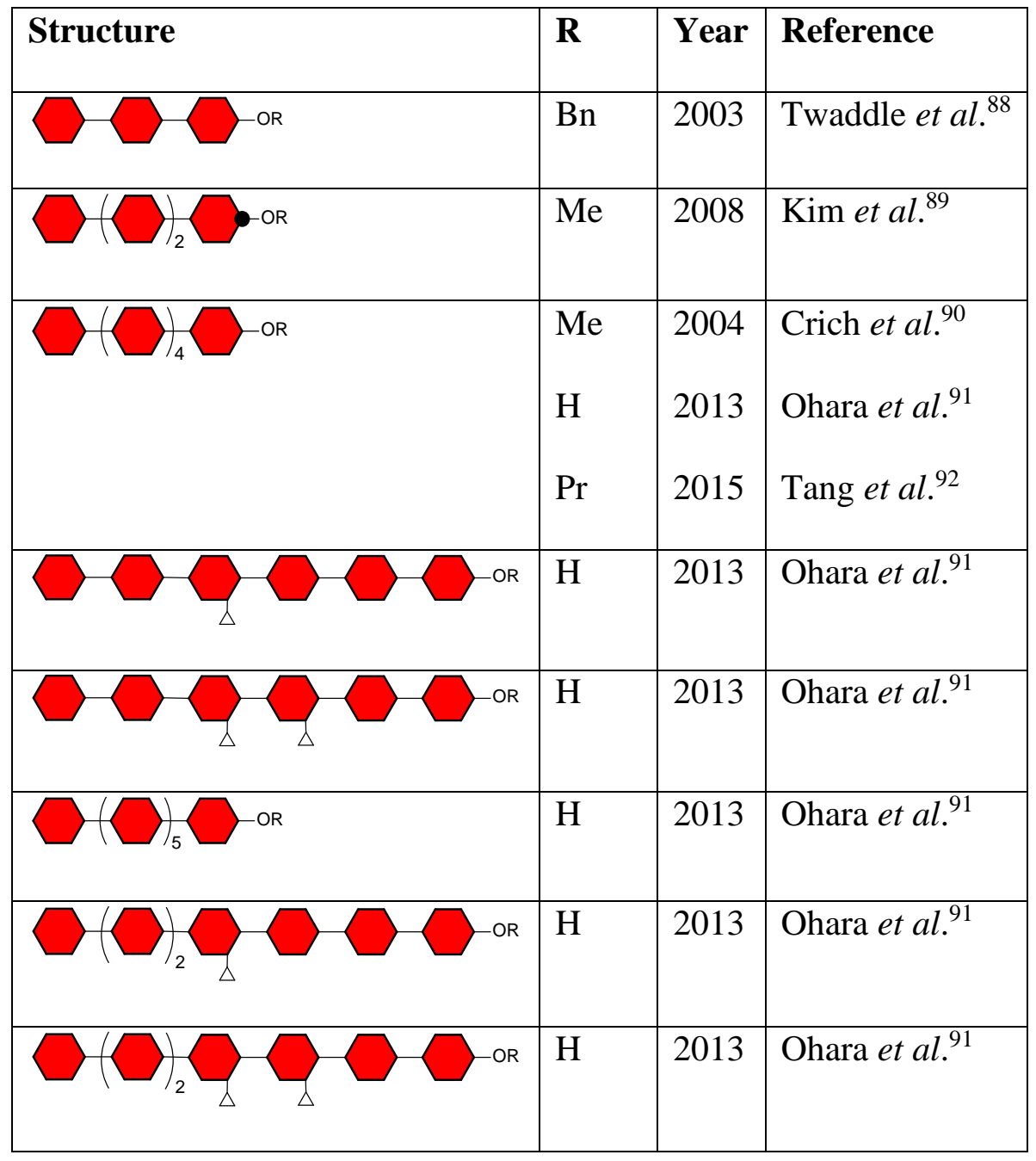




\begin{tabular}{|l|l|l|l|}
\hline $\mathrm{O}(\mathrm{O})_{6} \mathrm{O}$ & $\mathrm{C}_{6} \mathrm{H}_{11}$ & 2004 & Crich et al. $^{90}$ \\
$\mathrm{H}$ & 2013 & Ohara et al. ${ }^{91}$ \\
\hline & $\mathrm{H}$ & 2013 & Ohara et al. ${ }^{91}$ \\
\hline \\
\hline
\end{tabular}

In 2004, Crich and co-workers developed a direct approach for the synthesis of $\beta$-mannosides using 4,6-O-benzylidene-directed glycosylation via in situ generation of $\alpha$-mannosyl triflates from their thio- or sulfoxidoglycoside precursors. They employed this strategy in combination with a three step iterative glycosylation protocol to synthesize a $\beta$-linked hexamannoside as shown in Scheme $15 .{ }^{90}$ Benzylidene deprotection, followed by selective Piv protection of the primary alcohol in each case provided the acceptor ready for the glycosylation with 4,6-O-benzylidene-thiomannoside 141. High glycosylation yields were obtained in each case (71-82\%) and very good $\beta$-selectivity was achieved $(\alpha: \beta \sim 1: 10)$ 
Scheme 15. Three-step iterative glycosylation protocol to synthesize hexamannoside 146d by Crich and co-workers. ${ }^{\mathbf{9 0}}$
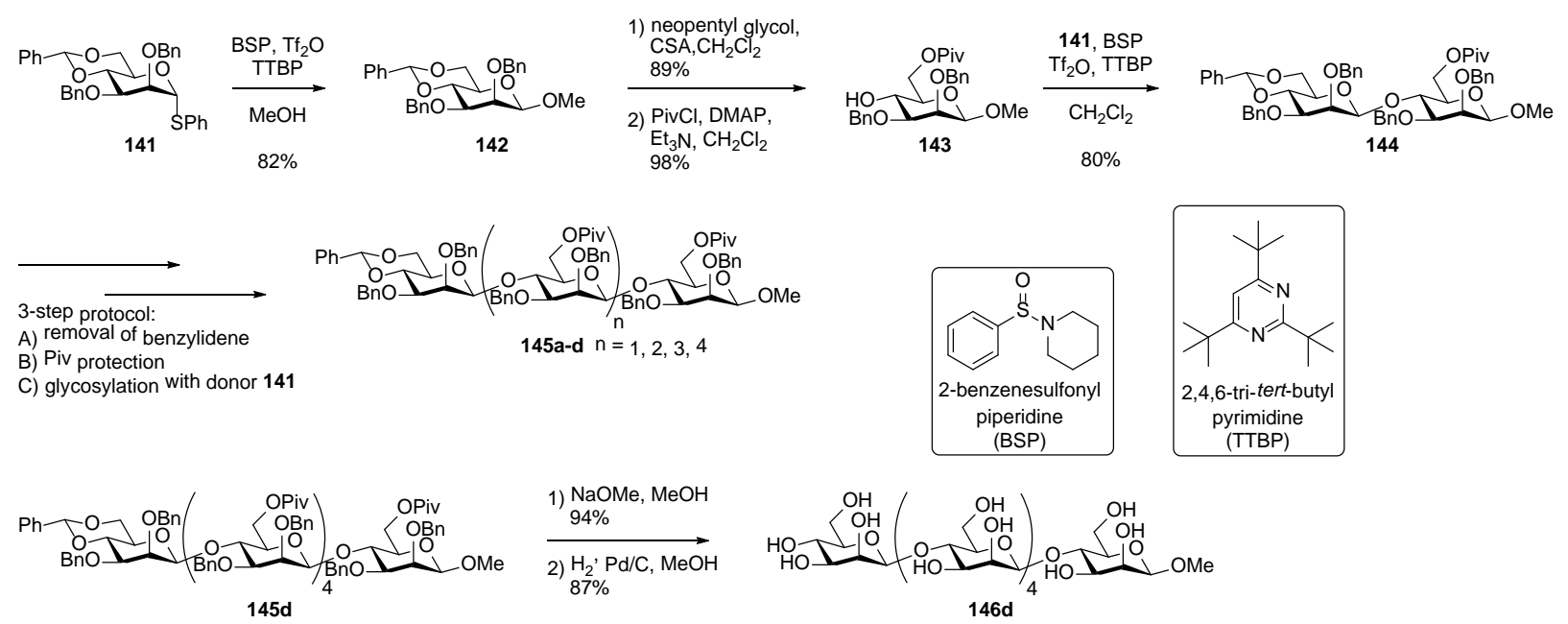

In 2008, Jeon and co-workers reported an efficient one-pot, three-step glycosylation strategy starting from a reducing sugar. A 4,6-O-benzylidene mannopyranose was treated with phthalic anhydride in the presence of $\mathrm{DBU}$, and the $\alpha$-mannosyl phthalate intermediate was further activated with triflic anhydride to generate a mannosyl triflate. Like Crich and co-workers, the group used 4,6-Obenzylidene protected mannose to impart stereoselectivity and form the desired $\beta$-mannosidic linkage. ${ }^{89}$

Another approach was taken by Pohl and co-workers in an automated solution phase synthesis of a $\beta$ $(1 \rightarrow 4)$-linked hexamannoside, shown in Scheme $16 .^{92}$ Inspired by the work of van der Marel and coworkers in their formation of $\beta$-mannosidic linkages using a mannuronate donor (section 7.5), Pohl and co-workers used a $\beta$-directing C-5 carboxylate strategy and synthesized the protected $\beta$-( $1 \rightarrow 4)$ hexamannoside 149 in an average yield of 75\% per step. Post-assembly, the mannuronic acid residues were reduced to mannans with DIBAL-H. 
Scheme 16. Automated solution phase synthesis of $\beta$-hexamannoside by Pohl and co-workers. ${ }^{92}$

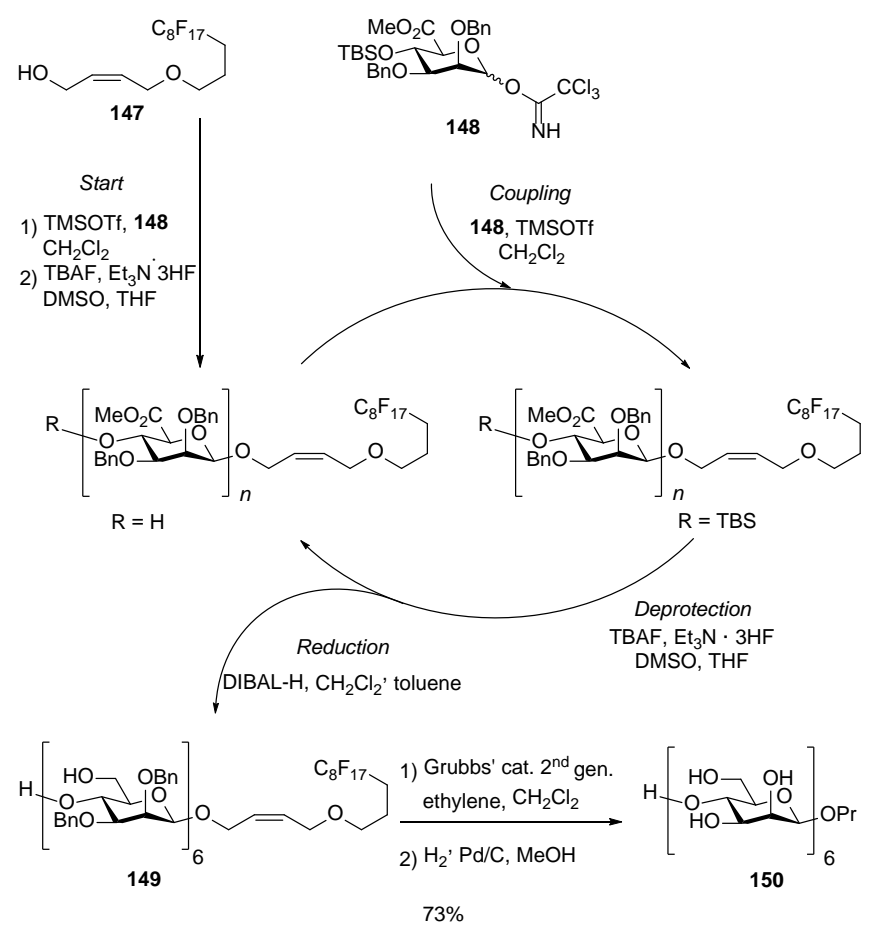

Indirect approaches requiring epimerization at C-2 in readily available $\beta$-glucosides have been used by other groups to synthesize linear $\beta$ - $(1 \rightarrow 4)$-linked mannans. ${ }^{88,91}$ Nikolaev and co-workers accessed $\beta$-(1 $\rightarrow 4)$-mannotriose from commercially available and cheap D-cellobiose octa-acetate $\mathbf{1 5 1}$ via an epimerizing $\mathrm{S}_{\mathrm{N}} 2$ reaction as shown in Scheme $17 .^{88}$ After some protecting group manipulations required to reach benzyl 4',6'-O-benzylidene-cellobioside diol 153, simultaneous epimerization of C2 and C-2' was performed via triflation followed by reaction with $\mathrm{Bu}_{4} \mathrm{NOBz}$, affording $\beta-(1 \rightarrow 4)-$ linked mannobiose 154 in 76\% yield. Mannobiose 156 was further coupled to glucose donor 157, forming a trisaccharide, which was then epimerized to give mannotriose $\mathbf{1 6 0}$ in a reasonable overall yield. 
Scheme 17. Synthesis of $\beta$-mannotriose through C-2 epimerization of glucoside by Nikolaev and coworkers. ${ }^{88}$
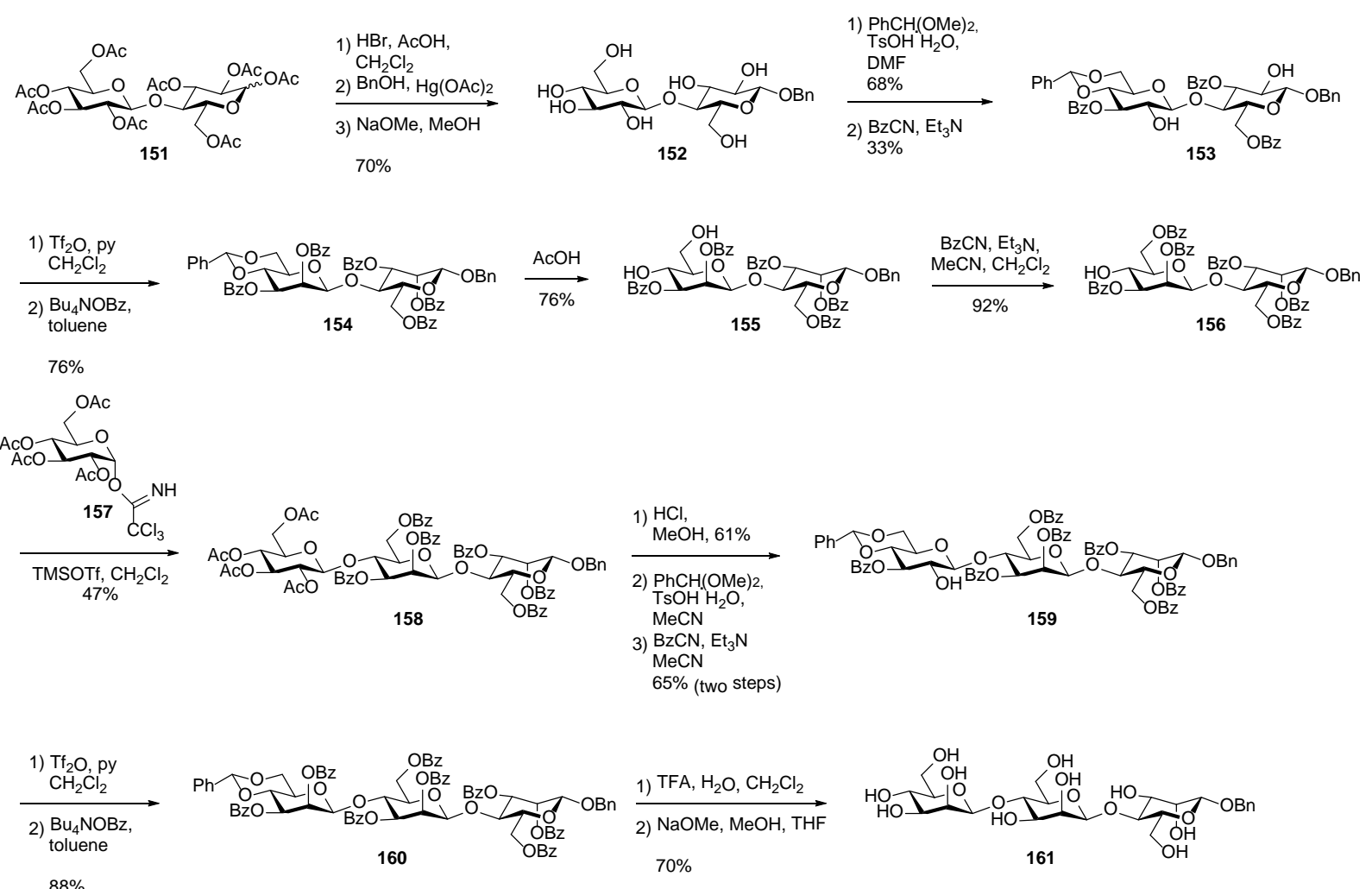

$88 \%$

A combination of direct and indirect strategies was used by Wong and co-workers in their synthesis of $\beta$-(1 $\rightarrow 4)$-linked hexa- to octamannans, where some of the targets were further acetylated at one or two positions along the backbone. ${ }^{91}$ An example of the convergent synthetic strategy taken to the three hexamannan targets 162, 163, 164 is presented in Scheme 18. The three oligosaccharides can be derived from a common protected hexamannan intermediate 165. As direct $\beta$-selective mannosylation remains challenging, the group chose to synthesize the hexamannoside $\mathbf{1 6 5}$ by an indirect method involving $\beta$-selective glucosylation of trimannoside acceptor 167 with mannoglucose donor $\mathbf{1 6 6}$. The subsequent epimerization of the glucose C-2 hydroxyl group was achieved via an oxidation-reduction sequence affording the desired $\beta$-mannoside. This methodology simultaneously allowed for 
acetylation at the designated positions. The trisaccharide fragments 166 and 167 could be obtained from monosaccharides 168 and 171 respectively by repeating direct $\beta$-selective mannosylations using 169 or $\mathbf{1 7 0}$ as the donors.

Scheme 18. Retrosynthetic analysis of hexamannans $162-164$ by Wong and co-workers. ${ }^{91}$

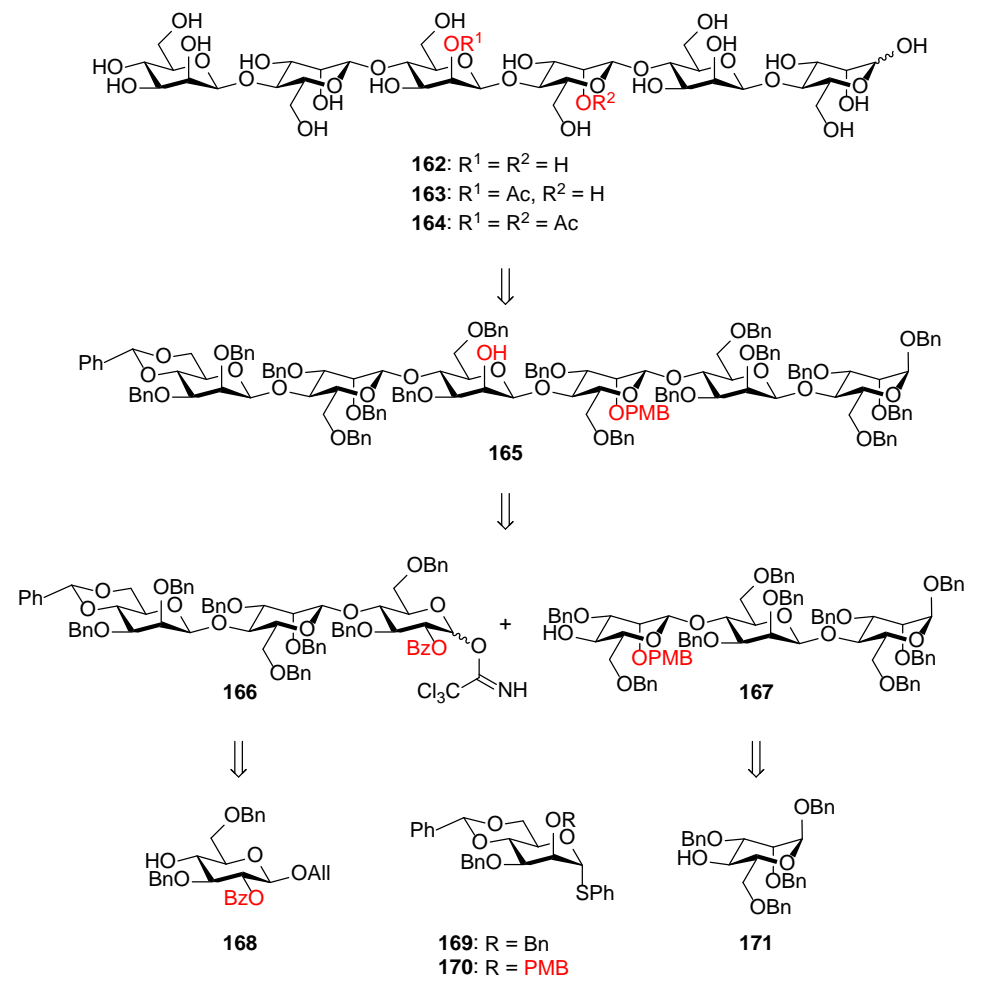

The authors used the same strategy, with a late $\beta$-glucosylation in $[4+3]$ and $[4+4]$ couplings followed by epimerization to get the hepta- and octamannans shown in Figure 12. 

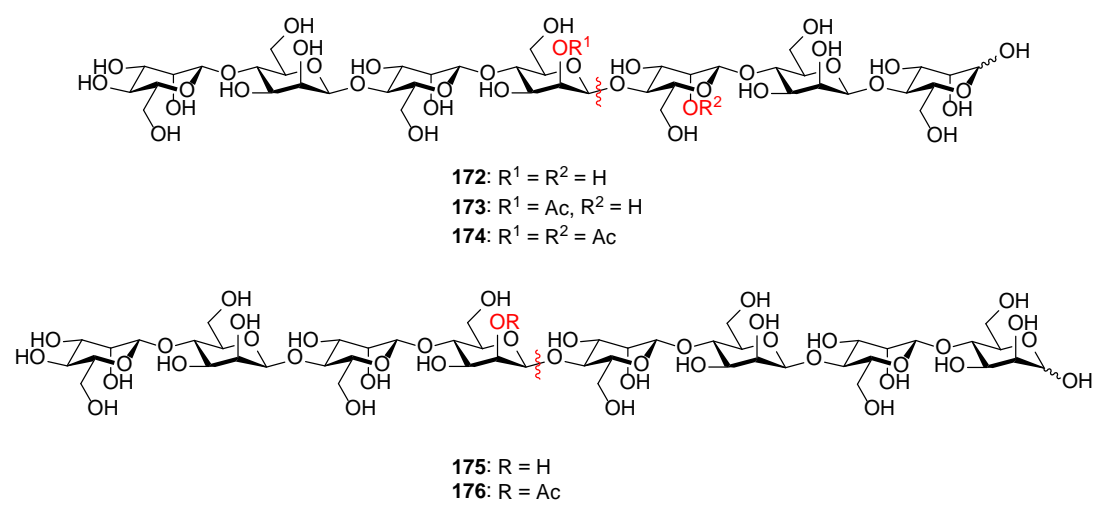

Figure 12. Hepta- and octamannans synthesized by Wong and co-workers. ${ }^{91}$

To date, only one synthesis of a galactoglucomannan fragment has been reported. The tetrasaccharide fragment 185 was synthesized by Leino and co-workers in 2012, using a linear synthesis involving a $\beta$-selective mannosylation with 4,6-O-benzylidene thiomannosyl donor $\mathbf{1 7 7}$, Scheme $19 .{ }^{93} \mathrm{~A} \beta$ selective glucosylation afforded trisaccharide 181, which was further selectively deprotected at the C6”' position. Finally, and following Ando and co-workers' discovery, ${ }^{94} \alpha$-selective galactosylation with di-tert-butylsilylene galactoside donor 183 afforded tetrasaccharide $\mathbf{1 8 4}$ ready for deprotection to reach the target 185 . 
Scheme 19. Synthesis of galactoglucomannan tetrasaccharide by Leino and co-workers. ${ }^{93}$

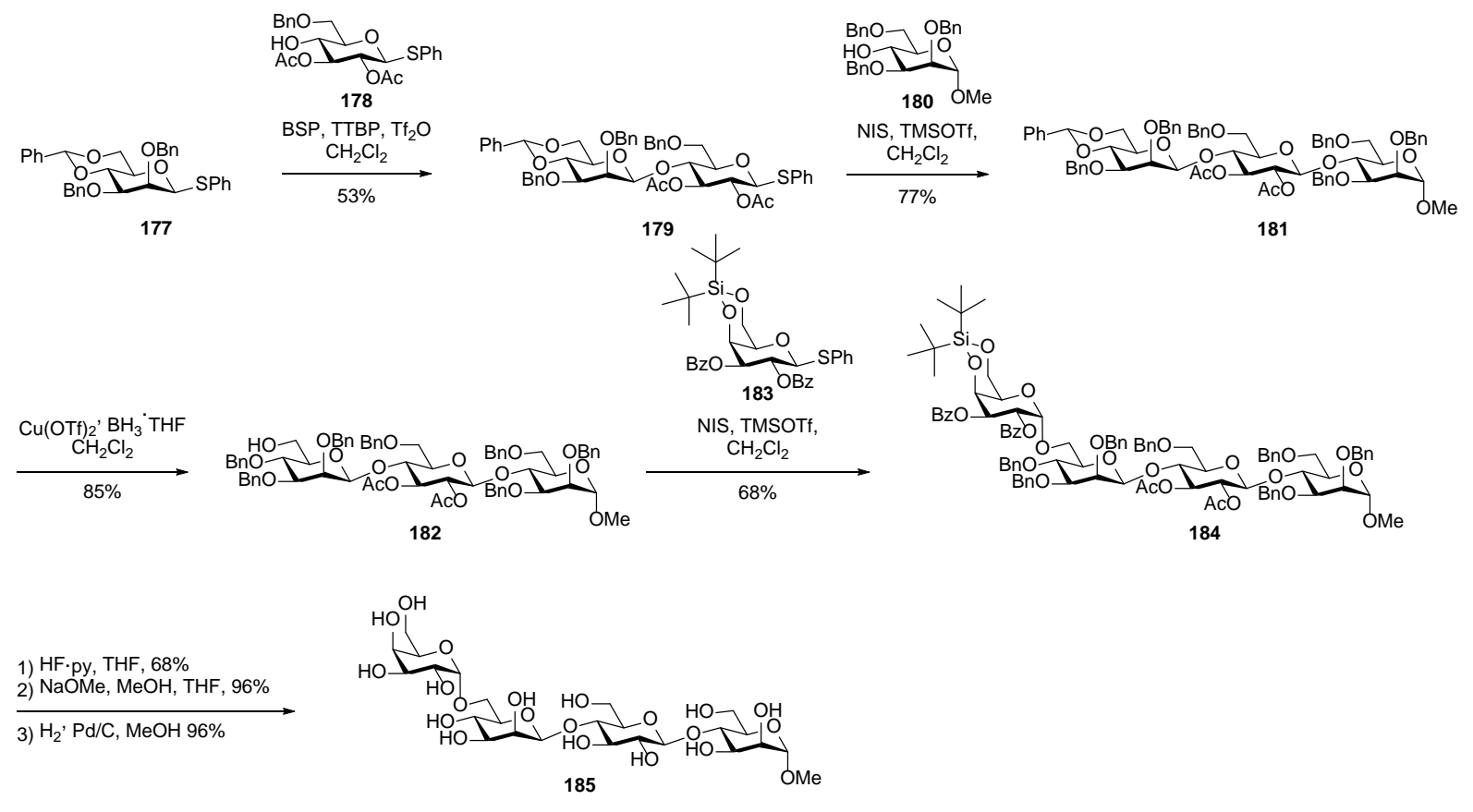




\section{Pectin}

Pectin was first discovered in 1790 by Vauquelin, ${ }^{95}$ being first described as 'pectin' in 1825 by Braconnot. ${ }^{96}$ The name derives from the Greek word pektikos, meaning 'congeal, solidify or curdle', and accurately describes the main characteristic of this group of polysaccharides. As a result of their ability to form gels, pectic polysaccharides have many industrial applications. They are used as gelling and stabilizing ingredient in a wide range of food products. They also fulfil important biological roles, including imparting mechanical strength and flexibility to the cell wall. Pectin therefore has multiple functions in plant growth, morphology, development, and defense. ${ }^{97}$ Pectic polysaccharides also play an important role in cell-cell adhesion. ${ }^{6}$

Pectins make up around 35\% of the dry weight of the primary cell wall in dicots and non-graminaceous monocots, $2-10 \%$ in grasses and other commelinoid primary walls, and up to $5 \%$ in woody tissue. ${ }^{98}$ Although pectin is structurally and functionally the most complex and heterogeneous class of polysaccharides in nature, it is relatively well-defined, being characterized by a high content of galacturonic acid (see Figure 13). It is widely believed that four to five pectic domains, namely, homogalacturonan (HG), rhamnogalacturonan I (RG-I), rhamnogalacturonan II (RG-II), and xylogalacturonan (XGA) and/or apiogalacturonan (AGA) are covalently linked to one another to form the pectin complex in muro. As yet, there is no sufficiently compelling evidence, as to how the different blocks are assembled in the macromolecule. Therefore, the fine-structure of pectin is still a matter of controversy and several models have been proposed. A review by Yapo in 2011 describes the two traditional models, one with alternating 'smooth' (HG) and 'hairy' (XGA, RG-I/RG-II) regions, the other proposing a backbone of RG-I, with side chains of HG, XGA and RG-II. The author argues that in the face of more recent analysis, the traditional models become less and less convincing 
as comprehensive descriptions of pectin. ${ }^{99}$ Irrespective of which model of polysaccharide structure one subscribes to, it is undisputed that pectins consist of distinct domains. HG and RG-I represent the two major kinds of backbone in pectin. While HG is a linear homopolymer of partially methyl esterified and/or acetylated $\alpha$-(1 $\rightarrow 4)$-linked D-galacturonic acid, the RG-I backbone is made up of alternating galacturonic acids and L-rhammnose monosaccharides, with various L-arabinan, Dgalactan and arabinogalactan side chains. Three more domains of pectin, xylogalacturonan (XGA), apiogalacturonan and rhamnogalacturonan II (RG-II) can be seen as structurally modified HG as they share the same backbone. While $25-75 \%$ of the galacturonic acid residues of XGA bear xylose substitution, RG-II is a complex branched HG having four different side chains, with a total of up to 29 different monosaccharides, including a number of rare sugars. ${ }^{100}$ More detail on the structure of the five pectic domains will be given further on in this section. Only few pectic oligosaccharides are available from the chemical or enzymatic degradation of polysaccharides. Although degradation techniques have been widely used for elucidating the structure of pectin (especially RG-I), the oligosaccharide fragments prepared in this way required extensive purification and were generally only obtained in analytical quantities. Furthermore, this approach has mostly been limited to isolation of linear backbone fragments since the techniques generally involve the removal of side chains. ${ }^{97}$ This fact has prompted chemists to devise synthetic approaches to pectic oligosaccharides, albeit to date only for a limited number of structures. A review by Nepogodiev and co-workers summarized the fragments of HG, RG-I and RG-II, which had been synthesized before $2011{ }^{101}$ These are included in the following discussion. 


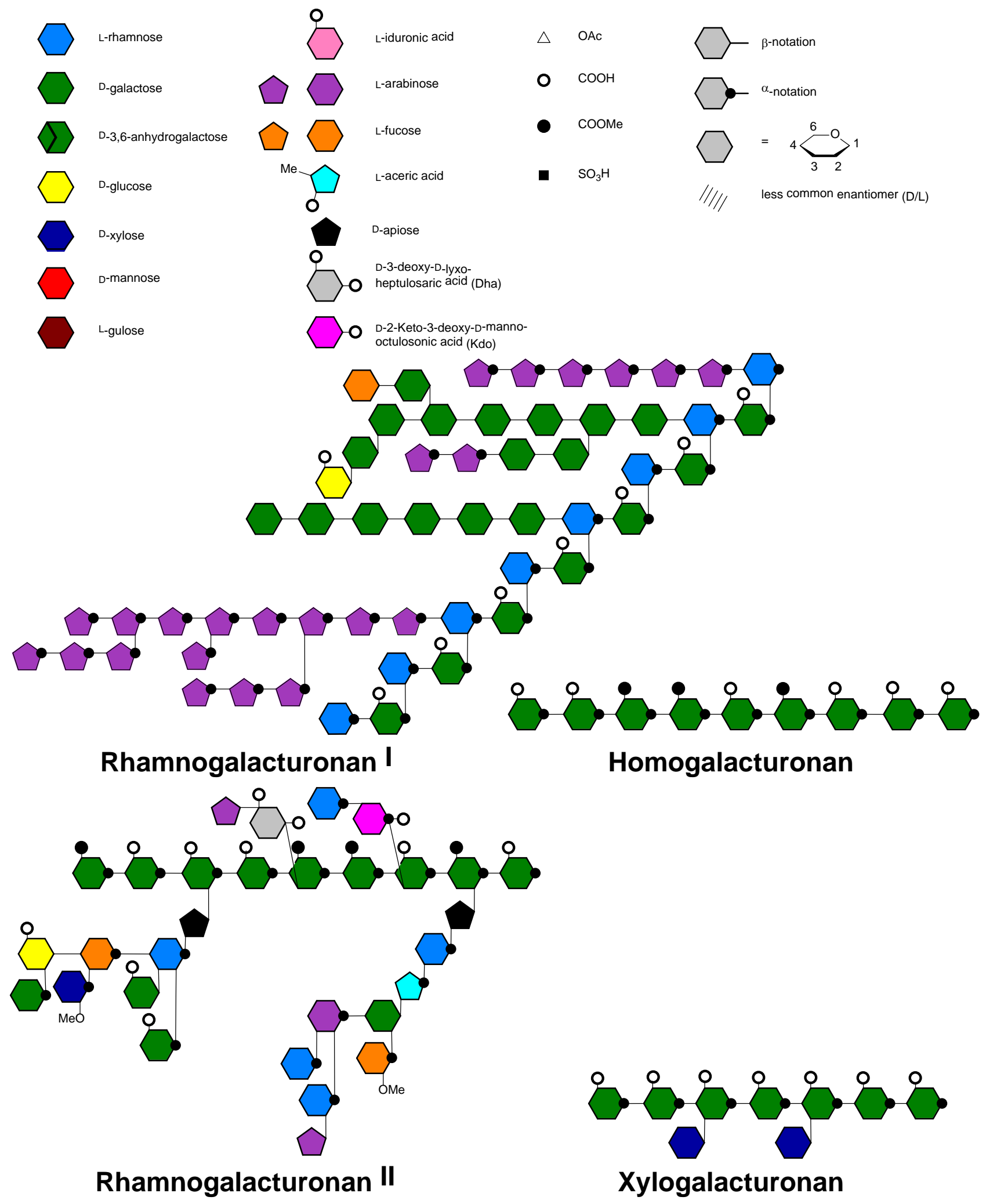

Figure 13. Schematic representation of the four domains of pectin. 


\subsection{Homogalacturonan}

\section{$\therefore+\infty$}

Figure 14. Homogalacturonan (HG) structure.

Homogalacturonan (HG), which is referred to as the 'smooth region' of pectin constitutes approximately $65 \%$ of the macromolecule. HG consists of a linear chain of $\alpha$-(1 $1 \rightarrow 4)$-linked galacturonic acid, which can be methyl esterified or acetylated at the C-2 and C-3 positions depending on the plant as well as the type of tissue. HG has been shown to be present in stretches of approximately 100 GalpA residues. ${ }^{102}$ It is believed that HG is synthesized as a highly methyl esterified form in the Golgi apparatus and then de-esterified enzymatically, once it has been deposited in the cell wall. ${ }^{98,103,104}$ The degree of methylation is well known to influence gelling capability as well as other physical properties of pectin. C-6 carboxylates of HG residues can interact with calcium ions to form a stable gel when more than 10 consecutive un-esterified galacturonic acid residues are present. ${ }^{6}$ Furthermore, the methyl esterified GalpA residues of HG can associate through hydrophobic interactions. ${ }^{100}$

Efforts to synthesize different fragments of $\mathrm{HG}$, in some cases with a distinct pattern of methyl esterification have provided a variety of oligomers ranging from tri- to dodecasaccharides, presented in Table 10.

Table 10. Overview of the synthesized homogalacturonan fragments.

\begin{tabular}{|l|l|l|l|}
\hline Structure & R & Year & Reference \\
\hline
\end{tabular}




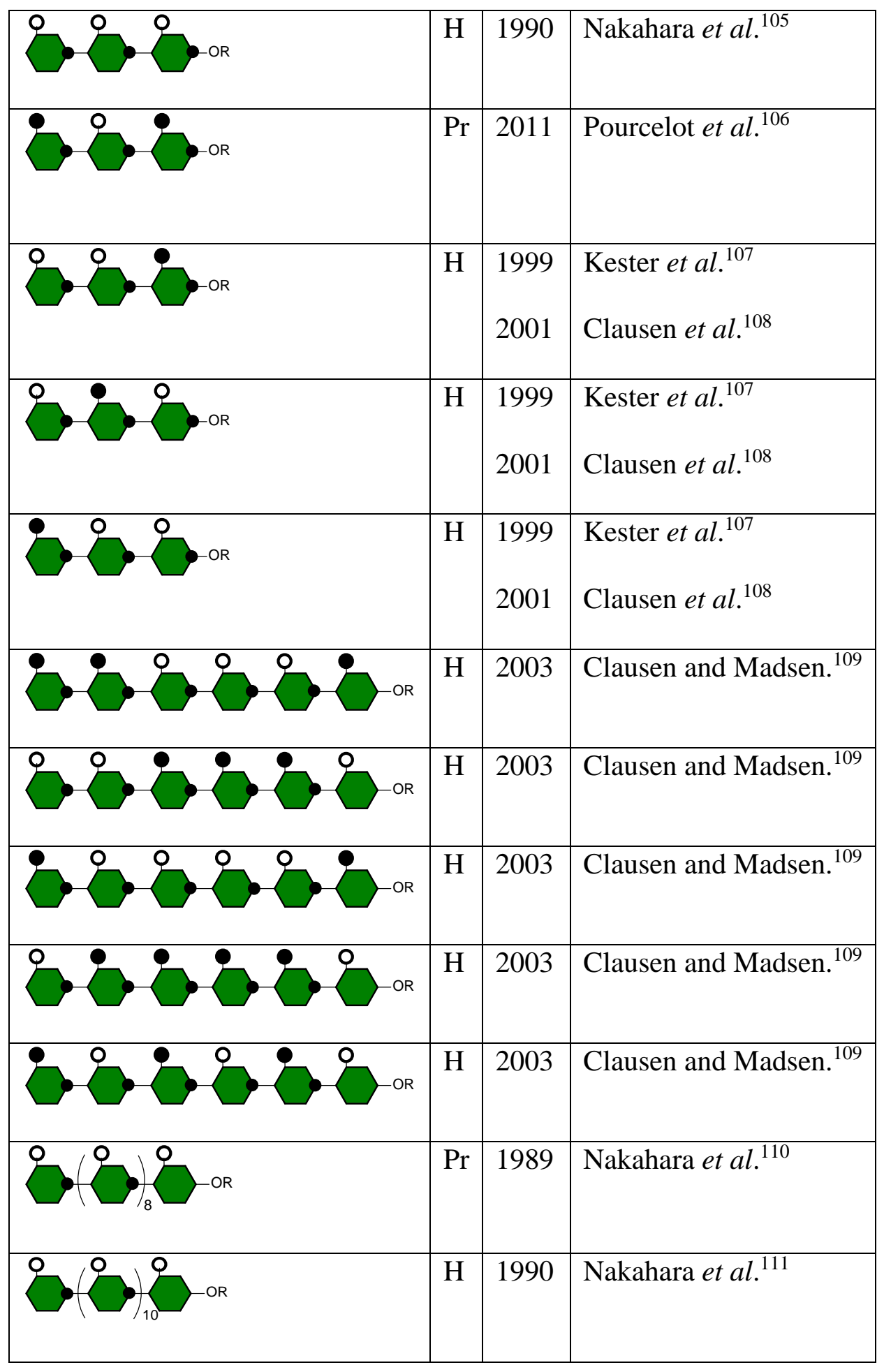


As is typical for the synthesis of glycuronides, two distinct approaches have been employed to reach oligomers of $\alpha$ - $(1 \rightarrow 4)$-linked D-GalpA: a post-glycosylation oxidation and a pre-glycosylation oxidation. A comprehensive microreview by van der Marel and co-workers explains the rational behind these two strategies. ${ }^{112}$ With post-glycosylation oxidation, often the preferred approach, the backbone of the target is assembled from aldose building blocks, followed by oxidation of the primary alcohols to carboxylic acids prior to or after global deprotection. The alternative pre-glycosylation oxidation strategy involves the glycosylation between protected uronic acid donors and acceptors. Due to the electron-withdrawing carboxylic acid group, galacturonic acid building blocks are substantially less reactive than the corresponding galactose derivatives, which makes this second approach challenging. In fact, only two syntheses of trigalacturonides have been reported using the pre-glycosylation oxidation method, and no oligomer longer than this has been produced.

The first was performed by Anker and co-workers in 1997 using thiophenyl galacturonides as glycosyl donors, as shown in Scheme $20 .{ }^{113}$ Good stereoselectivity and a high yield was obtained for the first glycosylation affording disaccharide 188. However, attempts to elongate the chain to a trisaccharide by coupling the thiogalacturonide 190 with the disaccharide acceptor 189 only afforded the target molecule in $45 \%$ yield. The trisaccharide 191 was not deprotected. Similar results were obtained by Kramer et al., also by glycosylating a disaccharide acceptor with a thiogalacturonide donor. Despite slight variations in the protecting group pattern, this group obtained the targeted trisaccharide in a similarly disappointing $48 \%$ yield. ${ }^{114}$ 
Scheme 20. Protected trigalacturonide synthesized through a pre-glycosylation oxidation strategy by Anker and co-workers. ${ }^{113}$
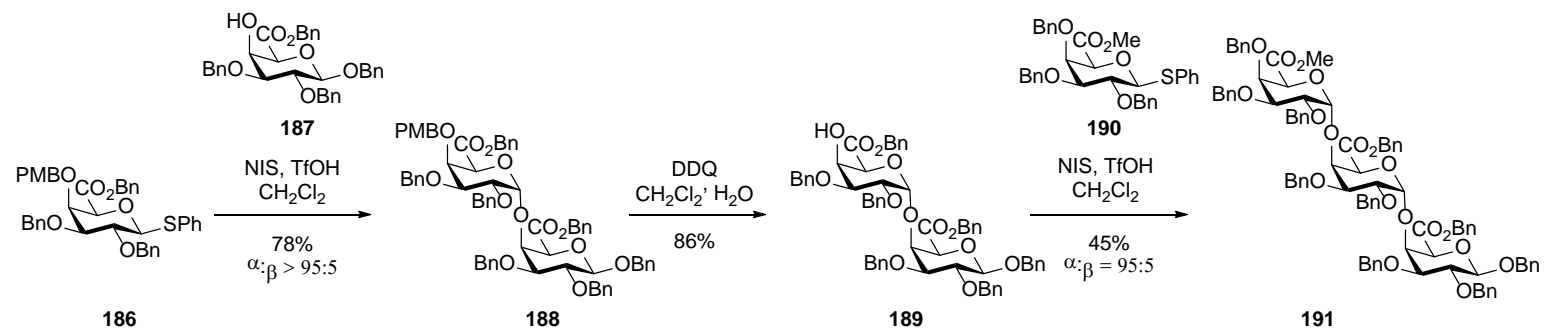

These results encouraged other groups to turn their attention to the post-glycosylation oxidation approach. Galactopyranose-based building blocks used for the synthesis of the neutral $\alpha-(1 \rightarrow 4)$-linked galactan backbone require a temporary protecting group at the C-6 position, which can release the primary alcohol prior to oxidation at a late stage of the synthesis. This method includes early work done by Nakahara and Ogawa in the 1990s. ${ }^{105,110,111}$ Among their elegant syntheses, the pinnacle remains the total synthesis of dodecagalacturonic acid using a highly convergent approach as shown in Scheme 21. ${ }^{111}$

They chose galactosyl fluorides as donors, which afforded highly stereoselective glycosylations and gave good yields (62-95\%). Acetyl groups were used as temporary protecting groups for all the primary alcohols, which were then selectively unmasked to afford the $\alpha$-(1 $\rightarrow 4)$-linked dodecagalactan 102. The alcohols were further oxidized to the corresponding carboxylic acids using a Swern ${ }^{115}$ followed by a Lindgren-Kraus-Pinnick oxidation ${ }^{116-118}$ affording the dodecagalacturonic acid product in 50\% yield. Final TBDPS deprotection and hydrogenolysis gave the target (203) in a good yield overall. 


\section{Scheme 21. Synthesis of dodecagalacturonic acid by Nakahara and Ogawa. ${ }^{\mathbf{1 1 1}}$}
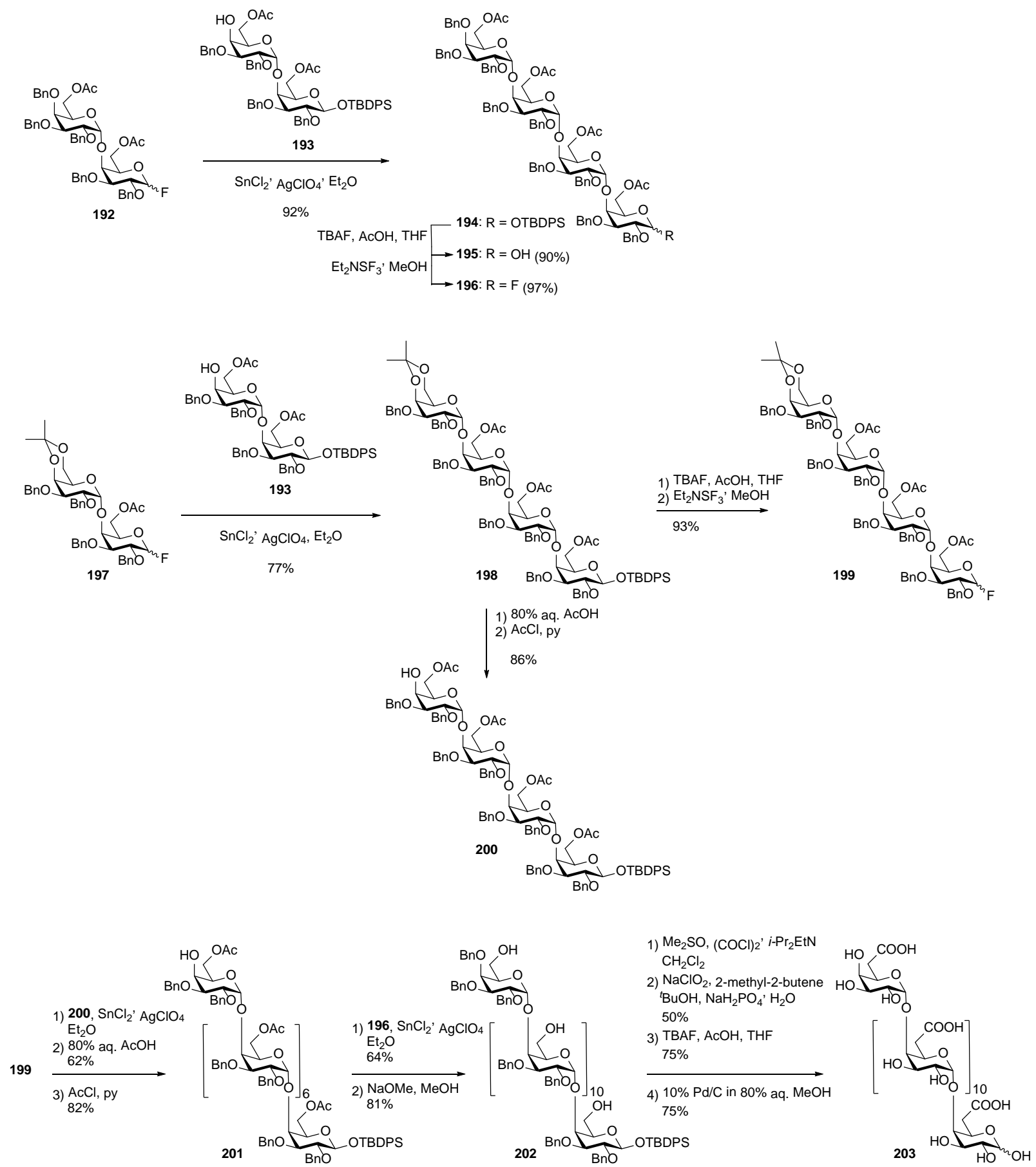
In order to synthesize some partially methyl-esterified hexagalacturonates, Madsen and co-workers introduced two orthogonal protecting groups at the C-6 positions of D-galactose: acetyl and paramethoxyphenyl (PMP). This enabled them to oxidize the C-6 position to the carboxylic acid or to the methyl ester selectively, and thereby synthesize tri- and hexagalacturonans with different methylation patterns. ${ }^{108,119}$ Their methodology was based on the repeated coupling of galactose mono- and disaccharide donors onto a galactose acceptor to produce hexagalacturonan backbones. They chose $n$ pentenyl donors, which provided good yields of the desired $\alpha$-anomers. An example of their synthesis of two partially-esterified hexamers is shown in Scheme 22. Tetrasaccharide acceptor 211, formed from disaccharide 208 by sequential glycosylation with pentenyl donor $209(\mathrm{ClAc}=$ chloroacetate $)$ was coupled with disaccharide donor $\mathbf{2 0 7}$ to form the pure $\alpha-(1 \rightarrow 4)$-linked hexagalactoside, which was further deacetylated to afford 212, the hexamer precursor of both targets. The oxidation to esters was carried out in a one-pot three-step procedure. The primary alcohols were first oxidized by DessMartin periodinane $\mathrm{e}^{120}$ to the aldehydes, which underwent a sodium chlorite oxidation to afford the corresponding carboxylic acids. The resulting acids were then esterified with either $\mathrm{TMSCHN}_{2}$ affording 213 or with $\mathrm{PhCHN}_{2}$ giving 214. The benzyl protection masked the positions destined to become carboxylic acids, and aided the purification of the intermediates. To complete the synthesis, the PMP-ethers were removed with cerium(IV) ammonium nitrate (CAN) and the primary alcohols were oxidized and esterified using the same one-pot three-step procedure, affording both benzyl and methyl esters. Hydrogenolysis afforded the two targets 215 and 216. 
Scheme 22. Example of two partially methyl esterified hexagalacturonic acids prepared by Madsen and co-workers. ${ }^{109}$

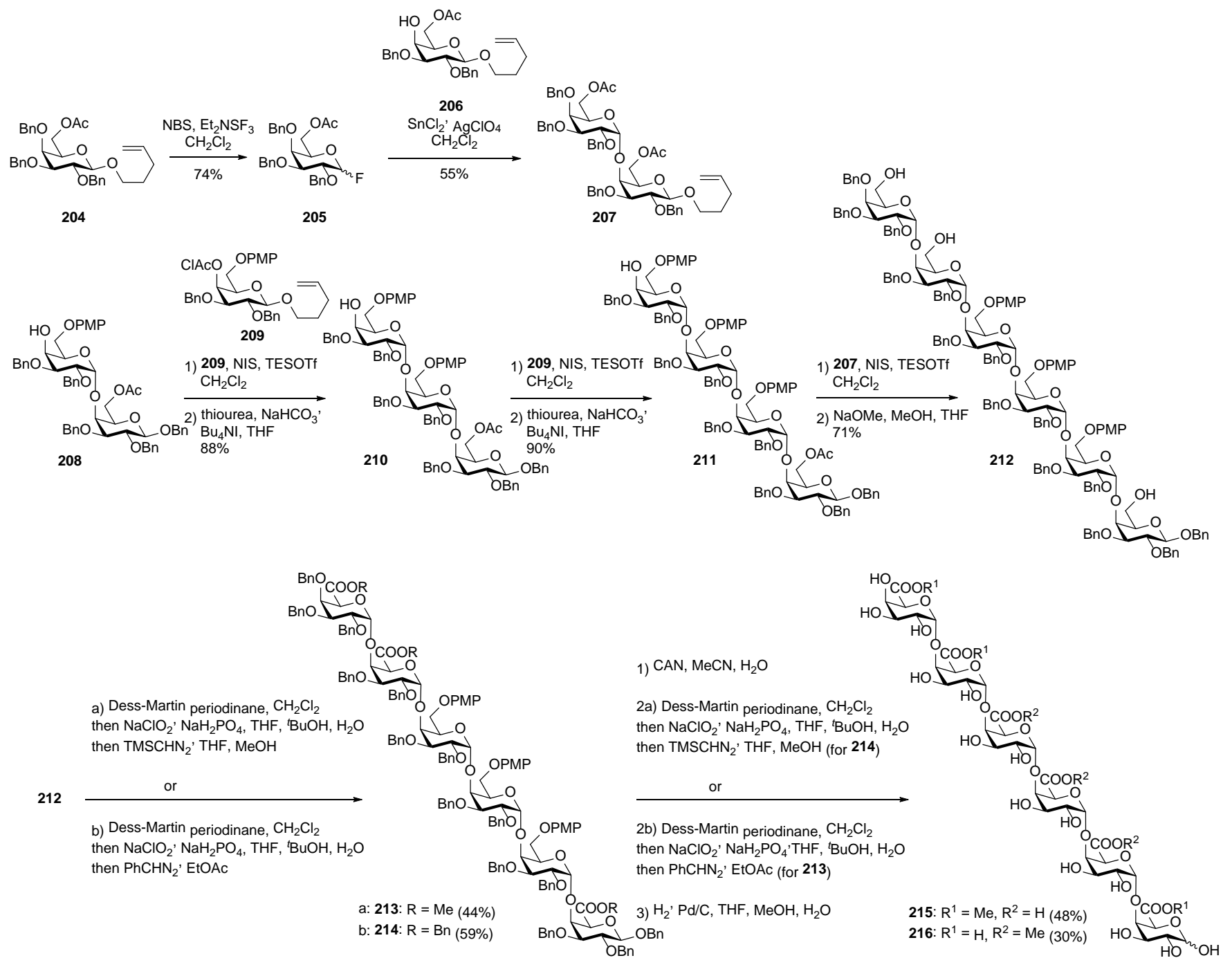




\subsection{Xylogalacturonan}

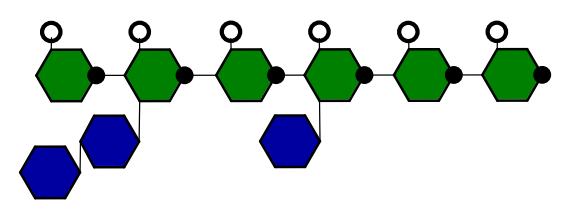

Figure 15. Example of XGA structure.

Xylogalacturonan (XGA) is similar to HG except that the backbone is substituted with single $\beta$ $(1 \rightarrow 3)$-linked xylose residues or short $\beta$ - $(1 \rightarrow 4)$-linked xylan side chains as shown in Figure $15 .{ }^{121}$ XGA-based glycans have not yet received attention from synthetic chemists.

\subsection{Apiogalacturonan}

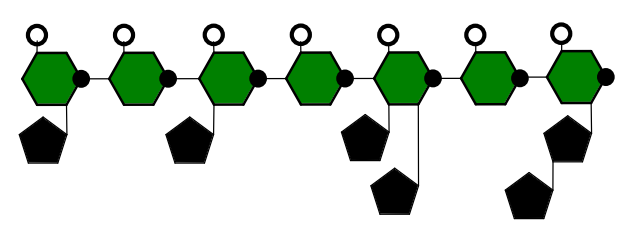

Figure 16. Example of AGA structure showing various types of branching points.

Apiogalacturonan (AGA) is found in the cell walls of aquatic plants such as duckweeds (Lemnaceae) and marine seagrasses (Zosteraceae). ${ }^{122}$ In AGA, $\beta$-D-apiofuranosyl residues are attached to the 2and/or 3-positions of selected GalpA monosaccharides in the HG chain in the form of mono- or sometimes short oligo-saccharides, as shown in Figure $16 .{ }^{6}$ While several groups have focused on the synthesis of apiose-containing oligosaccharides found in the RG-II region of pectin (see section 5.5), only two groups have reported the synthesis of oligosaccharides related to apiogalacturonan (see Table 11). 
Table 11 Three different synthetic AGA oligosaccharides.

\begin{tabular}{|l|l|l|l|}
\hline Structure & R & Year & Reference \\
\hline & & 2011 & Nepogodiev et al. ${ }^{124}$ \\
\hline & & & \\
\hline
\end{tabular}

As D-apiose is a rare sugar, all syntheses of D-apiose-containing oligosaccharides start with the preparation of the appropriate apiose derivative, usually from D-mannose, L-arabinose or D-xylose. ${ }^{125-}$ 128 Reimer and co-workers chose a pre-glycosylation oxidation approach to synthesize AGA disaccharide 225 as shown in Scheme 23. They started by preparing 2,3-O-isopropylidene apiofuranose 219 from D-mannose in five steps. ${ }^{126,127}$ Four additional transformations afforded thioapiofuranoside donor 222. Glycosylation of the 2-OH galacturonate acceptor 223 proceeded smoothly, giving disaccharide 224 in 83\% yield. Deprotection afforded the disaccharide 225 in $76 \%$ yield. 
Scheme 23. Synthesis of disaccharide 225 by Reimer and co-workers. ${ }^{123}$

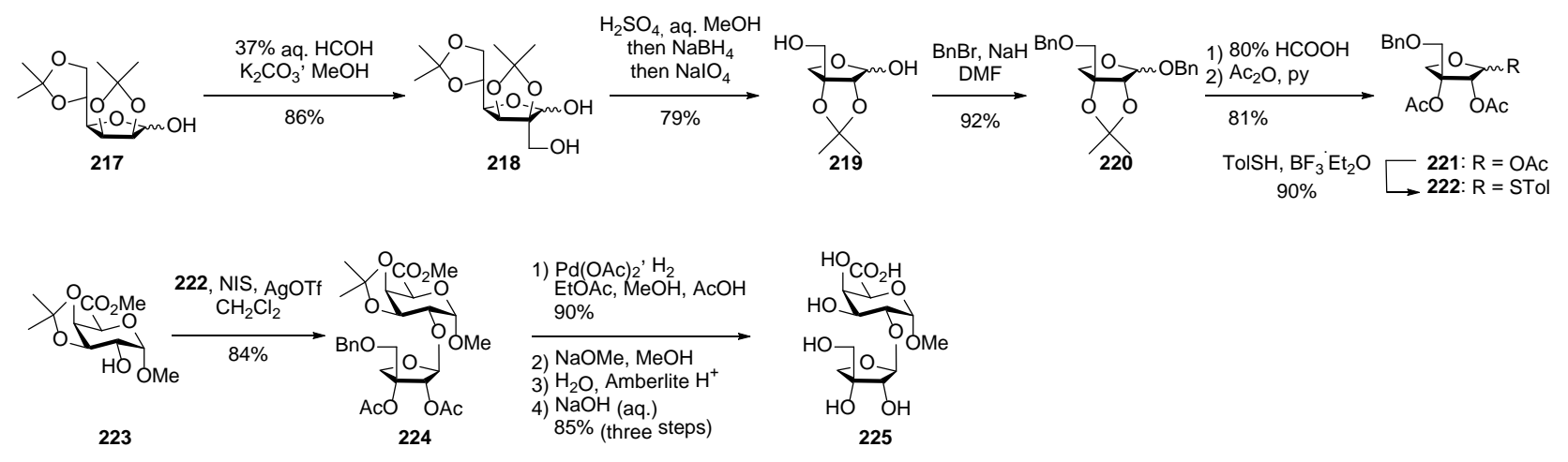

Some years later, in 2011, Field and co-workers synthesized the AGA fragments 225, 234 and 237 shown in Scheme 24. ${ }^{124}$ Like Reimer and co-workers, they prepared apiofuranoside donor 226 from D-mannose according to previously published procedures. Treatment of arylthio glycoside 226 with 90\% TFA followed by acetylation afforded triacetate 227 as an anomeric mixture. Coupling between 227 and 223 afforded the $\beta$-linked disaccharide 228 exclusively in 79\% yield, which was further deprotected to give the target disaccharide 225. Galacturonate acceptors with unprotected 3-OH or both 2- and 3-OH groups (239 and 235, respectively) were prepared and coupled with 227, leading to di- and tri-saccharides 233 and 236 in good yields. Cleavage of the ester protecting groups afforded the targeted apiogalacturonans 234 and 237. 
Scheme 24. Synthesis of di- and trisaccharide AGA fragments by Field and co-workers. ${ }^{124}$

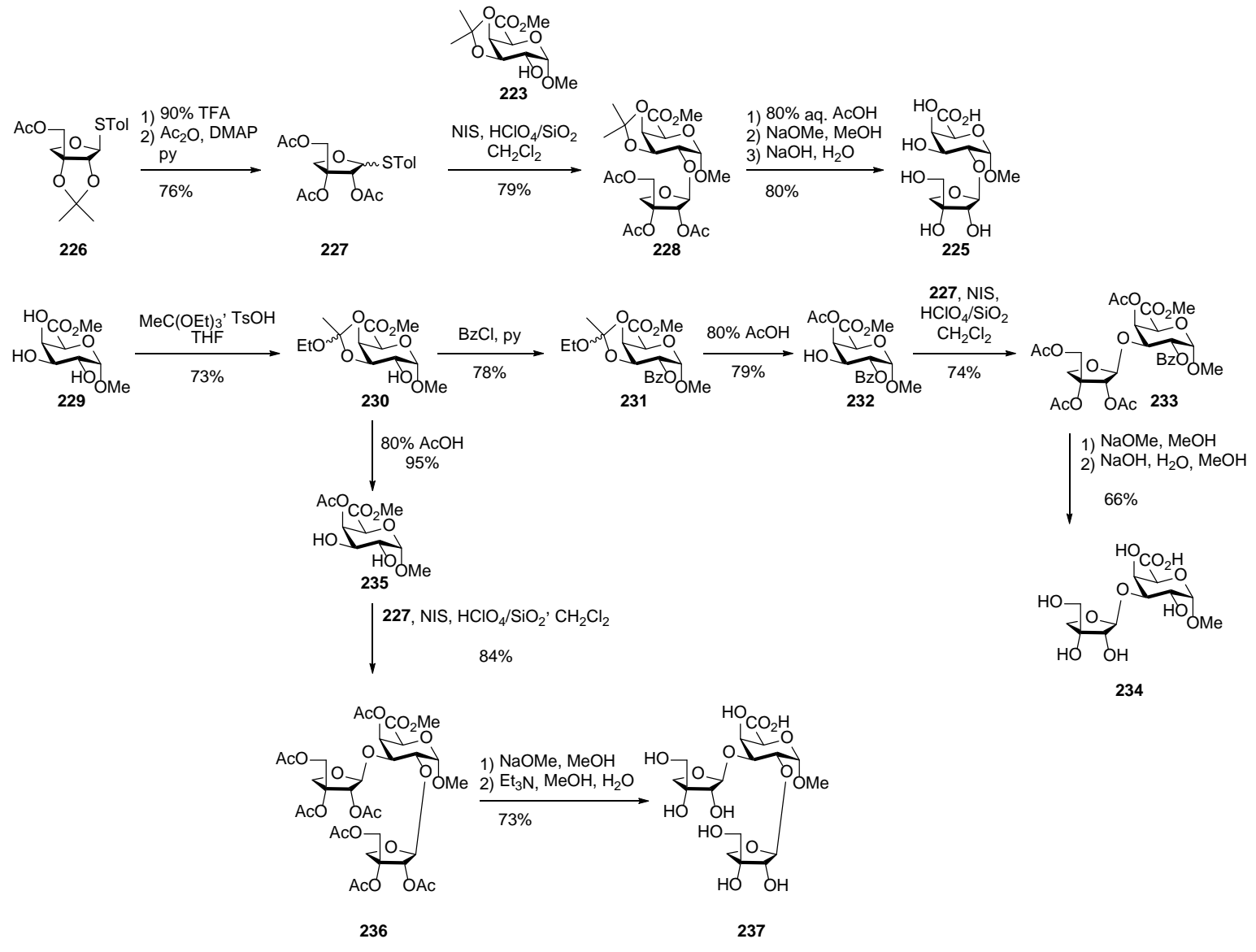




\subsection{Rhamnogalacturonan I}

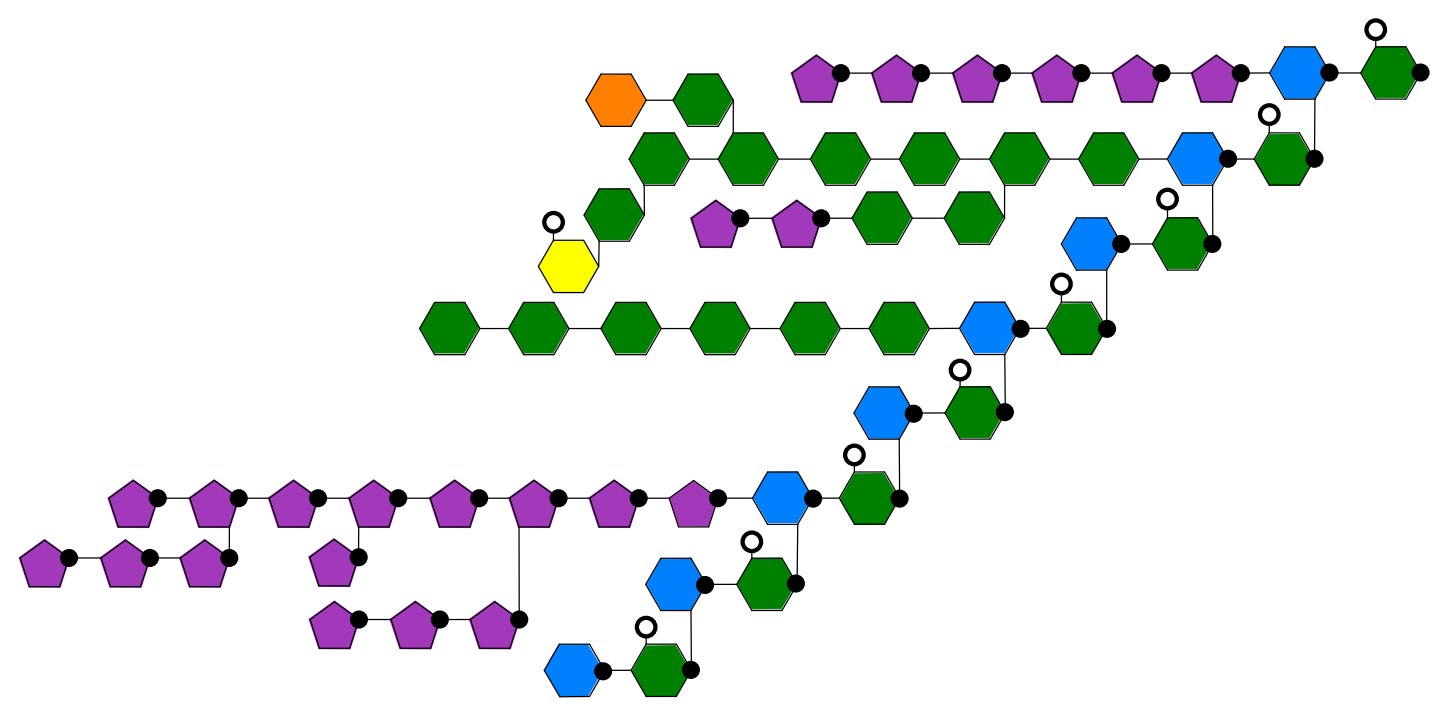

Figure 17. Representation of RG-I structure. ${ }^{98}$

RG-I (Figure 17) makes up 20-35\% of pectin. Its average length has not been determined, since isolated RG-I domains are generally accompanied by HG. However, the RG-I backbone has generally been found to be shorter than HG. Furthermore, the RG-I backbone is predicted to have a three-fold helix conformation. ${ }^{129}$ RG-I polysaccharides have repeating disaccharide units of $(1 \rightarrow 2)-\alpha-L-$ rhamnopyranosyl-( $1 \rightarrow 4)$ - $\alpha$-D-galactopyranuronic acid. The GalpA residues may be $O$-acetylated on C2-O and/or C3-O as seen for HG, but no methyl esterification has been observed. ${ }^{98}$ The diversity of RG-I stems from the variety of side chains that can decorate the C-4 positions of rhamnose. Depending on the plant source and the method of isolation, $20-80 \%$ of the rhamnosyl residues are found to be substituted. These side chains consist of three different types of branched oligosaccharides of varying length (1-20 residues): galactans, arabinogalactans (AG), and arabinans. ${ }^{98,130}$ Pectic arabinogalactans are usually divided into two main groups. ${ }^{131}$ Type I arabinogalactan (AG-I) is the most prevalent neutral pectic glycan and is especially abundant in citrus fruits and apples. It is characterized by a 
linear $\beta$-( $(1 \rightarrow 4)$-linked D-Galp chain, which can be substituted at the C-3 position by L-Araf residues and occasionally by arabinosyl oligosaccharides. It sometimes also carries galactan at the C-6 position. Type II arabinogalactan (AG-II) are highly branched polysaccharides composed of a backbone of $\beta-(1 \rightarrow 3)$ or $(1 \rightarrow 6)$-linked D-galactan, which can be (arabino)galactan-substituted at the C-6 or C-3 positions, respectively. ${ }^{97}$ Galactans are simply $\beta$-( $\left.1 \rightarrow 4\right)$-linked D-galactan chains and have been observed in lengths of up to 40 residues. Finally, the arabinans consist of $\alpha-(1 \rightarrow 5)$-linked LAraf residues with some degree of $(1 \rightarrow 3)$-branching. The glycosyl residues $\alpha$-L-fucosyl, $\beta$-Dglucuronosyl and 4-O-methyl $\beta$-D-glucuronosyl may also be present. ${ }^{98}$ The (arabino)galactans and arabinans will be discussed separately in section 6 .

\subsubsection{RG-I backbone}

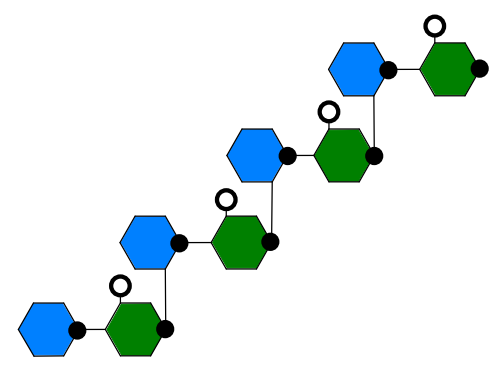

Figure 18. RG-I backbone structure.

Several syntheses of fragments of the RG-I backbone (Figure 18) have been carried out and an overview of the different oligosaccharides produced is shown in Table 12.

Table 12. Synthetic fragments of RG-I backbone.

\begin{tabular}{|l|l|l|l|}
\hline Structure & R & Year & Reference \\
\hline
\end{tabular}




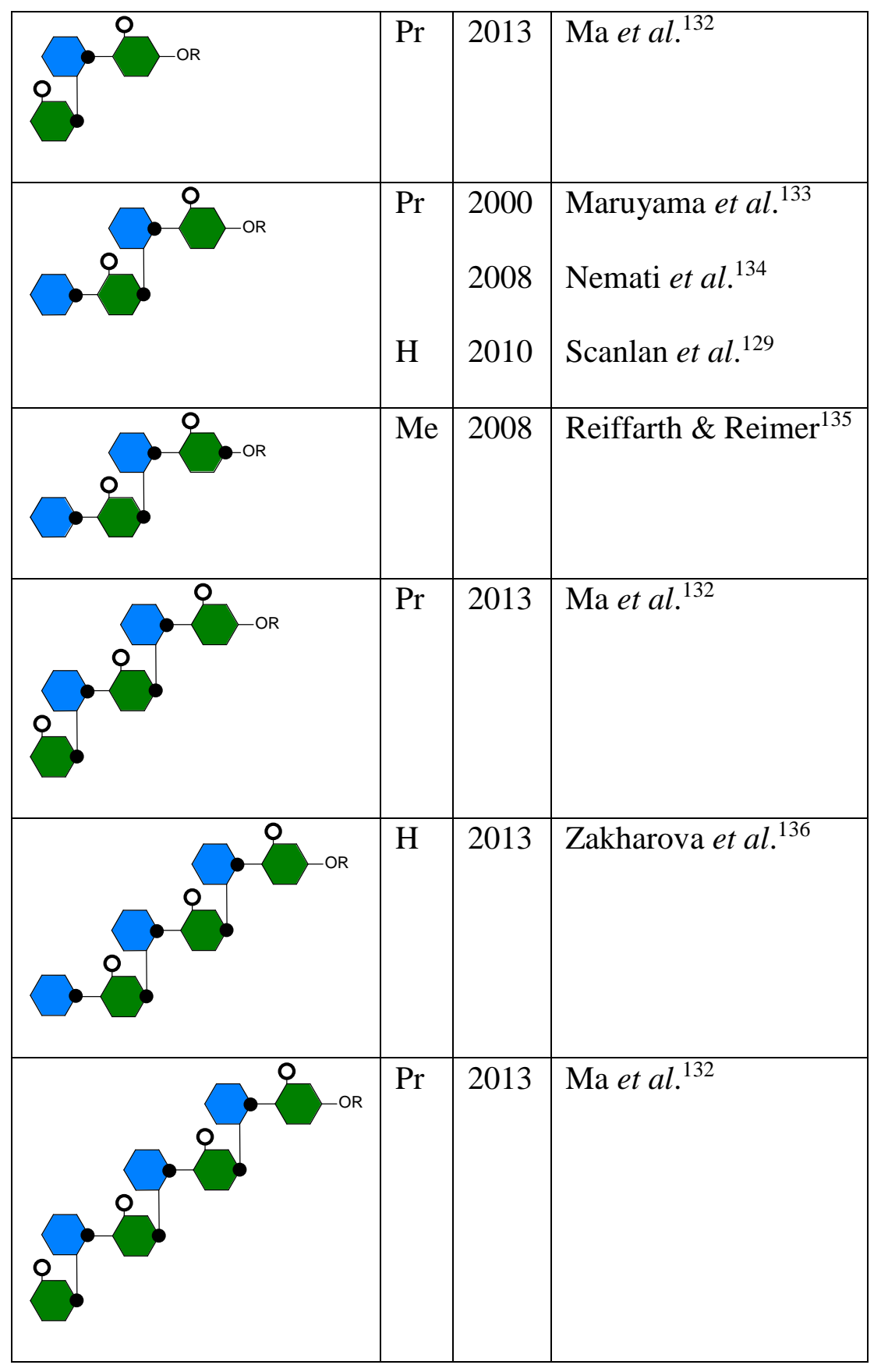

As with HG fragment syntheses, and more generally all oligosaccharides containing uronic acids, both pre-glycosylation oxidation and post-glycosylation oxidation approaches have been investigated by different groups. The former approach was chosen by Reiffarth \& Reimer ${ }^{135}$, also Vogel and co- 
workers ${ }^{134}$ and $\mathrm{Yu}$ and co-workers. ${ }^{132}$ In 2008, Reiffarth and Reimer ${ }^{135}$ used a block synthesis approach, coupling two disaccharide repeating units derived from the same disaccharide precursor, to form their target rhamnogalacturonan tetrasaccharide $\mathbf{2 4 4}$ as shown in Scheme 25. The C-4 positions of the rhamnosyl residues were orthogonally protected with an allyl group in order to allow potential introduction of RG-I side chains. An acetyl group was used to protect their C-2 positions to enable elongation of the backbone. Rhamnosyl thioglycoside donor 237 and methyl galacturonate acceptor 238 were coupled to form the key disaccharide intermediate 239. This was then further transformed in a three-step sequence to generate a new disaccharide acceptor 240, by removal of the 2-acetyl group, and a new trichloroacetimidate disaccharide donor 241. However, glycosylation of $\mathbf{2 4 0}$ with donor 241 turned out to be more difficult than expected. Tetrasaccharide 242 was obtained in only $39 \%$ yield and attempts to optimize the reaction by changing the promoter and donor types were unsuccessful. The fully deprotected tetrasaccharide methyl ester $\mathbf{2 4 3}$ was then reached over four steps in $33 \%$ overall yield and ester hydrolysis using $\mathrm{NaOH}$ followed by acidification afforded the desired rhamnogalacturonic acid tetrasaccharide 244 in 77\% yield. 
Scheme 25. Synthesis of an RG-I backbone tetrasaccharide fragment by Reiffarth \& Reimer. $^{\mathbf{1 3 5}}$

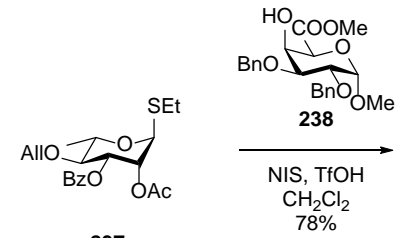

237

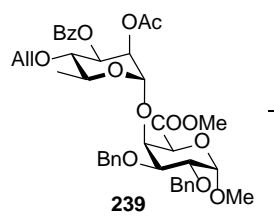

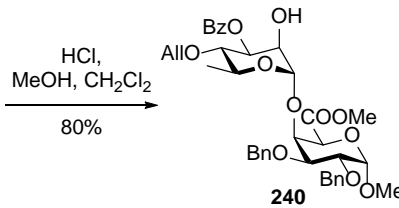

1) $\mathrm{H}_{2} \mathrm{SO}_{4}, \mathrm{AcOH}, \mathrm{Ac}_{2} \mathrm{O}(81 \%)$ 2) $4 \AA \mathrm{MS}, \mathrm{CH}_{2} \mathrm{Cl}_{2}, \mathrm{MeOH}(89 \%)$
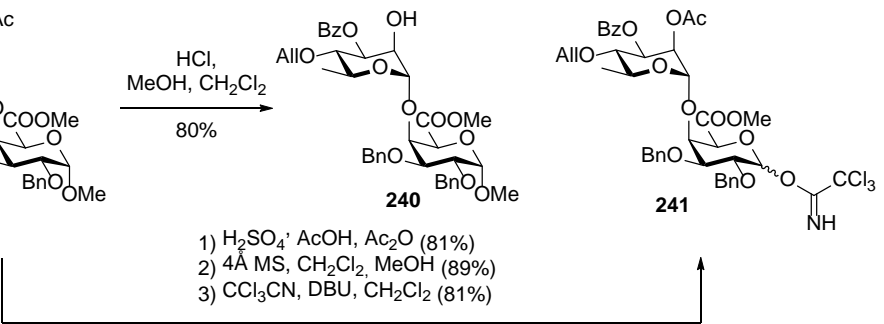

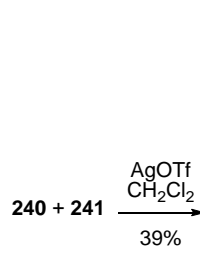

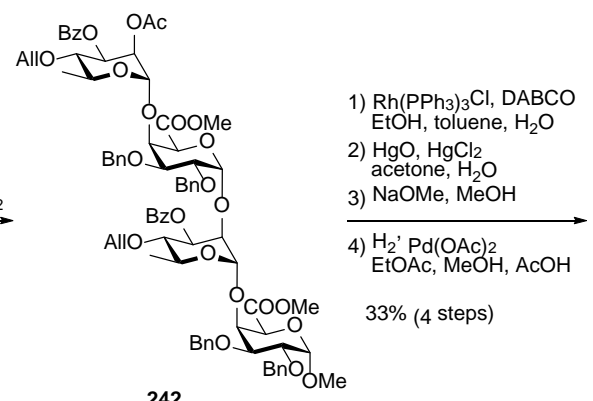

242

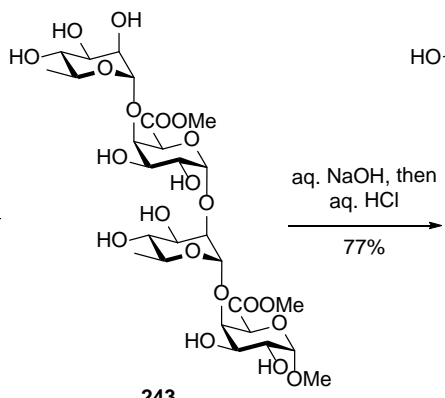

243

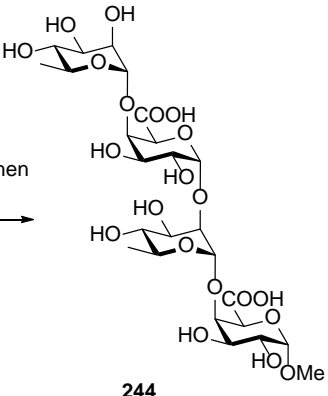

In 2008, Vogel and co-workers ${ }^{134}$ used a similar synthetic approach. Unlike Reiffarth \& Reimer, trimethylsilyl trifluoromethanesulfonate-promoted glycosylation with a similar trichloroacetimidate disaccharide donor and disaccharide acceptor ( $O-3^{\prime}$ and $O-4$ ' protection was modified compared to 240 and 241),provided them with the desired tetrasaccharide in 60\% yield. More recently, in 2013, Yu and co-workers ${ }^{132}$ reported the synthesis of tri-, penta-, and heptasaccharide fragments (251, 254 and 257) of the RG-I backbone using the pre-glycosylation oxidation approach with an iterative elongation of the chain, using disaccharide building block 248 (Scheme 26). The syntheses feature highly stereoselective formation of the $\alpha$-D-GalpA-linkage, with very good yields, when using $N$ phenyltrifluoroacetimidates as donors. 
Scheme 26. Synthesis of tri-, penta- and heptasaccharide fragments of RG-I backbone by Yu and coworkers. ${ }^{132}$
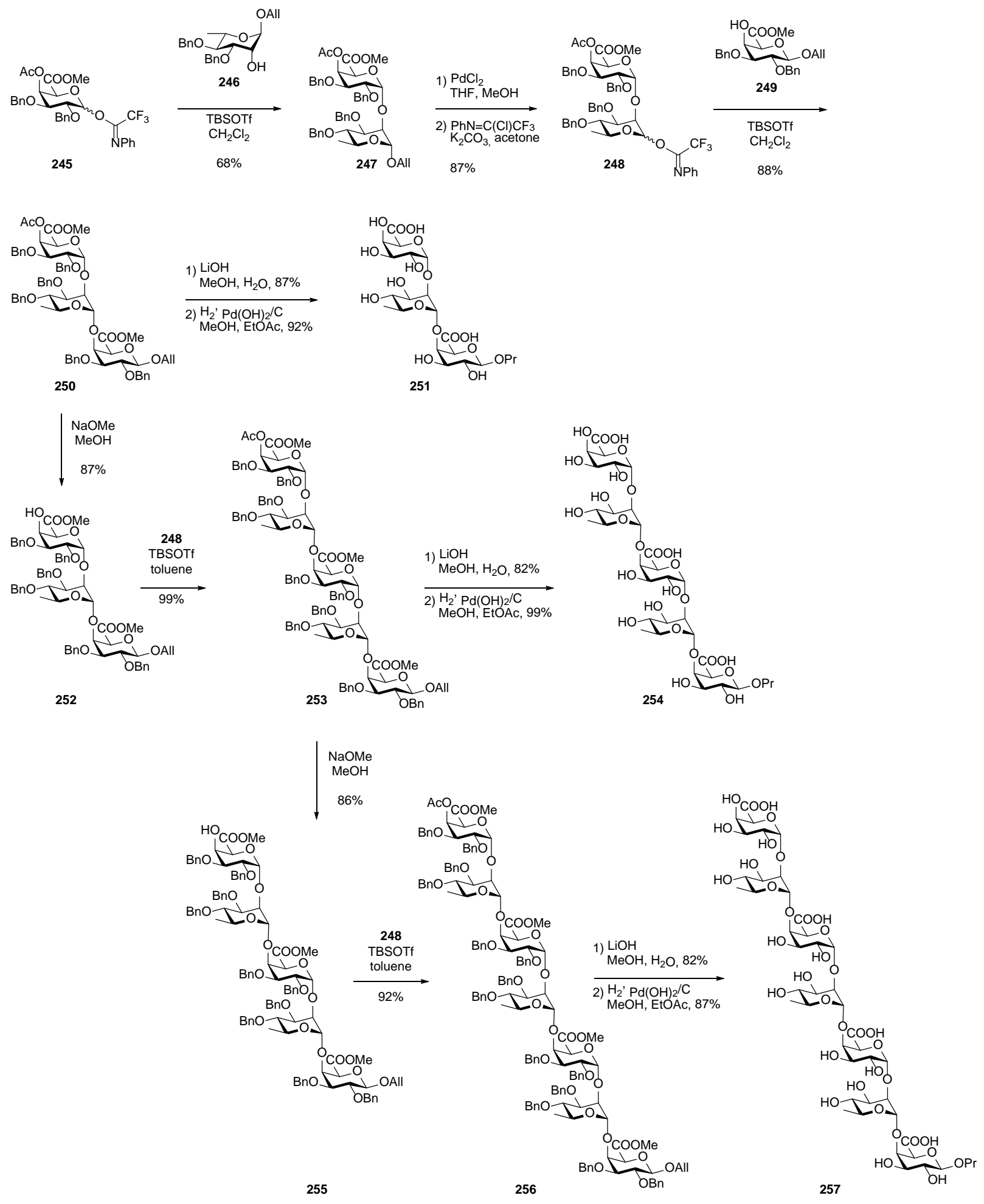
The three other groups who have synthesized RG-I backbone fragments used the post-glycosylation approach, i.e. synthesizing a neutral backbone and oxidizing the primary hydroxyl groups to the desired carboxylic acid functionality afterwards. ${ }^{129,133,136}$ In 2000, Takeda and co-workers prepared the unprotected propyl RG-I backbone tetrasaccharide 269 by employing trichloroacetimidate glycosyl donors (see Scheme 27). ${ }^{133}$ Selected rhamnose residues bore PMB protective groups at C-4, allowing for potential introduction of RG-I side chains. 
Scheme 27. Synthesis of fully unprotected propyl glycosyl tetrasaccharide of RG-I backbone by Takeda and co-workers. ${ }^{133}$

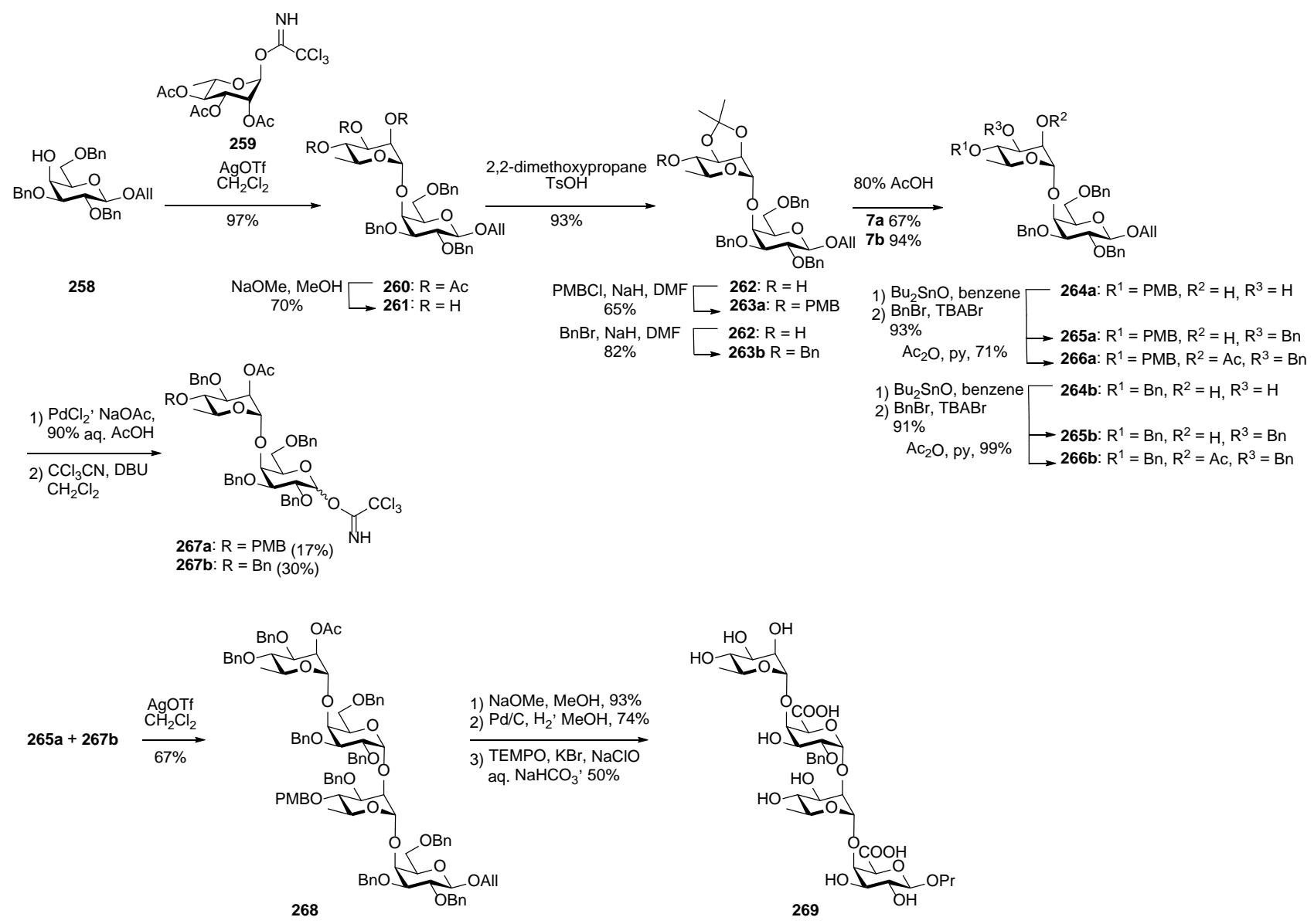

AgOTf-catalyzed glycosylation between allyl galactoside acceptor 258 and trichloroacetimidate donor 259 afforded the $\alpha$-linked disaccharide $\mathbf{2 6 0}$ in 97\% yield as a single stereoisomer. Protecting group manipulations afforded four differently protected disaccharides: two trichloroacetimidate donors 267a and 267b (PMB and Bn protected at the Rhap C-4, respectively) and two 2'-OH acceptors 265a and 265b. One noteworthy aspect is that the two-step conversion into trichloroacetimidate donors 267a and 267b resulted in modest yields (17\% and 30\%, respectively). Coupling of 265a and 267b gave the $\alpha$-linked tetrasaccharide $\mathbf{2 6 8}$ in 67\% yield. Deprotection followed by selective oxidation 
of the primary hydroxyl groups with 2,2,6,6-tetramethylpiperidin-1-oxyl (TEMPO), $\mathrm{KBr}$ and $\mathrm{NaClO}$ afforded the desired unprotected propyl tetrasaccharide $\mathbf{2 6 9}$ in 34\% yield over the three steps.

In the same year, Davis and co-workers used an orthogonal approach, combined with a late-stage oxidation strategy, to synthesize a fully unprotected RG-I backbone tetrasaccharide 281 and its corresponding methyl ester (see Scheme 28). ${ }^{129}$ Surprisingly, initial attempts to couple a galactorhamnosyl disaccharide donor to Galp $\mathrm{C}^{\prime}$ '-OH of a disaccharide acceptor failed. This was probably due to low reactivity of the acceptor, and forced the authors to change strategy and assemble the RG-I tetrasaccharide through galactosylation instead of rhamnosylation. The group used both trichloroacetimidates and ethylthioglycosides as donors, affording good glycosylation yields and $\alpha$ stereoselectivity. 
Scheme 28. Davis and co-workers’ synthesis of an RG-I backbone tetrasaccharide $281 .^{\mathbf{1 2 9}}$

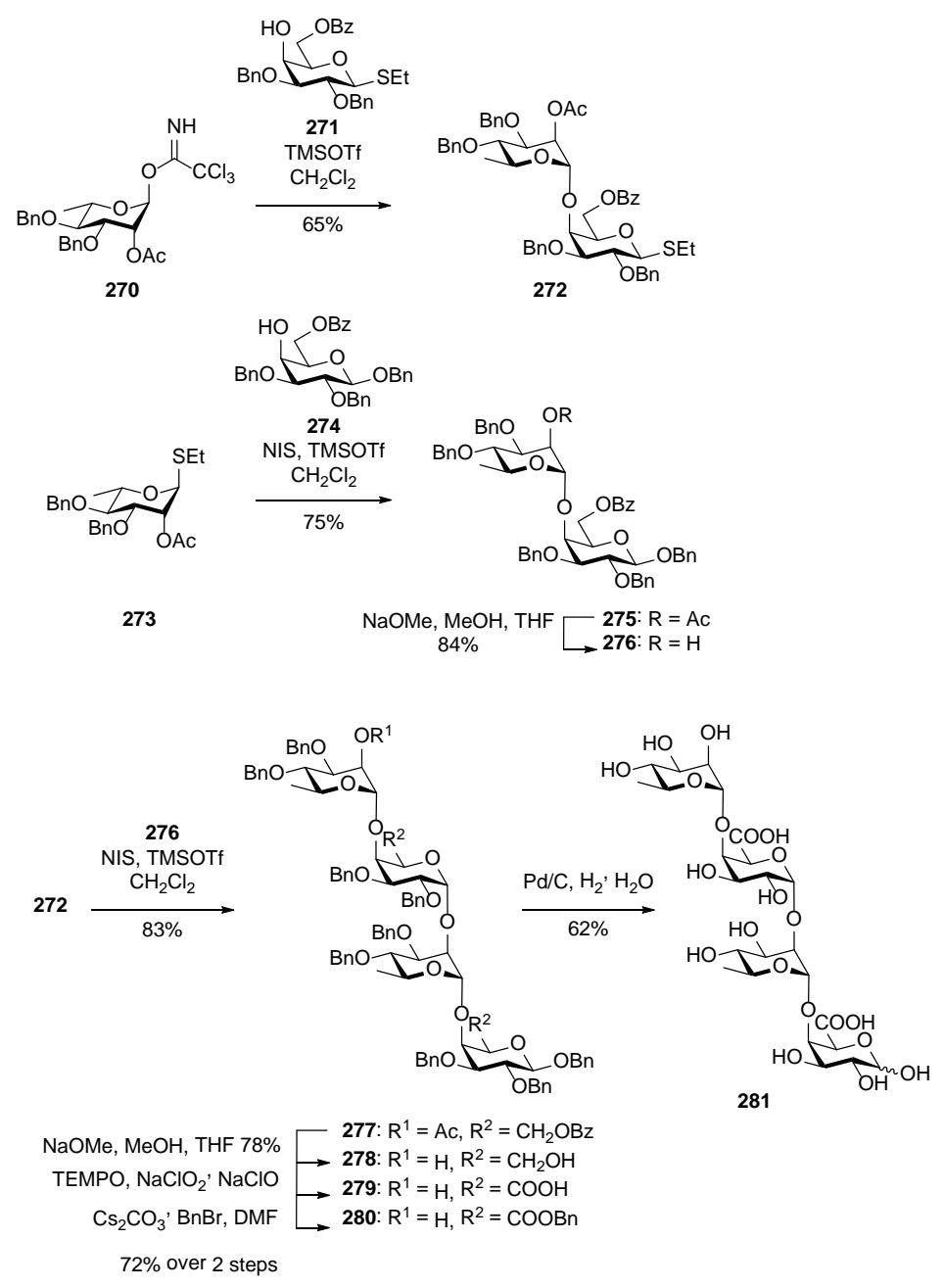

In 2013, Clausen and co-workers synthesized a fully unprotected hexasaccharide backbone of RG- I using a strategy relying on iterative coupling of a common pentenyl disaccharide glycosyl donor 284. ${ }^{136}$ The latter was prepared by an efficient chemoselective armed-disarmed coupling of a thiophenyl rhamnoside donor 282, with a pentenyl galactoside acceptor $\mathbf{2 8 3}$ bearing the strongly electron-withdrawing pentafluorobenzoyl ester ( $\mathrm{PFBz}$ ) protective group, as shown in Scheme 29. Two iterative glycosylations using pentenyl disaccharide $\mathbf{2 8 4}$ afforded hexasaccharide $\mathbf{2 8 9}$ in reasonable yields. Removal of the PFBz groups under Zemplén conditions afforded the Galp primary alcohols, 
which were oxidized with Dess-Martin periodinane to the aldehydes and then with $\mathrm{NaClO}_{2}$ to the desired carboxylic acids. As in many other cases, the carboxylic acids were protected with benzyl esters in order to facilitate purification. Palladium catalyzed hydrogenolysis gave the fully unprotected hexasaccharide 291.

Scheme 29. Fully unprotected hexasaccharide backbone of RG-I synthesized by Clausen and coworkers. ${ }^{136}$
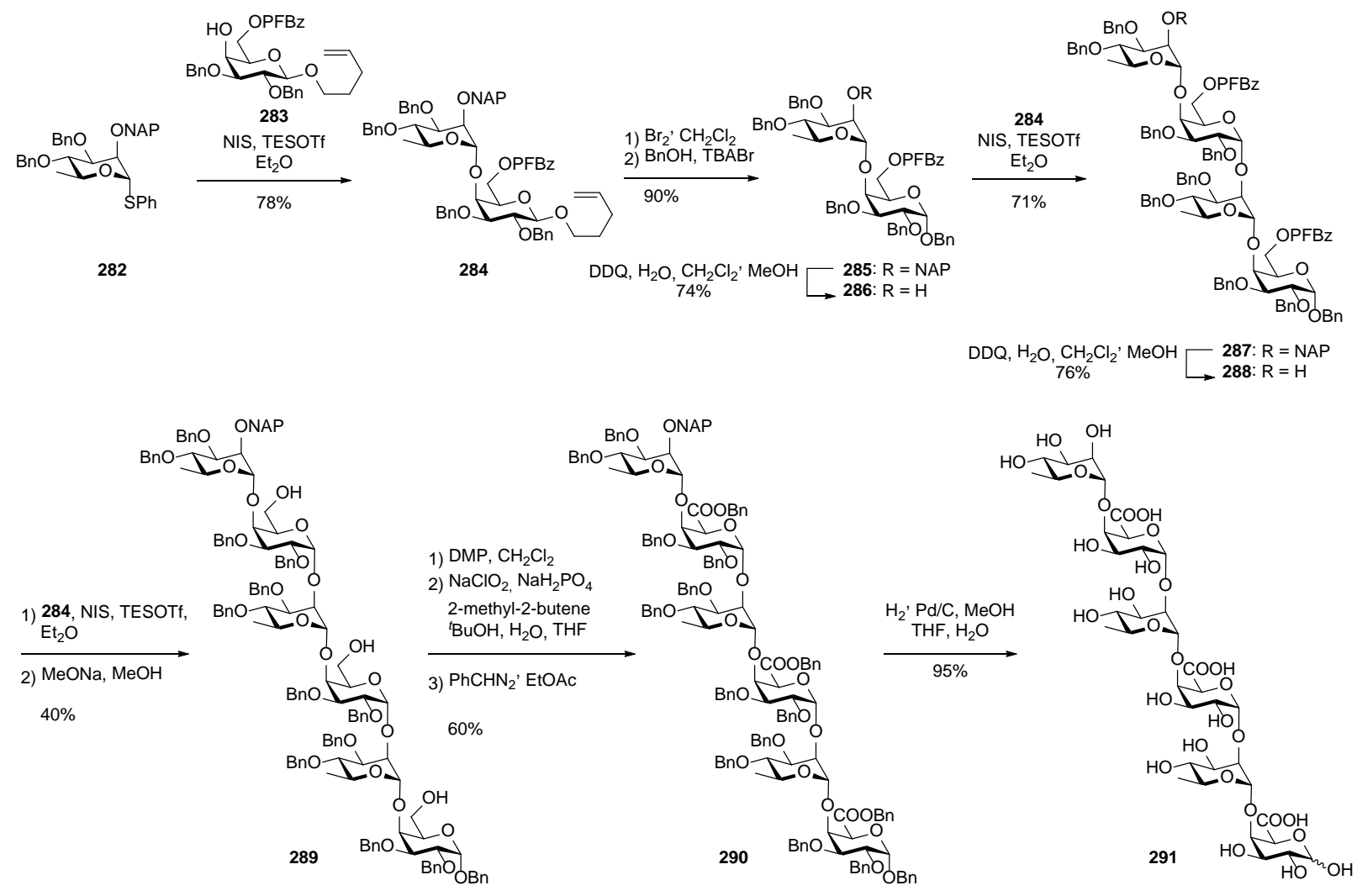

\subsubsection{RG-I side chains}

As explained in the introduction to rhamnogalacturonan I (section 5.4), RG-I has three main types of side chain: galactans, arabinogalactans and arabinans. Since (arabino)galactans are also found in 
arabinogalactan proteins (AGPs), oligosaccharides related to these structures will be discussed separately in Chapter 6.

\subsection{Rhamnogalacturonan II}
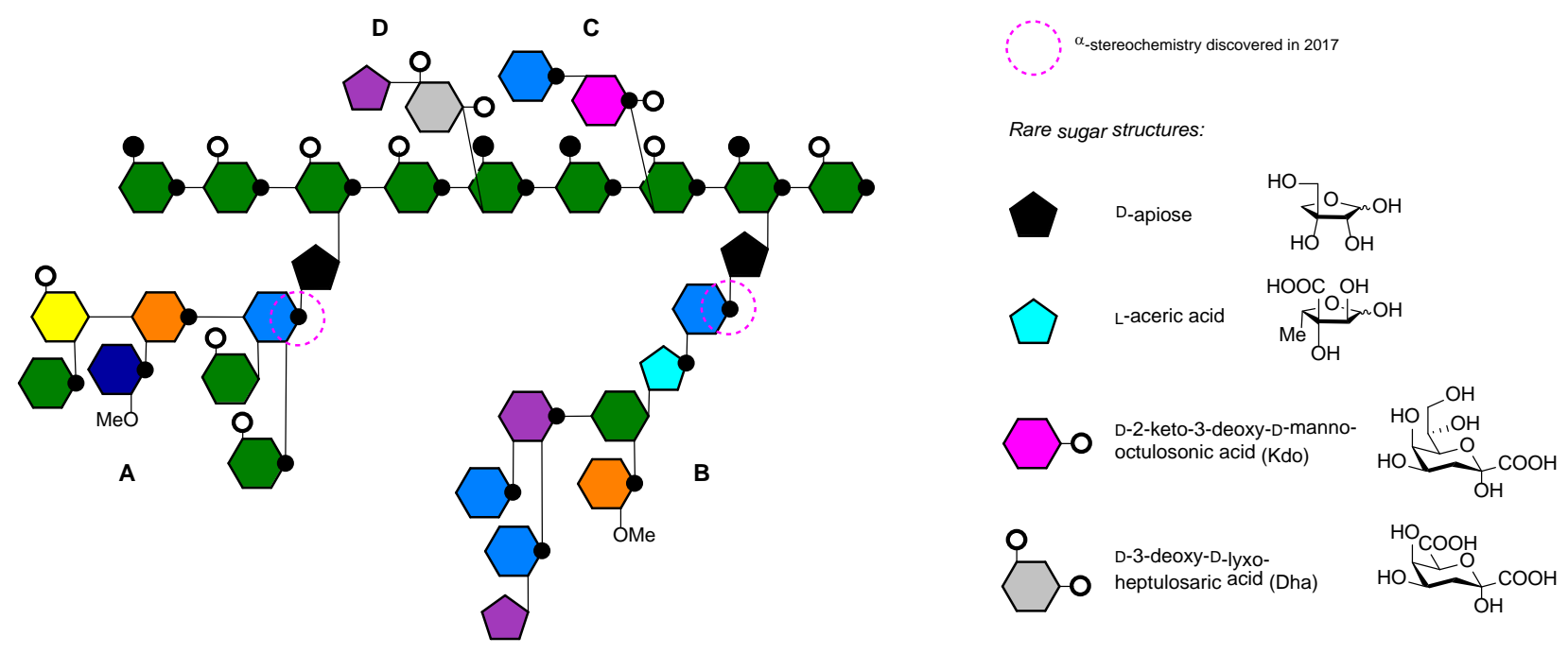

Figure 19. Schematic representation of RG-II based on the findings of Gilbert and co-workers. ${ }^{137}$

Rhamnogalacturonan II (RG-II) constitutes $~ 10 \%$ of pectin in the cell wall of higher plants and is a structurally complex branched pectic polysaccharide. ${ }^{97}$ It is present in above-average quantities in wine and other beverages obtained by fermentation of fruits and vegetables (one liter of red wine contains between 100 and $150 \mathrm{mg}$ of RG-II while around $20 \mathrm{mg}$ is present in a liter of white wine). ${ }^{138}$ Therefore, red wine has been used as a source of RG-II in several studies of this polysaccharide. ${ }^{139}$ Unlike RG-I, the RG-II structure has been regarded to have remarkably little variation and to be evolutionarily conserved in all vascular plants. Variations are minor and are limited to methylation and/or acetylation of the side chains. ${ }^{140}$ However, recent discoveries have shown evidence of variation also in the monosaccharide composition of the side chains. ${ }^{141}$ RG-II has an HG backbone, made up of 
seven to nine residues, and substituted by four different side chains (A-D), which can contain up to 29 monosaccharides, including a number of rare sugars (see Figure 19). ${ }^{100,101,142}$ These comprise Laceric acid (AcefA; 3-C-carboxy-5-deoxy-L-xylose), 2-keto-3-deoxy-D-manno-octulosonic acid (Kdop), 2-keto-3-deoxy-D-lyxo-heptulosaric acid (Dhap), D-apiose (Apif; 3-C-(hydroxymethyl)- $\beta$-Derythrose), L-galactose, 2-O-methyl-D-xylose and 2-O-methyl-L-fucose. The monosaccharides are connected by over 20 different glycosidic linkages. Side chains A and B are the largest and have been described as highly ramified octa- and heptasaccharides, respectively. ${ }^{143,144}$ The C and D side chains are disaccharides, and two extra side chains E and F, composed of a single L-arabinose residue linked to a mono- or di-substituted galacturonic acid residue respectively, have been isolated from red wine RG-II recently. ${ }^{100,137,145}$

Before 2000, knowledge of the primary structure of RG-II was mostly based on the determination of the glycosidic linkage composition (using methylation analysis) and identification of various oligosaccharide fragments by mass spectroscopy (after acid and/or enzymatic hydrolysis of RG-II). Recently, several NMR solution studies have helped determine the fine- and three-dimensional structure of the oligosaccharide. ${ }^{144,146,147}$ In 2000, Vidal and co-workers published a convincing NMR study of an RG-II fragment, which contained a hexasaccharide homogalacturonan backbone substituted by side chains B and D. ${ }^{146}$ Their structural studies showed that the original configurations postulated for the anomeric centers of two residues in the B-chain were incorrect. This led some other groups to look in more detail at the structure of RG-II. In 2003, Pérez and co-workers reported a thorough NMR investigation of RG-II. They reassigned most of the RG-II primary structure and used NOESY data to propose a conformational model of the oligosaccharide in solution. ${ }^{145}$ Nevertheless, several NMR assignments remained ambiguous. In 2017, Gilbert and co-workers published a revised 
model of the RG-II structure based on an impressive work including crystal structure of side chain B in complex with a glycosyl hydrolase combined with enzymatic degradation studies. This revised structure is the one shown in Figure $19 .{ }^{137}$ The main difference compared to previously proposed structures of RG-II is highlighted by pink circles: the L-Rhap-D-Apif linkage in chains A and B is $\alpha$ and not $\beta$. It has been observed that more than $90 \%$ of the RG-II in the cell wall self-assembles into a covalently cross-linked dimer in the presence of boron. RG-II is dimerized by borate ester formation involving the apiosyl residues of side chain A belonging to two different RG-II monomers, which results in networks of pectic polysaccharides. ${ }^{100}$ This secondary structure has been confirmed by ${ }^{11} \mathrm{~B}$ NMR. ${ }^{148}$ Several studies support the idea that RG-II and its borate crosslinking support cell adhesion and wall mechanical strength and are therefore significant for plant growth and development. ${ }^{149,150}$ All the knowledge about RG-II structure and function accumulated before 2004 is summarized in a comprehensive review by Darvill and co-workers. ${ }^{100}$

Most synthetic efforts have focused on side chain A and B, which also constitute most of the RG-II structure, as mentioned previously. Since many of the synthesized fragments are only disaccharides, the goal of synthesizing them was often not so much to study RG-II function, but rather to develop synthetic methods. Furthermore, as the chemical synthesis of some of the rare sugars present in RGII is not straightforward, we will refer the reader to selected articles reporting methods that have been developed for their preparation.

\subsubsection{RG-II side chain A}

Despite the fact that RG-II side chains were thought to be highly conserved in the plant kingdom, some variations in the composition of side chain A were reported by Léonard and co-workers in 
2013. ${ }^{141}$ They showed that in wild-type Arabidopsis plants, up to 45\% of L-fucose was replaced by Lgalactose (see Figure 20). The study also provided evidence that a large proportion of the GlcpA residues were methyl esterified and some of the $\beta$-GalpA residues were $O$-methylated at positions 3 and 4 (these variations are highlighted in red on Figure 20). Furthermore, until the work published by Gilbert and co-workers in 2017, it was believed that the Rhap-Apif linkage (shown in pink-dot circle on Figure 20) was a $\beta$-linkage, which was proved to be the wrong stereochemistry by Gilbert's group.
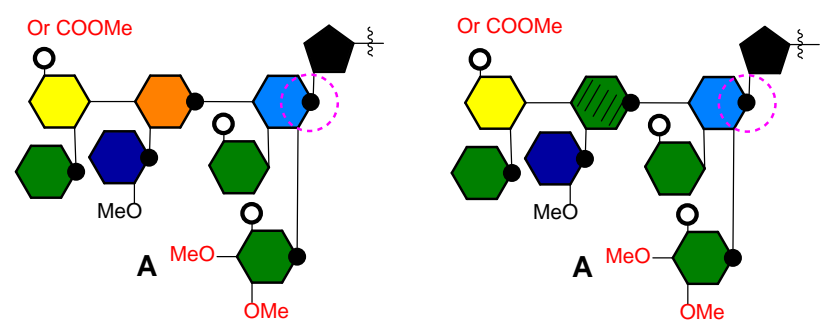

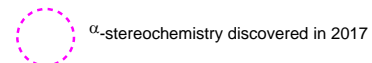

Figure 20. Schematic representation of side chain A including the variations across different plant species observed by Léonard and co-workers. ${ }^{141,145}$

Side chain A is attached to the homogalacturonan backbone residue via a D-Apif residue. ${ }^{151,152}$ Oneand two-dimensional ${ }^{1} \mathrm{H}$ NMR spectroscopic analysis showed that apiose is $\beta$-(1 $\left.\rightarrow 2\right)$-linked to GalpA. ${ }^{146}$ The synthesized fragments belonging exclusively to side chain A are reported in Table 13, while fragments found in both side chain A and B are presented in Table 14.

Table 13. Synthetic fragments found exclusively in RG-II side chain A.

\begin{tabular}{|l|l|l|l|}
\hline Structure & R & Year & Reference \\
\hline$\square(O \mathrm{OR}$ & Me & 1990 & Backman et al. ${ }^{153}$ \\
\hline
\end{tabular}




\begin{tabular}{|l|l|l|l|}
\hline & Me & 2005 & Chauvin et al. $^{154}$ \\
\hline & & & \\
\hline
\end{tabular}

Jansson and co-workers synthesized a Fucp-Rhap disaccharide by MeOTf-promoted glycosylation between 2,3,4-tri-O-benzyl-1-thio- $\beta$-L-fucopyranoside 292 and methyl 2,3-isopropylidene- $\alpha$-Lrhamnopyranoside 293 affording the desired $\alpha$-linked disaccharide 294 in 77\% yield as shown in Scheme $30 .{ }^{153}$

Scheme 30. $\alpha$-L-Fucp $(1 \rightarrow 2)-\alpha-L-R h a p O M e$ fragment synthesized by Jansson and co-workers. ${ }^{153}$

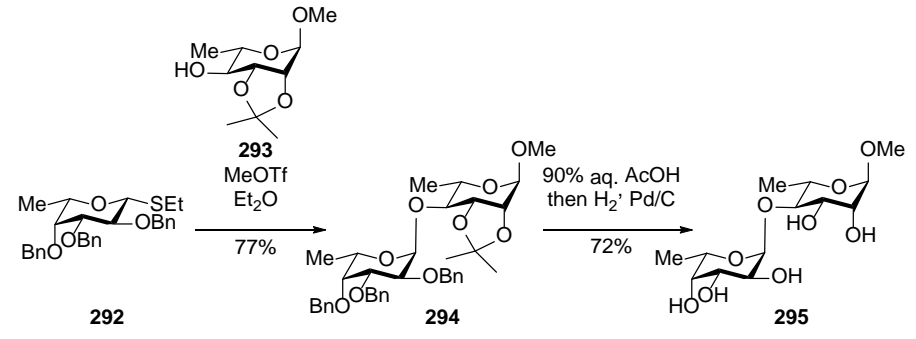

In 2005, Nepogodiev, Field and co-workers achieved the synthesis of branched tetrasaccharide fragment $\mathbf{3 0 8}$ following the route shown in Scheme 31. As this tetrasaccharide contains a combination of two 6-deoxy sugar residues (Rhap and Fucp) and two uronic acids (GalpA), they chose a post- 
glycosylation oxidation strategy in order to introduce the carboxylic acids in the very last step of their synthesis. The method was based on the use of the differentially protected rhamnoside 299. Sequential glycosylation afforded the neutral tetrasaccharide $\mathbf{3 0 7}$ in reasonable yields and stereoselectivities overall. Following deprotection of 307, the primary hydroxyl groups were successfully oxidized using TEMPO affording the target 308 in $47 \%$ yield.

Scheme 31. Synthesis of a branched tetrasaccharide fragment from side chain A by Nepogodiev, Field and co-workers. ${ }^{154}$
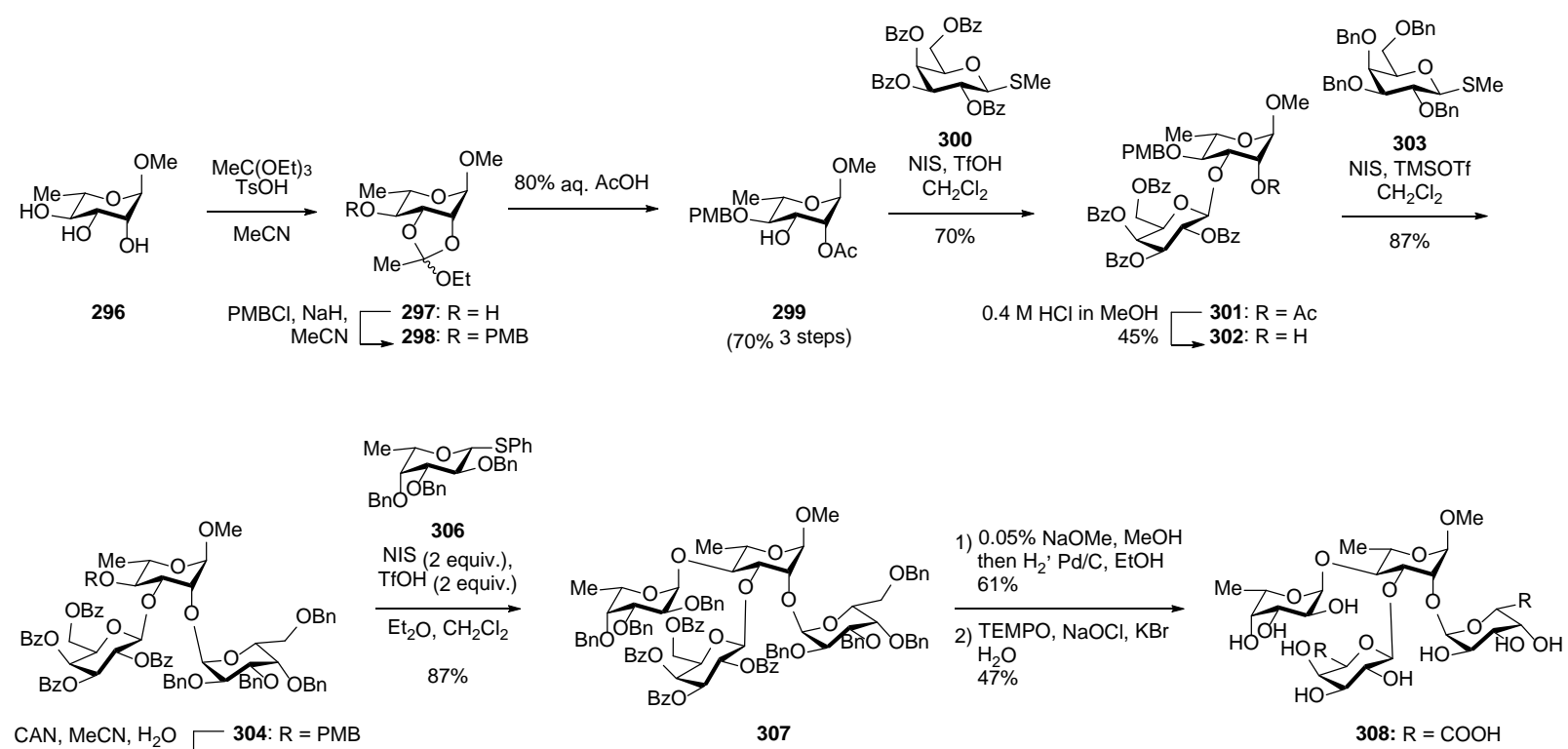

CAN, MeCN, $\mathrm{H}_{2} \mathrm{O}-304: \mathrm{R}=\mathrm{PMB}$

307

308: $\mathrm{R}=\mathrm{COOH}$

The linear trisaccharide $\alpha$-L-Rhap- $\left(1 \rightarrow 3^{\prime}\right)-\beta$-D-Apif- $(1 \rightarrow 2)-\alpha-\mathrm{D}-\mathrm{Gal} p$ is a fragment that is common to both side chain A and B. However, since the linkage between the rhamnose and the apiose residues was believed to be $\beta$ until 2017, chemists focused on synthesizing fragments with this configuration. Reimer and co-workers ${ }^{123}$ and Nepogodiev and co-workers ${ }^{155}$ both reported the synthesis of disaccharide elements of the fragment in 2004 ( $\beta$-D-Apif $(1 \rightarrow 2)-\alpha-\mathrm{D}-\mathrm{Gal} p$ and $\beta$-L-Rhap-( $\left.1 \rightarrow 3^{\text {') }}\right)-\beta$-DApif, respectively). In 2011, Nepogodiev, Field and co-workers ${ }^{124}$ reported the synthesis of the full structure (see Table 14). 
Table 14. Synthetic fragments found in both side chain A and side chain B of RG-II.

\begin{tabular}{|l|l|l|l|}
\hline Structure & R & Year & Reference \\
\hline & $\mathrm{Me}$ & 2004 & Buffet et al. $^{123}$ \\
\hline & & & \\
\hline
\end{tabular}

All these syntheses required access to the rare sugar apiose. As explained in section 5.3, D-apiose derivatives are usually produced from D-mannose, L-arabinose or D-xylose. ${ }^{125-128}$ The approach by Reimer and co-workers was described earlier (see Scheme 23). The two other fragments synthesized, required the challenging $\beta$-rhamnosylation to form $\beta$-L-Rhap-( $1 \rightarrow 3)-\beta$-D-Apif disaccharide. Unlike for $\beta$-mannosylation, only few methods for $\beta$-rhamnosylation have been reported. ${ }^{156,157}$ The first report by Hodosi and co-workers in 1997 described the $\mathrm{S}_{\mathrm{N}} 2$ coupling between a sugar triflate and an unprotected 1,2-O-stannylene acetal of L-rhamnopyranose. ${ }^{157}$ In 2003, Crich and Picione reported a second method enabling the direct formation of a $\beta$-L-rhamnoside by means of thiorhamnoside donors protected with a 2-O-sulfonate ester and, ideally, a 4-O-benzoyl ester. ${ }^{156}$ After attempting in vain to apply Hodosi’s method for the synthesis of $\beta$-L-Rhap-( $1 \rightarrow 3)-\beta$-D-Apif, Nepogodiev and co-workers decided to use a cyclic 2,3-carbonate rhamnosyl bromide donor as shown in Scheme 32. ${ }^{124}$ It is worth mentioning that the synthesis of thiophenyl apiofuranoside residue $\mathbf{3 1 0}$ required extensive 
optimization and was achieved through a tedious 9-steps synthesis from L-arabinose. The authors did test simpler protecting group schemes, but these strategies were unsuccessful. Koenigs-Knorr $\beta$ rhamnosylation between 313 and apiogalacturonate acceptor 312 afforded the desired core trisaccharide $\mathbf{3 1 4}$ in 59\% yield, which was deprotected in four steps to reach the target molecule. In 2012, Yasomanee and Demchenko demonstrated a third approach by forming a $\beta$-rhamnoside employing a picoloyl protecting group in the 3-position of a thioethyl rhamnose donor. ${ }^{158}$

Scheme 32. Synthesis of trisaccharide $\beta$-L-Rhap- $\left(1 \rightarrow 3^{\prime}\right)-\beta$-D-Apif $(1 \rightarrow 2)-\alpha-D-G a l p$ by Nepogodiev, Field and co-workers. ${ }^{124}$

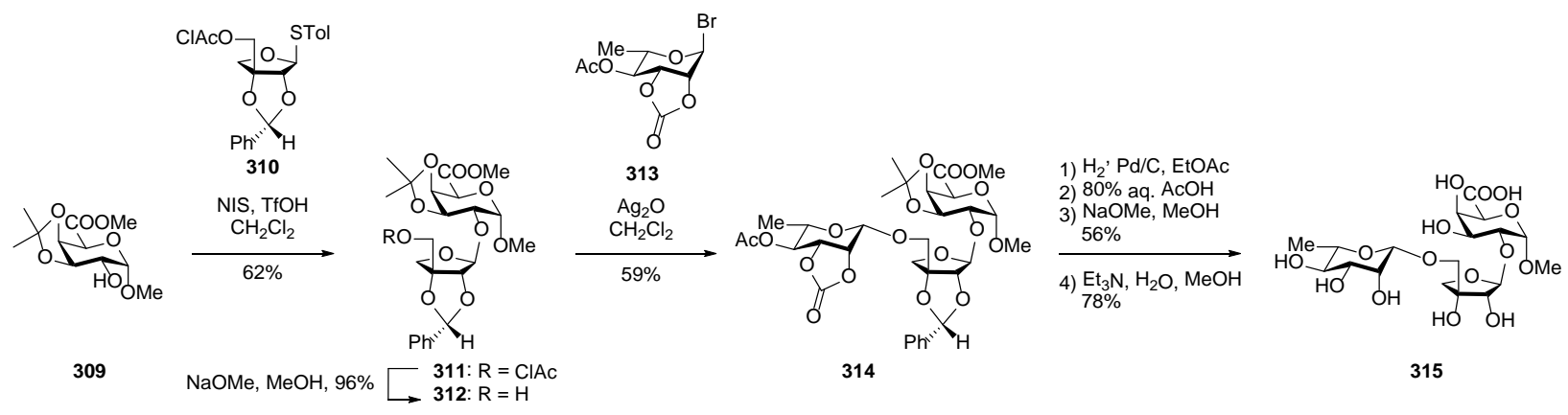




\subsubsection{RG-II side chain B}

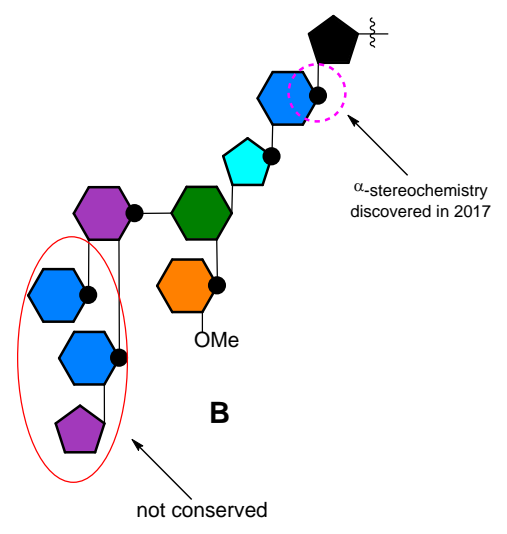

Figure 21. Side chain B of RG-II.

The most common structure of side chain B is represented in Figure 21. However, some variations have been observed depending on the plant species, which mainly involve the presence or absence of substituents at the $O-2$ and/or $O-3$ positions of the Arap residue. ${ }^{100}$ The different sugar substituents, which have been observed at these two positions by Pérez and co-workers, are summarized in Table 15. Furthermore, mono- $O$ - or di- $O$-acetylation can occur at the $O-3$ position of the AcefA residue as well as the $O-3 / O-4$ positions of 2-O-Me-Fucp. ${ }^{145}$

Table 15. Plant dependent variations observed by Pérez and co-workers for side chain B of RG-II. ${ }^{\mathbf{1 4 5}}$

\begin{tabular}{|c|c|c|}
\hline \multicolumn{2}{|c|}{ Glycose linked to Arap } & \multirow[t]{2}{*}{ Plant Source } \\
\hline $0-2$ & $O-3$ & \\
\hline$\beta$-L-Araf-(1 $\rightarrow 2)-\alpha$-L-Rhap & $\alpha$-L-Rhap & $\begin{array}{l}\text { Grape (wine) } \\
\text { Ginseng } \\
\text { Sycamore }\end{array}$ \\
\hline 3-O-Me $\alpha$-L-Rhap & 3-O-Me $\alpha$-L-Rhap & $\begin{array}{l}\text { P. bifurcatum } \\
\text { P. nudum }\end{array}$ \\
\hline
\end{tabular}




\begin{tabular}{|l|l|l|}
\hline$\alpha$-L-Rhap & 3-O-Me $\alpha$-L-Rhap & $\begin{array}{l}\text { C. thalictroides } \\
\text { L. tristachyum } \\
\text { P. bifurcatum }\end{array}$ \\
\hline$\alpha$-L-Rhap & $\mathrm{OH}$ & $\begin{array}{l}\text { A. thaliana } \\
\text { E. hyemale } \\
\text { S. kraussiana }\end{array}$ \\
\hline
\end{tabular}

The synthetic fragments of side chain B that have been reported to date are summarized in Table 16 and Table 14.

Table 16. Synthetic fragments found exclusively in RG-II side chain B.

\begin{tabular}{|l|l|l|l|}
\hline Structure & R & Year & Reference \\
\hline & $\mathrm{C}_{8} \mathrm{H}_{17}$ & 2000 & Mukherjee et al. $^{159}$ \\
\hline $\mathrm{O}$ & All & 2001 & Amer et al. ${ }^{160}$ \\
\hline & & & \\
\hline
\end{tabular}




\begin{tabular}{|l|l|l|l|}
\hline & & & \\
\hline
\end{tabular}

Although aceric acid (AcefA) has only been found in RG-II, and the development of synthetic routes to this unusual sugar started over five years ago, no RG-II fragments including aceric acid have yet been reported. Two main approaches have been developed for its synthesis: a 4-step approach from L-xylose ${ }^{163}$ and a 6-step synthesis from D-arabinose. ${ }^{164}$ Both Hindsgaul and co-workers ${ }^{159}$ and Kosma and co-workers ${ }^{160}$ reported the synthesis of 2 -O-Me- $\alpha$-L-Fucp $(1 \rightarrow 2)-\beta$-D-Galp early in the $21^{\text {st }}$ Century. The synthetic route employed by Hindsgaul and co-workers ${ }^{159}$ afforded the desired $\beta$-linked disaccharide 321 in a straightforward manner (Scheme 33).

Scheme 33. Synthesis of 2-O-Me- $\alpha$-L-Fucp $(1 \rightarrow 2)-\beta-\mathrm{D}-\mathrm{Gal} p$ by Hindsgaul and co-workers ${ }^{159}$

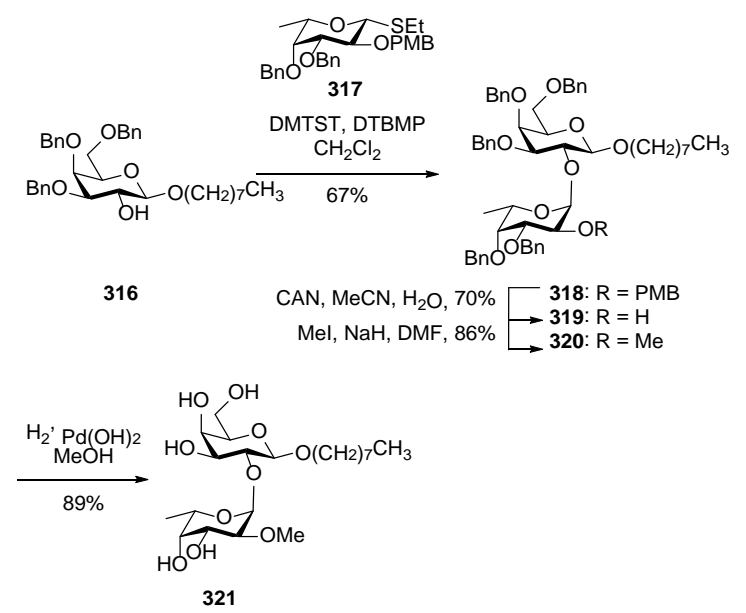

In 2007 Rao \& Boons reported the synthesis of two highly challenging targets: tetra- and hexasaccharide portions of side chain B containing the central L-Arap (338 and 337, respectively, Scheme 34) ${ }^{162}$ The tetrasaccharide 338 was chosen as a second target because some plant species, 
such as Arabidopsis, lack the $\beta$-L-Araf-( $1 \rightarrow 3)$-L-Rhap substituent on the 2-position of the L-Arap unit. This chemical synthesis was challenging because it involved a number of unusual monosaccharides, due to the steric hindrance around the central arabinopyranoside as well as the presence of both $(1 \rightarrow 2)$-cis-linked 2-O-methyl- $\alpha$-L-fucoside and $\beta$-L-arabinofuranoside residues, which are difficult to install stereoselectively. The authors first attempted a convergent [2+2+2] approach. However, the final glycosylation between tetrasaccharide acceptor 331 and a $\beta$-L-Araf-(1 $\rightarrow 3)$-L-Rhap donor gave an unacceptably low yield (8\%). The strategy was therefore revised and the final two monosaccharides were added sequentially as shown in Scheme 34 .

Glycosylation between 2-O-methyl thioethylfucoside donor 322 and galactosyl acceptor 323 carrying an electron withdrawing benzoyl ester group at the C-3 position afforded the desired $\alpha$-(1 $\rightarrow 2)$-linked disaccharide 324 in high yield and with high $\alpha$-selectivity. Reductive opening of the benzylidene acetal followed replacement of the ester protecting groups with benzyl ethers, in order increase the reactivity of acceptor 326. 
Scheme 34. Tetra- and hexasaccharide portions of side chain B synthesized by Rao \& Boons. ${ }^{\mathbf{1 6 2}}$

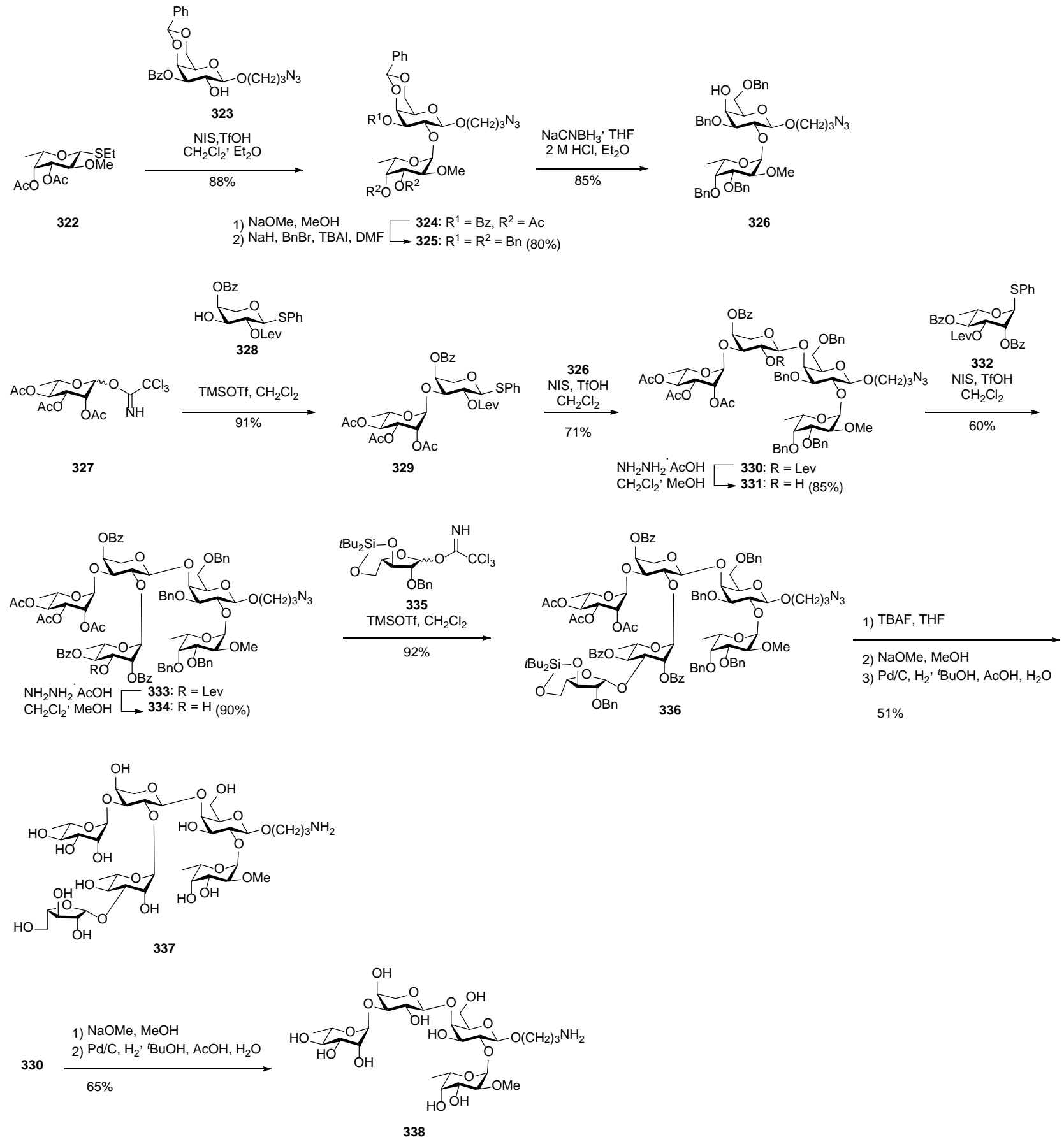

Chemoselective TMSOTf-promoted glycosylation between rhamnopyranosyl trichloroacetimidate donor 327 and thiophenyl arabinopyranoside 328 gave the desired $\alpha-(1 \rightarrow 3)$-linked disaccharide donor 
329 in 91\% yield, with high stereoselectivity, thanks to neighboring group participation from the acetyl ester of 327. This disaccharide was coupled with acceptor 326 using thiophilic promoter NIS/TfOH, affording the desired $\beta$-(1 $\rightarrow 3)$-linked tetrasaccharide 330 in $71 \%$ yield. Selective removal of the Lev group, followed by coupling with rhamnopyranoside donor 332 afforded $\alpha-(1 \rightarrow 2)$-linked pentasaccharide 333. After Lev removal, the pentasaccharide was glycosylated with the conformationally-constrained trichloroacetimidate arabinofuranosyl donor 335 affording hexasaccharide 336 in 91\% yield and, gratifyingly, exclusively as the $\beta$-anomer. Deprotection of both tetrasaccharide $\mathbf{3 3 0}$ and hexasaccharide $\mathbf{3 3 6}$ proceeded smoothly to afford the two target oligosaccharides.

\subsubsection{RG-II side chain $C$}

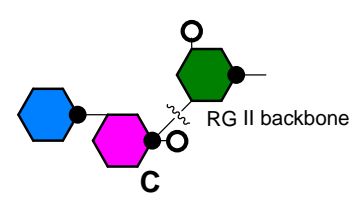

Figure 22. Side chain C of RG-II.

The $\mathrm{C}$ side chain of pectin, consisting of the disaccharide $\alpha$-L-Rhap-( $1 \rightarrow 5)-\mathrm{D}-\mathrm{KDO} p$, was first isolated and characterized in $1985 .{ }^{165}$ The disaccharide is linked to C3-O of a GalpA residue from the RG-II backbone (see Figure 22). Synthesis of this side chain has not yet been reported. However, the rare eight-carbon sugar $\alpha-\mathrm{D}-\mathrm{KDO} p$ is found in non-plant glycans, and therefore various synthetic procedures have been developed. ${ }^{165-168}$ 


\subsubsection{RG-II side chain D}

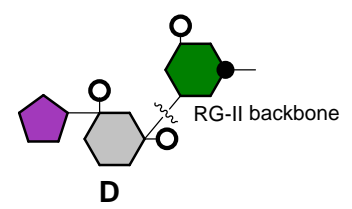

Figure 23. Side chain D of RG-II.

RG-II side chain $\mathrm{D}$, consisting of disaccharide $\beta$-L-Araf-( $1 \rightarrow 5)$-D-Dhap, was first isolated from pectin plant cell wall by Albersheim and co-workers in 1988. ${ }^{169}$ As for side chain C, this disaccharide is attached to the C-3 position of a galacturonic acid in the backbone (see Figure 23), and has not been synthesized either. However a procedure to synthesize the rare sugar 3-deoxy-D-lyxo-heptulosaric acid (Dhap) was reported in 1995 by Banaszek. ${ }^{170}$

\subsubsection{RG-II side chain $E / F$}

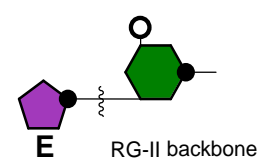

Figure 24. Side chain E of RG-II.

Several independent studies suggest that a single $\alpha$-L-Araf residue is linked to $O-3$ of one of the GalpA backbone residues of RG-II (see Figure 24). ${ }^{147,151,171}$ However, it has not yet been proven, whether this residue is linked to $O-3$ or $O-2$ of GalpA and no synthesis of this linkage has been reported. 


\section{6 (Arabino)galactans and arabinans}

Arabinogalactans, galactans and arabinans are the three main types of side chain in the pectin RG-I domain. However, arabinogalactans are also present in many plants as a constituent of hemicellulose and in arabinogalactan proteins. ${ }^{172}$

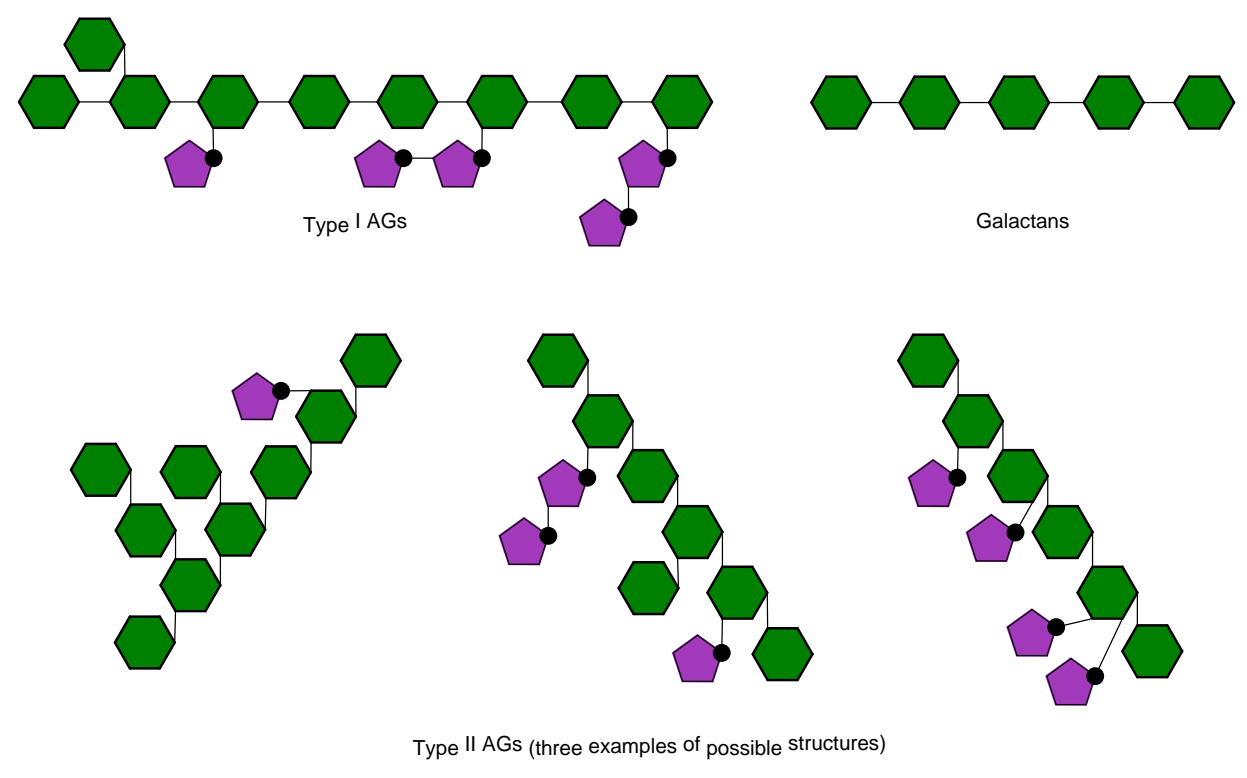

Figure 25. Exemplary structures of arabinogalactans (AGs) and galactans.

Arabinogalactans (AGs) are cell wall polysaccharides having high proportions of galactose and arabinose. They are widely present in the plant kingdom and occur as variable complex structures, whose composition is highly dependent on the plant and even cells from which they originate. They are not found to be well conserved. Arabinogalactans are usually divided into two groups: type I and type II, which are schematically represented in Figure $25 .{ }^{131}$ Type I AGs are characterized by a linear

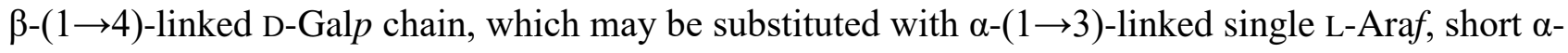
$(1 \rightarrow 3)$ - or $\alpha$-( $(1 \rightarrow 5)$-linked arabinan oligosaccharides, or with $\beta$-( $1 \rightarrow 6)$-linked galactose residues. ${ }^{97}$ 
Type I AGs are found in pectic complexes in seeds, bulbs and leaves and are mostly covalently bound to the RG-I backbone. ${ }^{172}$ Galactans are simply $\beta$-(1 $\left.\rightarrow 4\right)$-linked D-galactan chains. They have been observed in lengths of up to 40 residues. ${ }^{173}$ Type II AGs are highly branched polysaccharides composed of a $\beta$-( $(1 \rightarrow 3)$ or $(1 \rightarrow 6)$-linked D-galactan backbone frequently substituted at C-3 and/or C6 with $\beta$-galactan or arabinogalactan branching, and occasionally carrying C-2 substitution. ${ }^{97}$ This second type of AG exists in various plant tissues, including coniferous woods, mosses as well as gums, saps and exudates of angiosperms. ${ }^{131}$ Type II AGs make up the carbohydrate part of arabinogalactan proteins (AGPs) and account for over 90\% of the molecular mass of these complexes. Although the structure of arabinogalactans appears to be well established, new structural diversity is found in this class of polysaccharides occasionally. Huisman et al., for example, reported the presence of arabinose residues in the galactan backbone as well as a terminal L-Arap residue in the side chains of type I AG from soybean pectin. ${ }^{174} \mathrm{NMR}$ analysis has clearly demonstrated that type I AGs are covalently bound to rhamnose in RG-I and this is the main type of pectic arabinogalactan. ${ }^{172,175}$ However, Cordeiro and co-workers analyzed pectin from starfruit and found evidence of both type I and II AGs among the RG-I side chains. ${ }^{176}$ The next section will give an overview of the AG fragments prepared by chemical synthesis.

\subsection{Type I AGs and galactans}

$\beta$ - $(1 \rightarrow 4)$-linked galactan synthesis is challenging, due to the low accessibility and reactivity of the axially disposed C4-OH. There is a requirement for protecting groups at both $\mathrm{C}-3$ and $\mathrm{C}-6$, which increases steric hindrance around the nucleophile. Until 2016, only four groups had reported syntheses of $\beta$-(1 $1 \rightarrow 4)$-D-galacto-oligosaccharides, of which, three only reached the trisaccharide level. ${ }^{177-178}$ 
Lately a small library of oligogalactans including linear tetra-, penta-, hexa-, and heptasaccharides have been synthesized by Clausen and co-workers. ${ }^{179}$ As commented on by Sakamoto and Ishimura in 2013, the low availability of pure type I AG oligosaccharides has hindered the study of galactonolytic enzymes. ${ }^{180}$ No synthesis of type I AGs had been reported until early 2017, when Pfrengle and co-workers produced a set of type I AGs and determined the substrate specificities of three $\beta$-( $(1 \rightarrow 4)$-endogalactanases. ${ }^{181}$ The galactans and type I AGs that have so far been synthesized are presented in Table 17.

Table 17. Synthetic $\beta-(1 \rightarrow 4)$-linked galactans including type I AGs.

\begin{tabular}{|c|c|c|c|}
\hline Structure & $\mathbf{R}$ & Year & Reference \\
\hline & $\begin{array}{l}\mathrm{Pr} \\
\mathrm{Me} \\
\mathrm{H}\end{array}$ & $\begin{array}{l}1984 \\
1987 \\
2001\end{array}$ & $\begin{array}{l}\text { El-Shenawy \& Schuerch }{ }^{177} \\
\text { Kováč \& Taylor }{ }^{182} \\
\text { Lichtenthaler et al. }{ }^{183}\end{array}$ \\
\hline & $\begin{array}{l}\mathrm{PMP} \\
\left(\mathrm{CH}_{2}\right)_{5} \mathrm{NH}_{2}\end{array}$ & $\begin{array}{l}2001 \\
2017\end{array}$ & $\begin{array}{l}\text { Lichtenthaler et al. }{ }^{183} \\
\text { Bartetzko et al. }{ }^{181}\end{array}$ \\
\hline & $\begin{array}{l}\text { PMP } \\
\mathrm{H}\end{array}$ & $\begin{array}{l}2001 \\
2016\end{array}$ & $\begin{array}{l}\text { Lichtenthaler et al. }{ }^{183} \\
\text { Andersen et al. }{ }^{179}\end{array}$ \\
\hline & $\begin{array}{l}\text { PMP } \\
\mathrm{H} \\
\left(\mathrm{CH}_{2}\right)_{5} \mathrm{NH}_{2}\end{array}$ & $\begin{array}{l}2001 \\
2016 \\
2017\end{array}$ & $\begin{array}{l}\text { Lichtenthaler et al. }{ }^{183} \\
\text { Andersen et al. }{ }^{179} \\
\text { Bartetzko et al. }{ }^{181}\end{array}$ \\
\hline$\overline{1}$ & $\mathrm{H}$ & 2016 & Andersen et al. ${ }^{179}$ \\
\hline
\end{tabular}




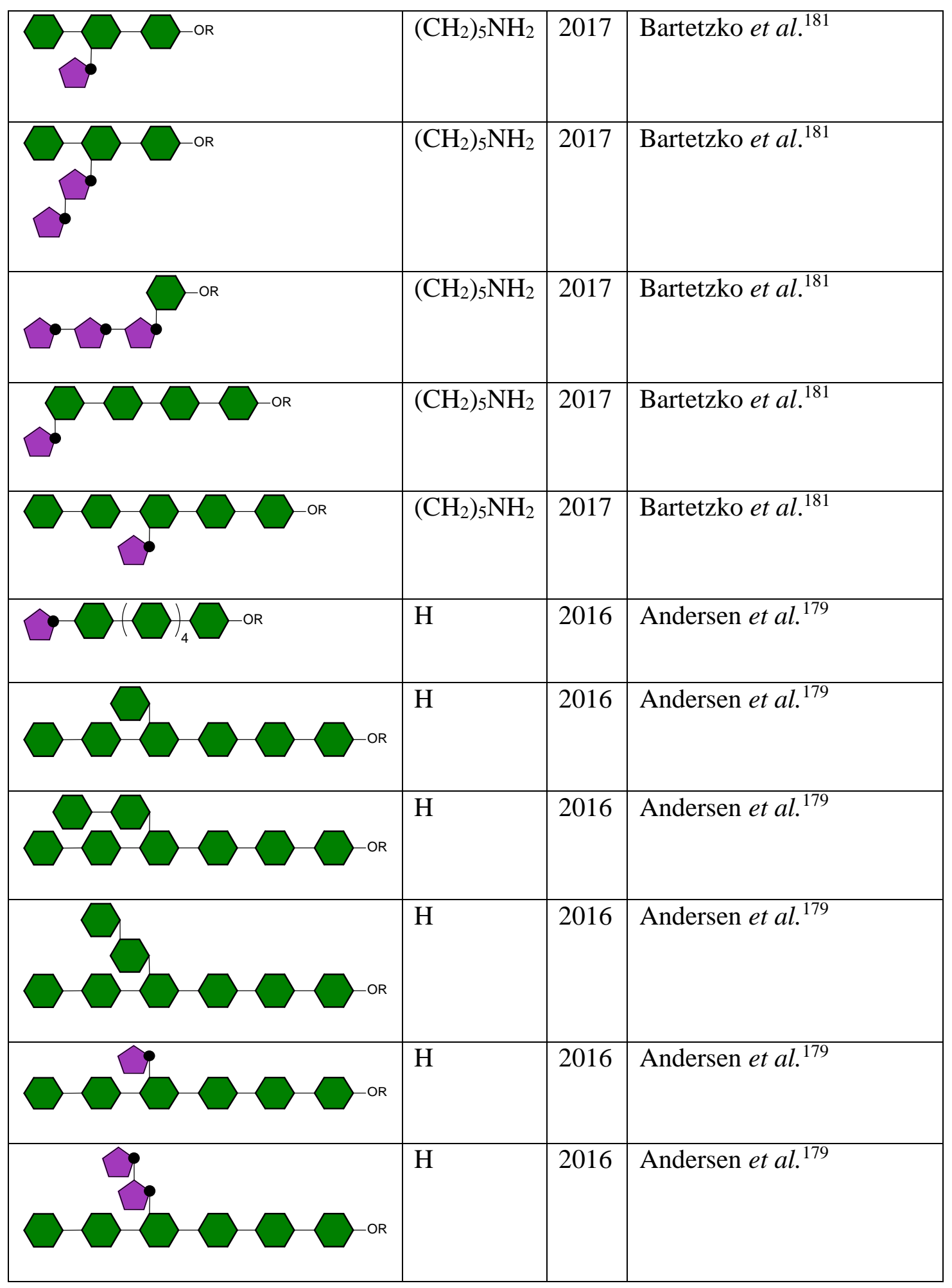


The first reported synthesis of a linear $\beta-(1 \rightarrow 4)$-D-galactan trisaccharide was achieved by Schuerch \& El-Shenawy ${ }^{177}$ and is shown in Scheme 35.

Scheme 35. Synthesis of protected $\beta-(1 \rightarrow 4)$-D-galactotriose 16 by Schuerch \& El-Shenawy. ${ }^{177}$
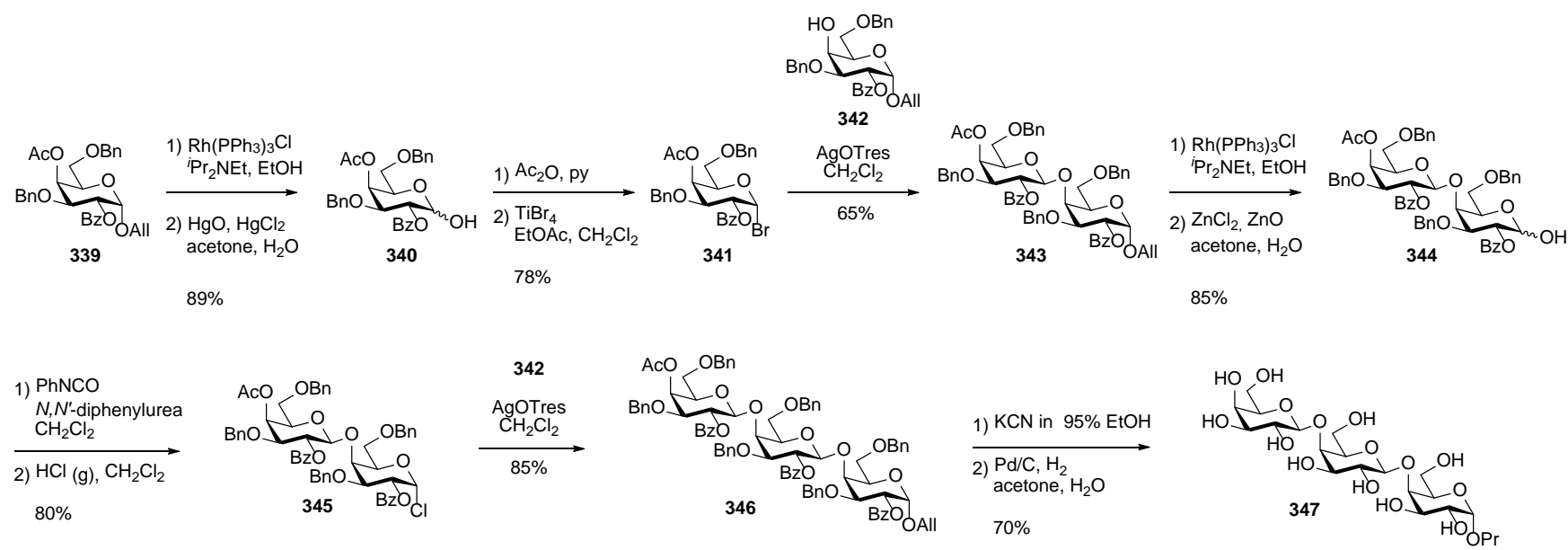

The key building block 339 carried an allyl group as an exchangeable protecting group at the anomeric center and an acetyl group for temporarily blocking the 4-position. A benzoyl group at the C-2 position ensured neighboring group participation to form the desired $\beta$-linkage. Finally, benzyl groups were used to block the remaining hydroxyl groups. Acceptor 342 was coupled to glycosyl bromide $\mathbf{3 4 0}$ in a silver tresylate (2,2,2-trifluoroethanesulfonate, OTres) catalyzed glycosylation reaction providing the disaccharide 343 in $65 \%$ yield. This disaccharide was then converted into the corresponding glycosyl chloride 345, over four steps, with an overall yield of 69\%. A second glycosylation of acceptor 342 afforded the trisaccharide 346 in 85\% yield, and this could easily be deprotected to afford the target 347. Further selective deacetylation of the di- and trisaccharide did not proceed well, and this strategy did not enable the authors to elongate the chain in a convergent way as they had hoped. 
To improve the efficiency of this galactotriose synthesis, Kovác \& Taylor suggested another approach starting from acceptor 348. ${ }^{182}$ This was converted to the glycosyl chloride 349 in two steps (Scheme 36). Coupling of acceptor $\mathbf{3 4 8}$ and donor $\mathbf{3 4 9}$ promoted by silver trifluoromethanesulfonate gave the desired disaccharide 350 in 62\% yield. The bromoacetyl group was selectively removed with thiourea to give acceptor 351, which was once again glycosylated with glycosyl chloride 349. However, in this case, the glycosylation went slower and the trisaccharide $\mathbf{3 5 2}$ could only be obtained in 35\% yield. Further elongation was thus not feasible in this case either.

Scheme 36. Synthesis of $\beta-(1 \rightarrow 4)$-D-galactriose by Kovác $\&$ Taylor. ${ }^{182}$
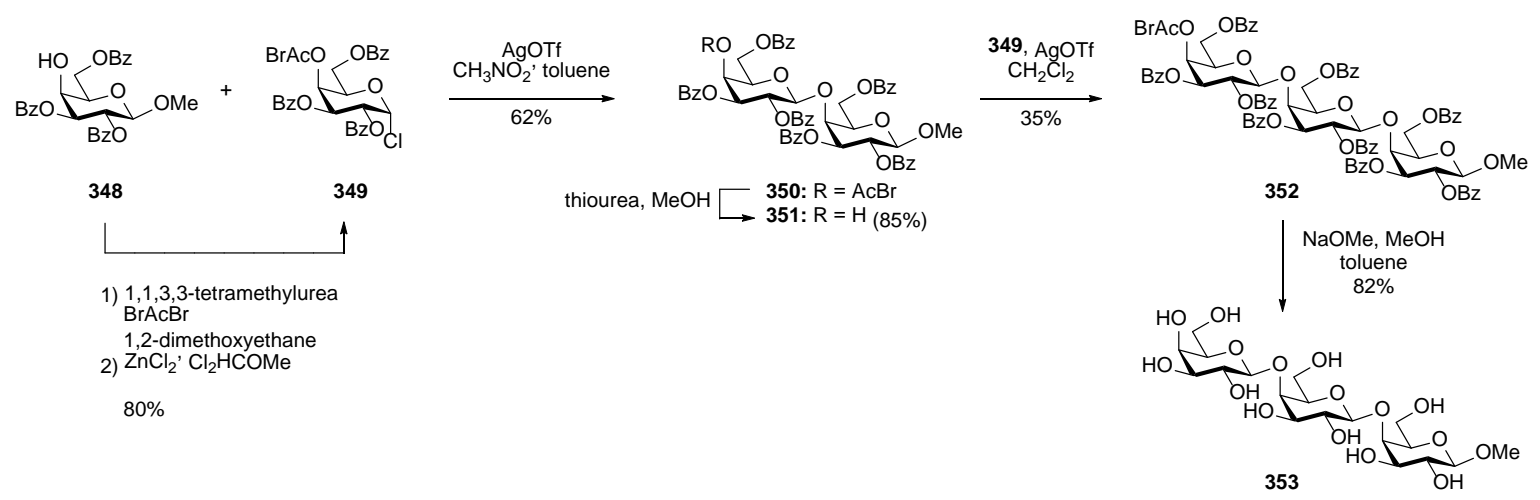

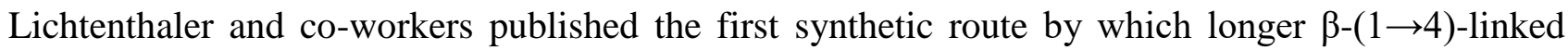
galactans, up to a hexasaccharide, could be produced (Scheme 37). ${ }^{183}$ An iterative block strategy and easy transformation of the PMP acceptors into thioglycoside donors really did make this a convergent synthesis. Furthermore, the protecting group pattern was judiciously designed to minimize steric hindrance around the unreactive galactosyl-4-OH. Hence, allyl and/or benzyl groups were chosen for C-3 and C-6 in order to enhance the nucleophilicity of the acceptor. In this case, a pivaloyl ester was chosen for C-2 protection. The acetyl group could then be used for blocking C-4, as mild Zemplén 
conditions will not remove the Piv ester. MeOTf-mediated glycosylation of thioglycoside building block 354 and acceptor 355 afforded the disaccharide 356 in a good yield (79\%). This could then be turned both into a new disaccharide donor 357 (by glycosylation with TMSSPh) or a new disaccharide acceptor 358 (by deacetylation). Two rounds of glycosylation then afforded the hexasaccharide $\mathbf{3 6 1}$ on a gram scale. In comparison with the two previous studies, this strategy afforded remarkably high glycosylation yields, considering the low reactivity of the Galp C-4 position. However, the removal of the protecting groups, especially the allyl group, turned out to be challenging, and a five-step procedure was necessary to reach the target $\mathbf{3 6 2}$. 
Scheme 37. Synthesis of $\beta$-(1 $\rightarrow 4)$-D-hexagalactoside 362 by Lichtenthaler and co-workers. ${ }^{\mathbf{1 8 3}}$

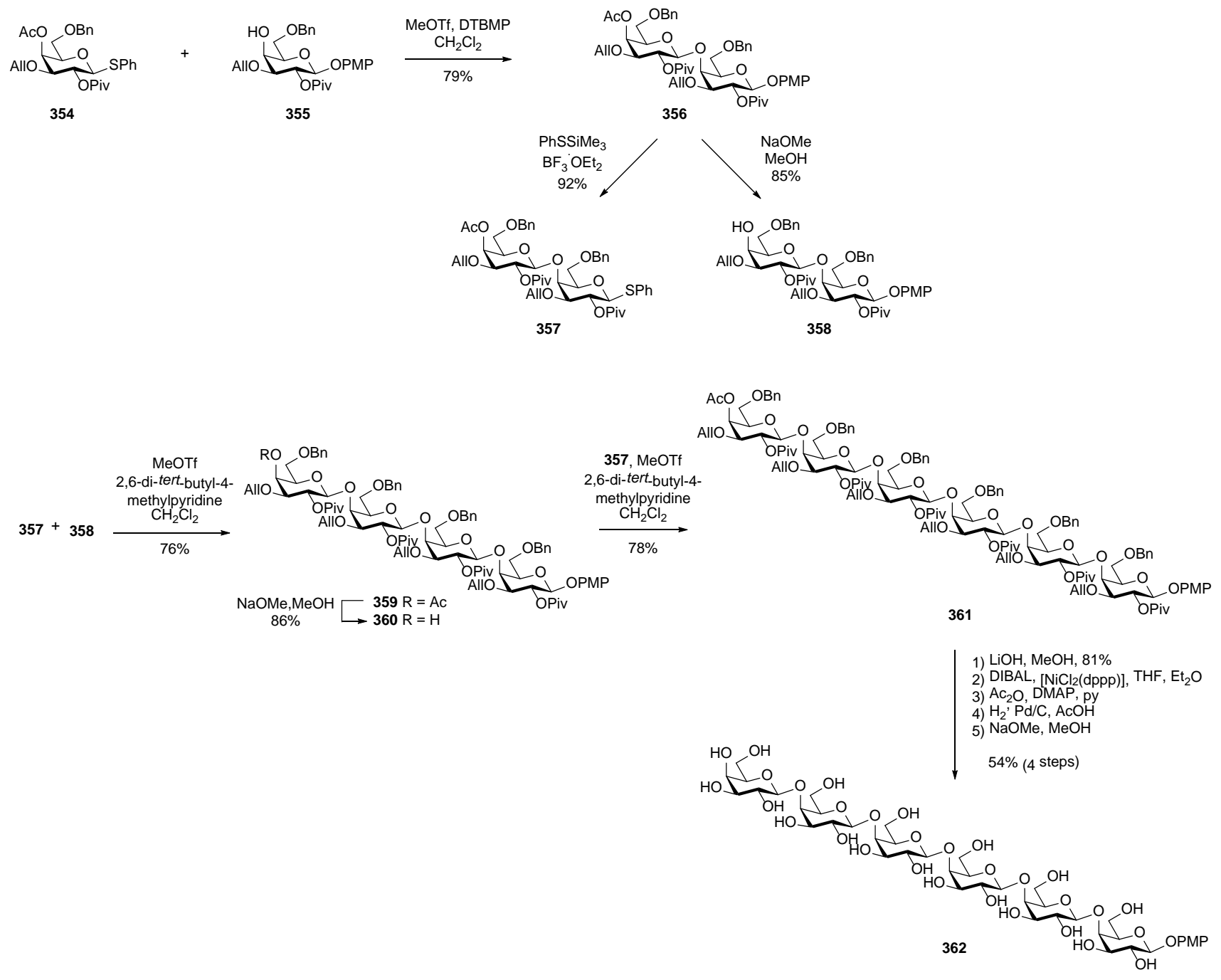

Clausen and co-workers achieved the synthesis of a set of galactooligosaccharides with a $\beta-(1 \rightarrow 4)$ linked backbone and the potential for $(1 \rightarrow 6)$-branching. The group conducted a convergent block synthesis, using a disaccharide building block to create linear oligosaccharides of varying lenghts. TMSOTf-mediated coupling of trifluoroacetimidate donor 363 and acceptor 364 afforded the key pentenyl disaccharide 365 in $83 \%$ yield (Scheme 38). ${ }^{179}$ 
Scheme 38. Synthesis of linear $\beta-(1 \rightarrow 4)-D-p e n t a-$ and heptasaccharides by Clausen and coworkers. $^{179}$

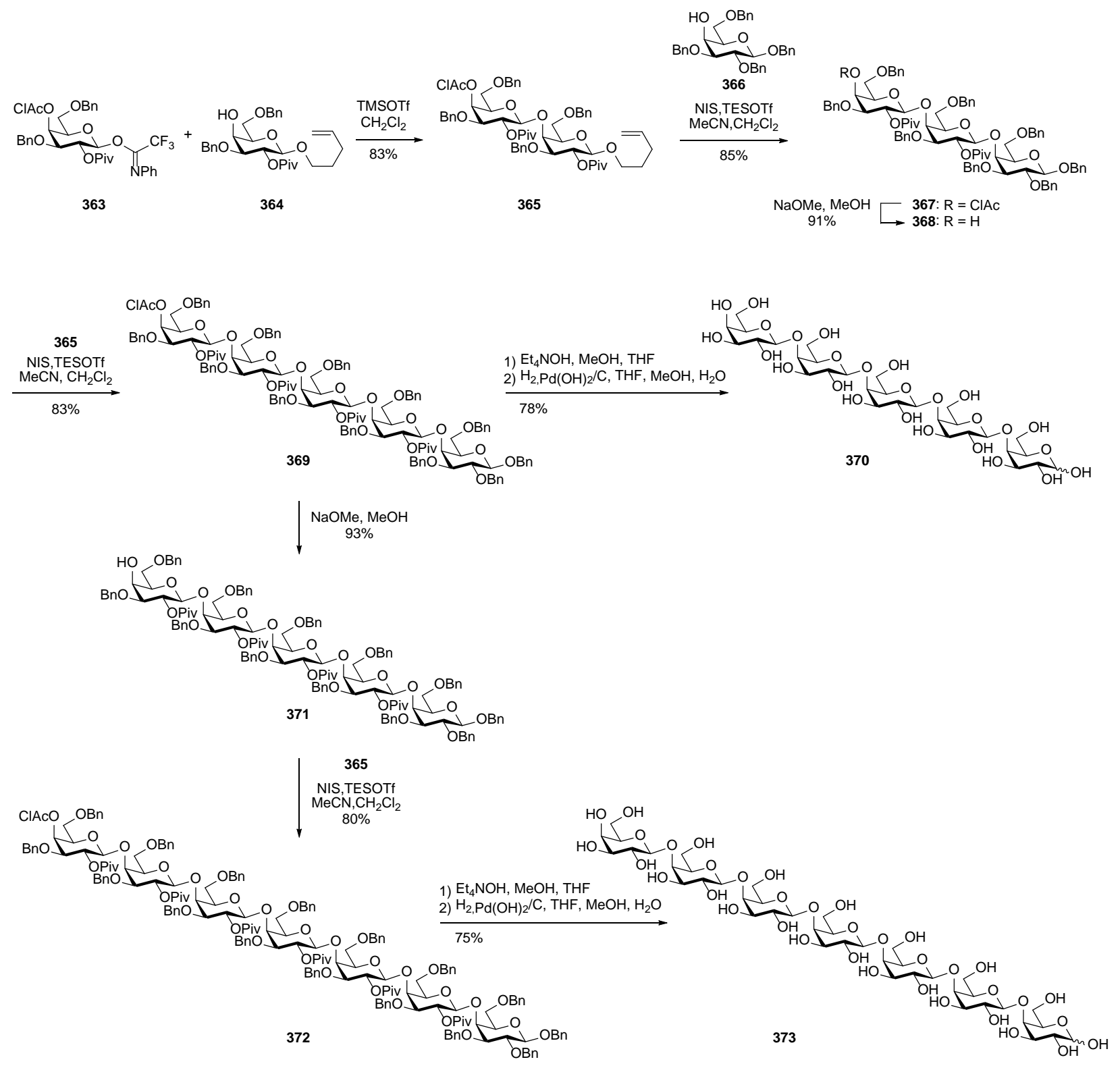

NIS-TESOTf-mediated glycosylation of the monosaccharide acceptor 366, with disaccharide $\mathbf{3 6 5}$, afforded the trisaccharide 367 . Selective deprotection of the chloroacetyl group, followed by coupling with 365, enabled the synthesis both of a linear penta- and heptasaccharide (369 and 372, respectively) 
in high yields. Finally, de-esterification by treatment with $\mathrm{Et}_{4} \mathrm{NOH}$, followed by hydrogenolysis gave the targets $\mathbf{3 7 0}$ and $\mathbf{3 7 3}$ in $\mathbf{7 8 \%}$ and $\mathbf{7 5 \%}$ yield, respectively.

In 2017, Pfrengle and co-workers reported the synthesis of a small library of type I AG oligosaccharides through an automated solid phase sequence, using the six monosaccharide building blocks 121, 374-378 shown in Scheme 39. Fmoc-protected galactose building blocks 374 and 375 were required for the synthesis of the $\beta-(1 \rightarrow 4)$-linked backbone. A temporary Lev protecting group was used at the C-3 position of building block 375, allowing for substitution. A third galactose building block (376) with an Fmoc group in the C-3 position was used to prepare a mixed-linkage galactan (383). Both benzyl ethers and benzoyl esters were used as permanent protecting groups for the remaining positions. Finally, the three L-arabinofuranosides 121, 377 and 378 were used for the side chains. 
Scheme 39. Automated assembly of type I AGs by Pfrengle and co-workers. ${ }^{181}$
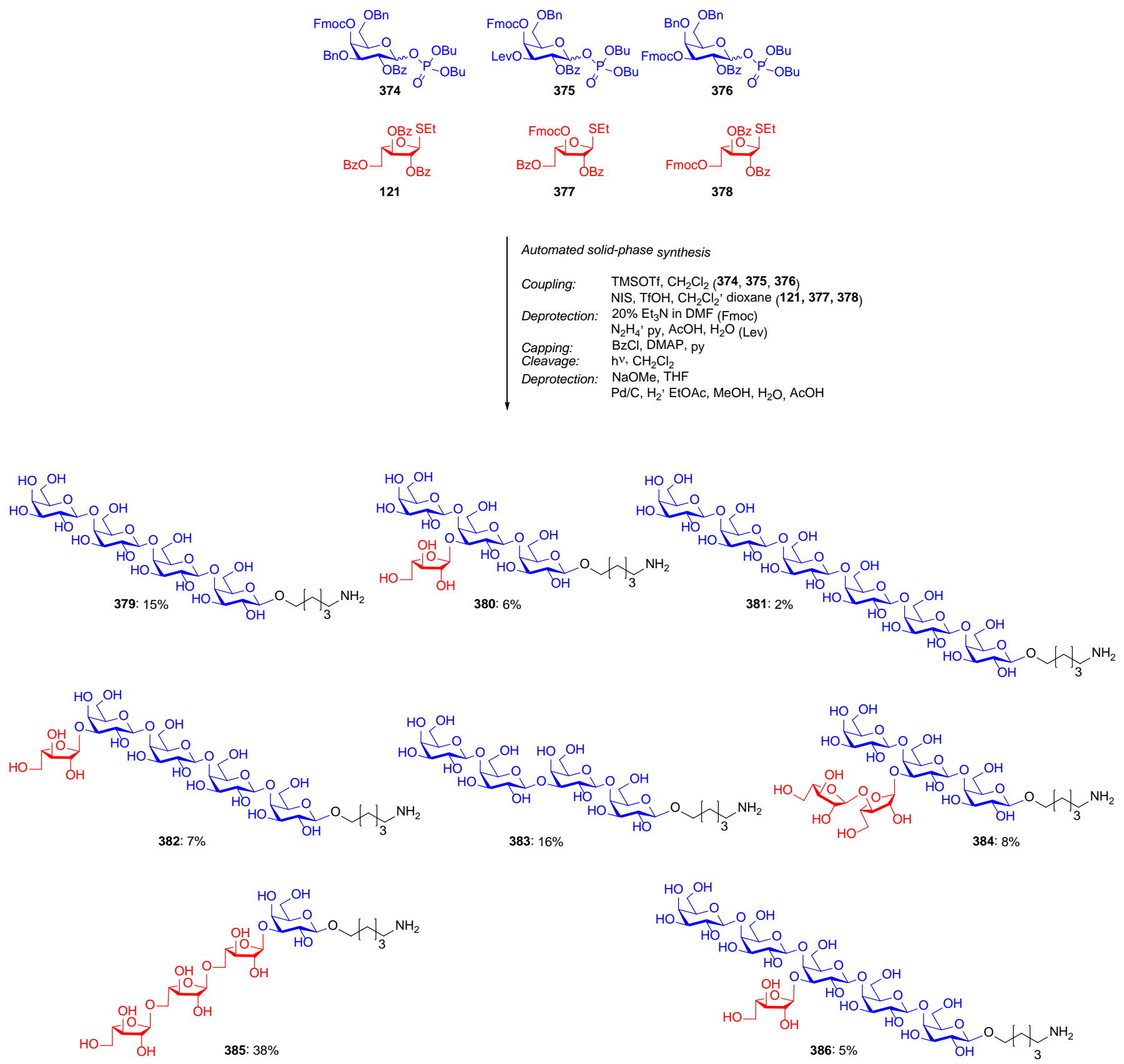


\subsection{Type II AGs}

Various different type II arabinogalactans have been produced by several groups and the synthesized fragments are presented in Table 18 and Table 19. For the most part, arabinogalactans with a $\beta-(1 \rightarrow 6)-$ galactan backbone have been synthesized (Table 19), but two groups reported the synthesis of some fragments containing a $\beta$-(1 $\rightarrow 3)$-galactan backbone, which is mostly found in arabinogalactan proteins (AGPs, Table 18). ${ }^{184,185}$

Table 18. Synthetic type II AG fragments containing a $\beta-(1 \rightarrow 3)$-linked backbone.

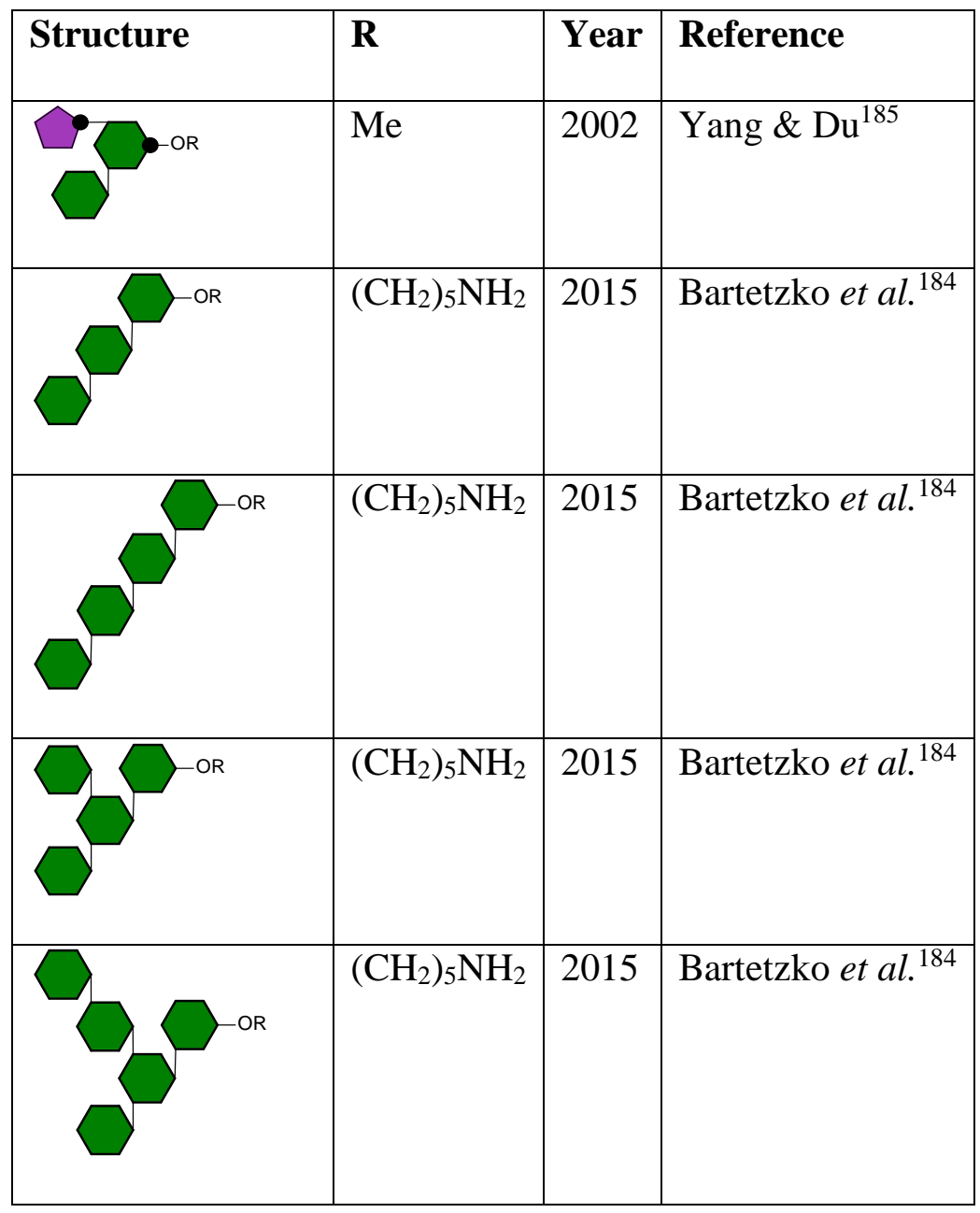




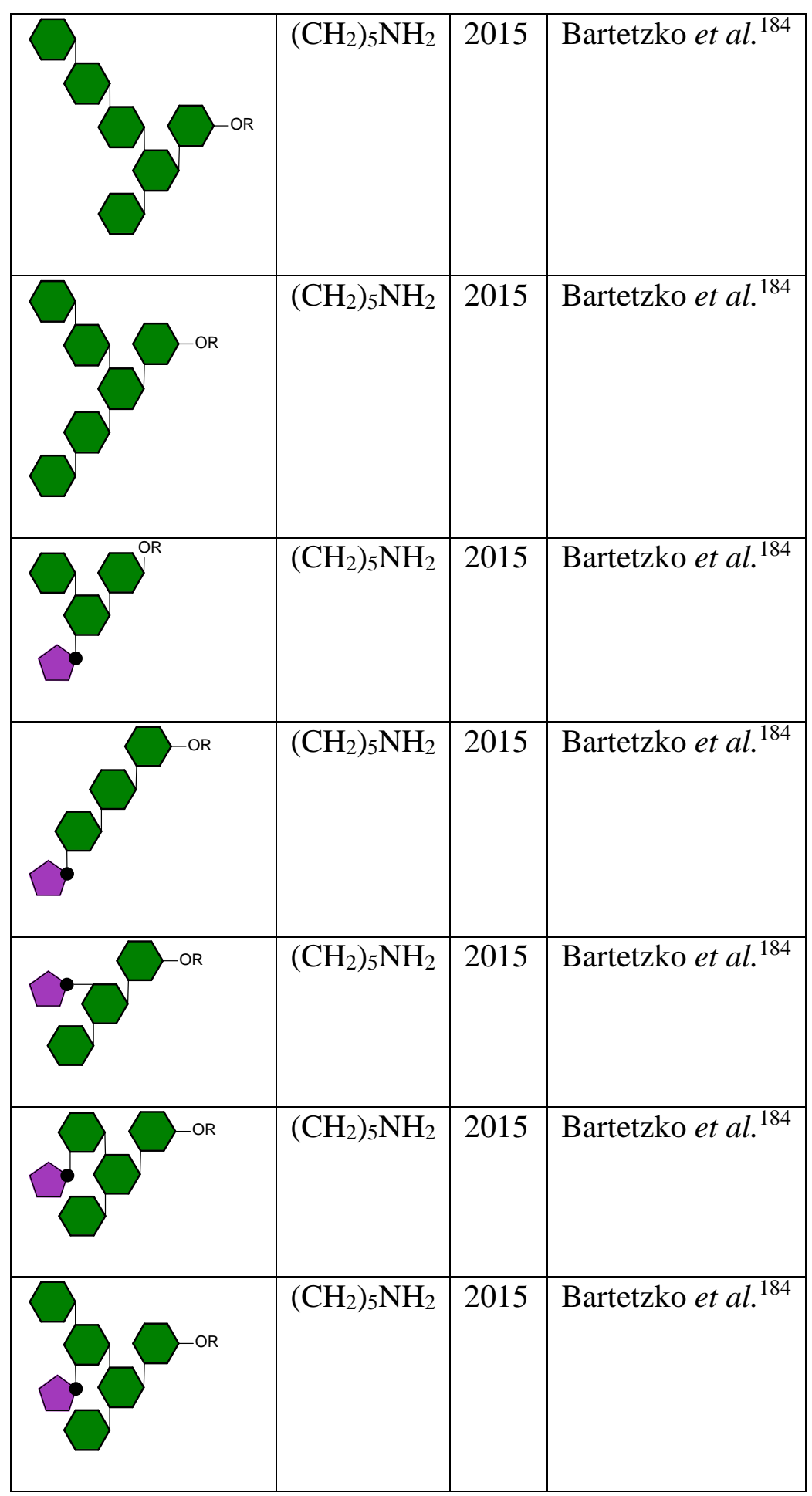




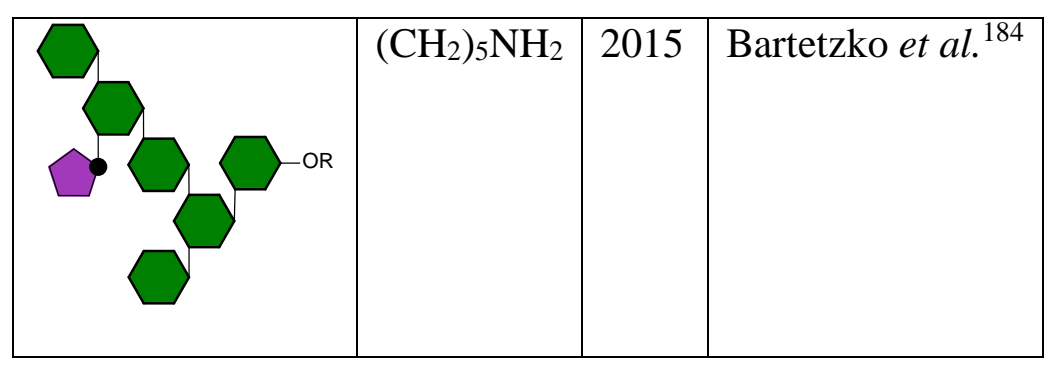

The only solution phase synthesis of $\beta-(1 \rightarrow 3)$-linked type II arabinogalactan was achieved by Yang \& Du in 2002 and is presented in Scheme $40 .{ }^{185}$ Regioselective glycosylation of diol galactoside 388 with arabinose donor 387 afforded the desired $\alpha$-linked disaccharide 389 in $76 \%$ yield. Standard protecting group manipulations gave acceptor 391, which could be further selectively coupled with trichloroacetimidate donor 392, affording protected trisaccharide 393 in 94\% yield. Deprotection gave the desired trisaccharide 394.

Scheme 40. Synthesis of type-II arabinogalactan trisaccharide 394 by Yang \& Du. ${ }^{\mathbf{1 8 5}}$

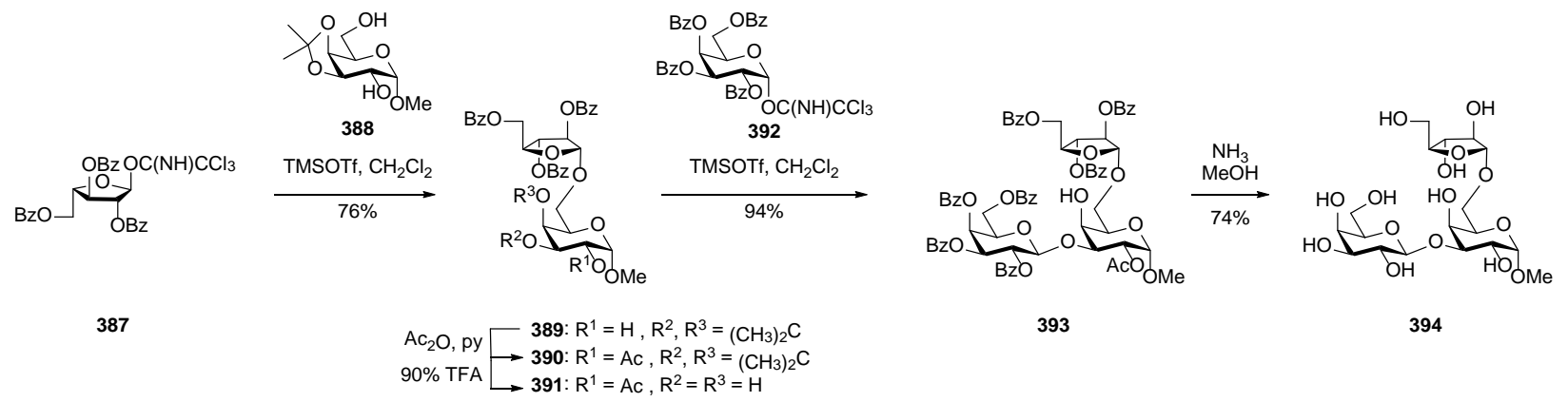

In 2015, Pfrengle and co-workers published the synthesis of a small library of 14 type II AGPs through an automated solid phase approach using the four monosaccharide building blocks 121, 376, 395 and 396 (Scheme 41). ${ }^{184}$ Both linear and branched oligomers were synthesized as well as arabinogalactan fragments that had either a $\beta$-( $1 \rightarrow 3)$ - or a $\beta-(1 \rightarrow 6)$-galactan backbone. 
Scheme 41. Examples of the type II AG fragments obtained by Pfrengle and co-workers. ${ }^{\mathbf{1 8 4}}$

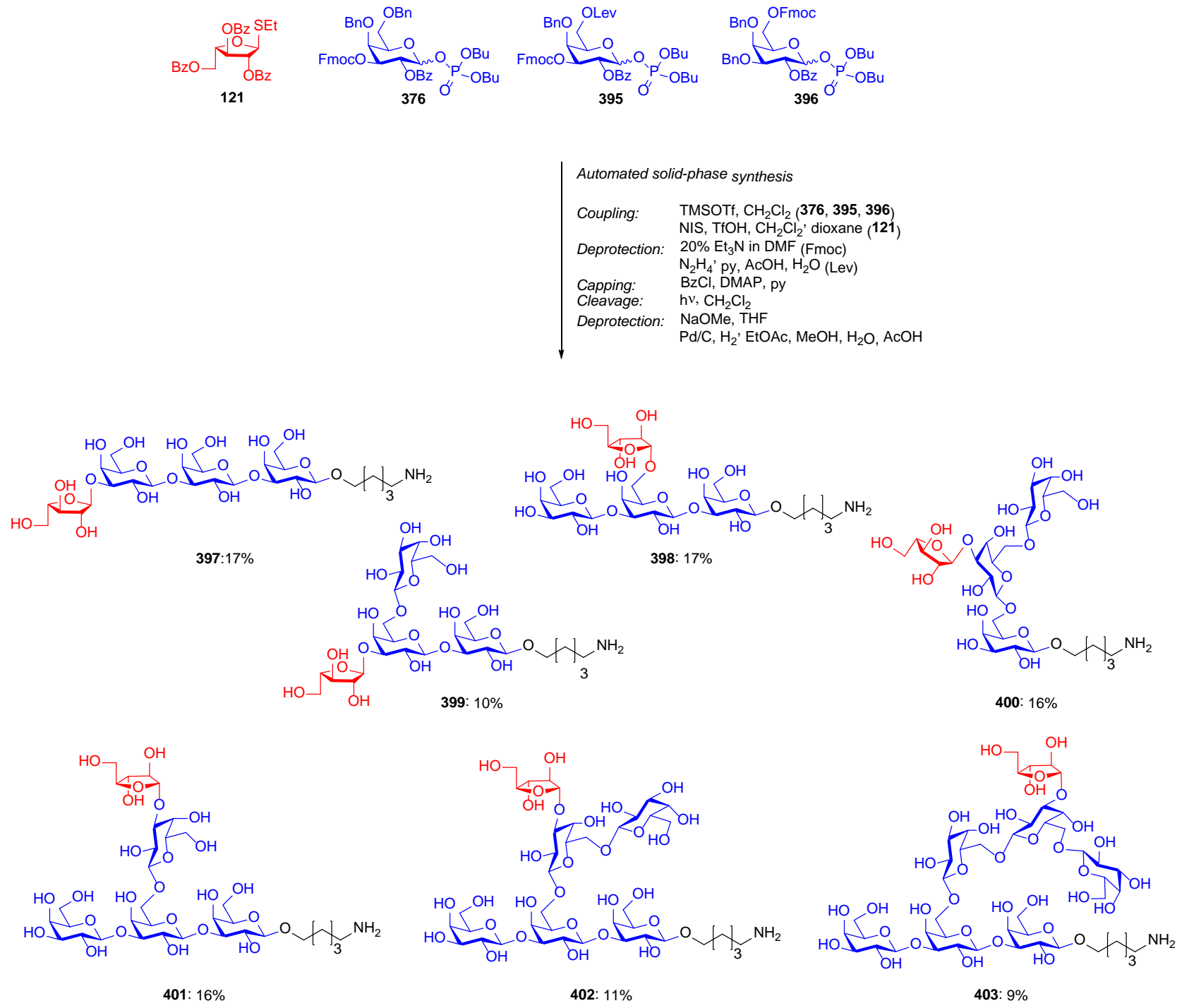

Table 19. Synthetic type II AG fragments containing a $\beta-(1 \rightarrow 6)$-linked backbone.

\begin{tabular}{|l|l|l|l|}
\hline Structure & R & Year & Reference \\
\hline & $\left(\mathrm{CH}_{2}\right)_{5} \mathrm{NH}_{2}$ & 2015 & Bartetzko et al. $^{184}$ \\
\hline
\end{tabular}




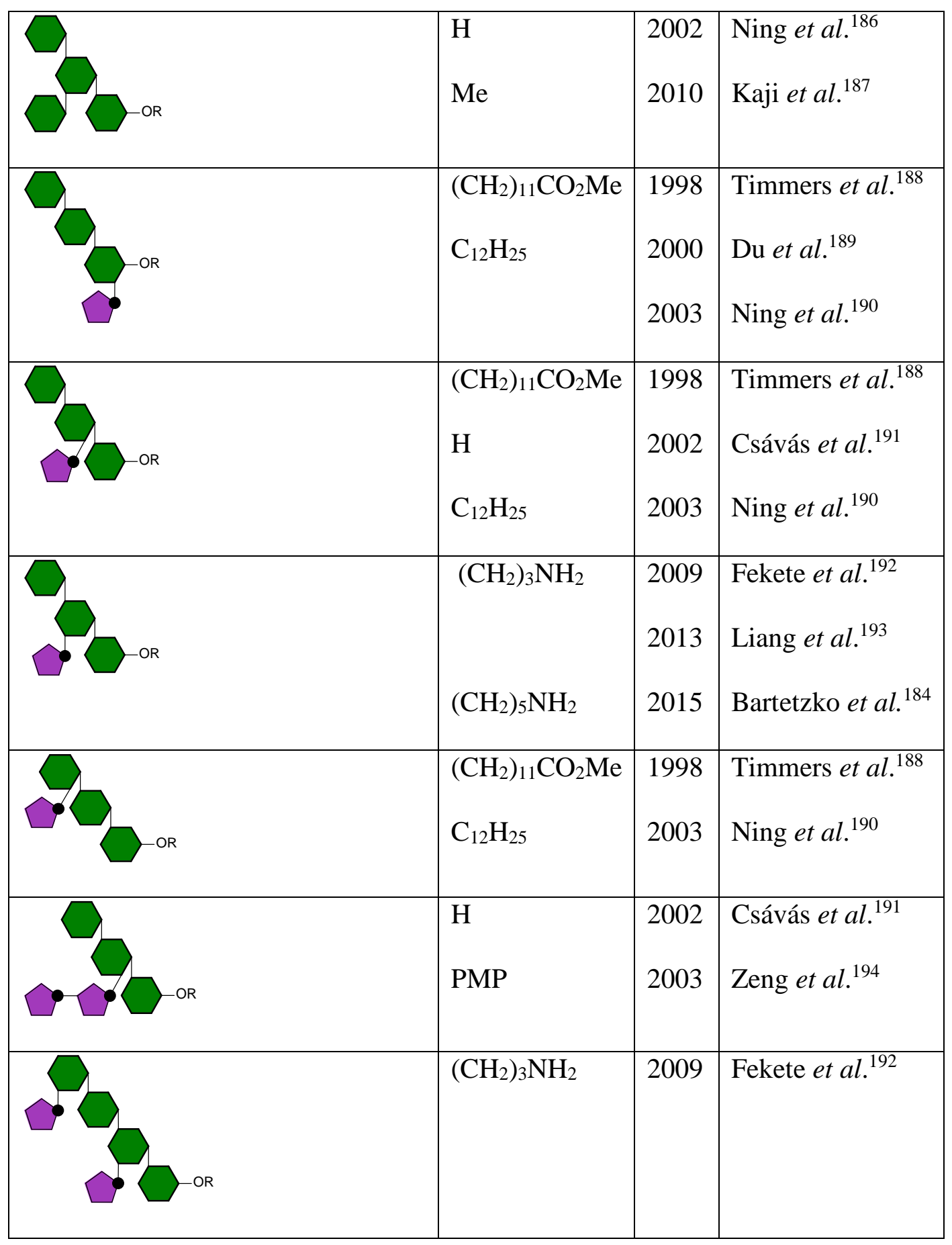




\begin{tabular}{|l|l|l|l|}
\hline & & & \\
& & & \\
& & & \\
& & & \\
\hline
\end{tabular}




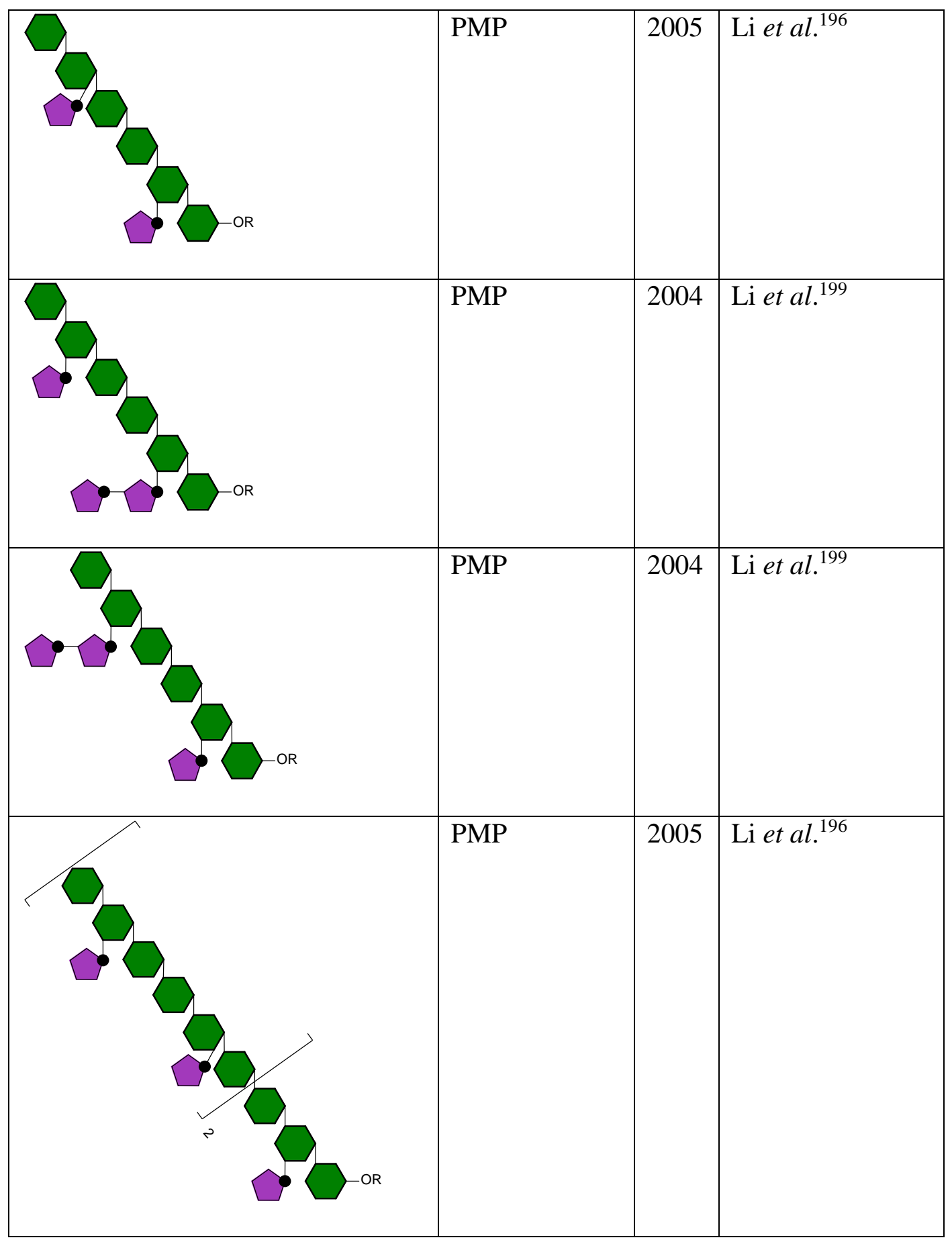

The first synthesis of a tetrameric arabinogalactan with a $\beta-(1 \rightarrow 6)$-linked backbone was achieved in 1998 by van Boom and co-workers, based on 1,2-anhydrosugar building blocks, as shown in Scheme 
42. ${ }^{188}$ The group synthesized three different tetrasaccharide analogues, differing in the position of the arabinofuranosyl side chain, which was linked either to the 2-, 2'- or 2''-position of the trisaccharide backbone. To afford the three targets, an oxidative coupling of galactals was undertaken. This methodology involved a two-step procedure starting with stereoselective epoxidation of a suitablyprotected galactal $\mathbf{4 0 4}$ with 3,3-dimethyldioxirane, followed by $\mathrm{ZnCl}_{2}$-catalyzed condensation of the resulting 1,2-anhydrosugar with a galactal acceptor. This glycal approach afforded an unprotected 2hydroxyl function, ready for glycosylation with an arabinosyl donor in order to introduce the branching. 
Scheme 42. Example of one of the three tetrameric arabinogalactans containing a $\beta$-(1 $\rightarrow 6)$-linked backbone prepared by van Boom and co-workers. ${ }^{\mathbf{1 8 8}}$
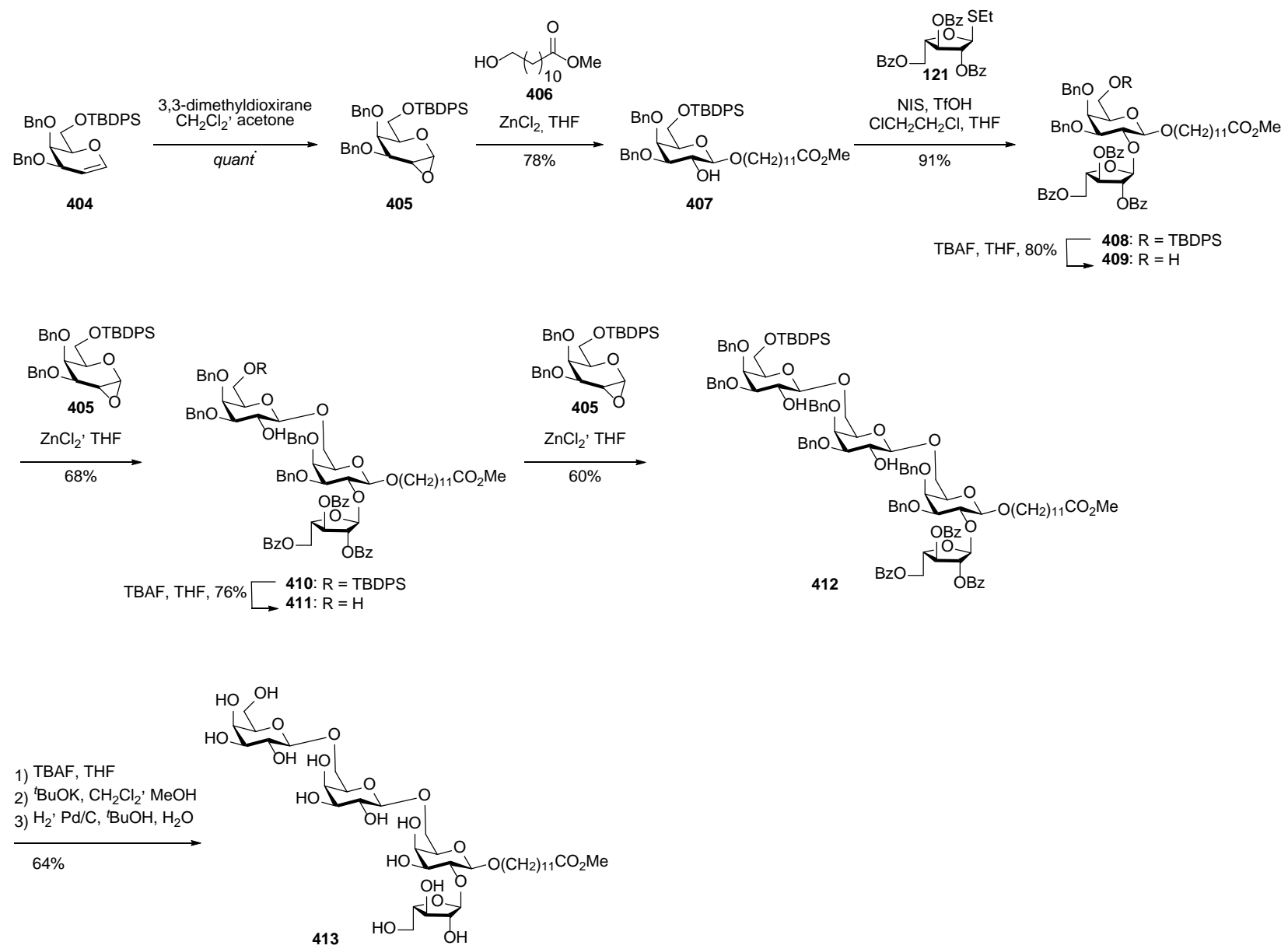

Kong and co-workers later reported several syntheses of well-defined arabinogalactans carrying different lengths of arabinan side chain. ${ }^{189,194-196,198,199}$ They started by producing a tetrasaccharide in 2000, and by 2005, they had reached a chain length of up to 20 residues. As one example of their work, the synthesis of octaarabinogalactan 429 is presented in Scheme $43 .{ }^{198}$ This target consists of a $\beta$-(1 $\rightarrow 6)$-linked pentagalactan carrying arabinofuranosyl and diarabinofuranosyl branches at its 2", 'and 2'-positions, respectively. 
Scheme 43. Synthesis of octaarabinogalactan by Kong and co-workers. ${ }^{198}$
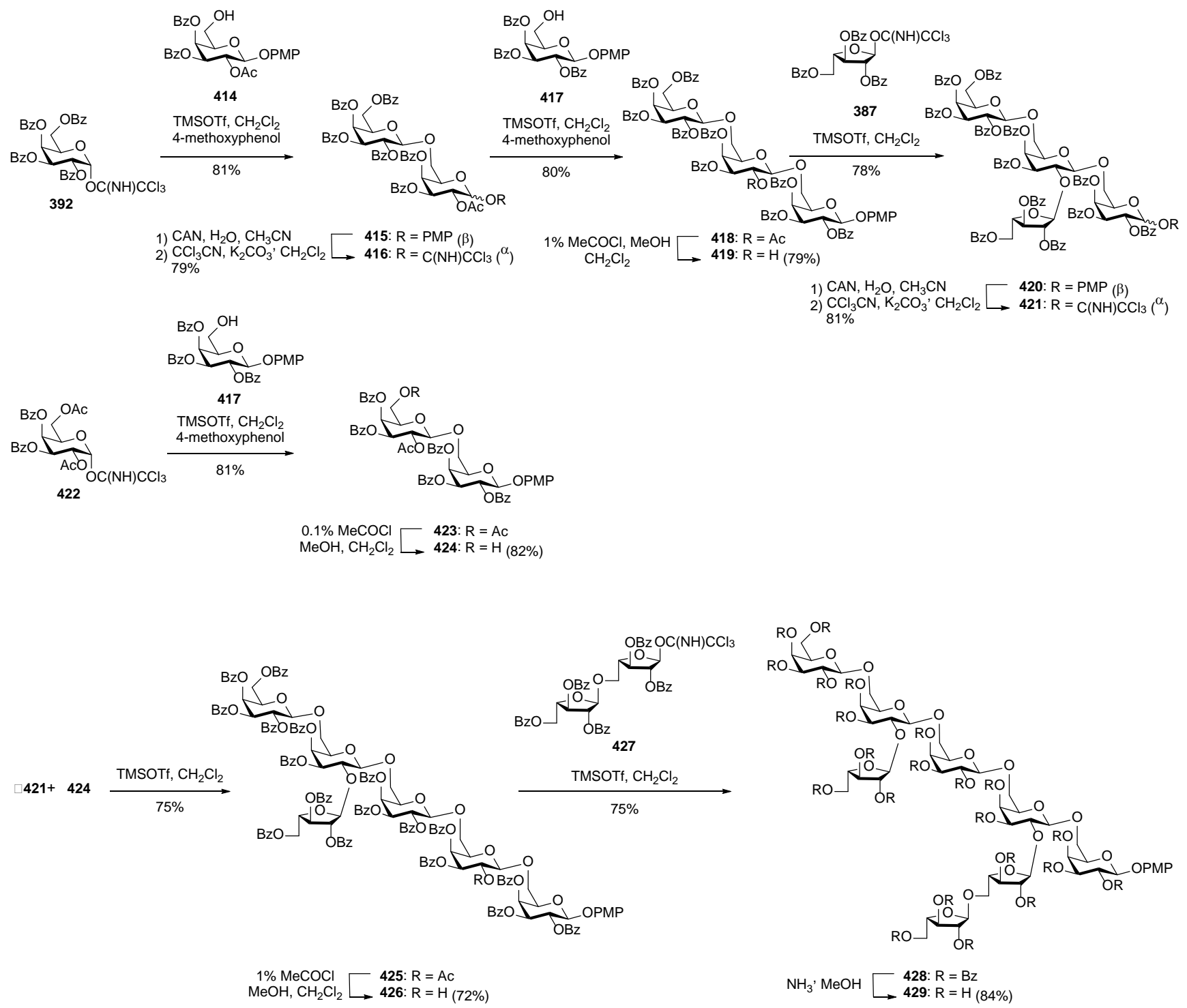

Branching at both the C-2 and C-3 positions is a well-known characteristic for AGs. In order to evaluate differences in immunomodulating activity between C-2 and C-3 branched variants, the same group synthesized a series of model AGs in 2005. To illustrate their method, the retrosynthetic analysis of the arabinogalactan 20-mer is shown in Scheme $44 .{ }^{196}$ The synthesis of the key tetrasaccharide building blocks 431-433 was achieved from the monosaccharides 387, 417, 422, 434 and 435. 
Through coupling reactions between the tetrasaccharides, the authors reached arabinogalactans of varying lengths, up to the longest (430), with twenty monosaccharides.

Scheme 44. Retrosynthetic analysis of AG 430 synthesized by Kong and co-workers. ${ }^{\mathbf{1 9 6}}$
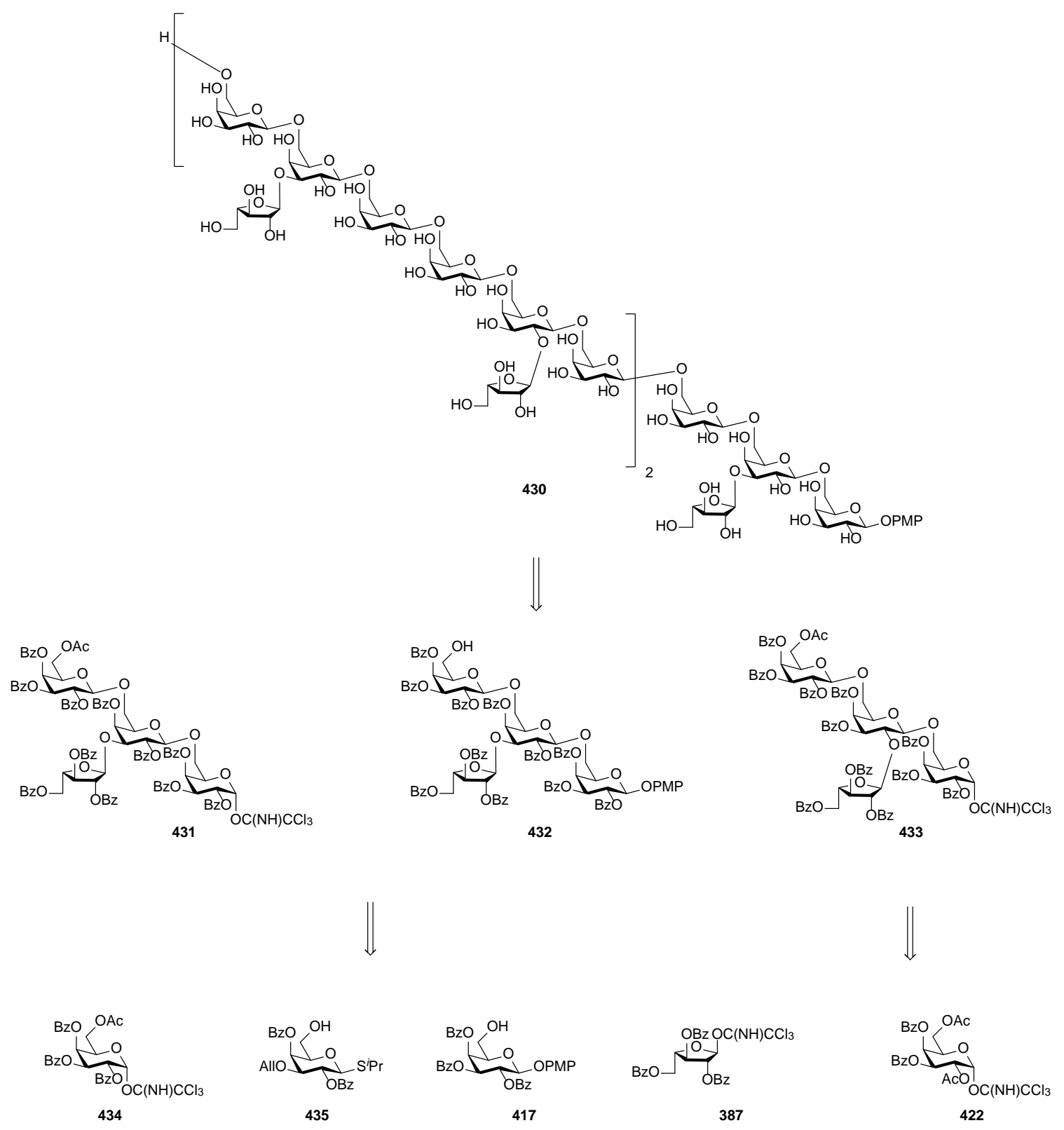
Separately, the groups of Yang and Zhang have developed one-pot glycosylation strategies for the synthesis of 3,6-branched tetra- and hexaarabinogalactan. Both groups relied on the same galactopyranosyl thioglycoside diol $\mathbf{4 3 6}$ as a key glycosylating agent, as shown in Scheme 45. Zhang and co-workers, achieved the synthesis of the hexasaccharide $\mathbf{4 4 1}$ from the assembly of two disaccharides and two monosaccharides, in a one-pot procedure involving three glycosylation reactions, with an overall yield of $60 \%{ }^{197}$
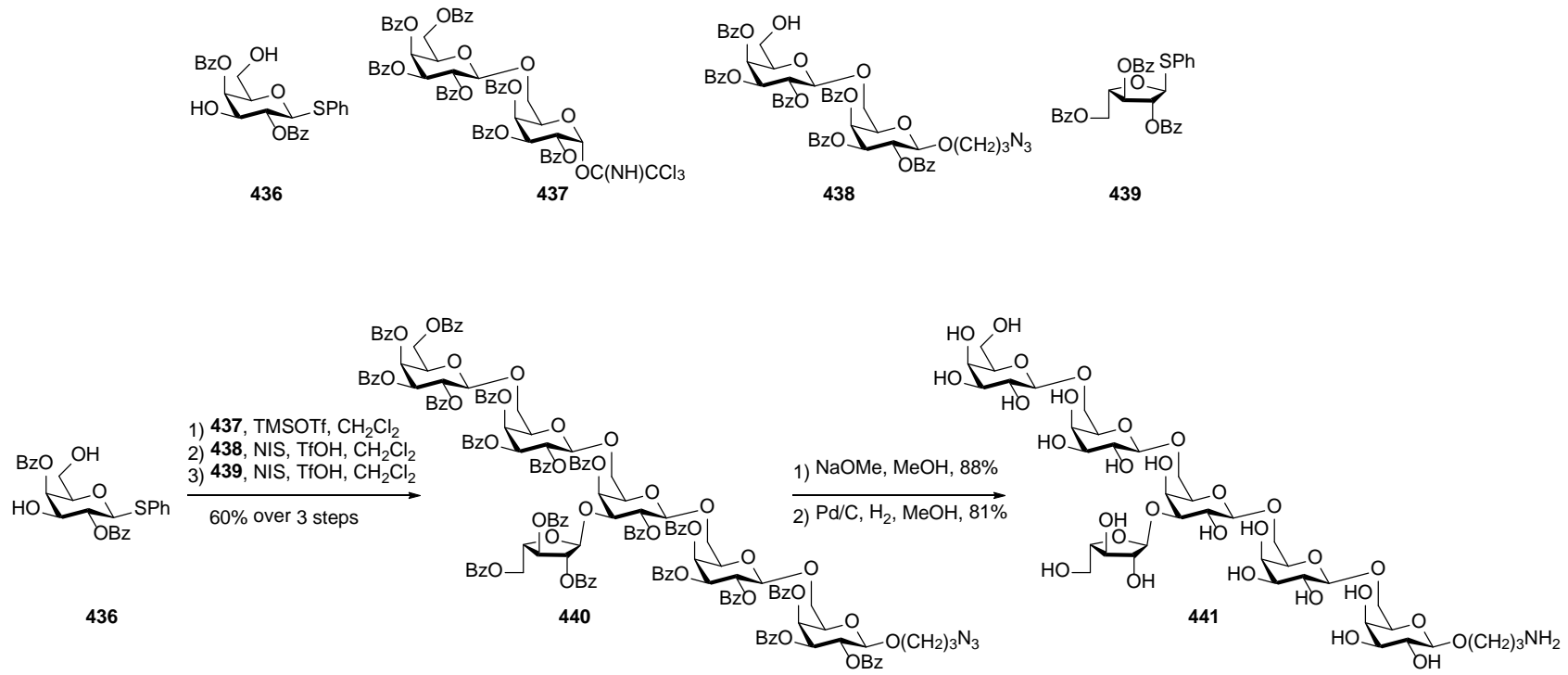

Scheme 45. One-pot synthesis to reach a hexaarabinogalactan by Zhang and co-workers. ${ }^{\mathbf{1 9 7}}$

In the same manner and starting from the same key monosaccharide building block 436, Yang and co-workers achieved the synthesis of their tetrasaccharide in a one-pot manner, reaching the target in 52\% yield over three glycosylation steps. 


\subsection{Arabinans}

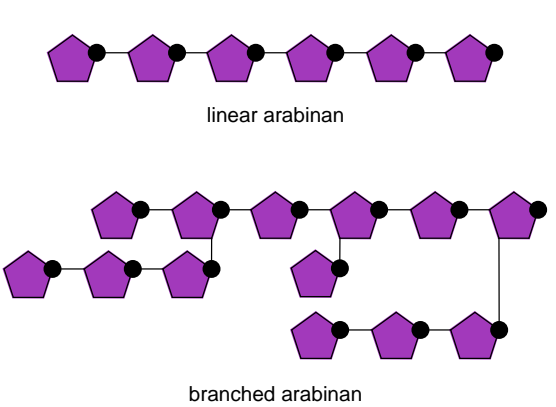

Figure 26. Example of linear and branched arabinan structures.

Arabinans consist of $\alpha-(1 \rightarrow 5)$-linked L-Araf residues, with some degree of $\alpha-(1 \rightarrow 3)$ and/or $\alpha-(1 \rightarrow 2)$ branching, as shown in Figure 26. In many schematic representations of pectin, the arabinan side chains are shown as being attached directly to the rhamnose units of the RG-I backbone. ${ }^{6,99,200-202}$ Very limited evidence for this claim has been reported, however. Most arabinan has been observed as being linked to galactose. A great deal of work has been carried out on synthesizing oligomers of Darabinofuranosides from bacterial cell walls highlighted by a highly efficient assembly of a 92-mer polysaccharide published in 2017 by Xin-Shan and co-workers. ${ }^{203}$ Significantly fewer syntheses of Larabinofuranosides have been reported and they are presented in Table 20.

Table 20. Synthetic $\alpha$-L-arabinofuranosides.

\begin{tabular}{|l|l|l|l|}
\hline Structure & R & Year & Reference \\
\hline & Me & 1986 & Nepogodiev et al. ${ }^{204}$ \\
\hline & Me & 1995 & Kaneko ${\text { et } \text { al. }^{205}}^{\text {OR }}$ \\
\hline
\end{tabular}




\begin{tabular}{|l|l|l|l|}
\hline$\bullet\left({ }^{\circ}\right)_{6} \bullet^{-O R}$ & All & 1999 & Du et al. ${ }^{206,207}$ \\
\hline
\end{tabular}

The first synthesis of a diarabinofuranoside was carried out by Arnd \& Graffi in $1976 .{ }^{208}$ Ten years later, Nepogodiev and co-workers reported the synthesis of a linear $\alpha-(1 \rightarrow 3)$-linked L-arabinotrioside as shown in Scheme $46 .{ }^{204} \mathrm{TrClO}_{4}$-mediated coupling of disaccharide $\mathbf{4 4 4}$ with monosaccharide $\mathbf{4 4 5}$ afforded trisaccharide $\mathbf{4 4 6}$ in 85\% yield. This was further deesterified to obtain the target triarabinan 447.

Scheme 46. Synthesis of a linear $\alpha$-( $1 \rightarrow 3$ )-linked L-arabinotrioside by Nepogodiev and co-workers. ${ }^{204}$

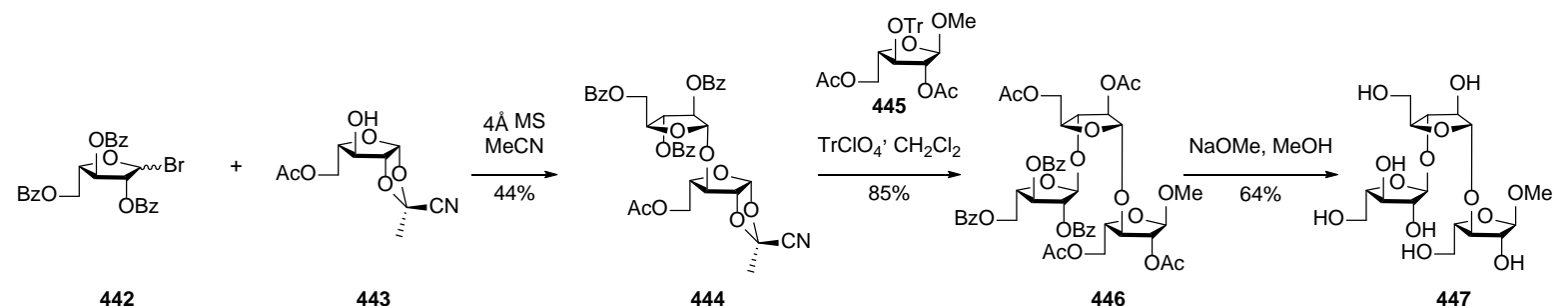

442

443

444

446

447

In 1995, Kusakabe and co-workers synthesized all three $\alpha$-L-diarabinofuranosides as well as the trisaccharide shown in Table 20. ${ }^{205,209}$ Koenigs-Knorr glycosylations promoted by AgOTf afforded the four targets. The synthesis of the trisaccharide also involved simultaneous couplings onto the 3and 5-positions of the reducing end monosaccharide. A year later, Kong and co-workers reported the synthesis of a linear octaarabinan, bearing an allyl group at the anomeric position, as shown in Scheme 47. ${ }^{206}$ They were able to perform a regioselective glycosylation between the perbenzoylated trichloroacetimidate donor $\mathbf{3 8 7}$ and the unprotected allyl $\alpha$-L-arabinofuranoside $\mathbf{4 4 8}$ to obtain partially protected disaccharide $\mathbf{4 4 9}$ in 78\% yield. The latter was converted both to the diol disaccharide $\mathbf{4 5 0}$ and the trichloroacetimidate disaccharide donor $\mathbf{4 5 1}$, which were further coupled in a selective manner 
to form arabinotetrasaccharide $\mathbf{4 5 2}$ in $79 \%$ yield. This could then be converted into both a new acceptor 453, holding five free hydroxyl groups and a new donor 454. By coupling these, an octasaccharide was obtained, which, after deprotection, afforded the desired target $\mathbf{4 5 5}$ in $\mathbf{7 1 \%}$ over the four last steps. 
Scheme 47. Synthesis of linear allyl octa- $\alpha-(1 \rightarrow 5)$-L-arabinofuranoside by Kong and co-workers. ${ }^{206}$
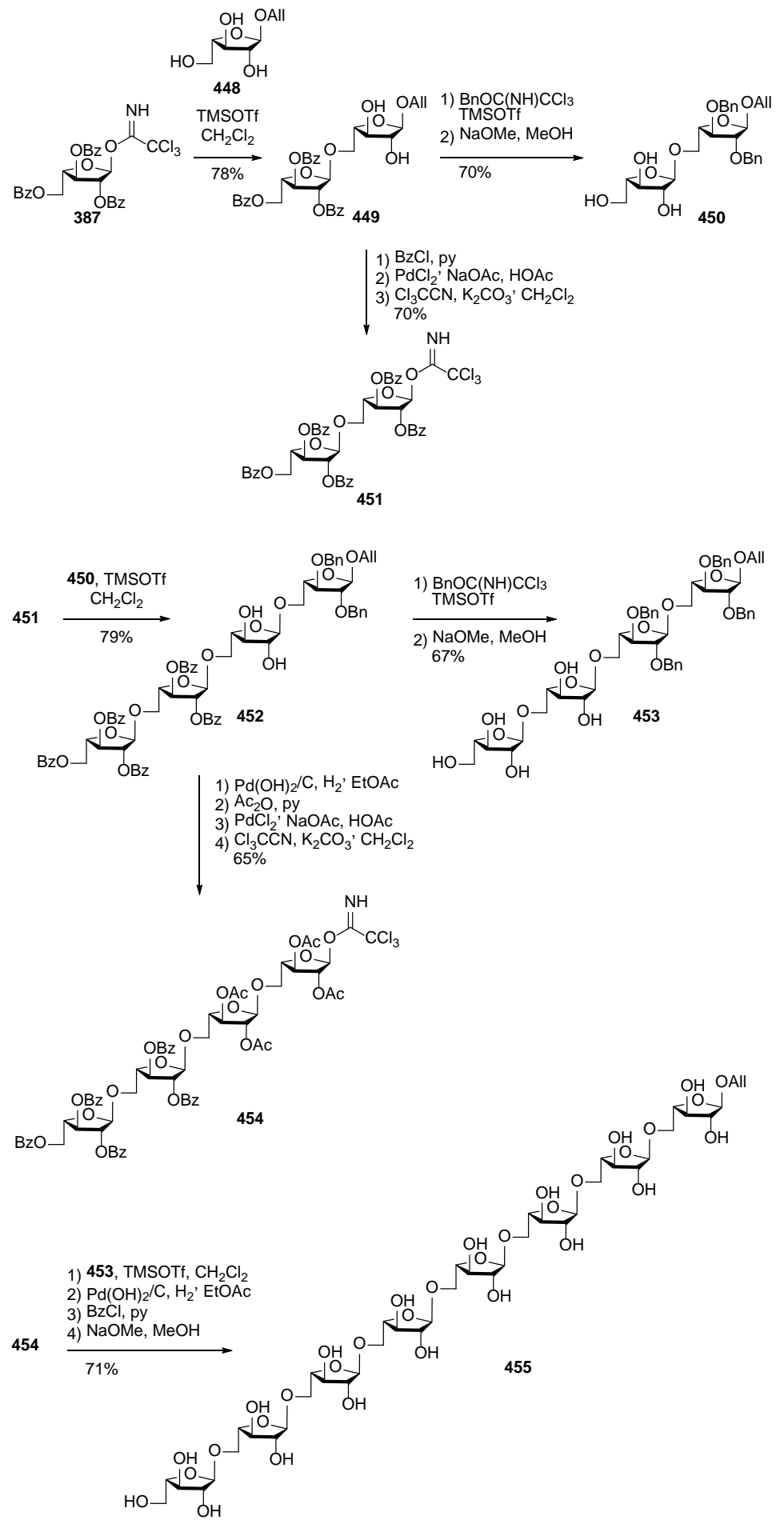
Most recently, Yang and co-workers have synthesized a fully-protected pentaarabinan composed of a linear $\alpha$ - $(1 \rightarrow 5)$-linked arabinotrioside substituted with an $\alpha$-L-arabinose unit at the 3- and 3'-positions through an elegant four-component one-pot synthesis. ${ }^{210}$ 


\section{Polysaccharides exclusive to algae}

This section focuses on the most common polysaccharides found exclusively in algal cell walls: glucuronans, carrageenans, agarans, alginates, fucans and ulvans. $\beta-(1 \rightarrow 3)$-D-Xylans have also been isolated from the cell wall of green algae. ${ }^{211,212}$ So far, only one paper by Kong and Chen reports the synthesis of such structures. ${ }^{213} \mathrm{~A}$ few other, more complex and highly branched sulfated heteropolysaccharides (xylofucoglucans, xylofucoglucuronans, etc.) have been identified as minor components in polysaccharide isolates from brown algae. However, their structures have not yet been fully elucidated, and they have never been the subject of chemical synthesis, therefore they will not be discussed further in this section. ${ }^{214}$

\subsection{Glucuronans}

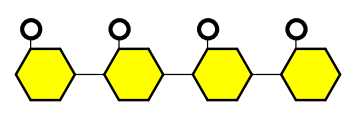

Figure 27. Glucuronan structure.

Glucuronans are $\beta$-(1 $\rightarrow 4)$-D-polyglucuronic acids, i.e. anionic homopolymers as shown in Figure 27. These polysaccharides have been extracted from the cell wall of green algae such as Ulva and Enteromorpha compressa. ${ }^{215,216}$ The biological activity of the glucuronans has only been considered recently, and no efforts to isolate them were reported before the year $2000 .{ }^{217}$ In 2009, Redouan and co-workers reported a rapid process to extract glucuronans selectively in large amounts from the green algae Ulva lactura, using enzymatic depolymerization. The process could potentially be used on an industrial scale to produce bioactive glucuronic acid oligosaccharides. ${ }^{218}$ In 1998, Isogai and co- 
workers prepared some glucuronan oligosaccharides from cellulose using TEMPO-mediated oxidation, work which could open up a new field of cellulose exploitation. ${ }^{219}$ No chemical synthesis of a glucuronan longer than a disaccharide has been reported to date, and these disaccharides were produced to optimize the TEMPO-oxidation of cellobiose.

\subsection{Carrageenans}

The carrageenans are a family of highly-sulfated D-galactans found in the cell walls of certain red seaweeds of the Rhodophyte class. This family of polysaccharides has the ability to form thermoreversible gels or viscous solutions in the presence of salts. They are organized into ten different types of carrabiose repeating units that differ by their degree of sulfation, and the presence or absence of 3,6-anhydrogalactose residues (see Figure 28). 


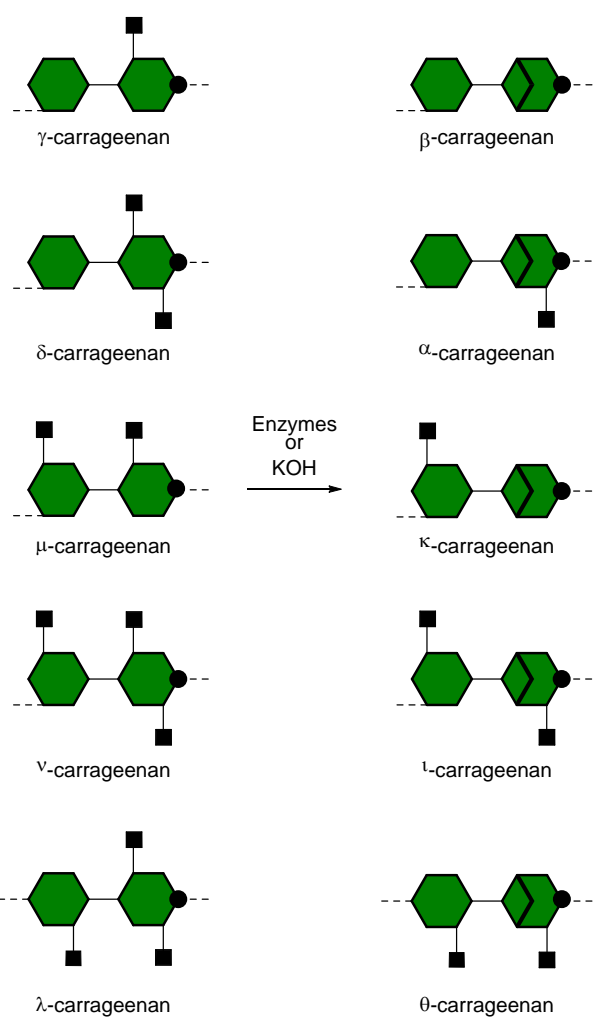

Figure 28. Schematic representation of the ten types of idealized disaccharide repeating units of carrageenans.

Natural carrageenans are non-homologous polysaccharides. This diverse family of glycans shares a common galactan backbone (carrabiose) of alternating 3-linked- $\beta$-D-galactopyranose and 4-linked- $\alpha$ D-galactopyranose. It has been shown that hot alkaline treatment of the carrageenan having a 4-linkeda-D-galactopyranose residue sulfated at the 6 position leads to cyclization, forming the 3,6-anhydro rings. ${ }^{220,221}$ During carrageenan biosynthesis, this transformation is catalyzed by enzymes. No synthesis of this type of algal polysaccharide has been reported to date. 


\subsection{Agarans}

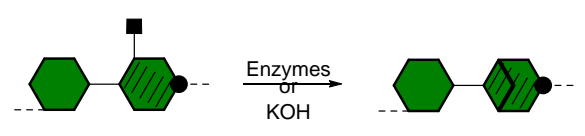

Figure 29. Agarobiose backbone units.

The agarans are another family of sulfated galactans found in red seaweeds. As with carrageenans, agarans have linear chains of alternating 3-linked $\beta$-galactopyranosyl residues and 4-linked- $\alpha$ galactopyranosyl residues. They differ from carrageenans in that the latter are L-Galp. As in carrageenans, these residues can have 3,6-anhydro bridges (Figure 29). In 1991, Lahaye reported that at least eleven different agarobiose structures could be identified depending on the type of red alga. ${ }^{222}$ The common modifications observed were mainly the presence of sulfate substituents, pyruvate, urinate and methoxy groups. Red seaweeds producing agaran were named agarophytes, while the ones producing carrageenans were called carrageenophytes. However, it has recently been shown that some carrageenophytes also synthesize considerable amounts of agaran or DL-hybrid galactans. ${ }^{223}$ No organic synthesis of agaran has yet been reported.

\subsection{Porphyrans}

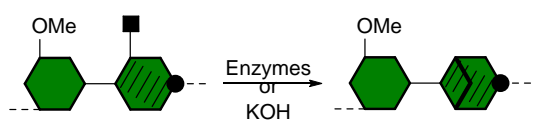

Figure 30. Porphyran repeating unit. 
The porphyrans are polysaccharides found in the red alga Porphyra umbilicalis, which was characterized by Rees in $1961 .^{224}$ This family of glycans shares the same backbone as agarans, but are substituted with 6-O-methylation of the D-galactose units as shown in Figure $30 .^{225}$ Similar to carrageenans, Rees and co-workers showed that suitably linked L-galactose 6-sulphate units in porphyrans can be converted quantitatively by alkaline treatment into 3,6-anhydrogalactose. ${ }^{224}$ This type of oligosaccharide has not received attention from synthetic chemists yet.

\subsection{Alginates}

The alginates are a family of polysaccharides present in both brown algae and some gram-negative bacteria. They are composed of two uronic acids: D-mannuronic acid (M) and L-guluronic acid (G, the C5 epimer of $\mathrm{M})$. The monomers are connected by $(1 \rightarrow 4)$ glycosidic linkages, with a 1,2-cis configuration. The residues are arranged in either homopolymeric (polymannuronate -MM-, or polyguluronate -GG-) or heteropolymeric (-MG-) segments, as shown in Figure 31.226,19

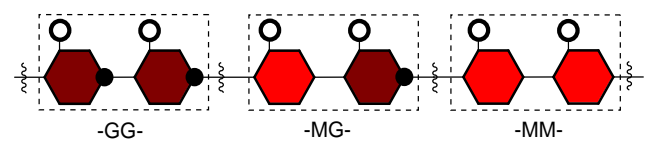

Figure 31. Block composition of alginates.

These anionic polysaccharides can be isolated from marine brown algae. They have widespread application in the biomaterial and food industries due to their gelling properties. It has been shown that G-block-rich alginates increase gel strength by forming links with calcium, bridging two 
antiparallel chains, as described earlier for homogalacturonan (see section 5.1) ${ }^{227}$ Alginates also offer putative medical benefits, so there is considerable interest in generating chemically well-defined alginate fragments. The assembly of mixed alginate sequences -MG- is particularly challenging, as it requires the synthesis of $\beta$-D-mannuronic acid and $\alpha$-L-guluronic acid, both of which have 1,2-cis linkages. Only one synthesis of mixed sequence alginate oligosaccharides has in fact been reported, by Codée and co-workers in 2015. ${ }^{228}$ Table 21 gives an overview of all the alginate fragments synthesized to date.

Table 21. Synthetic alginates fragments.

\begin{tabular}{|l|l|l|l|}
\hline Structure & R & Year & Reference \\
\hline & $\left(\mathrm{CH}_{2}\right)_{3} \mathrm{NH}_{2}$ & 2006 & van den Bos et al. ${ }^{229}$ \\
Codée et al. ${ }^{230}$
\end{tabular}




\begin{tabular}{|l|l|l|l|}
\hline & $\mathrm{Pr}$ & 2009 & Chi et al. $^{233}$ \\
\hline & $\mathrm{Pr}$ & 2009 & Chi et al. $^{233}$ \\
\hline & $\left(\mathrm{CH}_{2}\right)_{2} \mathrm{NHAc}^{23}$ & 2015 & Zhang et al. $^{228}$ \\
\hline & $\left(\mathrm{CH}_{2}\right)_{2} \mathrm{NHAc}$ & 2015 & Zhang et al. $^{228}$ \\
\hline
\end{tabular}

As mentioned earlier (section 4.5), forming the $\beta$-mannosidic linkage is considered one of the biggest challenges in carbohydrate chemistry. Lately, syntheses of -MM- fragments up to dodecamers have been published. In 2006, van der Marel and co-workers discovered the use of 1-thiomannuronate ester donors in the stereocontrolled formation of 1,2-cis mannuronic linkages. ${ }^{229}$ They proved that the $\beta$ selectivity of the mannuronate ester comes from the stereoelectronic influence of the C-5 ester and demonstrated the efficiency of this strategy in the generation of longer alginate oligosaccharides (up to a pentasaccharide) using a block coupling strategy (Scheme 48$){ }^{230}$ Thioglycosyl donors were preactivated prior to coupling, and it was shown that judicious choice of promoter was crucial in ensuring high yields as the oligomers grew in length. Excellent $\beta$-selectivity was maintained in all glycosylation reactions and was not compromised by the size of the coupling partners. 
Scheme 48. Assembly of mannuronate ester oligomers (-MM-) by van der Marel and co-workers. ${ }^{230}$
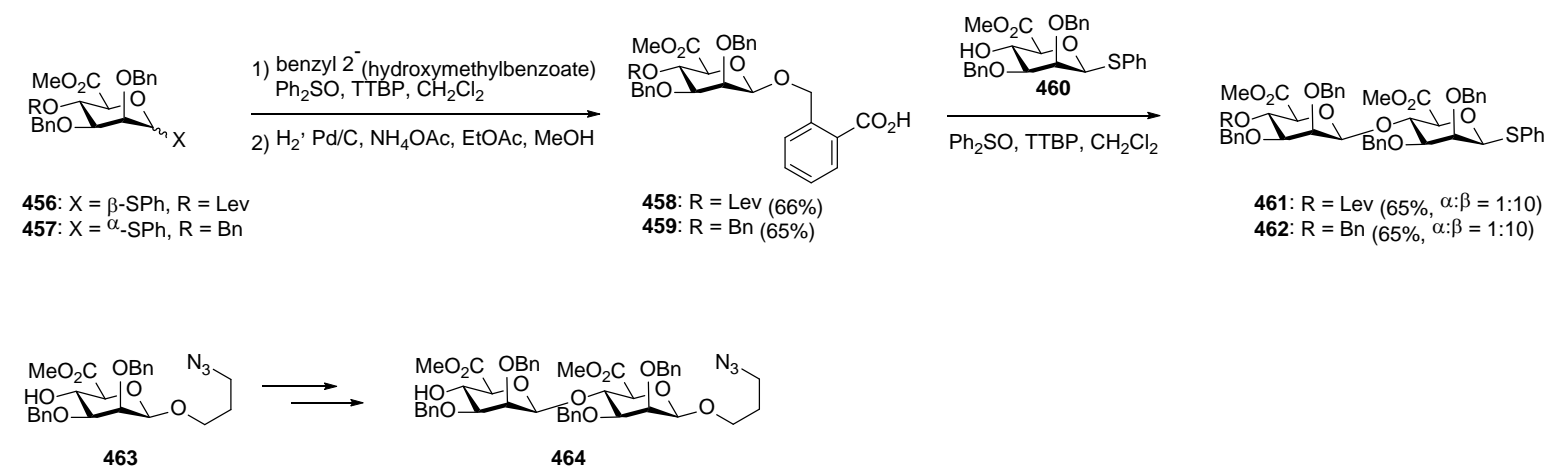

463

464

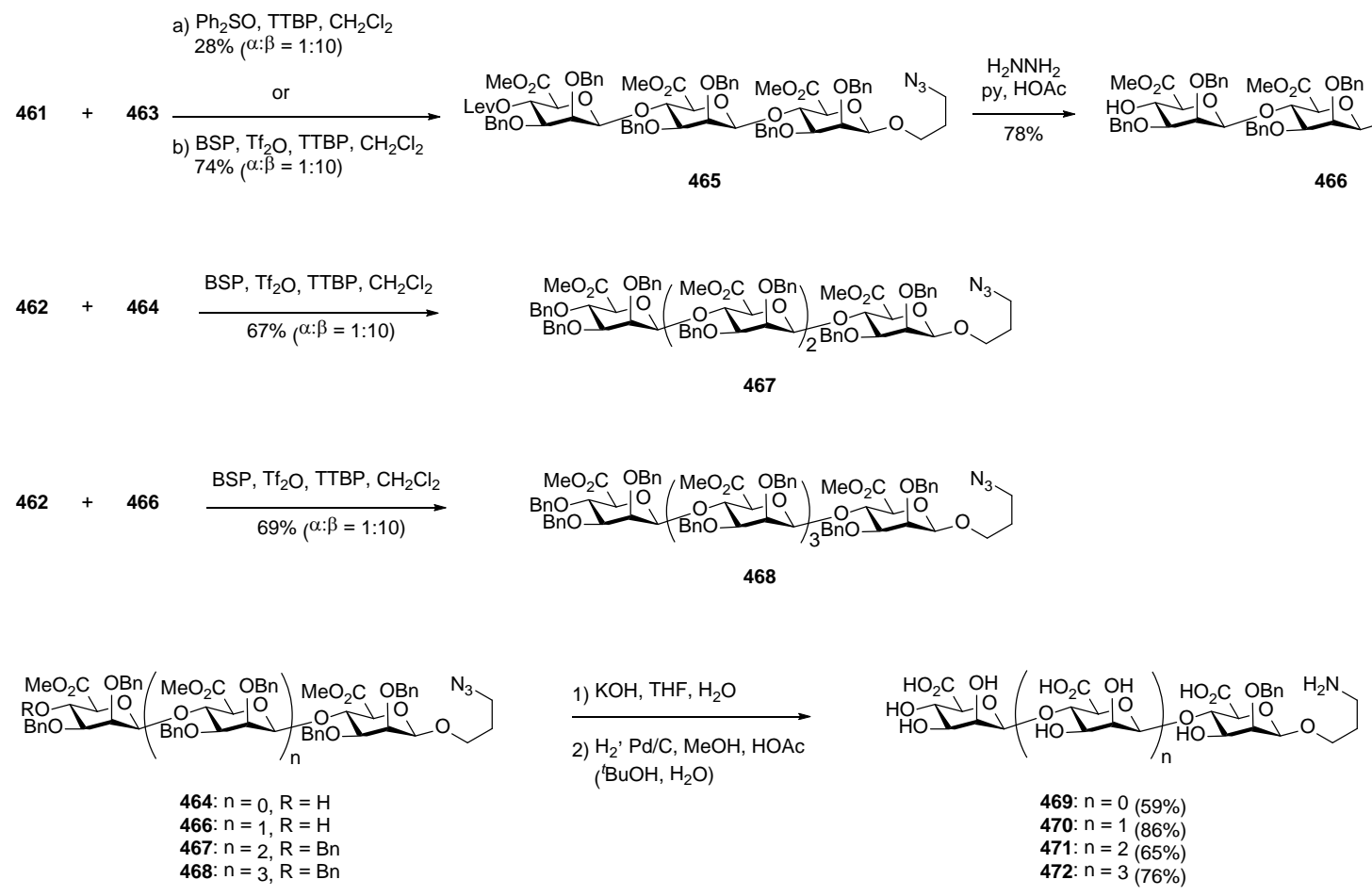

Mannuronic acid donors were also used by Codée and co-workers in an automated solid-phase synthesis, to build alginates up to a dodecasaccharide. Trifluoroacetimidate donors were used as building blocks, since pre-activation of donors was not possible on their solid phase synthesizer and because the nature of the linker prohibited the use of soft electrophiles required for the activation of 
thioglycosides. The stereodirecting effect of the C-5 carboxylate again provided the desired $(1 \rightarrow 2)$ cis glycosides with excellent stereoselectivity.

The synthesis of short L-guluronic acid oligomers (-GG- blocks up to a tetrasaccharide) has been achieved by only two groups, Hung and co-workers ${ }^{233}$ and van der Marel, Codée and co-workers. ${ }^{232}$ As L-gulose and L-guluronic acid are rare sugars, they are not commercially available and need to be synthesized prior to use, as shown in Scheme 49.

Scheme 49. Synthesis of L-gulose. ${ }^{232,233}$

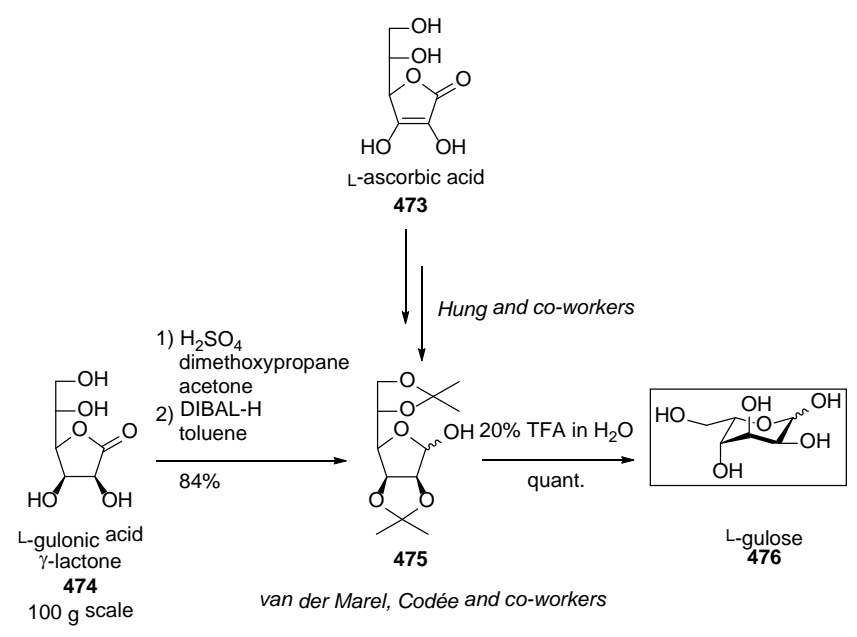

In contrast to D-mannopyranose, L-gulopyranose has an intrinsic preference for the formation of 1,2cis-glycosidic bonds without the need to incorporate stereodirecting groups. Furthermore, Codée and co-workers demonstrated that L-guluronic acid donors are less stereoselective in glycosylation reactions than L-gulose donors. ${ }^{232}$ Therefore, a post-glycosylation oxidation strategy has been the preferred approach for the synthesis of -GG- block oligosaccharides. 
After screening the efficiency of several gulose donors, Codée and co-workers found that a dehydrative glycosylation ${ }^{234}$ with hemiacetal $\mathbf{4 7 9}$ gave the best yield, and $\alpha$-selectivity, in the glycosylation step. They achieved the synthesis of a guluronic acid trisaccharide, as shown in Scheme $50 .^{232}$

Scheme 50. Synthesis of guluronic acid trisaccharide (-GGG-) by Codée and co-workers. ${ }^{232}$

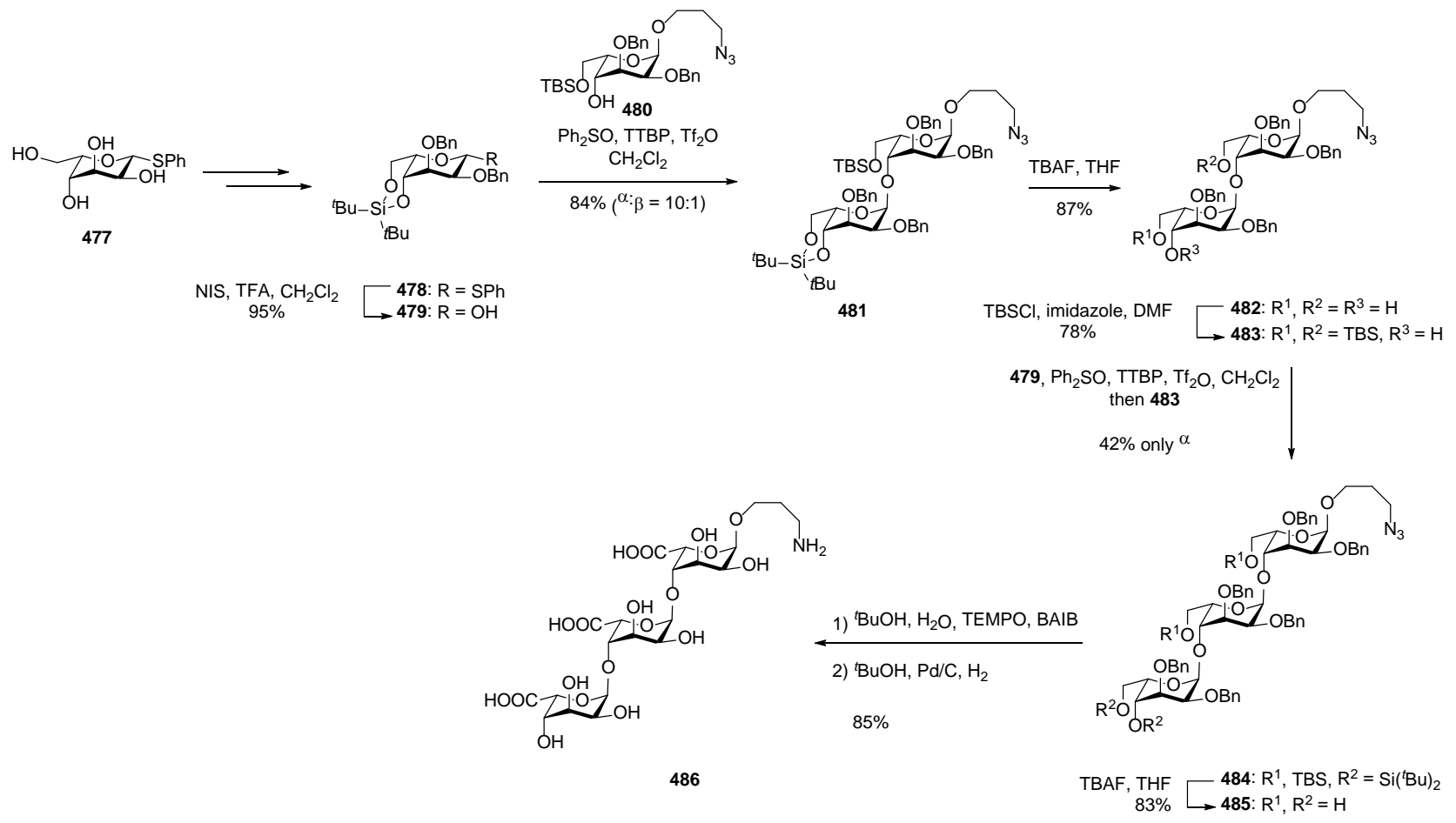

Hung and co-workers employed 1,6-anhydrogulose synthons to lock the $\mathrm{C} 4-\mathrm{OH}$ in a more accessible environment and increase the reactivity of the nucleophile. ${ }^{233}$

As mentioned above, only one synthesis of alginate sequences containing both $\mathrm{M}$ and $\mathrm{G}$ residues has been reported, by Codée and co-workers in $2015 .{ }^{228}$ They decided on an approach employing GM building blocks, thus featuring a mannuronic acid donor, and pre-glycosylation oxidation in order to 
minimize functional-group manipulation at a late stage of the synthesis. The preparation of the building blocks required for the assembly of the longer oligosaccharides is presented in Scheme 51. Glycosylation between the silylene-protected gulose imidate donor $\mathbf{4 8 7}$ and mannuronic acid acceptor 488 or 463 led to GM dimers 489 and 495, respectively, in good yields and with high stereoselectivities. A desilylation/oxidation/methyl ester formation sequence afforded GM acceptor building blocks 490 and 496. The trifluoroacetimidate GM donor 493 was then obtained from 490 in an $83 \%$ yield over three steps.

Scheme 51. GM donor and acceptor building blocks for the synthesis of mixed alginate oligosaccharides by Codée and co-workers. ${ }^{228}$
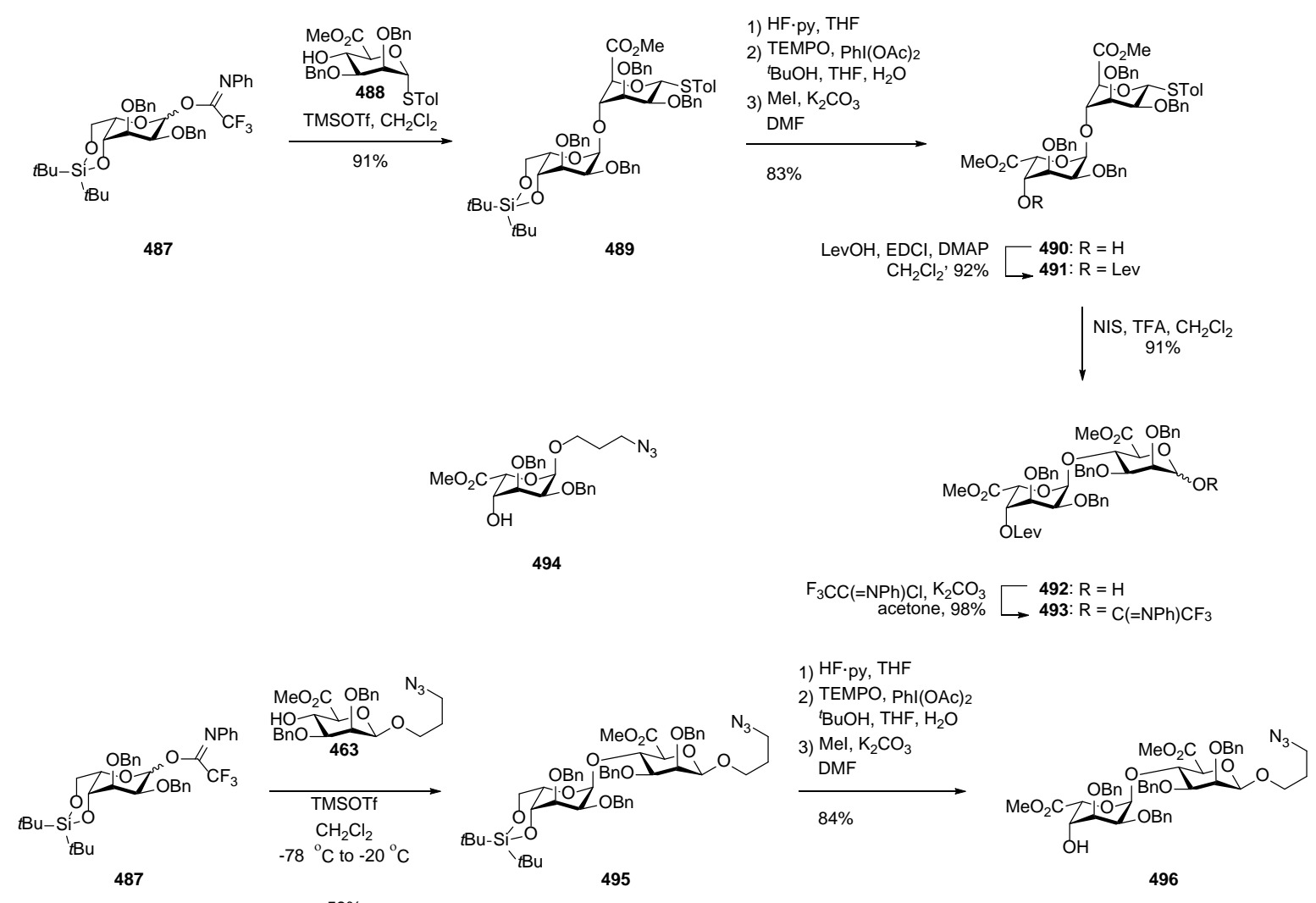
With the GM donors and acceptors in hand, the assembly of larger -GM- oligomers could proceed. This was successfully achieved for structures ranging from the GMG trisaccharide to a GMGMGMG heptasaccharide (Scheme 52). 
Scheme 52. Assembly of -GM- oligomers up to heptasaccharide by Codée and co-workers. ${ }^{228}$
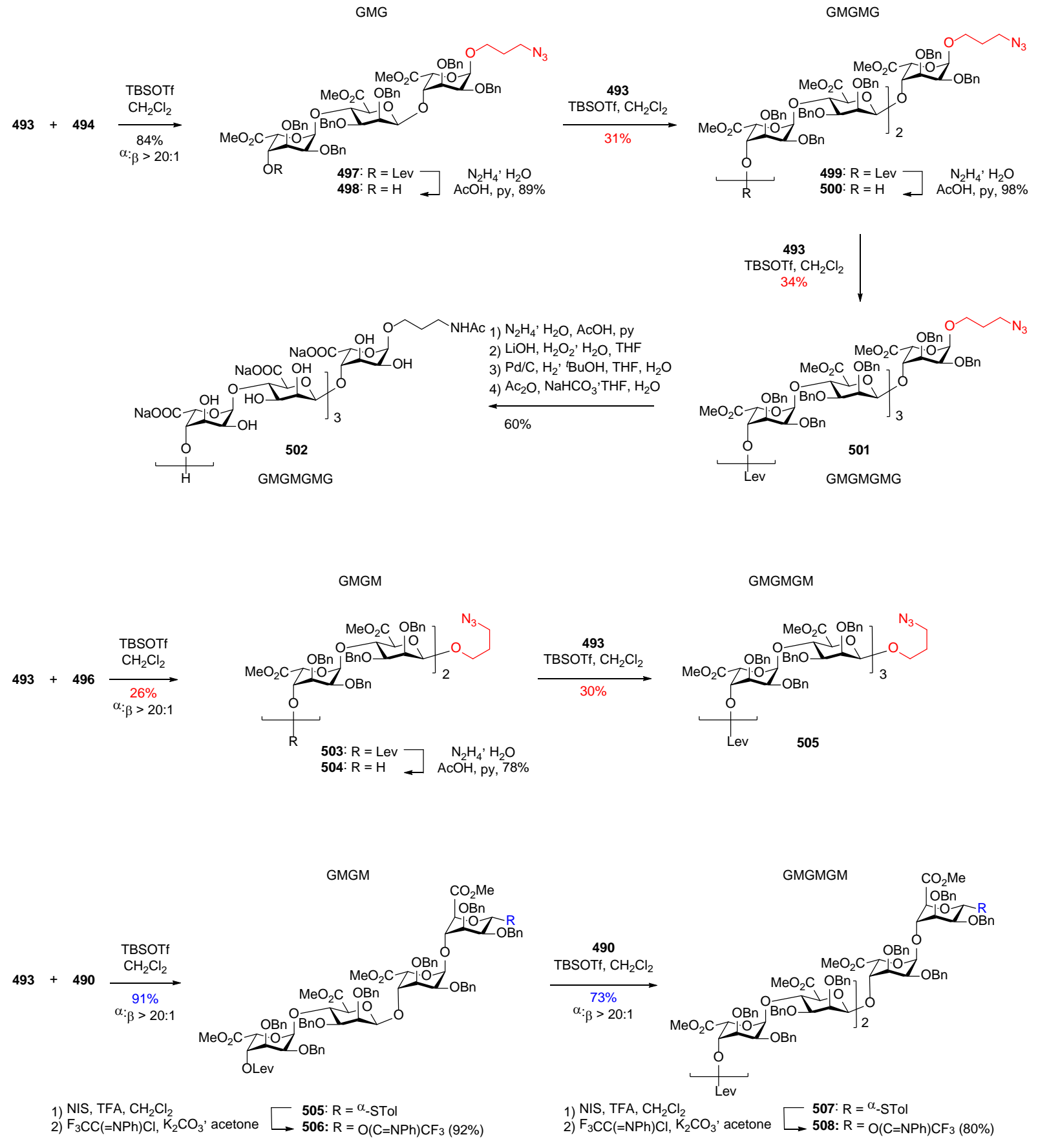

Surprisingly, the nature of the reducing end anomeric center of the GM acceptor had a tremendous effect on the efficiency of glycosylation by influencing the conformation of the acceptor. The rigid 
GM acceptor 496, bearing a $\beta$-linked anomeric azidopropyl spacer, led to lower glycosylation yields (26-34\%), whereas the conformationally-flexible GM- $\alpha$-STol acceptor $\mathbf{4 9 0}$ gave much better yields (73-91\%). ${ }^{235}$ The GMGGMG hexasaccharide was synthesized using a [2+3+1] approach with mannuronic acid donors, as summarized in Error! Reference source not found..

Scheme 53. Convergent assembly of GMGGMG hexasaccharide by Codée and co-workers. ${ }^{228}$

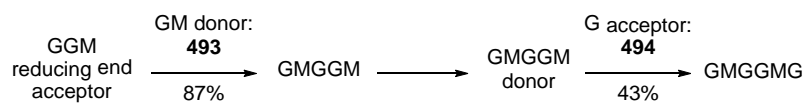

All the oligomers were deprotected by removal of the levulinoyl groups, saponification of the methyl esters, debenzylation plus azide reduction and finally acetylation of the spacer amine group as shown for heptamer $\mathbf{5 0 2}$ in Scheme 52.

\subsection{Fucans}

In 1913, Kylin reported the first extraction of "fucoidin" from marine brown algae. ${ }^{236}$ Most of the fucose containing sulfated polysaccharides (FCSPs) found in brown algae are fucoidans, which are heteropolymers of sulfated fucans. These polysaccharides can account for more than $40 \%$ of the dry weight of isolated cell walls in brown algae. ${ }^{237}$ Fucoidans have been found to have two types of homofucose backbone chains as shown in Figure 32. Type I consists of $(1 \rightarrow 3)$-linked $\alpha$-L-

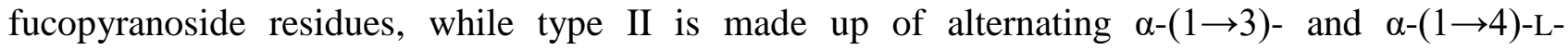
fucopyranoside residues. ${ }^{238}$ The complexity and heterogeneity of fucoidans is due to the sulfation pattern, which differs depending both on the type of alga as well as between cell types. Sulfation can 
occur at the $O-2, O-3$, and/or $O-4$ position of the fucose residues. Acetylation has also been observed at various positions of the backbone, as has the presence of other sugar residues such as $\alpha$-Dglucuronopyranosyl or $\alpha$-L-fucopyranosyl. ${ }^{237}$

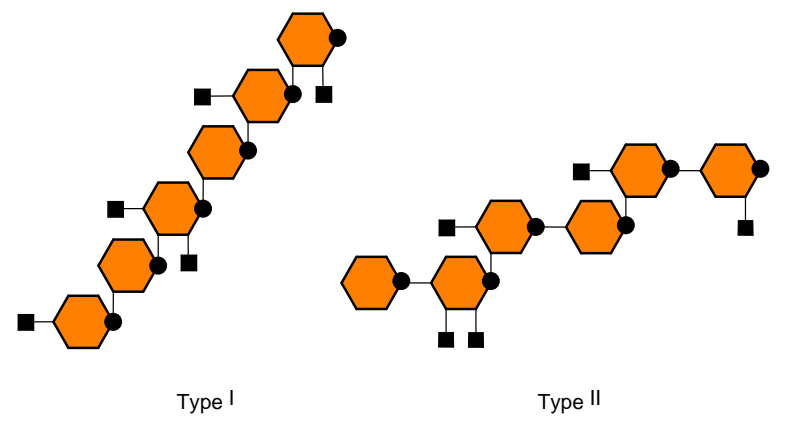

Figure 32. The two types of homofucose backbone chains found in brown seaweed fucoidans with examples of sulfation patterns.

It has been known for some time that fucoidans act as modulators of coagulation. ${ }^{239}$ But how their sulfation pattern and conformation influence biological activity has not been studied. Early in the $21^{\text {st }}$ Century, synthetic chemists began showing interest in these targets, aiming to synthesize certain welldefined oligofucans and help elucidate their structure-activity relationship. An overview of the type I and type II fucan and fucoidan fragments synthesized are shown in Table 22 and Table 23, respectively.

Table 22. Synthetic type I fucan/fucoidan fragments.

\begin{tabular}{|l|l|l|l|}
\hline Structure & R & Year & Reference \\
\hline & $\operatorname{Pr}$ & 2003 & Gerbst et al. $^{240}$ \\
\hline
\end{tabular}




\begin{tabular}{|l|l|l|l|}
\hline & & & \\
\hline
\end{tabular}




\begin{tabular}{|l|l|l|l|}
\hline & & & \\
\hline
\end{tabular}




\begin{tabular}{|l|l|l|l|}
\hline & & & \\
\hline
\end{tabular}




\begin{tabular}{|l|l|l|l|}
\hline & & & \\
\end{tabular}

Table 23. Synthetic type II fucan/fucoidan fragments.

\begin{tabular}{|l|l|l|l|}
\hline Structure & R & Year & Reference \\
\hline$\square-O R$ & Pr & 2011 & ${\text { Krylov et al. }{ }^{241}}^{-O R}$ \\
\hline
\end{tabular}




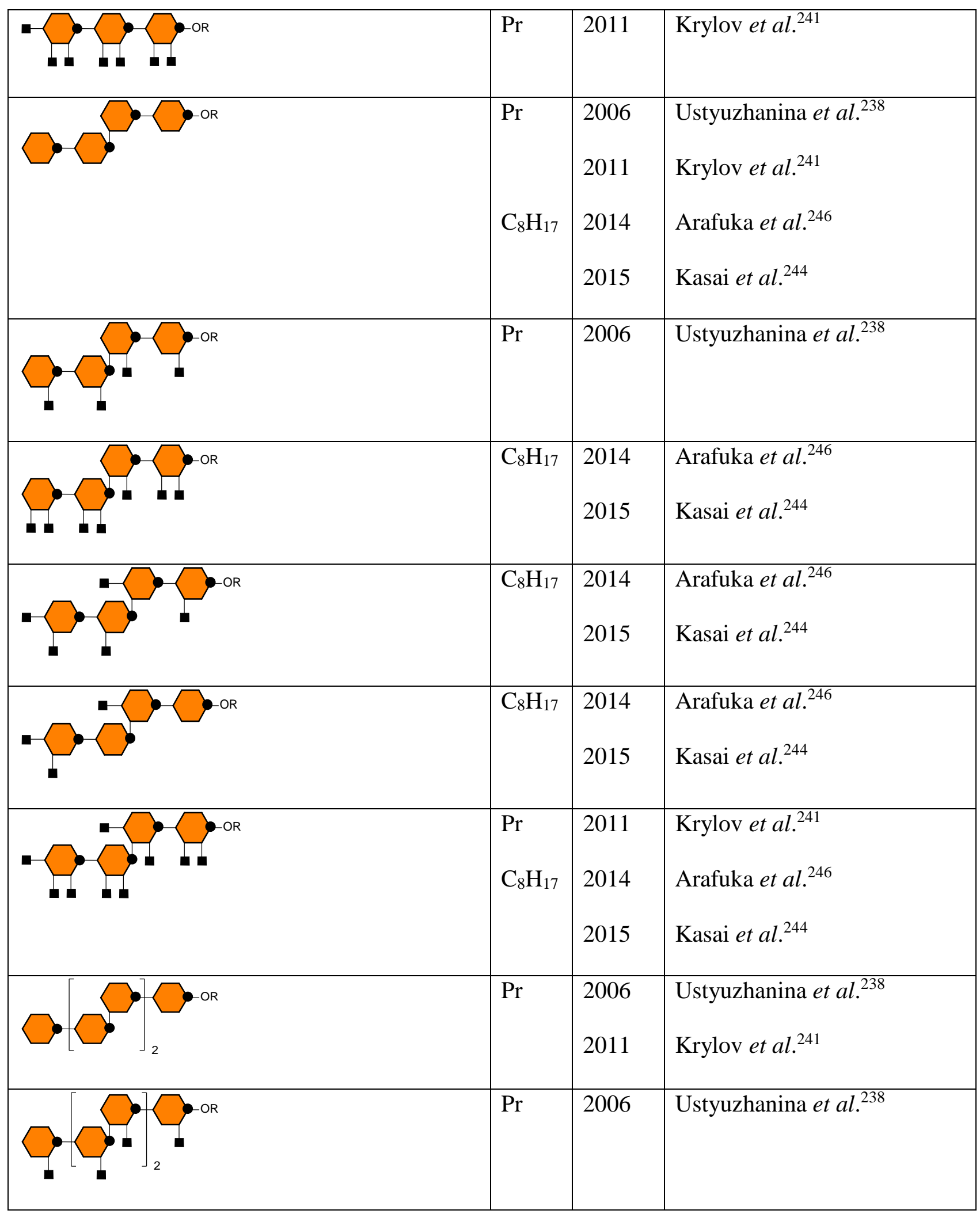




\begin{tabular}{|l|l|l|l|}
\hline & Pr & 2011 & Krylov et al. $^{241}$ \\
\hline
\end{tabular}

In 2003, Nifantiev and co-workers reported the first synthesis of the two type I fucoidan trisaccharides 515 and 516 (Scheme 54). ${ }^{240}$ Both fucotriosides were prepared by use of the readily accessible disaccharide acceptor 509. ${ }^{247,248}$ Regio- and stereoselective glycosylation with fucosyl bromide donor 510, promoted by mercury salts afforded the protected $\alpha$-linked trisaccharide $\mathbf{5 1 1}$ in $65 \%$ yield. Saponification and subsequent catalytic hydrogenolysis provided fucotrioside target $\mathbf{5 1 5}$ in a good yield overall. Protecting group manipulations and sulfation gave trisaccharide 514. The latter was deprotected to afford the sulfated fucotrioside target $\mathbf{5 1 6 .}$

Scheme 54. First type I fucan and fucoidan synthesized by Nifantiev and co-workers. ${ }^{240}$

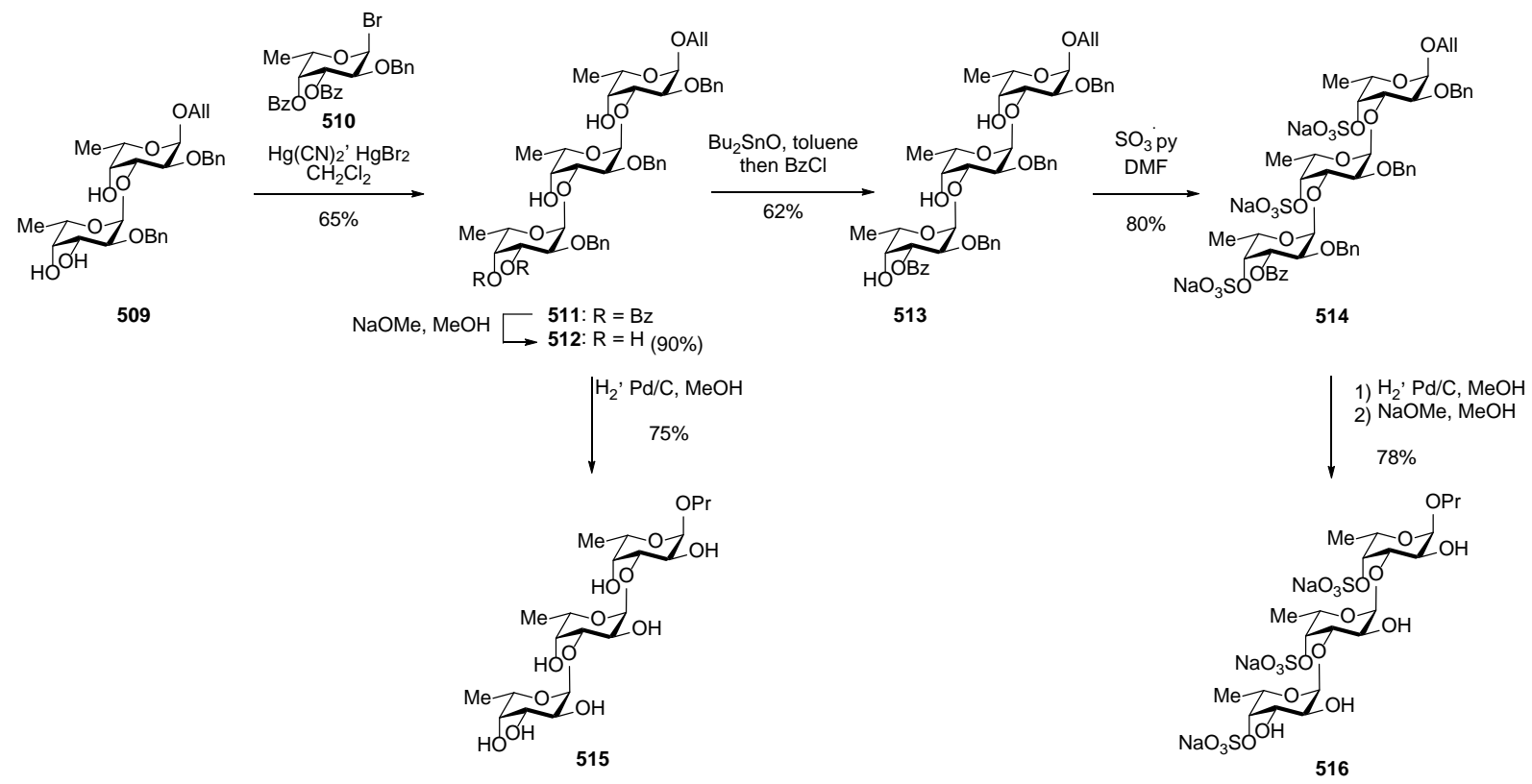


By applying a stepwise elongation strategy with thioglycoside donors, Du and co-workers subsequently reported the synthesis of a fully sulfated tetrasaccharide with a $\beta$-configured octyl group at the reducing end. ${ }^{243}$ In 2006, Nifantiev and co-workers developed a method using [2+2], [2+4] and [4+4] coupling reactions to produce oligofucoidans of both type I and type II, employing trichloroacetimidates as donors. ${ }^{238}$ Inspired by these syntheses and in order also to generate type I oligofucoidans of uneven length, Li and co-workers decided to apply a [2+2] coupling strategy to produce the tetrasaccharide, followed by an iterative assembly of the remaining targets, as shown in Scheme 55. ${ }^{245}$ They used 4-O-benzoyl protecting groups, claiming this improved the $\alpha$ stereoselectivity of the glycosylation steps through remote participation, in combination with 3-Oacetyl and 2-O-benzyl groups. This way, they could produce two different sulfation patterns from each oligofucoidan precursor.

Scheme 55. Retrosynthetic analysis of sulfated tetra- to octafucosides by Li and co-workers. ${ }^{245}$
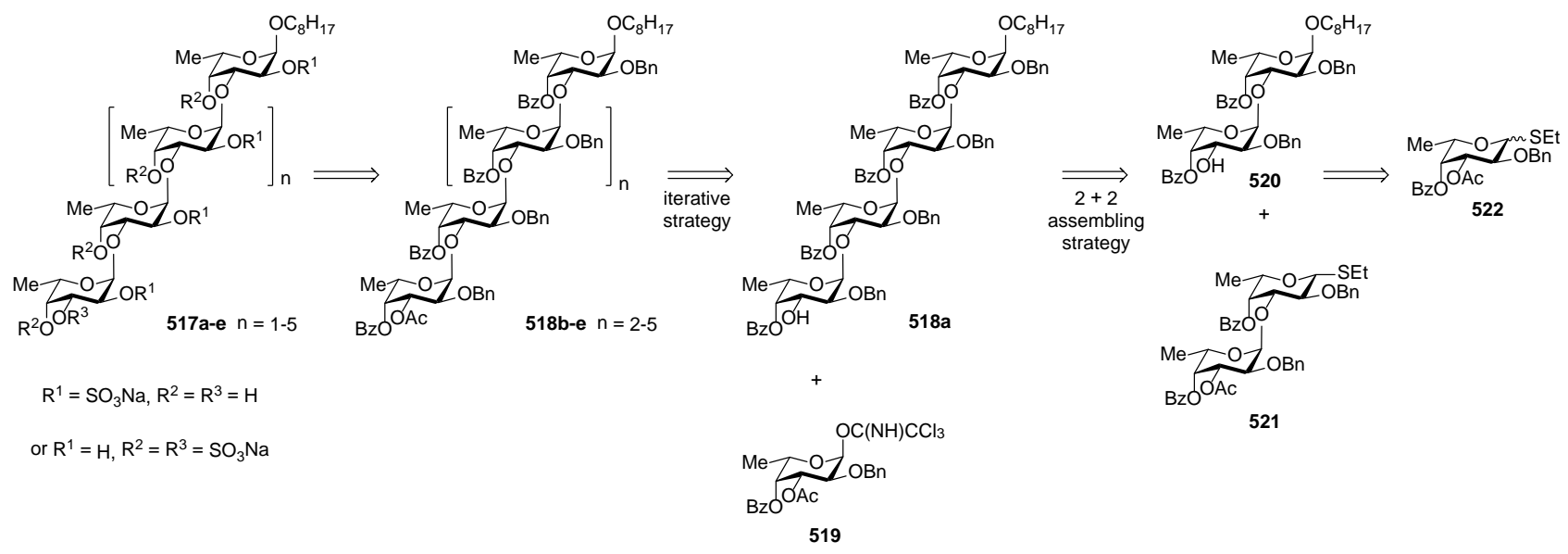

Per-O-sulfation of organic compounds containing many hydroxy groups can require lengthy reaction times (of up to several days) and high temperatures, as well as substantial excess of the sulfating 
reagent. Even so, one may still produce mixtures of partially sulfated products. This happened to Nifantiev and co-workers as they tried to synthesize a fully sulfated tetrafucoside. As a result, they developed an improved TfOH-promoted per-O-sulfation protocol with sulfur trioxide/pyridine, enabling the reaction to take place at $0{ }^{\circ} \mathrm{C}$ and over a shorter period of time. ${ }^{249}$ They then adapted this method for use in their previously developed block strategy, synthesizing per-O-sulfated type I and II oligofucoidans from two to sixteen fucose residues. To their surprise, when using TfOH to promote the sulfation, they observed an unusual rearrangement of the reducing pyranose residue into the corresponding furanose. As this pyranoside-into-furanoside rearrangement is of great interest in the synthesis of furanoside containing oligosaccharide targets, the group later explored its mechanism and optimized this reaction. ${ }^{250}$ To avoid the rearrangement, they exchanged TfOH for TFA and this produced the desired targets without by-products.

In 2014 and 2015, Toshima and co-workers designed a series of type I and type II fucoidan tetrasaccharides with different sulfation patterns. ${ }^{246,251}$ An orthogonal deprotection strategy utilizing the common key intermediates $\mathbf{5 2 8}$ and $\mathbf{5 3 1}$ (Scheme 56), carrying three types of protecting groups ( $\mathrm{Bn}, \mathrm{Bz}$ and $\mathrm{PMB}$ ) enabled an effective synthesis of the eight targets. The synthesis of the tetrafucoside precursor $\mathbf{5 2 8}$ for the type II fragments is presented in Scheme 56. 
Scheme 56. Key tetrasaccharides precursor 528 and 531 by Toshima and co-workers. ${ }^{246}$
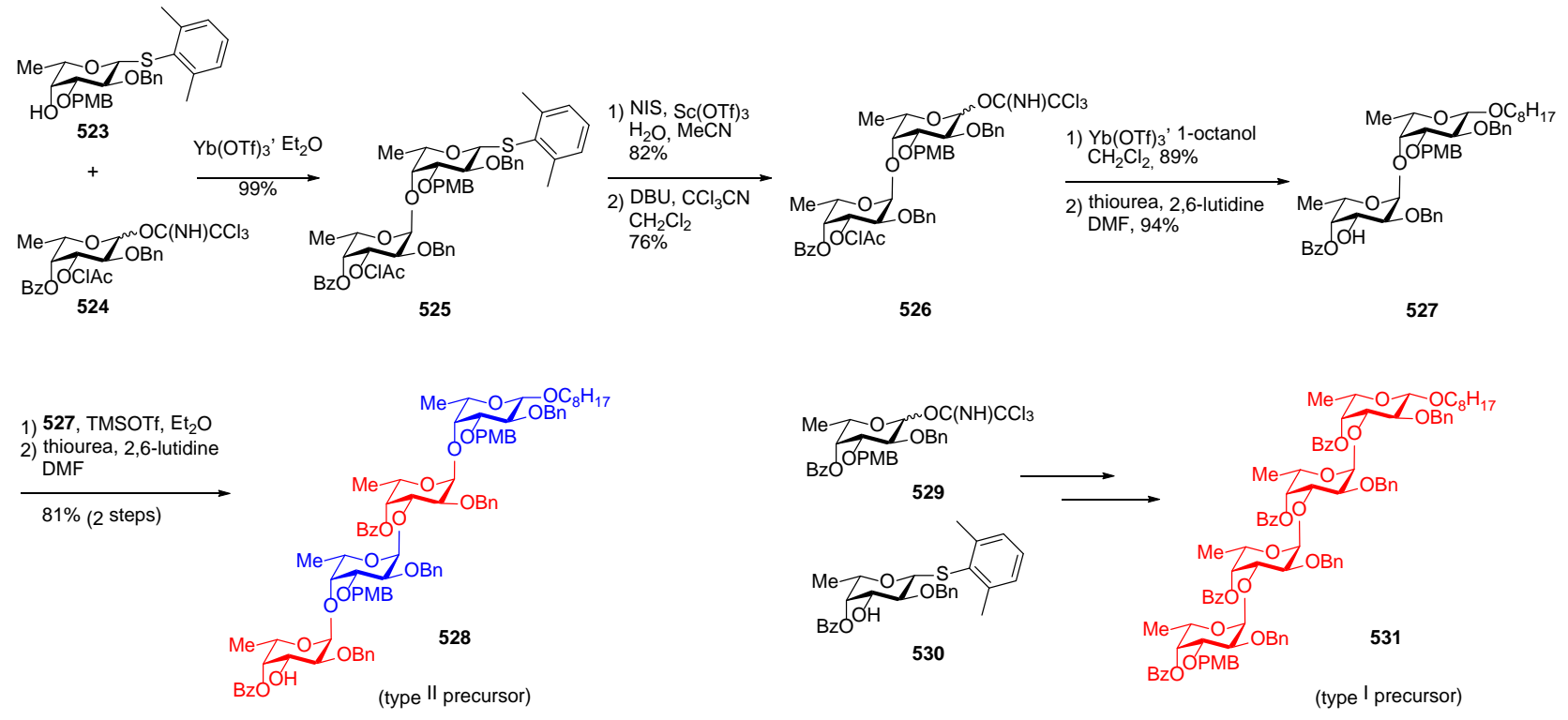

Chemoselective glycosylation of 523 with 524, promoted by $\mathrm{Yb}(\mathrm{OTf})_{3}$, provided the desired $\alpha$ $(1 \rightarrow 4)$-linked disaccharide 525 with very good stereoselectivity. The latter could be converted into a trichloroacetimidate donor 526 and a new disaccharide acceptor 527 in two steps. Condensation of 527 with 1-octanol using $\mathrm{Yb}(\mathrm{OTf})_{3}$ afforded the corresponding octyl fucoside with surprisingly high $\beta$-stereoselectivity. TMSOTf-promoted coupling of the two difucosides, followed by deprotection of the ClAc group provided the key intermediate 528 as a single isomer in $81 \%$ yield over two steps. For the five type II fucoidan targets, the deprotection and sulfation steps are presented in Scheme 57. 
Scheme 57. Deprotection and sulfation of 528 to afford five type II tetrafucoidans 532-536. ${ }^{246}$

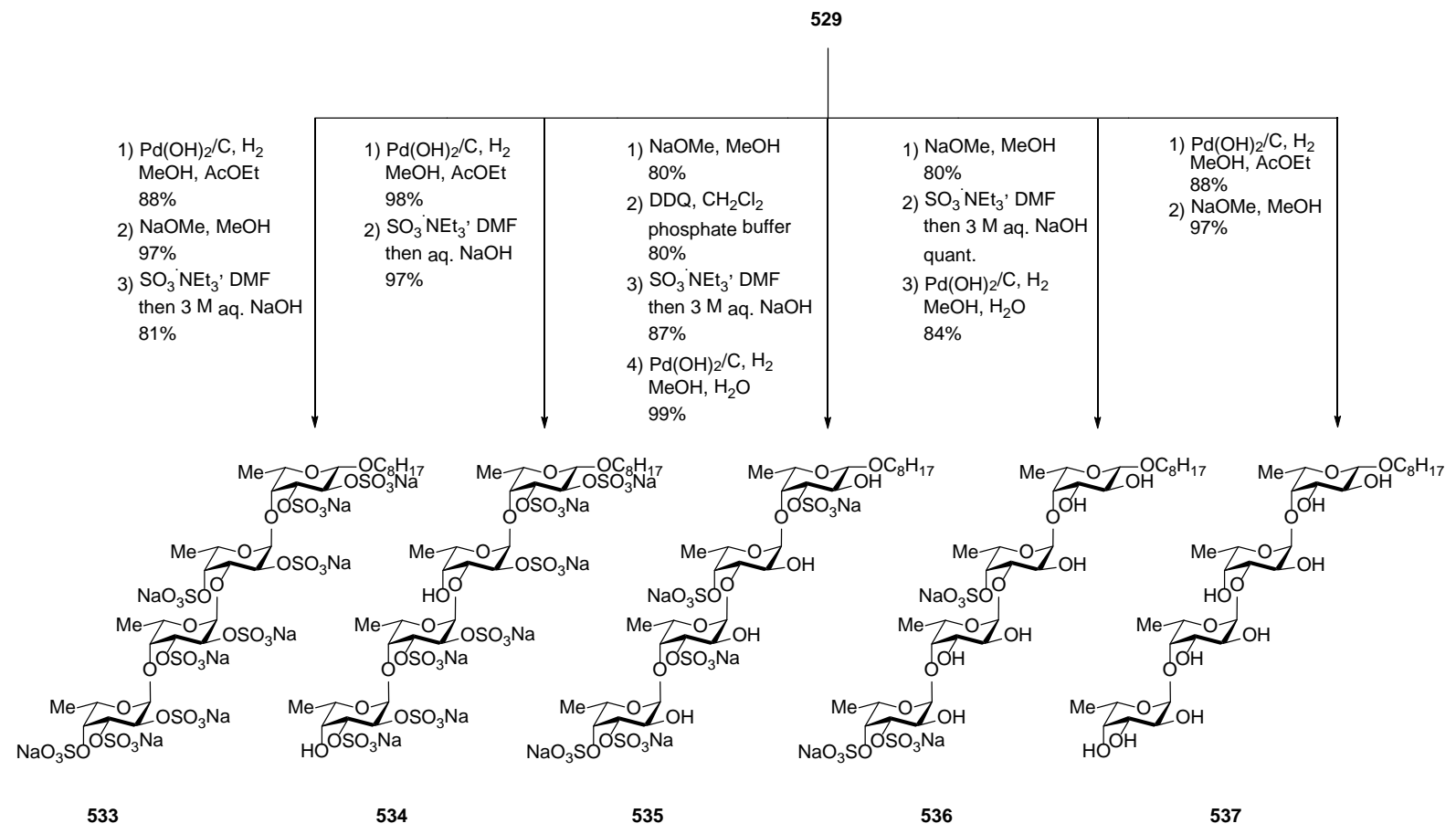

A recent discovery showed that the fucoidan from the brown seaweed Chordaria flagelliformis contains an $\alpha$-(1 $\rightarrow 3)$-linked polyfucopyranoside backbone with one third of the fucopyranosyl residues bearing $\alpha$-(1 $\rightarrow 2)$-linked D-glucuronic acid substituents, and with half of the uronic acids carrying $\alpha$-( $1 \rightarrow 4)$-L-fucofuranosides. ${ }^{252}$ In 2016, Nifantiev and co-workers achieved the synthesis of a selectively $O$-sulfated branched pentasaccharide of this type (548) as shown in Scheme $58 .^{242}$ 
Scheme 58. Synthesis of two branched type I fucoidan pentasaccharides by Nifantiev and coworkers. ${ }^{242}$
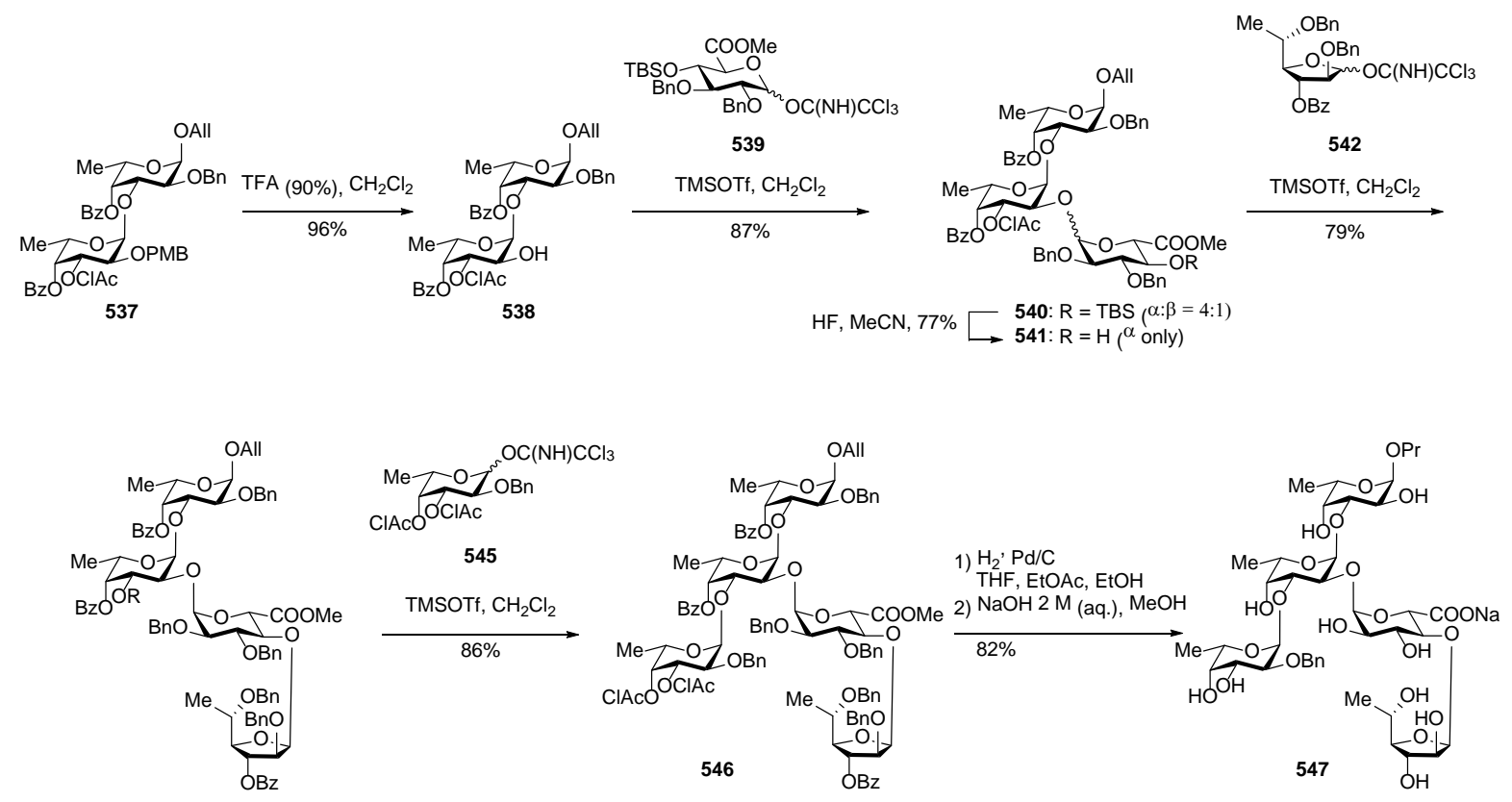

thiourea, $\mathrm{MeOH}, 80 \% \square$ 543: $\mathrm{R}=\mathrm{ClAC}$

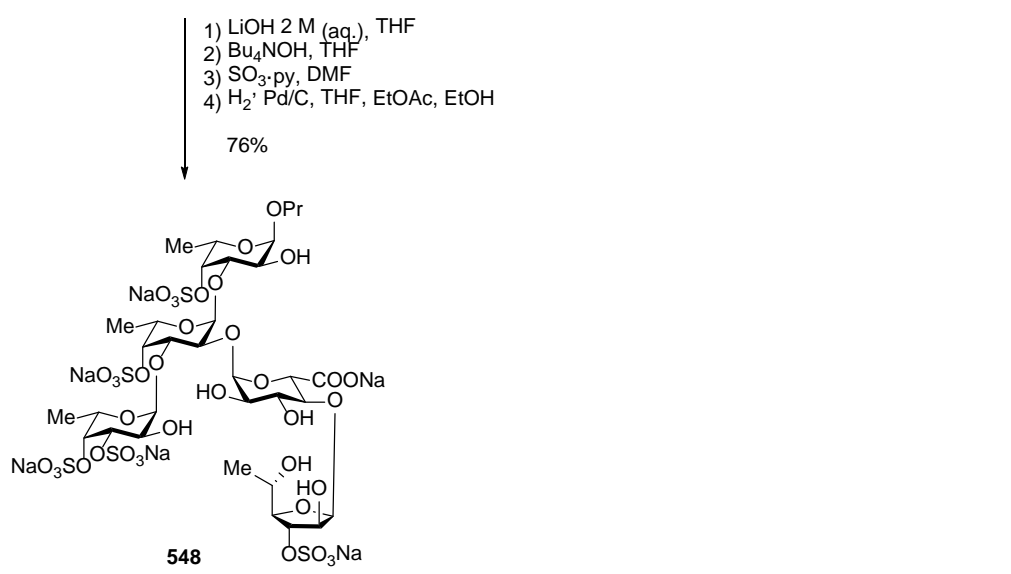

The assembly of both pentasaccharide targets 547 and 548 started with glycosylation between difucopyranoside acceptor 538 and glucuronate donor 539, affording the trisaccharide 540 as a 4:1 $\alpha$ : $\beta$-mixture. The pure $\alpha$-isomer 540 could be isolated after removal of the TBS group. This acceptor was then glycosylated with fucofuranosyl donor 542 to give a mixture of $\alpha$ - and $\beta$-linked tetrasaccharides in a ratio of 10:1. The desired $\alpha$-anomer (isolated in 79\% yield) was deprotected and 
subsequently coupled with fucopyranoside donor 545, giving the core pentasaccharide 546 in $86 \%$ yield. The target $\mathbf{5 4 7}$ was obtained after removal of all protecting groups. Alternatively, saponification of 546, followed by $O$-sulfation and hydrogenolysis afforded the partially sulfated target 548 .

\subsection{Ulvans}

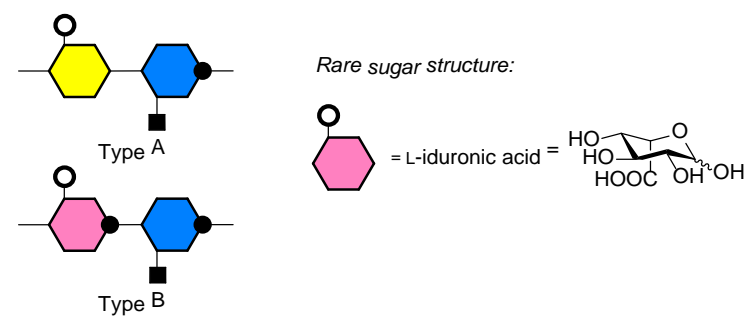

Figure 33. The two major types of disaccharide repeating units in ulvans.

Ulvans are water-soluble sulfated heteropolysaccharides, which have been extracted from the cell walls of green marine algae. They represent between 8 and $29 \%$ of the dry weight of the cell wall. ${ }^{253,254}$ A review dealing with the structure and functional properties of ulvans was written by Lahaye and Robic in 2007. ${ }^{254}$ The determination of the sugar sequences in ulvans represents a big challenge since the polysaccharide composition varies widely and is dependent on algal source and ecophysiological variation. ${ }^{254}$ However, acid hydrolysis and / or enzymatic degradation of cell walls from different green seaweeds has shown the presence of L-rhamnose, L-xylose, D-glucuronic and L-iduronic acid. These sugars are mostly distributed in disaccharide repeating units. Among these, the two most frequent are ulvanobiuronic acid 3-sulfate Type A ( $\beta$-D-GlcpA-( $1 \rightarrow 4)-\alpha$-L-Rhap3S-( $1 \rightarrow 4)$ ) and Type B ( $\alpha$-L-IdopA-(1 $\rightarrow 4)-\alpha$-L-Rhap3S-( $1 \rightarrow 4))$, represented in Figure 33. Other less frequently occurring units containing glucuronic acid on $O-2$ of rhamnose 3 -sulfate or partially sulfated xylose replacing 
the uronic acid have been found. ${ }^{255}$ No chemical synthesis of this type of oligosaccharide has been undertaken to date.

\section{Conclusion}

Plant cell wall polysaccharides include some of the most complex macromolecules found in nature. For this reason, synthetic chemists have focused their attention on synthesizing well-defined oligosaccharide fragments, as set out in this review. Not only are these targets extremely valuable in studying protein-carbohydrate interactions, but they also help advance the development of new methodologies in carbohydrate chemistry. Interest in this area is increasing, as witnessed by the many contributions over the past twenty years. The more recent progress in automated synthesis holds particular promise, as it is well suited to producing libraries of closely-related fragments of larger polysaccharides. There is clearly no lack of unexplored structures to serve as inspiration for synthetic chemists, especially within the marine polysaccharides. As this review makes clear, there is no consensus as to the types of aglycone chosen for the targets: everything from reducing sugars over simple alkyl groups to linkers predisposed to immobilization and / or conjugation is represented in the review. More homogeneity in this choice, along with the establishment of a central repository for synthetic oligosaccharides, represent areas, where we believe there is room for benefiting future research. Nonetheless, we remain convinced that synthetic glycans will continue to provide breakthroughs in the understanding of plant cell wall biology and physiology.

\section{Author Information}




\section{Corresponding Author}

E-mail: mhc@kemi.dtu.dk

ORCID

Mads H. Clausen: 0000-0001-9649-1729

Notes

The authors declare no competing financial interest.

\section{Biographies}

Christine Kinnaert graduated from the Ecole Nationale des Industries Chimiques. Her thesis research was carried out at Glaxo Smith-Kline and encompassed conformational analysis of polysaccharides. She obtained her Ph. D. from the group of Prof. Mads H. Clausen at the Technical University of Denmark in 2017. The subject of her thesis research was chemical synthesis of oligosaccharides related to algal cell wall glycans. Christine is currently pursuing postdoctoral research at DTU.

Mathilde Daugaard obtained her M. Sc. (2011) and Ph. D. (2016) from the Technical University of Denmark under the supervision of Prof. Thomas E. Nielsen and Prof. Mads H. Clausen, respectively. The Ph. D. thesis research involved carbohydrate synthesis, more specifically preparation of $\alpha$-Larabinans from rhamnogalacturonan I. She is currently employed by the Danish biopharmaceutical company Nuevolution.

Faranak Nami obtained her M. Sc. in 2012 from Aarhus University under the supervision of Associate Professor Henrik H. Jensen. The work centered on the synthesis of ibogaine analogues inducing an 
inward conformation of the human serotonin transporter. Her Ph. D. was obtained in 2016 from the Technical University of Denmark under the supervision of Professor Mads H. Clausen. Faranak worked on oligosaccharide synthesis with the aim of carrying out enzymatic studies.

Mads H. Clausen obtained his Ph.D. from the Technical University of Denmark in 2002 under the supervision of Prof. Robert Madsen. He was a postdoctoral fellow at Harvard University from 20022004 in the group of Prof. Andrew G. Myers, where he worked on total synthesis of enediyne antibiotics. In 2004, he started his independent career at the Department of Chemistry, Technical University of Denmark, where he has been Professor of Chemical Biology since 2014. His research interests center on chemical biology and bioorganic chemistry and include medicinal chemistry, oligosaccharide and lipid synthesis and developing methods for library synthesis.

\section{Acknowledgments}

We are highly grateful to Ms. Adeline Berger and Dr. Helen North for providing the image used for Figure 3. We acknowledge financial support from the Danish Council for Independent Research "A biology-driven approach for understanding enzymatic degradation of complex polysaccharide systems” (Grant Case no.: 107279), the Carlsberg Foundation, the Danish Strategic Research Council (GlycAct and SET4Future projects), the Villum Foundation (PLANET project) and the Novo Nordisk Foundation (Biotechnology-based Synthesis and Production Research). 


\section{$\underline{\text { References }}$}

(1) Ivakov, A.; Persson, S. Plant Cell Walls. In eLS; John Wiley \& Sons: Chichester, 2012.

(2) Keegstra, K. Plant Cell Walls. Plant Physiol. 2010, 154, 483-486.

(3) Whitney, S. E. C.; Gothard, M. G. E.; Mitchell, J. T.; Gidley, M. J. Roles of Cellulose and Xyloglucan in Determining the Mechanical Properties of Primary Plant Cell Walls. Plant Physiol. 1999, 121, 657-664.

(4) Scheller, H. V.; Ulvskov, P. Hemicelluloses. Annu. Rev. Plant Biol. 2010, 61, 263-289.

(5) Gillis, P. P.; Mark, R. E.; Tang, R. C. Elastic Stiffness of Crystalline Cellulose in the FoldedChain Solid State. J. Mater. Sci. 1969, 4, 1003-1007.

(6) Caffall, K. H.; Mohnen, D. The Structure, Function, and Biosynthesis of Plant Cell Wall Pectic Polysaccharides. Carbohydr. Res. 2009, 344, 1879-1900.

(7) Zykwinska, A.; Thibault, J. F.; Ralet, M. C. Competitive Binding of Pectin and Xyloglucan with Primary Cell Wall Cellulose. Carbohydr. Polym. 2008, 74, 957-961.

(8) Zykwinska, A. W.; Ralet, M. J.; Garnier, C. D.; Thibault, J. J. Evidence for in Vitro Binding of Pectin Side Chains to Cellulose. Plant Physiol. 2005, 139, 397-407.

(9) Popper, Z. A.; Fry, S. C. Widespread Occurrence of a Covalent Linkage between Xyloglucan and Acidic Polysaccharides in Suspension-Cultured Angiosperm Cells. Ann. Bot. 2005, 96, 9199.

(10) Ellis, M.; Egelund, J.; Schultz, C. J.; Bacic, A. Arabinogalactan-Proteins (AGPs): Key Regulators at the Cell Surface. Plant Physiol. 2010, 153, 403-419.

(11) Jamet, E.; Albenne, C.; Boudart, G.; Irshad, M.; Canut, H.; Pont-Lezica, R. Recent Advances in Plant Cell Wall Proteomics. Proteomics 2008, 8, 893-908. 
(12) Lee, S. J.; Saravanan, R. S.; Damasceno, C. M. B.; Yamane, H.; Kim, B. D.; Rose, J. K. C. Digging Deeper into the Plant Cell Wall Proteome. Plant Physiol. Biochem. 2004, 42, 979988.

(13) Doblin, M. S.; Pettolino, F.; Bacic, A. Evans Review: Plant Cell Walls: The Skeleton of the Plant World. Funct. Plant Biol. 2010, 37, 357-381.

(14) Fry, S. C. Plant Cell Walls. In eLS; John Wiley \& Sons, Ltd, 2001; pp 1-11.

(15) Burton, R. A.; Gidley, M. J.; Fincher, G. B. Heterogeneity in the Chemistry, Structure and Function of Plant Cell Walls. Nat. Chem. Biol. 2010, 6, 724-732.

(16) Sørensen, I.; Domozych, D.; Willats, W. G. T. How Have Plant Cell Walls Evolved? Plant Physiol. 2010, 153, 366-372.

(17) Kenrick, P.; Crane, P. R. The Origin and Early Evolution of Plants on Land. Nature 1997, 389, 33-39.

(18) Becker, B.; Marin, B. Streptophyte Algae and the Origin of Embryophytes. Ann. Bot. 2009, 103, 999-1004.

(19) Michel, G.; Tonon, T.; Scornet, D.; Cock, J. M.; Kloareg, B. The Cell Wall Polysaccharide Metabolism of the Brown Alga Ectocarpus Siliculosus. Insights into the Evolution of Extracellular Matrix Polysaccharides in Eukaryotes. New Phytol. 2010, 188, 82-97.

(20) Popper, Z. A.; Tuohy, M. G. Beyond the Green: Understanding the Evolutionary Puzzle of Plant and Algal Cell Walls. Plant Physiol. 2010, 153, 373-383.

(21) Popper, Z. A. Evolution and Diversity of Green Plant Cell Walls. Curr. Opin. Plant Biol. 2008, 11, 286-292.

(22) Popper, Z. A.; Michel, G.; Herve, C.; Domozych, D. S.; Willats, W. G.; Tuohy, M. G.; Kloareg, B.; Stengel, D. B. Evolution and Diversity of Plant Cell Walls: From Algae to Flowering Plants. 
Annu. Rev. Plant Biol. 2011, 62, 567-590.

(23) Popper, Z. A.; Ralet, M. C.; Domozych, D. S. Plant and Algal Cell Walls: Diversity and Functionality. Ann. Bot. 2014, 114, 1043-1048.

(24) Fangel, J. U.; Ulvskov, P.; Knox, J. P.; Mikkelsen, M. D.; Harholt, J.; Popper, Z. A.; Willats, W. G. T. Cell Wall Evolution and Diversity. Front. Plant Sci. 2012, 3, 1-8.

(25) Tolonen, L. K.; Juvonen, M.; Niemelä, K.; Mikkelson, A.; Tenkanen, M.; Sixta, H. Supercritical Water Treatment for Cello-Oligosaccharide Production from Microcrystalline Cellulose. Carbohydr. Res. 2015, 401, 16-23.

(26) Takeo, K.; Yasato, T.; Kuge, T. Synthesis of $\alpha$ - and $\beta$-Cellotriose Hendecaacetates and of Several 6,6',6"'-tri-Substituted Derivatives of Methyl $\beta$-Cellotrioside. Carbohydr. Res. 1981, 93, 148-156.

(27) Takeo, K.; Okushio, K.; Fukuyama, K.; Kuge, T. Synthesis of Cellobiose, Cellotriose, Cellotetraose and Lactose. Carbohydr. Res. 1983, 121, 163-173.

(28) Rodriguez, E.; Stick, R. The Synthesis of Active-Site Directed Inhibitors of Some $\beta$-Glucan Hydrolases. Aust. J. Chem. 1990, 43, 665-679.

(29) Xu, J.; Vasella, A. Oligosaccharide Analogues of Polysaccharides. Helv. Chim. Acta 1999, 82, $1728-1752$.

(30) Chang, S.; Han, J.; Tseng, S. Y.; Lee, H.; Lin, C.; Lin, Y.; Jeng, W.; Wang, A. H.; Wu, C.; Wong, C. Glycan Array on Aluminum Oxide-Coated Glass Slides through Phosphonate Chemistry. J. Am. Chem. Soc. 2010, 132, 13371-13380.

(31) Dallabernardina, P.; Schuhmacher, F.; Seeberger, P. H.; Pfrengle, F. Automated Glycan Assembly of Xyloglucan Oligosaccharides. Org. Biomol. Chem. 2016, 14, 309-313.

(32) Sugawara, F.; Nakayama, H.; Ogawa, T. Synthetic Studies on Rhynchosporoside: 
Stereoselective Synthesis of 1-O- and 2-O-Cellotriosyl-3-Deoxy-2(R)-and -2(S)-Glycerol. Carbohydr. Res. 1983, 123, C25-C28.

(33) Nicolaou, K. C.; Randall, J. L.; Furst, G. T. Stereospecific Synthesis of Rhynchosporosides, a Family of Fungal Metabolites Causing Scald Disease in Barley and Other Grasses. J. Am. Chem. Soc. 1985, 107, 5556-5558.

(34) Sugawara, F.; Nakayama, H.; Strobel, G. A.; Ogawa, T. Stereoselective Synthesis of 1- and 2O- $\alpha$-D-Cellotriosyl-3-Deoxy-2(R)- and 2(S)-Glycerols Related to Rhynchosporoside. Agric. Biol. Chem. 1986, 50, 2261-2271.

(35) Nishimura, T.; Nakatsubo, F. First Synthesis of Cellooctaose by a Convergent Synthetic Method. Carbohydr. Res. 1996, 294, 53-64.

(36) Koenigs, W.; Knorr, E. Über Einige Derivate Des Traubensuckers Und Der Galactose. Berichte der Dtsch. Chem. Gesellschaft 1901, 34, 957-981.

(37) Zemplén, G.; Pacsu, E. Über Die Verseifung Acetylierter Zucker Und Verwandter Substanzen. Berichte der Dtsch. Chem. Gesellschaft 1929, 62, 1613-1614.

(38) Nishimura, T.; Nakatsubo, F.; Murakami, K. Synthetic Studies of Cellulose XI. High Yield Synthesis of Cellotetraose Derivative by Convergent Synthetic Method from an Acyl Glucose Derivative. Mouzai Gakkaishi 1994, 40, 44-49.

(39) Schmidt, R. R.; Michel, J. Facile Synthesis of $\alpha$ - and $\beta$-O-Glycosyl Imidates; Preparation of Glycosides and Disaccharides. Angew. Chem. Int. Ed. 1980, 19, 731-732.

(40) Kariyone, K.; Yazawa, H. Oxidative Cleavage of B, $\gamma$-Unsaturated Ether. Tetrahedron Lett. 1970, 33, 2885-2888.

(41) Schultze, E. Zur Kenntniss Der Chemischen Zuzammensetzung Der Pflanzlichen Zellmembranen. Ber. Dtsch. Chem. Ges. 1891, 24, 2277-2287. 
(42) Ebringerová, A.; Hromádková, Z.; Heinze, T. Hemicellulose. In Polysaccharides I; SpringerVerlag: Berlin, 2005; Vol. 186, pp 1-67.

(43) Wotovic, A.; Jacquinet, J. C.; Sinaÿ, P. Synthesis of Oligosaccharins: A Chemical Synthesis of Propyl O- $\beta$-D-Galactopyranosyl-(1,2)-O- $\alpha$-D-Xylopyranosyl-(1,6)-O- $\beta$-D-Glucopyranosyl(1,4)-3-D-Glucopyranoside. Carbohydr. Res. 1990, 205, 235-245.

(44) Sakai, K.; Nakahara, Y.; Ogawa, T. Total Synthesis of Nonasaccharide Repeating Unit of Plant Cell Wall Xyloglucan: An Endogenous Hormone Which Regulates Cell Growth. Tetrahedron Lett. 1990, 31, 3035-3038.

(45) Watt, D. K.; Brasch, D. J.; Larsen, D. S.; Melton, L. D.; Simpson, J. Oligosaccharides Related to Xyloglucan: Synthesis and X-Ray Crystal Structure of Methyl $\alpha$-L- Fucopyranosyl-(1 $\rightarrow 2)$ -

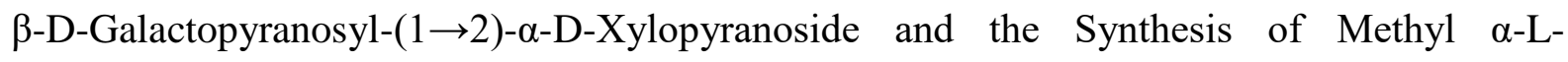
Fucopyranosyl-( $(1 \rightarrow 2)-\beta$-D-Galactopyranosyl-( $1 \rightarrow 2)-\beta$-D-Xylopyranosid. Carbohydr. Res. 2000, 325, 300-312.

(46) Merrifield, R. B. Solid Phase Peptide Synthesis. I. The Synthesis of a Tetrapeptide. J. Am. Chem. Soc. 1963, 85, 2149-2154.

(47) Eller, S.; Collot, M.; Yin, J.; Hahm, H. S.; Seeberger, P. H. Automated Solid-Phase Synthesis of Chondroitin Sulfate Glycosaminoglycans. Angew. Chemie Int. Ed. 2013, 52, 5858-5861.

(48) Plante, O. J.; Andrade, R. B.; Seeberger, P. H. Synthesis and Use of Glycosyl Phosphates as Glycosyl Donors. Org. Lett. 1999, 1, 211-214.

(49) Manners, D. J.; Masson, A. J.; Patterson, J. C. The Structure of a $\beta$-(1 $\rightarrow 3)$-D-Glucan from Yeast Cell Walls. Biochem. J. 1973, 135, 19-30.

(50) Scherp, P.; Grotha, R.; Kutschera, U. Occurrence and Phylogenetic Significance of Cytokinesis-Related Callose in Green Algae, Bryophytes, Ferns and Seed Plants. Plant Cell 
Rep. 2001, 20, 143-149.

(51) Ellinger, D.; Voigt, C. A. Callose Biosynthesis in Arabidopsis with a Focus on Pathogen Response: What We Have Learned within the Last Decade. Ann. Bot. 2014, 114, 1349-1358.

(52) Tanaka, H.; Kawai, T.; Adachi, Y.; Hanashima, S.; Yamaguchi, Y.; Ohno, N.; Takahashi, T.

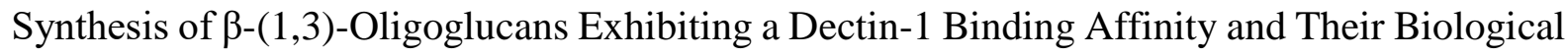
Evaluation. Bioorg. Med. Chem. 2012, 20, 3898-3914.

(53) Takeo, K.; Maki, K.; Wada, Y.; Kitamura, S. Synthesis of the Laminara-Oligosaccharide Methyl $\beta$-Glycosides of Dp 3-8. Carbohydr. Res. 1993, 245, 81-96.

(54) Adamo, R.; Tontini, M.; Brogioni, G.; Romano, M. R.; Costantini, G.; Danieli, E.; Proietti, D.; Berti, F.; Costantino, P. Synthesis of Laminarin Fragments and Evaluation of a $\beta-(1 \rightarrow 3)$ Glucan Hexasaccaride-CRM 197 Conjugate as Vaccine Candidate against Candida Albicans. J. Carbohydr. Chem. 2011, 30, 249-280.

(55) Jamois, F.; Ferrières, V.; Guégan, J. P.; Yvin, J. C.; Plusquellec, D.; Vetvicka, V. Glucan-like Synthetic Oligosaccharides: Iterative Synthesis of Linear Oligo- $\beta-(1,3)-G l u c a n s$ and Immunostimulatory Effects. Glycobiology 2005, 15, 393-407.

(56) de Jong, A. R.; Volbeda, A. G.; Hagen, B.; van den Elst, H.; Overkleeft, H. S.; van der Marel, G. A.; Codée, J. D. C. A Second-Generation Tandem Ring-Closing Metathesis Cleavable Linker for Solid-Phase Oligosaccharide Synthesis. Eur. J. Org. Chem. 2013, 29, 6644-6655.

(57) Zeng, Y.; Kong, F. Synthesis of $\beta$-D-Glucose Oligosaccharides from Phytophthora Parasitica. Carbohydr. Res. 2003, 338, 2359-2366.

(58) Huang, G.; Mei, X.; Liu, M. Synthesis of (R)-2,3-epoxypropyl( $1 \rightarrow 3)-\beta$-D-Pentaglucoside. Carbohydr. Res. 2005, 340, 603-608.

(59) Yashunsky, D. V.; Tsvetkov, Y. E.; Nifantiev, N. E. Synthesis of 3-Aminopropyl Glycoside of 


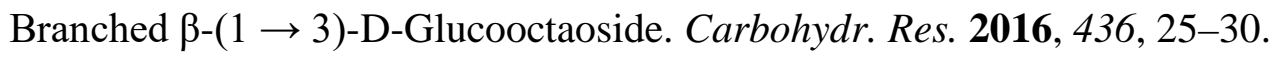

(60) Mo, K.; Li, H.; Mague, J. T.; Ensley, H. E. Synthesis of the $\beta-1,3-G l u c a n$, Laminarahexaose: NMR and Conformational Studies. Carbohydr. Res. 2009, 344, 439-447.

(61) Elsaidi, H. R. H.; Paszkiewicz, E.; Bundle, D. R. Synthesis of a 1,3 $\beta$-Glucan Hexasaccharide Designed to Target Vaccines to the Dendritic Cell Receptor, Dectin-1. Carbohydr. Res. 2015, 408, 96-106.

(62) Liao, G.; Zhou, Z.; Burgula, S.; Liao, J.; Yuan, C.; Wu, Q.; Guo, Z. Synthesis and Immunological Studies of Linear Oligosaccharides of $\beta$-Glucan As Antigens for Antifungal Vaccine Development. Bioconjug. Chem. 2015, 26, 466-476.

(63) Tanaka, H.; Kawai, T.; Adachi, Y.; Ohno, N.; Takahashi, T. $\beta(1,3)$ Branched Heptadeca- and Linear Hexadecasaccharides Possessing an Aminoalkyl Group as a Strong Ligand to Dectin-1. Chem. Commun. 2010, 46, 8249-8251.

(64) Liao, G.; Burgula, S.; Zhou, Z.; Guo, Z. A Convergent Synthesis of 6- O -Branched $\beta$-Glucan Oligosaccharides. Eur. J. Org. Chem. 2015, 2942-2951.

(65) Weishaupt, M. W.; Hahm, H. S.; Geissner, A.; Seeberger, P. H. Automated Glycan Assembly of Branched $\beta-(1 \rightarrow 3)$-Glucans to Identify Antibody Epitopes. Chem. Commun. 2017, 53, 3591-3594.

(66) Weishaupt, M. W.; Matthies, S.; Seeberger, P. H. Automated Solid-Phase Synthesis of a $\beta$ (1,3)-Glucan Dodecasaccharide. Chem. Eur. J. 2013, 19, 12497-12503.

(67) Popper, Z. A.; Fry, S. C. Primary Cell Wall Composition of Bryophytes and Charophytes. Ann. Bot. 2003, 91, 1-12.

(68) Sørensen, I.; Pettolino, F. A.; Wilson, S. M.; Doblin, M. S.; Johansen, B.; Bacic, A.; Willats, W. G. T. Mixed-Linkage $(1 \rightarrow 3),(1 \rightarrow 4)-\beta$-D-Glucan Is Not Unique to the Poales and Is an 
Abundant Component of Equisetum Arvense Cell Walls. Plant J. 2008, 54, 510-521.

(69) Dallabernardina, P.; Schuhmacher, F.; Seeberger, P. H.; Pfrengle, F. Mixed-Linkage Glucan Oligosaccharides Produced by Automated Glycan Assembly Serve as Tools To Determine the Substrate Specificity of Lichenase. Chem. A Eur. J. 2017, 23, 1-7.

(70) Simmons, T. J.; Mortimer, J. C.; Bernardinelli, O. D.; Pöppler, A.-C.; Brown, S. P.; DeAzevedo, E. R.; Dupree, R.; Dupree, P. Folding of Xylan onto Cellulose Fibrils in Plant Cell Walls Revealed by Solid-State NMR. Nat. Commun. 2016, 7, 1-9.

(71) Rennie, E. A.; Scheller, H. V. Xylan Biosynthesis. Curr. Opin. Biotechnol. 2014, 26, 100-107.

(72) Faik, A. Xylan Biosynthesis: News from the Grass. Plant Physiol. 2010, 153, 396-402.

(73) Balakshin, M.; Capanema, E.; Berlin, A. Isolation and Analysis of Lignin-Carbohydrate Complexes Preparations with Traditional and Advanced Methods: A Review. In Studies in Natural Products Chemistry; Atta-ur-Rahman, Ed.; Elsevier B.V., 2014; Vol. 42, pp 83-115.

(74) Hirsch, J.; Kováč, P.; Petráková, E. An Approach to the Systematic Synthesis of (1 $\rightarrow 4)-\beta-D-$ Xylo-Oligosaccharides. Carbohydr. Res. 1982, 106, 203-216.

(75) Kováč, P.; Hirsch, J. Systematic, Sequential Synthesis of (1 $\rightarrow 4)-\beta$-D-Xylo-Ligosaccharides and Their Methyl $\beta$-Glycosides. Carbohydr. Res. 1981, 90, C5-C7.

(76) Takeo, K.; Ohguchi, Y.; Hasegawa, R.; Kitamura, S. Synthesis of $(1 \rightarrow 4)-\beta$-D-XyloOligosaccharides of Dp 4-10 by a Blockwise Approach. Carbohydr. Res. 1995, 278, 301-313.

(77) Schmidt, D.; Schuhmacher, F.; Geissner, A.; Seeberger, P. H.; Pfrengle, F. Automated Synthesis of Arabinoxylan-Oligosaccharides Enables Characterization of Antibodies That Recognize Plant Cell Wall Glycans. Chem. Eur. J. 2015, 21, 5709-5713.

(78) Oscarson, S.; Svahnberg, P. Synthesis of Uronic Acid-Containing Xylans Found in Wood and Pulp. J. Chem. Soc. Perkin Trans. 1 2001, 100, 873-879. 
(79) Kováč, P.; Hirsch, J.; Kováčik, V.; Kočiš, P. The Stepwise Synthesis of an Aldopentaouronic Acid Derivative Related to Branched (4-O-Methylglucurono)xylans. Carbohydr. Res. 1980, 85, 41-49.

(80) Senf, D.; Ruprecht, C.; de Kruijff, G. H. M.; Simonetti, S. O.; Schuhmacher, F.; Seeberger, P. H.; Pfrengle, F. Active Site Mapping of Xylan-Deconstructing Enzymes with Arabinoxylan Oligosaccharides Produced by Automated Glycan Assembly. Chem. - A Eur. J. 2017, 23, 31973205.

(81) Helferich, B.; Schmitz-Hillebrecht, E. Eine Neue Methode Zur Synthese von Glykosiden Der Phenole. Ber. Dtsch. Chem. Ges. 1933, 66, 378-383.

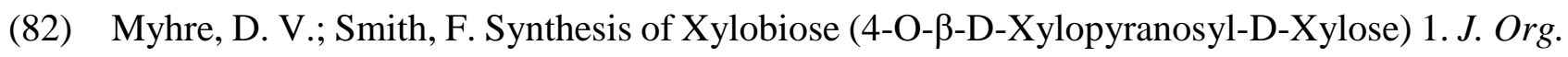
Chem. 1961, 26, 4609-4612.

(83) Kováč, P.; Hirsch, J. Sequential Synthesis and 13C-N.M.R. Spectra of Methyl $\beta$-Glycosides of

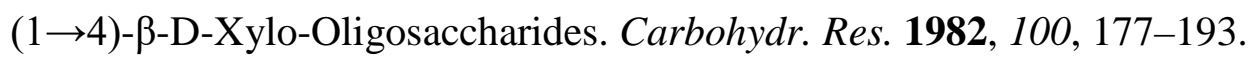

(84) Fürst, A.; Plattner, P. A. 2- $\alpha$-, 3- $\alpha$ - Und 2-B, 3- $\beta$-Oxido-Chlolestane; Konfiguration Der 2-OxyCholestane. Helv. Chim. Acta 1949, 32, 275-283.

(85) Moreira, L. R. S.; Filho, E. X. F. An Overview of Mannan Structure and Mannan-Degrading Enzyme Systems. Appl. Microbiol. Biotechnol. 2008, 79, 165-178.

(86) Gridley, J. J.; Osborn, H. M. I. Recent Advances in the Construction of $\beta$-D-Mannose and $\beta$ D-Mannosamine Linkages. J. Chem. Soc. Perkin Trans. 1 2000, 10, 1471-1491.

(87) Lichtenthaler, F. W. 2-Oxoglycosyl (“Ulosyl”) and 2-Oximinoglycosyl Bromides: Versatile Donors for the Expedient Assembly of Oligosaccharides with $\beta$ - D-Mannose, $\beta$ - L-Rhamnose, N-Acetyl- $\beta$ - D-Mannosamine, and N-Acetyl- $\beta$-D-Mannosaminuronic Acid Units. Chem. Rev. 2011, 111, 5569-5609. 
(88) Twaddle, G. W. J.; Yashunsky, D. V; Nikolaev, A. V. The Chemical Synthesis of $\beta-(1 \rightarrow 4)-$ Linked D-Mannobiose and D-Mannotriose. Org. Biomol. Chem 2003, 1, 623-628.

(89) Kim, K. S.; Fulse, D. B.; Baek, J. Y.; Lee, B.-Y.; Jeon, H. B. Stereoselective Direct Glycosylation with Anomeric Hydroxy Sugars by Activation with Phthalic Anhydride and Trifluoromethanesulfonic Anhydride Involving Glycosyl Phthalate Intermediates. J. Am. Chem. Soc. 2008, 130, 8537-8547.

(90) Crich, D.; Banerjee, A.; Yao, Q. Direct Chemical Synthesis of the $\beta$-D-Mannans: The $\beta-(1 \rightarrow 2)$ and $\beta-(1 \rightarrow 4)$ Series. J. Am. Chem. Soc. 2004, 126, 14930-14934.

(91) Ohara, K.; Lin, C.-C.; Yang, P.-J.; Hung, W.-T.; Yang, W.-B.; Cheng, T. J. R.; Fang, J.-M.; Wong, C.-H. Synthesis and Bioactivity of $\beta-(1 \rightarrow 4)$-Linked Oligomannoses and Partially Acetylated Derivatives. J. Org. Chem. 2013, 78, 6390-6411.

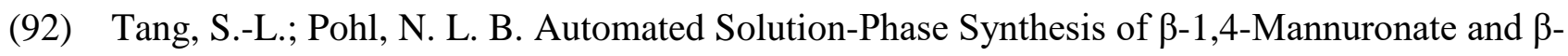
1,4-Mannan. Org. Lett. 2015, 17, 2642-2645.

(93) Ekholm, F. S.; Ardá, A.; Eklund, P.; André, S.; Gabius, H.-J.; Jiménez-Barbero, J.; Leino, R. Studies Related to Norway Spruce Galactoglucomannans: Chemical Synthesis, Conformation Analysis, NMR Spectroscopic Characterization, and Molecular Recognition of Model Compounds. Chem. Eur. J. 2012, 18, 14392-14405.

(94) Imamura, A.; Ando, H.; Korogi, S.; Tanabe, G.; Muraoka, O.; Ishida, H.; Kiso, M. Di-TertButylsilylene (DTBS) Group-Directed $\alpha$-Selective Galactosylation Unaffected by C-2 Participating Functionalities. Tetrahedron Lett. 2003, 44, 6725-6728.

(95) Vauquelin, M. Analyse Du Tamarin. Ann. Chim. 1790, 5, 92-106.

(96) Braconnot, H. Recherche Sur Un Nouvel Acid Universellement Répandu Dans Tous Les Végétaux. Ann. Chim. Phys. 1825, 2, 173-178. 
(97) Mohnen, D. Pectin Structure and Biosynthesis. Curr. Opin. Plant Biol. 2008, 11, 266-277.

(98) Ridley, B. L.; O’Neill, M. A.; Mohnen, D. Pectins: Structure, Biosynthesis, and Oligogalacturonide-Related Signaling. Phytochemistry 2001, 57, 929-967.

(99) Yapo, B. M. Pectic Substances: From Simple Pectic Polysaccharides to Complex Pectins-A New Hypothetical Model. Carbohydr. Polym. 2011, 86, 373-385.

(100) Neill, M. A. O.; Ishii, T.; Albersheim, P.; Darvill, A. G. Rhamnogalacturonan II : Structure and Function of a Borate Cross-Linked Cell. Annu. Rev. Plant Biol. 2004, 55, 109-139.

(101) Nepogodiev, S. A.; Field, R. A.; Damager, I. Chapter 3:Approaches to Chemical Synthesis of Pectic Oligosaccharides. In Annual Plant Reviews, Volume 41: Plant Polysaccharides, Biosynthesis and Bioengineering; Ulvskov, P., Ed.; Blackwell Publishing Ltd: West Sussex, United Kingdom, 2011; Vol. 41, pp 65-92.

(102) Yapo, B. M.; Lerouge, P.; Thibault, J. F.; Ralet, M. C. Pectins from Citrus Peel Cell Walls Contain Homogalacturonans Homogenous with Respect to Molar Mass, Rhamnogalacturonan I and Rhamnogalacturonan II. Carbohydr. Polym. 2007, 69, 426-435.

(103) Willats, W. G. T.; McCartney, L.; Mackie, W.; Knox, J. P. Pectin: Cell Biology and Prospects for Functional Analysis. Plant Mol. Biol. 2001, 47, 9-27.

(104) Petersen, B. O.; Meier, S.; Duus, J. Ø.; Clausen, M. H. Structural Characterization of Homogalacturonan by NMR Spectroscopy-Assignment of Reference Compounds. Carbohydr. Res. 2008, 343, 2830-2833.

(105) Nakahara, Y.; Ogawa, T. Synthesis of (1 ->4)-Linked Galacturonic Acid Trisaccharides, a Proposed Plant Wound-Hormone and a Stereoisomer. Carbohydr. Res. 1990, 200, 363-375.

(106) Pourcelot, M.; Barbier, M.; Landoni, M.; Couto, A.; Grand, E.; Kovensky, J. Synthesis of Galacturonate Containing Disaccharides and Protein Conjugates. Curr. Org. Chem. 2011, 15, 
3523-3534.

(107) Kester, H. C. M.; Magaud, D.; Roy, C.; Anker, D.; Doutheau, A.; Shevchik, V.; HugouvieuxCotte-Pattat, N.; Benen, J. A. E.; Visser, J. Performance of Selected Microbial Pectinase on Sythetic Monomethyl-Esterified Di- and Trigalacturonates. J Biol Chem 1999, 274, 3705337059.

(108) Clausen, M. H.; Jørgensen, M. R.; Thorsen, J.; Madsen, R. A Strategy for Chemical Synthesis of Selectively Methyl-Esterified Oligomers of Galacturonic Acid. J. Chem. Soc. Perkin Trans. $12001,543-551$.

(109) Clausen, M. H.; Madsen, R. Synthesis of Hexasaccharide Fragments of Pectin. Chem. Eur. J. 2003, 9, 3821-3832.

(110) Nakahara, Y.; Ogawa, T. Stereocontrolled Synthesis of the Propyl Glycoside of a Decagalacturonic Acid, a Model Compound for the Endogenous Phytoalexin Elicitor-Active Oligogalacturonic. Carbohydr. Res. 1989, 194, 95-114.

(111) Nakahara, Y.; Ogawa, T. Stereoselective Total Synthesis of Dodecagalacturonic Acid, a Phytoalexin Elicitor of Soybean. Carbohydr. Res. 1990, 205, 147-159.

(112) van den Bos, L. J.; Codée, J. D. C.; Litjens, R. E. J. N.; Dinkelaar, J.; Overkleeft, H. S.; van der Marel, G. A. Uronic Acids in Oligosaccharide Synthesis. Eur. J. Org. Chem. 2007, 3963-3976.

(113) Magaud, D.; Grandjean, C.; Doutheau, A.; Anker, D.; Shevchik, V.; Cotte-Pattat, N.; RobertBaudouy, J. An Efficient and Highly Stereoselective $\alpha(1 \rightarrow 4)$ Glycosylation between Two DGalacturonic Acid Ester Derivatives. Tetrahedron Lett. 1997, 38, 241-244.

(114) Kramer, S.; Nolting, B.; Ott, A.; Vogel, C. Synthesis of Homogalacturonan Fragments. J. Carbohydr. Chem. 2000, 19, 891-921.

(115) Omura, K.; Swern, D. Oxidation of Alcohols by “activated” Dimethyl Sulfoxide. A Preparative, 
Steric and Mechanistic Study. Tetrahedron 1978, 34, 1651-1660.

(116) Bal, B. S.; Childers, W. E.; Pinnick, H. W. Oxidation of A, $\beta$-Un Saturated Aldehydes. Tetrahedron 1981, 37, 2091-2096.

(117) Kraus, G. A.; Roth, B. Synthetic Studies toward Verrucarol. 2. Synthesis of the AB Ring System. J. Org. Chem. 1980, 45, 4825-4830.

(118) Lindgren, B. O.; Nilsson, T.; Husebye, S.; Mikalsen, Ø.; Leander, K.; Swahn, C.-G. Preparation of Carboxylic Acids from Aldehydes (Including Hydroxylated Benzaldehydes) by Oxidation with Chlorite. Acta Chem. Scand. 1973, 27, 888-890.

(119) Clausen, M. H.; Madsen, R. Synthesis of Hexasaccharide Fragments of Pectin. Chemistry 2003, 9, 3821-3832.

(120) Dess, D. B.; Martin, J. C. Readily Accessible 12-I-5 Oxidant for the Conversion of Primary and Secondary Alcohols to Aldehydes and Ketones. J. Org. Chem. 1983, 48, 4155-4156.

(121) Schols, H. A.; Bakx, E. J.; Schipper, D.; Voragen, A. G. J. A Xylogalacturonan Subunit Present in the Modified Hairy Regions of Apple Pectin. Carbohydr. Res. 1995, 279, 265-279.

(122) Hart, D. A.; Kindel, P. K. Isolation and Partial Characterization of Apiogalacturonans from the Cell Wall of Lemna Minor. Biochem. J. 1970, 116, 569-579.

(123) Buffet, M. a J.; Rich, J. R.; McGavin, R. S.; Reimer, K. B. Synthesis of a Disaccharide Fragment of Rhamnogalacturonan II. Carbohydr. Res. 2004, 339, 2507-2513.

(124) Nepogodiev, S. A.; Fais, M.; Hughes, D. L.; Field, R. a. Synthesis of Apiose-Containing Oligosaccharide Fragments of the Plant Cell Wall: Fragments of Rhamnogalacturonan-II Side Chains A and B, and Apiogalacturonan. Org. Biomol. Chem. 2011, 9, 6670-6684.

(125) Koós, M.; Mosher, H. S. A Convenient Synthesis of Apiose. Carbohydr. Res. 1986, 146, 335341. 
(126) Nachman, R. J.; Hönel, M.; Williams, T. M.; Halaska, R. C.; Mosher, H. S. Methyl 3-Formyl 2,3-O-Isopropylidene-D-Erythrofuranoside (D-Apiose Aldal) and Derivatives. J. Org. Chem. 1986, 51, 4802-4806.

(127) Ho, P.-T. Branched-Chain Sugars. Reaction of Furanoses with Formaldehyde: A Simple Synthesis of D- and L-Apiose. Can. J. Chem. 1979, 57, 381-383.

(128) Williams, D. T.; Jones, J. K. N. The Chemistry of Apiose. Part I. Can. J. Chem. 1964, 42, 6972.

(129) Scanlan, E. M.; Mackeen, M. M.; Wormald, M. R.; Davis, B. G. Synthesis and Solution-Phase Conformation of the RG-I Fragment of the Plant Polysaccharide Pectin Reveals a ModificationModulated Assembly Mechanism. J. Am. Chem. Soc. 2010, 132, 7238-7239.

(130) Mossine, V. V; Glinsky, V. V; Mawhinney, T. P. Food-Related Carbohydrate Ligands for Galectins. In Food and Feed Chemistry; Columbia, USA., 2008; pp 235-270.

(131) Clarke, A. E.; Anderson, R. L.; Stone, B. A. Form and Function of Arabinogalactans and Arabinogalactan-Proteins. Phytochemistry 1979, 18, 521-540.

(132) Ma, Y.; Cao, X.; Yu, B. Synthesis of Oligosaccharide Fragments of the Rhamnogalacturonan of Nerium Indicum. Carbohydr. Res. 2013, 377, 63-74.

(133) Maruyama, M.; Takeda, T.; Shimizu, N.; Hada, N.; Yamada, H. Synthesis of a Model Compound Related to an Anti-Ulcer Pectic Polysaccharide. Carbohydr. Res. 2000, 325, 8392.

(134) Nemati, N.; Karapetyan, G.; Nolting, B.; Endress, H.-U.; Vogel, C. Synthesis of Rhamnogalacturonan I Fragments by a Modular Design Principle. Carbohydr. Res. 2008, 343, 1730-1742.

(135) Reiffarth, D.; Reimer, K. B. Synthesis of Two Repeat Units Corresponding to the Backbone of 
the Pectic Polysaccharide Rhamnogalacturonan I. Carbohydr. Res. 2008, 343, 179-188.

(136) Zakharova, A. N.; Madsen, R.; Clausen, M. H. Synthesis of a Backbone Hexasaccharide Fragment of the Pectic Polysaccharide Rhamnogalacturonan I. Org. Lett. 2013, 15, 1826-1829.

(137) Ndeh, D.; Rogowski, A.; Cartmell, A.; Luis, A. S.; Baslé, A.; Gray, J.; Venditto, I.; Briggs, J.; Zhang, X.; Labourel, A.; Terrapon, N.; Buffetto, F.; Nepogodiev, S.; Xiao, Y.; Field, R. A.; Zhu, Y.; O’Neill, M. A.; Urbanowicz, B. R.; York, W. S.; Davies, G. J.; Abbott, D. W.; Ralet, M-C.; Martens, E. C.; Henrissat, B.; Gilbert, H. J. Complex Pectin Metabolism by Gut Bacteria Reveals Novel Catalytic Functions. Nature 2017, 544, 65-70.

(138) Pellerin, P.; Neill, M. A.; Pierre, C.; Cabanis, M.-T.; Darvill, A. G.; Albersheim, P.; Moutounet, M. Leat Complexation in Wines with the Dimers of the Grape Pectic Polysaccharide Rhamnogalacturonan II. Int. J. Sci. Vigne Vin 1997, 31, 33-41.

(139) Pellerin, P.; Doco, T.; Vidal, S.; Williams, P.; Brillouet, J. M.; O’Neill, M. A. Structural Characterization of Red Wine Rhamnogalacturonan II. Carbohydr. Res. 1996, 290, 183-197.

(140) Whitcombe, A. J.; O’Neill, M. A.; Steffan, W.; Albersheim, P.; Darvill, A. G. Structural Characterization of the Pectic Polysaccharide, Rhamnogalacturonan-II. Carbohydr. Res. 1995, $271,15-29$.

(141) Pabst, M.; Fischl, R. M.; Brecker, L.; Morelle, W.; Fauland, A.; Köfeler, H.; Altmann, F.; Léonard, R. Rhamnogalacturonan II Structure Shows Variation in the Side Chains Monosaccharide Composition and Methylation Status within and across Different Plant Species. Plant J. 2013, 76, 61-72.

(142) Scheller, H. V.; Jensen, J. K.; Sørensen, S. O.; Harholt, J.; Geshi, N. Biosynthesis of Pectin. Physiol. Plant. 2006, 129, 283-295.

(143) Glushka, J. N.; Terrell, M.; York, W. S.; Neill, M. A. O.; Gucwa, A.; Darvill, A. G.; 
Albersheim, P.; Prestegard, J. H. Primary Structure of the 2-O-Methyl-a- L -Fucose-Containing Side Chain of the Pectic Polysaccharide , Rhamnogalacturonan II. Carbohydr. Res. 2003, 338, $341-352$.

(144) Penhoat, H. C.; Gey, C.; Pellerin, P.; Perez, S. An NMR Solution Study of the MegaOligosaccharide, Rhamnogalacturonan II. J. Biomol. NMR 1999, 14, 253-271.

(145) Pérez, S.; Rodríguez-Carvajal, M. A.; Doco, T. A Complex Plant Cell Wall Polysaccharide: Rhamnogalacturonan II. A Structure in Quest of a Function. Biochimie 2003, 85, 109-121.

(146) Vidal, S.; Doco, T.; Williams, P.; Pellerin, P.; York, W. S.; O’Neill, M. A.; Glushka, J.; Darvill, A. G.; Albersheim, P. Structural Characterization of the Pectic Polysaccharide Rhamnogalacturonan II: Evidence for the Backbone Location of the Aceric Acid-Containing Oligoglycosyl Side Chain. Carbohydr. Res. 2000, 326, 277-294.

(147) Rodríguez-Carvajal, M. A.; Hervé du Penhoat, C.; Mazeau, K.; Doco, T.; Pérez, S. The ThreeDimensional Structure of the Mega-Oligosaccharide Rhamnogalacturonan II Monomer: A Combined Molecular Modeling and NMR Investigation. Carbohydr. Res. 2003, 338, 651-671.

(148) Ishii, T.; Matsunaga, T. Isolation and Characterization of a Boron-Rhamnogalacturonan-II Complex from Cell Walls of Sugar Beet Pulp. Carbohydr. Res. 1996, 284, 1-9.

(149) Funakawa, H.; Miwa, K. Synthesis of Borate Cross-Linked Rhamnogalacturonan II. Front. Plant Sci. 2015, 6, 1-8.

(150) Ishii, T.; Matsunaga, T.; Hayashi, N. Formation of Rhamnogalacturonan II-Borate Dimer in Pectin Determines Cell Wall Thickness of Pumpkin Tissue. Plant Physiol. 2001, 126, 16981705.

(151) Melton, L. D.; McNeil, M.; Darvill, A. G.; Albersheim, P. Structural Characterization of Oligosaccharides Isolated from the Pectic Polysaccharide RG-II. Carbohydr. Res. 1986, 146, 
279-305.

(152) Spellman, M. W.; McNeil, M.; Darvill, A. G.; Albersheim, P.; Dell, A. Characterization of a Structurally Complex Heptasaccharide Isolated from the Pectic Polysaccharide Rhamnogalacturonan II. Carbohydr. Res. 1983, 122, 131-153.

(153) Backman, I.; Jansson, P.; Kenne, L. Synthesis, NMR and Conformational Studies of Some 1, 4-Linked Disaccharides. J. Chem. Soc., Perkin Trans. 1 1990, 50, 1383-1388.

(154) Chauvin, A.-L.; Nepogodiev, S. A.; Field, R. A. Synthesis of a 2,3,4-Triglycosylated Rhamnoside Fragment of Rhamnogalacturonan-II Side Chain A Using a Late Stage Oxidation Approach. J. Org. Chem. 2005, 70, 960-966.

(155) Chauvin, A.-L.; Nepogodiev, S. A.; Field, R. A. Synthesis of an Apiose-Containing Disaccharide Fragment of Rhamnogalacturonan-II and Some Analogues. Carbohydr. Res. 2004, 339, 21-27.

(156) Crich, D.; Picione, J. Direct Synthesis of the $\beta$-L-Rhamnopyranosides. Org. Lett. 2003, 5, 781784.

(157) Hodosi, G.; Kovac, P. A Fundamentally New, Simple, Stereospecific Synthesis of Oligosaccharides Containing the $\beta$-Mannopyranosyl and $\beta$-Rhamnopyranosyl Linkage. J. Am. Chem. Soc. 1997, 119, 2335-2336.

(158) Yasomanee, J. P.; Demchenko, A. V. Effect of Remote Picolinyl and Picoloyl Substituents on the Stereoselectivity of Chemical Glycosylation. J. Am. Chem. Soc. 2012, 134, 20097-20102.

(159) Mukherjee, A.; Palcic, M. M.; Hindsgaul, O. Synthesis and Enzymatic Evaluation of Modified Acceptors of Recombinant Blood Group A and B Glycosyltransferases. Carbohydr. Res. 2000, 326, $1-21$.

(160) Amer, H.; Hofinger, A.; Puchberger, M.; Kosma, P. Synthesis of O-Methylated Disaccharides 
Related to Excretory/secretory Antigens of Toxocara Larvae. J. Carbohydr. Chem. 2001, 20, 719-731.

(161) Rao, Y.; Buskas, T.; Albert, A.; O’Neill, M. a; Hahn, M. G.; Boons, G.-J. Synthesis and Immunological Properties of a Tetrasaccharide Portion of the B Side Chain of Rhamnogalacturonan II (RG-II). Chembiochem 2008, 9, 381-388.

(162) Rao, Y.; Boons, G.-J. A Highly Convergent Chemical Synthesis of Conformational Epitopes of Rhamnogalacturonan II. Angew. Chem. Int. Ed. Engl. 2007, 46, 6148-6151.

(163) Jones, N. A.; Nepogodiev, S. A.; MacDonal, C. J.; Hughes, D. L.; Field, R. A. Synthesis of the Branched-Chain Sugar Aceric Acid: A Unique Component of the Pectic Polysaccharide Rhamnogalacturonan-II. J. Org. Chem. Notes 2005, 70, 8556-8559.

(164) Timmer, M.; Stocker, B. L.; Seeberger, P. H. De Novo Synthesis of Aceric Acid and an Aceric Acid Building Block. J. Org. Chem. Notes 2006, 71, 8294-8297.

(165) York, W. S.; Darvill, A. G.; McNeil, M.; Albersheim, P. 3-Deoxy-D-Manno-2-Octulosonic Acid (KDO) Is a Component of Rhamnogalacturonan II, a Pectic Polysaccharide in the Primary Cell Walls of Plants. Carbohydr. Res. 1985, 138, 109-126.

(166) Unger, F. M.; Stix, D.; Schulz, G. The Anomeric Configurations of the Two Ammonium (Methyl 3-Deoxy-D-Manno-2-Octulopyranosid)onate Salts (Methyl $\alpha$ - and $\beta$-Ketopyranosides of Kdo). Carbohydr. Res. 1980, 80, 191-195.

(167) van der Klein, P. A. M.; Boons, G. J. P. H.; Veeneman, G. H.; van der Marel, G. A.; van Boom, J. H. An Efficient Route to 3-Deoxy-D-Manno-2-Octulosonic Acid (KDO) Derivatives via a 1,4-Cyclic Sulfate Approach. Tetrahedron Lett. 1989, 30, 5477-5480.

(168) Feng, Y.; Dong, J.; Xu, F.; Liu, A.; Wang, L.; Zhang, Q.; Chai, Y. Efficient Large Scale Syntheses of 3-Deoxy-D-Manno-2-Octulosonic Acid (Kdo) and Its Derivatives. Org. Lett. 
2015, 17, 2388-2391.

(169) Stevenson, T. T.; Darvill, A. G.; Albersheim, P. 3-Deoxy-D-Lyxo-2-Heptulosaric Acid, a Component of the Plant Cell-Wall Polysaccharide Rhamnogalacturonan-II. Carbohydr. Res. 1988, 179, 269-288.

(170) Banaszek, A. The First Synthesis of Acid ( DHA ) Derivatives. Tetrahedron 1995, 51, 42314238.

(171) Thomas, J. R.; Darvill, A. G.; Albersheim, P. Isolation and Structural Characterization of the Pectic Polysaccharide Rhamnogalacturonan II from Walls of Suspension-Cultured Rice Cells. Carbohydr. Res. 1989, 185, 261-277.

(172) Heredia, A.; Jiménez, A.; Guillén, R. Composition of Plant Cell Walls. Z. Lebensm. Unters. Forsch. 1995, 200, 24-31.

(173) Nakamura, A.; Furuta, H.; Maeda, H.; Takao, T.; Negamatsu, Y. Structural Studies by Stepwise Enzymatic Degradation of the Main Backbone of Soybean Soluble Polysaccharides Consisting of Galacturonan and Rhamnogalacturonan. Biosci. Biotechnol. Biochem. 2002, 66, 1301-1313.

(174) Huisman, M. M. H.; Brüll, L. P.; Thomas-Oates, J. E.; Haverkamp, J.; Schols, H. A.; Voragen, A. G. J. The Occurrence of Internal $(1 \rightarrow 5)$-Linked Arabinofuranose and Arabinopyranose Residues in Arabinogalactan Side Chains from Soybean Pectic Substances. Carbohydr. Res. 2001, 330, 103-114.

(175) Hinz, S. W. A.; Verhoef, R.; Schols, H. A.; Vincken, J. P.; Voragen, A. G. J. Type I Arabinogalactan Contains $\beta$-D-Galp-( $1 \rightarrow 3)-\beta$-D-Galp Structural Elements. Carbohydr. Res. 2005, 340, 2135-2143.

(176) Leivas, C. L.; Iacomini, M.; Cordeiro, L. M. C. Pectic Type II Arabinogalactans from Starfruit (Averrhoa Carambola L.). Food Chem. 2016, 199, 252-257. 
(177) El-Shenawy, H.; Schuerch, C. Synthesis and Characterization of Propyl O- $\beta$-D-

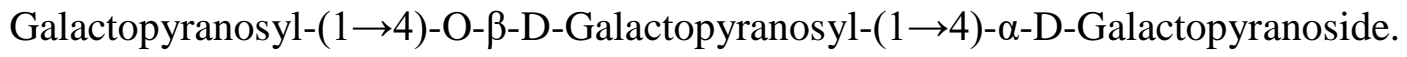

Carbohydr. Res. 1984, 131, 239-246.

(178) Oberthur, M.; Peters, S.; Kumar Saibal, D.; Lichtenthaler, F. W. Synthesis of Linear $\beta-(1 \rightarrow 4)-$ Galacto Hexa- and Heptasaccharides and Studies Directed towards Cyclogalactans. Carbohydr. Res. 2002, 337, 2171-2180.

(179) Andersen, M. C. F.; Kračun, S. K.; Rydahl, M. G.; Willats, W. G. T.; Clausen, M. H. Synthesis of $\beta$-1,4-Linked Galactan Side-Chains of Rhamnogalacturonan I. Chem. - Eur. J. 2016, 22, $11543-11548$.

(180) Sakamoto, T.; Ishimaru, M. Peculiarities and Applications of Galactanolytic Enzymes That Act on Type I and II Arabinogalactans. Appl. Microbiol. Biotechnol. 2013, 97, 5201-5213.

(181) Bartetzko, M. P.; Schuhmacher, F.; Seeberger, P. H.; Pfrengle, F. Determining Substrate Specificities of $\beta-1,4$-Endogalactanases Using Plant Arabinogalactan Oligosaccharides Synthesized by Automated Glycan Assembly. J. Org. Chem. 2017, 82, 1842-1850.

(182) Kovác, P.; Taylor, R. B. Alternative Syntheses and Related NMR Studies of Precursors for Internal $\beta$-D-Galactopyranosyl Residues in Oligosaccharides, Allowing Chain Extension at O4. Carbohydr. Res. 1987, 167, 153-173.

(183) Lichtenthaler, F. W.; Oberthur, M.; Peters, S. Directed and Efficient Syntheses of $\beta-(1->4)-$ Linked Galacto-Oligosaccharides. Eur. J. Org. Chem. 2001, 3849-3869.

(184) Bartetzko, M. P.; Schuhmacher, F.; Hahm, H. S.; Seeberger, P. H.; Pfrengle, F. Automated Glycan Assembly of Oligosaccharides Related to Arabinogalactan Proteins. Org. Lett. 2015, $17,4344-4347$.

(185) Yang, F.; Du, Y. Synthesis of Oligosaccharide Derivatives Related to Those from Sanqi, a 
Chinese Herbal Medicine from Panax Notoginseng. Carbohydr. Res. 2002, 337, 485-491.

(186) Ning, J.; Wang, H.; Yi, Y. A Simple Approach to 3,6-Branched Galacto-Oligosaccharides and Its Application to the Syntheses of a Tetrasaccharide and a Hexasaccharide Related to the Arabinogalactans (AGs). Tetrahedron Lett. 2002, 43, 7349-7352.

(187) Kaji, E.; Nishino, T.; Ishige, K.; Ohya, Y.; Shirai, Y. Regioselective Glycosylation of Fully Unprotected Methyl Hexopyranosides by Means of Transient Masking of Hydroxy Groups with Arylboronic Acids. Tetrahedron Lett. 2010, 51, 1570-1573.

(188) Timmers, C. M.; Wigchert, S. C. M.; Leeuwenburgh, M. A.; van der Marel, G. A.; van Boom, J. H. Synthesis of Tetrameric Arabinogalactans Based on 1,2-Anhydrosugars. European J. Org. Chem. 1998, 1, 91-97.

(189) Du, Y.; Pan, Q.; Kong, F. Synthesis of a Tetrasaccharide Representing a Minimal Epitope of an Arabinogalactan. Carbohydr. Res. 2000, 323, 28-35.

(190) Ning, J.; Yi, Y.; Yao, Z. An Efficient Method for the Synthesis of 2,6-Branched GalactoOligosaccharides and Its Applications to the Synthesis of Three Tetrasaccharides and a Hexasaccharide Related to the Arabinogalactans (AGs). Synlett 2003, 14, 2208-2212.

(191) Csávás, M.; Borbás, A.; Szilágyi, L.; Lipták, A. Successful Combination of (Methoxydimethyl)methyl (MIP) and (2-Naphthyl)methyl (NAP) Ethers for the Synthesis of Arabinogalactan-Type Oligosaccharides. Synlett 2002, 6, 887-890.

(192) Fekete, A.; Borbás, A.; Antus, S.; Lipták, A. Synthesis of 3,6-Branched Arabinogalactan-Type Tetra- and Hexasaccharides for Characterization of Monoclonal Antibodies. Carbohydr. Res. 2009, 344, 1434-1441.

(193) Liang, X.-Y.; Liu, Q.-W.; Bin, H.-C.; Yang, J.-S. One-Pot Synthesis of Branched Oligosaccharides by Use of Galacto- and Mannopyranosyl Thioglycoside Diols as Key 
Glycosylating Agents. Org. Biomol. Chem. 2013, 11, 3903-3917.

(194) Zeng, Y.; Li, A.; Kong, F. A Concise Synthesis of Arabinogalactan with $\beta-(1 \rightarrow 6)$ Galactopyranose Backbone and $\alpha-(1 \rightarrow 2)$ Arabinofuranose Side Chains. Tetrahedron Lett. 2003, 44, 8325-8329.

(195) Gu, G.; Yang, F.; Du, Y.; Kong, F. Synthesis of a Hexasaccharide That Relates to the Arabinogalactan Epitope. Carbohydr. Res. 2001, 336, 99-106.

(196) Li, A.; Kong, F. Concise Syntheses of Arabinogalactans with $\beta-(1 \rightarrow 6)$-Linked Galactopyranose Backbones and $\alpha-(1 \rightarrow 3)$ - and $\alpha-(1 \rightarrow 2)$-Linked Arabinofuranose Side Chains. Bioorg. Med. Chem. 2005, 13, 839-853.

(197) Huang, H.; Han, L.; Lan, Y.-M.; Zhang, L.-L. One-Pot Synthesis of a 3,6-Branched Hexaarabinogalactan Using Galactopyranosyl Thioglycoside Diol as a Key Glycosylating Agent. J. Asian Nat. Prod. Res. 2014, 16, 640-647.

(198) Li, A.; Zeng, Y.; Kong, F. An Effective Synthesis of an Arabinogalactan with a $\beta-(1 \rightarrow 6)-$ Linked Galactopyranose Backbone and $\alpha-(1 \rightarrow 2)$ Arabinofuranose Side Chains. Carbohydr. Res. 2004, 339, 673-681.

(199) Li, A.; Kong, F. Syntheses of Arabinogalactans Consisting of $\beta-(1 \rightarrow 6)$-Linked DGalactopyranosyl Backbone and $\alpha-(1 \rightarrow 3)$-Linked L-Arabinofuranosyl Side Chains. Carbohydr. Res. 2004, 339, 1847-1856.

(200) Vincken, J.-P.; Schols, H. A.; Oomen, R. J. F. J.; Mccann, M. C.; Ulvskov, P.; Voragen, A. G. J.; Visser, R. G. F. If Homogalacturonan Were a Side Chain of Rhamnogalacturonan I . Implications for Cell Wall Architecture. Plant Physiol. 2003, 132, 1781-1789.

(201) Sakamoto, T.; Sakai, T. Analysis of Structure of Sugar-Beet Pectin by Enzymatic Methods. Phytochemistry 1995, 39, 821-823. 
(202) Øbro, J.; Harholt, J.; Scheller, H. V.; Orfila, C. Rhamnogalacturonan I in Solanum Tuberosum Tubers Contains Complex Arabinogalactan Structures. Phytochemistry 2004, 65, 1429-1438.

(203) Wu, Y.; Xiong, D.-C.; Chen, S.-C.; Wang, Y.-S.; Ye, X.-S. Total Synthesis of Mycobacterial Arabinogalactan Containing 92 Monosaccharide Units. Nat. Commun. 2017, 8, 14851.

(204) Nepogodiev, S. A.; Backinowsky, L. V.; Kochetkov, N. K. No Title. Bioorg. Khim. 1986, 12, 940-946.

(205) Kaneko, S.; Kawabata, Y.; Ishii, T.; Gama, Y.; Kusakabe, I. The Core Trisaccharide of a-LArabinofuranan : Synthesis of Methyl L-Arabinofuranoside. Carbohydr. Res. 1995, 268, 307311.

(206) Du, Y.; Pan, Q.; Kong, F. Regio- and Stereoselective Synthesis of 1-5-Linked a-LArabinofuranosyl Oligosaccharides. Synlett 1999, 10, 1648-1650.

(207) Du, Y.; Pan, Q.; Kong, F. An Efficient and Concise Regioselective Synthesis of $\alpha-(1 \rightarrow 5)-$ Linked L-Arabinofuranosyl Oligosaccharides. Carbohydr. Res. 2000, 329, 17-24.

(208) Arndt, D.; Graffi, A. The Synthesis of P-Nitrophenyl 5-O- $\alpha$-L-Arabinofuranosyl- $\alpha$-LArabinofuranoside. Carbohydr. Res. 1976, 48, 128-131.

(209) Kawabata, Y.; Kaneko, S.; Kusakabe, I.; Gama, Y. Synthesis of Regioisomeric Methyl a-LArabinofuranobiosides. Carbohydr. Res. 1995, 267, 39-47.

(210) Deng, L.; Liu, X.; Liang, X.; Yang, J. Regioselective Glycosylation Method Using Partially Protected Arabino- and Galactofuranosyl Thioglycosides as Key Glycosylating Substrates and Its Application to One-Pot Synthesis of Oligofuranoses. J. Org. Chem. 2012, 77, 3025-3037.

(211) Yamagaki, T.; Maeda, M.; Kanazawa, K.; Ishizuka, Y.; Nakanishi, H. Structures of Caulerpa Cell Wall Microfibril Xylan with Detection of $\beta-1,3-X y l o o l i g o s a c c h a r i d e s$ as Revealed by Matrix-Assisted Laser Desorption Ionization/Time of Flight/Mass Spectrometry. Biosci. 
Biotechnol. Biochem. 1996, 60, 1222-1228.

(212) Umemoto, Y.; Shibata, T.; Araki, T. D-Xylose Isomerase from a Marine Bacterium, Vibrio Sp. Strain XY-214, and D-Xylulose Production from $\beta$-1,3-Xylan. Mar. Biotechnol. 2012, 14, 1020.

(213) Chen, L.; Kong, F. An Efficient and Practical Synthesis of $\beta$-(1 $\rightarrow 3)$-Linked Xylooligosaccharides. Carbohydr. Res. 2002, 337, 2335-2341.

(214) Synytsya, A.; Copiková, J.; Kim, W. J.; Park, Y. I. Cell Wall Polysaccharides of Marine Algae. In Springer Handbook of Marine Biotechnology; Se-Kwon, K., Ed.; 2015; pp 543-590.

(215) Ray, B. Polysaccharides from Enteromorpha Compressa: Isolation, Purification and Structural Features. Carbohydr. Polym. 2006, 66, 408-416.

(216) Domozych, D. S.; Ciancia, M.; Fangel, J. U.; Mikkelsen, M. D.; Ulvskov, P.; Willats, W. G. T. The Cell Walls of Green Algae: A Journey through Evolution and Diversity. Front. Plant Sci. 2012, 3, 1-7.

(217) Abouraïcha, E. F.; El Alaoui-Talibi, Z.; Tadlaoui-Ouafi, A.; El Boutachfaiti, R.; Petit, E.; Douira, A.; Courtois, B.; Courtois, J.; El Modafar, C. Glucuronan and Oligoglucuronans Isolated from Green Algae Activate Natural Defense Responses in Apple Fruit and Reduce Postharvest Blue and Gray Mold Decay. J. Appl. Phycol. 2017, 29, 471-480.

(218) Redouan, E.; Cedric, D.; Emmanuel, P.; Mohamed, E. G.; Bernard, C.; Philippe, M.; Cherkaoui, E. M.; Josiane, C. Improved Isolation of Glucuronan from Algae and the Production of Glucuronic Acid Oligosaccharides Using a Glucuronan Lyase. Carbohydr. Res. 2009, 344, $1670-1675$.

(219) Isogai, A.; Kato, Y. Preparation of Polyuronic Acid from Cellulose by TEMPO-Mediated Oxidation. Cellulose 1998, 5, 153-164. 
(220) Distantina, S.; Wiratni; Fahrurrozi, M.; Rochmadi. Carrageenan Properties Extracted From. Int. J. Chem. Mol. Nucl. Mater. Metall. Eng. 2011, 5, 487-491.

(221) Hoffmann, R. A.; Gidley, M. J.; Cooke, D.; Frith, W. J. Effect of Isolation Procedures on the Molecular Composition and Physical Properties of Eucheuma Cottonii Carrageenan. Food Hydrocoll. 1995, 9, 281-289.

(222) Lahaye, M.; Rochas, C. Chemical Structure and Physico-Chemical Properties of Agar. Hydrobiologia 1991, 221, 137-148.

(223) Perez Recalde, M.; Canelón, D. J.; Compagnone, R. S.; Matulewicz, M. C.; Cerezo, A. S.; Ciancia, M. Carrageenan and Agaran Structures from the Red Seaweed Gymnogongrus Tenuis. Carbohydr. Polym. 2016, 136, 1370-1378.

(224) Rees, D. A. Estimation of the Relative Amounts of Isomeric Sulphate Esters in Some Sulphated Polysaccharides. J. Chem. Soc. 1961, 5168-5171.

(225) Rees, D. A.; Conway, E. The Structure and Biosynthesis of Porphyran: A Comparison of Some Samples. Biochem. J. 1962, 84, 411-416.

(226) Haug, A.; Larsen, B.; Smidsrød, O. Uronic Acid Sequence in Alginate from Different Sources. Carbohydr. Res. 1974, 32, 217-225.

(227) Draget, K. I.; Smidsrød, O.; Skjåk-Broek, G. Alginates from Algae. In Polysaccharides and Polyamides in the Food Industry; Steinbuchel, A., Rhee, S. K., Eds.; 2005.

(228) Zhang, Q.; van Rijssel, E. R.; Walvoort, M. T. C.; Overkleeft, H. S.; van der Marel, G. A.; Codée, J. D. C. Acceptor Reactivity in the Total Synthesis of Alginate Fragments Containing

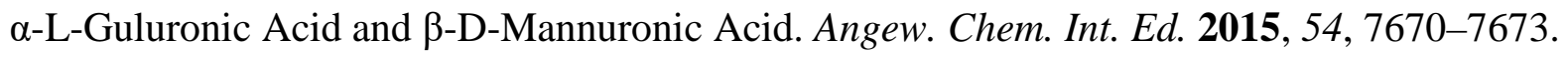

(229) van den Bos, L. J.; Dinkelaar, J.; Overkleeft, H. S.; van der Marel, G. a. Stereocontrolled Synthesis of $\beta$-D-Mannuronic Acid Esters: Synthesis of an Alginate Trisaccharide. J. Am. 
Chem. Soc. 2006, 128, 13066-13067.

(230) Codée, J. D. C.; van den Bos, L. J.; de Jong, A.-R.; Dinkelaar, J.; Lodder, G.; Overkleeft, H. S.; van der Marel, G. A. The Stereodirecting Effect of the Glycosyl C5-Carboxylate Ester: Stereoselective Synthesis of $\beta$-Mannuronic Acid Alginates. J. Org. Chem. 2009, 74, 38-47.

(231) Walvoort, M. T. C.; van den Elst, H.; Plante, O. J.; Kröck, L.; Seeberger, P. H.; Overkleeft, H. S.; van der Marel, G. A.; Codée, J. D. C. Automated Solid-Phase Synthesis of $\beta$-Mannuronic Acid Alginates. Angew. Chem. Int. Ed. 2012, 51, 4393-4396.

(232) Dinkelaar, J.; Van Den Bos, L. J.; Hogendorf, W. F. J.; Lodder, G.; Overkleeft, H. S.; Codée, J. D. C.; Van Der Marel, G. A. Stereoselective Synthesis of L-Guluronic Acid Alginates. Chem. Eur. J. 2008, 14, 9400-9411.

(233) Chi, F. C.; Kulkarni, S. S.; Zulueta, M. M. L.; Hung, S. C. Synthesis of Alginate Oligosaccharides Containing L-Guluronic Acids. Chem. Asian J. 2009, 4, 386-390.

(234) Garcia, B. A.; Poole, J. L.; Gin, D. Y. Direct Glycosylations with 1-Hydroxy Glycosyl Donors Using Trifluoromethanesulfonic Anhydride and Diphenyl Sulfoxide. J. Am. Chem. Soc. 1997, 119, 7597-7598.

(235) Zhang, Q.; van Rijssel, E. R.; Overkleeft, H. S.; van der Marel, G. A.; Codée, J. D. C. On the Reactivity of Gulose and Guluronic Acid Building Blocks in the Context of Alginate Assembly. European J. Org. Chem. 2016, 14, 2393-2397.

(236) Kylin, H. Zur Biochemie Der Meeresalgen. Physiol. Chemie 1913, 83, 171-197.

(237) Berteau, O.; Mulloy, B. Sulfated Fucans, Fresh Perspectives: Structures, Functions, and Biological Properties of Sulfated Fucans and an Overview of Enzymes Active toward This Class of Polysaccharide. Glycobiology 2003, 13, 29-40.

(238) Ustyuzhanina, N.; Krylov, V.; Grachev, A.; Gerbst, A.; Nifantiev, N. Synthesis, NMR and 
Conformational Studies of Fucoidan Fragments, 8: Convergent Synthesis of Branched and Linear Oligosaccharides. Synthesis (Stuttg). 2006, 23, 4017-4031.

(239) Chargaff, E.; Bancroft, F. W.; Stanley-brown, M. Studies on the Chemistry of Blood Coagulation. J. Biol. 1936, 4, 155-161.

(240) Gerbst, A. G.; Ustuzhanina, N. E.; Grachev, A. A.; Khatuntseva, E. A.; Tsvetkov, D. E.; Shashkov, A. S.; Usov, A. I.; Preobrazhenskaya, M. E.; Ushakova, N. A.; Nifantiev, N. E. Synthesis, NMR and Conformational Studies of Fucoidan Fragments. V. Linear 4,4',4"-Tri-OSulfated and Parent Non-sulfated $(1 \rightarrow 3)$-Fucotrioside Fragments. J. Carbohydr. Chem. 2003, 22, 109-122.

(241) Krylov, V. B.; Kaskova, Z. M.; Vinnitskiy, D. Z.; Ustyuzhanina, N. E.; Grachev, A. A.; Chizhov, A. O.; Nifantiev, N. E. Acid-Promoted Synthesis of per-O-Sulfated Fucooligosaccharides Related to Fucoidan Fragments. Carbohydr. Res. 2011, 346, 540-550.

(242) Vinnitskiy, D. Z.; Krylov, V. B.; Ustyuzhanina, N. E.; Dmitrenok, A. S.; Nifantiev, N. E. The Synthesis of Heterosaccharides Related to the Fucoidan from Chordaria Flagelliformis Bearing an $\alpha$-L-Fucofuranosyl Unit. Org. Biomol. Chem. 2016, 14, 598-611.

(243) Hua, Y.; Gu, G.; Du, Y. Synthesis and Biological Activities of Octyl 2,3,4-Tri-O-Sulfo- $\alpha$-LFucopyranosyl-(1 $\rightarrow 3$ )-2,4-Di-O-Sulfo- $\alpha$-L-Fucopyranosyl-(1 $\rightarrow 3)-2,4-D i-O-S u l f o-\alpha-L-$

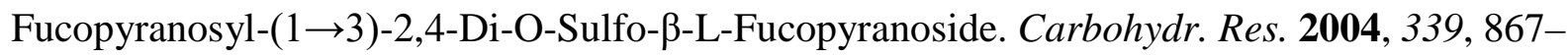
872.

(244) Kasai, A.; Arafuka, S.; Koshiba, N.; Takahashi, D.; Toshima, K. Systematic Synthesis of LowMolecular Weight Fucoidan Derivatives and Their Effect on Cancer Cells. Org. Biomol. Chem. 2015, 13, 10556-10568. 
(245) Zong, C.; Li, Z.; Sun, T.; Wang, P.; Ding, N.; Li, Y. Convenient Synthesis of Sulfated Oligofucosides. Carbohydr. Res. 2010, 345, 1522-1532.

(246) Arafuka, S.; Koshiba, N.; Takahashi, D.; Toshima, K. Systematic Synthesis of Sulfated Oligofucosides and Their Effect on Breast Cancer MCF-7 Cells. Chem. Commun. 2014, 50, 9831-9834.

(247) Gerbst, A. G.; Ustuzhanina, N. E.; Grachev, A. A.; Zlotina, N. S.; Khatuntseva, E. A.; Tsvetkov, D. E.; Shashkov, A. S.; Usov, A. I.; Nifantiev, N. E. Synthesis, NMR, and Conformational

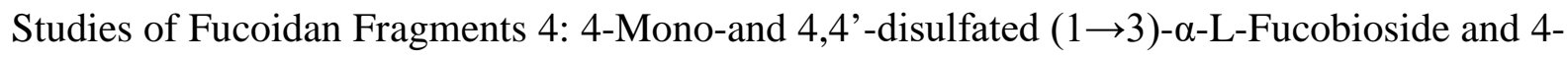
Sulfated Fucoside Fragments. J. Carbohydr. Chem. 2002, 21, 313-324.

(248) Gerbst, A. G.; Ustuzhanina, N. E.; Grachev, A. A.; Khatuntseva, E. A.; Tsvetkov, D. E.; Whitfield, D. M.; Berces, A.; Nifantiev, N. E. Synthesis, NMR, and Conformational Studies of Fucoidan Fragments. III. Effect of Benzoyl Group At O-3 on Stereoselectivity of Glycosylation by 3-O- and 3,4-Di-O-Benzoylated 2-O-Benzylfucosyl Bromides. J. Carbohydr. Chem. 2001, 20, 821-831.

(249) Krylov, V. B.; Ustyuzhanina, N. E.; Grachev, A. A.; Nifantiev, N. E. Efficient Acid-Promoted per-O-Sulfation of Organic Polyols. Tetrahedron Lett. 2008, 49, 5877-5879.

(250) Krylov, V. B.; Argunov, D. A.; Vinnitskiy, D. Z.; Verkhnyatskaya, S. A.; Gerbst, A. G.; Ustyuzhanina, N. E.; Dmitrenok, A. S.; Huebner, J.; Holst, O.; Siebert, H.-C.; et al. Pyranosideinto-Furanoside Rearrangement: New Reaction in Carbohydrate Chemistry and Its Application in Oligosaccharide Synthesis. Chem. - A Eur. J. 2014, 20, 16516-16522.

(251) Ustyuzhanina, N. E; Fomitskaya, P. A.; Gerbst, A. G.; Dmitrenok, A. S.; Nifantiev, N. E. Synthesis of the Oligosaccharides Related to Branching Sites of Fucosylated Chondroitin Sulfates from Sea Cucumbers. Mar. Drugs 2015, 13, 770-787. 
(252) Bilan, M. I.; Vinogradova, E. V.; Tsvetkova, E. A.; Grachev, A. A.; Shashkov, A. S.; Nifantiev, N. E.; Usov, A. I. A Sulfated Glucuronofucan Containing Both Fucofuranose and Fucopyranose Residues from the Brown Alga Chordaria Flagelliformis. Carbohydr. Res. 2008, 343, 2605-2612.

(253) Stadnik, M. J.; De Freitas, M. B. Algal Polysaccharides as Source of Plant Resistance Inducers. Trop. Plant Pathol. 2014, 39, 111-118.

(254) Lahaye, M.; Robic, A. Structure and Function Properties of Ulvan, a Polysaccharide from Green Seaweeds. Biomacromolecules 2007, 8, 1765-1774.

(255) Robic, A.; Gaillard, C.; Sassi, J. F.; Leral, Y.; Lahaye, M. Ultrastructure of Ulvan: A Polysaccharide from Green Seaweeds. Biopolymers 2009, 91, 652-664. 


\section{TOC Graphic}

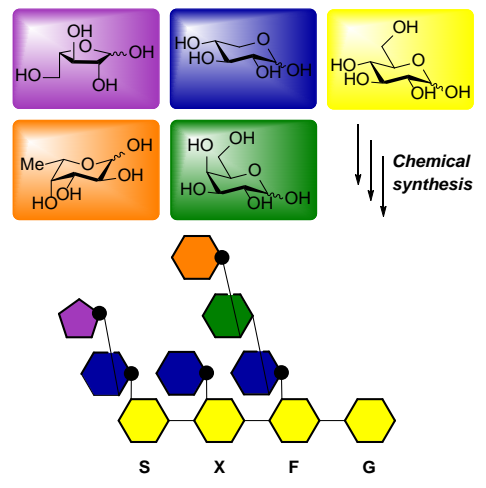

